JOSÉ EDUARDO ALAMY FILHO

\title{
Modelação numérica de processos de sedimentação em escoamentos turbulentos e análise da ressuspensão em canais
}

Tese apresentada à Escola de Engenharia de São Carlos, da Universidade de São Paulo, como parte dos requisitos para a obtenção do título de Doutor em Engenharia Civil.

Área de Concentração: Hidráulica e Saneamento.

Orientador: Prof. Tit. Harry Edmar Schulz

São Carlos

2006 
Ficha catalográfica preparada pela Seção de Tratamento da Informação do Serviço de Biblioteca - EESC/USP

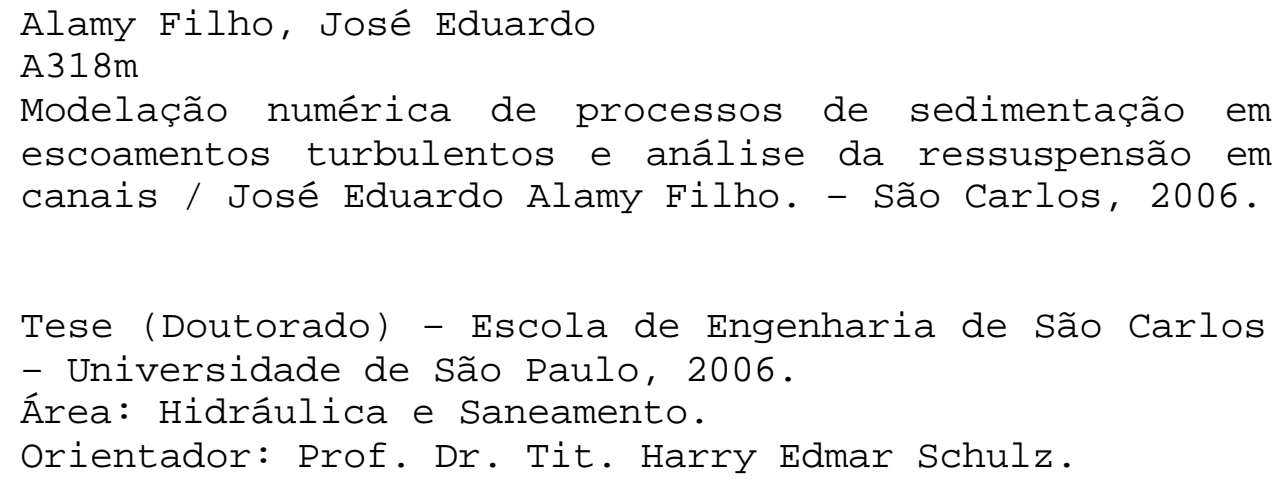

1. Turbulência. 2. Transporte de sedimentos. 3. Simulação de grandes escalas. 4. Método de fronteira imersa. I. Título. 
A tarde morria! Nas águas barrentas As sombras das margens deitavam-se longas.

Na esguia atalaia das árvores secas Ouvia-se um triste chorar de arapongas.

A tarde morria!... Dos ramos, das lascas, Das pedras, do líquen, das heras, dos cardos As trevas rasteiras com o ventre por terra Saíam quais negros, cruéis leopardos.

A tarde morria! Mais funda nas águas Lavava-se a galha do escuro ingazeiro... Ao fresco arrepio dos ventos cortantes Em músico estalo rangia o coqueiro.

Sussurro profundo! Marulho gigante! Talvez - um silêncio!... Talvez-uma orquestra... Da folha, do cálix, das asas, do inseto... Do átomo-à estrela... do verme - à floresta!...

As garças metiam o bico vermelho Por baixo das asas, da brisa ao açoite. E a terra na vaga azul do infinito Cobria a cabeça co'as penas da noite!

Somente por vezes, dos jungles das bordas Dos golfos enormes daquela paragem, Erguia a cabeça surpreso, inquieto, Coberto de limos - um touro selvagem.

Então as marrecas, em torno boiando, $O$ vôo encurvavam medrosas, à toa... E o tímido bando pedindo outras praias Passava gritando por sobre a canoa!... 


\section{Agradecimentos}

Esta não é, certamente, a parte do texto mais difícil de escrever. Todavia, também não é das mais fáceis. A redação dos Agradecimentos remete a nossa memória a tempos passados, fazendo-nos, por eles, viajar até o presente. Escrever estas páginas tão sucintas é também recordar... Dessas lembranças, a primeira delas remete-se à primeira viagem a São Carlos, na ocasião em que vinha prestar a prova para o Mestrado. Cheguei a São Carlos para passar dois anos e acabei ficando uma boa temporada. Na verdade é isso que ocorre com muitos de nós: chegamos aqui, ficamos e, até prolongamos nossa estada por mais tempo. Mas a despedida é praticamente inexorável. São Carlos é o universo transitório de uma fase da vida transitória. Aqui, pode-se se dizer que o Brasil se encontra e, aos poucos, se despede. Talvez, não exista outra cidade onde se possa conhecer, de forma tão próxima e sem sair do lugar, a diversidade de culturas, costumes, sotaques do nosso país. Parece que essa "convergência de povos", somada às distâncias das terras natais, contribui para o encadeamento de muitas amizades. A estes amigos, ficam meus agradecimentos, implícitos nessas palavras breves.

Os agradecimentos fundamentais remetem-se aos meus pais José Eduardo e Angela, aos meus irmãos Karla e João Paulo e aos meus avós Joffre e Maria Helena, Waldemar e Tereza. Sem eles nada disso aqui seria possível para mim. Conquistas rigorosamente individuais não existem, pois sempre há uma confluência de pensamentos e esforços de várias pessoas num sentido comum. Vocês, meus familiares, constituem a base de tudo e serão para sempre os alicerces sólidos de todos os meus triunfos.

Agradecimentos especiais são destinados à Nágela, pelo carinho e paciência, atenuando a minha ansiedade e, sobretudo, ajudando a me reerguer nos momentos em que eu achava que poderia sucumbir.

Sucumbir ... Muitas vezes, naqueles momentos em que as idéias, embora numerosas, parecem não produzir efeitos, esta palavra parece rodear nossos pensamentos. Não se resume a essência de um doutoramento num texto só, porque as id éias produzidas nesta fase precisam estar bem concatenadas. Neste sentido, cada elo é construído às expensas de muita leitura e muitas "metodologias intermediárias", lentamente (e pacientemente) refinadas ao longo do tempo para produzir resultados paulatinamente melhores. Como, muitas vezes os passos não são longos, a palavra sucumbir nos surge quais abismos laterais que parecem estreitar a 
caminhada até a nossa meta. Por isto, o apoio das pessoas que nos são queridas é imprescindível.

Agradeço ao amigo Leonardo Barra, por muitas vezes guiar-me pelos caminhos certos, aos amigos Peter Cheung, Tinil Carrijo, Klebber Formiga, Johannes, Caco e, aos companheiros mais próximos, Fernando Braga e Alexandre Kepler. Não poderia deixar de citar os amigos Marcelo Barroso, André Oliveira, Sérgio Luís, Leonardo Soares, Cristiano das Neves, Álvaro Fontana e Carlos, imortalizado em São Carlos como o popular "Cabral". Também não poderia me esquecer dos amigos Hélio, Adelena, Luciana, Karina, Lara e Monique. Todos aqui, de certa forma, nos acompanhamos nas aflições e sucessos. Agradeço ao velho amigo Fabiano, por um voto de confiança que foi especialmente fundamental num momento difícil, além da amizade fraterna de muitos anos.

O futebol... Doutorar é caminhar com a cabeça fervilhando de idéias, por isto o futebol funcionava como uma espécie de refúgio descentralizador para muitos de nós. Aí, é difícil não lembrar do início de tudo. Das tardes de quinta-feira pelos idos de 1999 e dos personagens "atletas" Zeedu (no caso, eu mesmo), Vinícius, Tibério, Fábio, Jorge, João Fernando, Iran, Marcelo, Nikolas, Roger e os dois “Andrés”, o Oliveira e o Schuster. Isto no mestrado. No doutorado, o futebol marcou-se pelas manhãs de sábado e pela incomparável "Confraria dos Pernetas" nas noites de quarta. Aqui, deixo os meus agradecimentos aos bons amigos Alexandre (Fininho), Fernandão, Maurício, Chico Vela, Claudião e a todos os demais, pelos tantos momentos memoráveis.

Agradeço ao senhor Álvaro e à dona Zulmira pelo zelo constante durante todos estes anos.

Agradeço ao professor Harry Edmar Schulz, por ser mais que um orientador, por ser sempre um amigo e incentivador. Trabalhar com o professor Harry e poder absorver um pouco dos seus conhecimentos foi para mim, motivo de grande honra.

Agradeço especialmente aos professores Dagoberto Camargo Caria, Hans George Arens, Fazal Hussain Chaudhry, Swami Marcondes Villela, Dante Contin Neto, Harry Edmar Schulz e Aristeu da Silveira Neto por me guiarem nesse caminho "das águas".

Não poderia deixar de agradecer a todos os bons amigos cujo apoio foi imprescindível para abrir o caminho até o final desta pesquisa. Tenho muita gratidão por todos.

A FAPESP (Fundação de Apoio à Pesquisa do Estado de São Paulo) nos foi sempre atenciosa e seu apoio foi fundamental para a condução e conclusão deste trabalho. 


\section{Resumo}

ALAMY FILHO, J. E. Modelação numérica de processos de sedimentação em escoamentos turbulentos e análise da ressuspensão em canais. 2006. $231 \mathrm{f}$. Tese (Doutorado) - Escola de Engenharia de São Carlos, Universidade de São Paulo, São Carlos, 2006.

O estudo do transporte de sedimentos, partindo da estimativa de estruturas turbulentas relevantes, constituiu o principal foco deste trabalho. Assim, a equação de transporte de massa (Advecção-Difusão) foi aplicada em conjunto com as equações de Navier-Stokes e da Continuidade filtradas. Neste contexto, houve a necessidade de uma descrição conveniente da turbulência, o que ocorreu mediante a aplicação da Simulação de Grandes Escalas acoplada a modelos de viscosidade turbulenta sub-malha. O Método de Fronteira Imersa foi utilizado na modelação da interface sólido/fluido, representada pela geometria de fundo dos canais. As equações de Navier-Stokes filtradas e da Continuidade foram resolvidas numericamente pelo Método de Passos Fracionados, o qual estabeleceu o almejado acoplamento entre ambas. Na discretização das equações governantes foi utilizado o Método de Diferenças Finitas, aplicado sobre malhas deslocadas. Os esquemas explícitos de Adams-Bashforth (de segunda e quarta ordens) foram utilizados no avanço temporal das velocidades do escoamento e das concentrações de sedimentos. Uma nova formulação para a velocidade de sedimentação foi desenvolvida analiticamente, enquanto que eventuais fluxos de ressuspensão foram impostos como condição de contorno no fundo do canal. Todos os códigos computacionais, que estabeleceram as diretrizes e a lógica de cálculo, foram criados no contexto deste trabalho. Os resultados obtidos indicam que a Simulação de Grandes Escalas, associada ao Método de Fronteira Imersa, considerando velocidade de sedimentação conforme aqui modelada, e ainda utilizando a equação de Advecção-Difusão para o transporte de massa, constituem ferramentas altamente adequadas à estimativa do transporte de sedimentos pela água.

Palavras-chave: Turbulência, Transporte de sedimentos, Simulação de Grandes Escalas, Método de Fronteira Imersa. 


\section{Abstract}

ALAMY FILHO, J. E. Numerical modeling of settling processes in turbulent flows and channel re-suspension analysis. 2006. 231 p. Thesis (Doctoral) - Escola de Engenharia de São Carlos, Universidade de São Paulo, São Carlos, 2006.

The goal of this work is the research of sediment transport phenomena, deriving from outstanding turbulent eddies estimative. Thus, the mass transport equation (AdvectionDiffusion) was connected with the filtered Navier-Stokes and Continuity equations. In this context, the Large-Eddy Simulation and sub-grid viscosity modeling established a convenient description of turbulence effects. The Immersed Boundary Method was applied to model solid/fluid interface, represented here by the shapes of channel bottom. The filtered NavierStokes and Continuity equations were solved by the Fractional Step Method. The equations were discretized with the Finite Difference Method, applied over staggered grids, whereas explicit Adams-Bashforth schemes (second and forth orders) were used in temporal advancement of velocities and sediment concentration fields. A new analytical formulation for settling velocity was obtained, while fortuitous re-suspension flux was applied like a boundary condition in the channel bottom. The computational code was totally developed in this work. The results of present simulations show that Large-Eddy Simulation coupled to the Immersed Boundary Method, considering, yet, the settling velocity of particles and the Advection-Diffusion equation for mass transport, constitute potential tools for sediment transport evaluation in water flows.

Keywords: Turbulence, Sediment transport, Large-Eddy Simulation, Immersed Boundary Method. 


\section{Lista de Figuras}

FIGURA 2.1 - Nos escoamentos laminares, as perturbações são inibidas até que seja atingida uma situação de equilíbrio. Nos escoamentos turbulentos qualquer perturbação injetada é amplificada, tornando o sistema naturalmente instável

FIGURA 2.2 - As diversas escalas de turbulência podem coexistir, indicando a característica chamada de multiplicidade de escalas. Note-se que, numa simulação numérica, a captura de todas as escalas só é possível com uma discretização muito refinada

FIGURA 2.3 - O espectro de energia cinética turbulenta relaciona a escala de comprimento das estruturas turbulentas com o nível de energia que elas possuem

FIGURA 2.4 - Cascata de energia cinética turbulenta. A energia recebida pelas grandes estruturas turbilhonares é distribuída para as menores escalas, num sentido preferencial de transmissão, até que haja dissipação completa nas escalas viscosas

FIGURA 2.5 - Espectros de energia para diferentes números de Reynolds (retirado de BHATTACHARJEE e NO, 2001). Quanto mais o escoamento se aproxima de ser turbulento, maior é o número de escalas e, portanto, maior é a largura do espectro de energia

FIGURA 2.6 - Diagrama resumo sobre as diferentes formas de modelagem da turbulência

FIGURA 2.7 - Refinamentos espacial e temporal para a SND: as células devem ter, pelo menos, dimensões equivalentes às escalas dissipativas $\left(\ell_{d}\right)$ e os incrementos de tempo devem equivaler à duração destas escalas $(\tau)$. Estes dois aspectos permitem estimar numericamente campos de velocidade e pressão rigorosamente instantâneos .......

FIGURA 2.8 - Número de células (graus de liberdade) exigidas pela SND para diferentes números de Reynolds

FIGURA 2.9 - Na modelagem clássica, uma grandeza instantânea, como por exemplo a velocidade, é dividida em duas escalas: a média mais a sua flutuação temporal $\left(u_{i}=\bar{u}_{i}+u_{i}^{\prime}\right)$

FIGURA 2.10 - Diferença entre campos de velocidade instantâneos e médios. A representação do escoamento apenas pela escala média temporal alivia as instabilidades

FIGURA 2.11 - Critérios para suspensão incipiente de sedimentos baseados nas condições de cisalhamento junto ao leito dos canais (retirado de VAN RIJN, 1984) 
FIGURA 2.12 - Estruturas turbilhonares de origem cisalhante entre duas regiões de velocidades distintas

FIGURA 2.13 - Surgimento de turbilhões de grande escala com origem cisalhante a jusante das cristas de uma duna

FIGURA 2.14 - Origem das estruturas explosivas que ocorrem sobre o fundo de canais (retirado de SILVEIRA NETO, 2003): (a) vista frontal; (b) esquema de vista longitudinal; (c) vista ampliada

FIGURA 2.15 - Desenvolvimento longitudinal de estruturas explosivas sobre um fundo plano (retirado de PIOMELLI, 1999)

FIGURA 2.16 - Mecanismo de suspensão de sedimento do leito de um canal (retirado de RASHDI et al., 1990)

FIGURA 2.17 - Esquema dos vórtices de Görtler sobre uma superfície côncava (retirado de SILVEIRA NETO, 2003) .

FIGURA 2.18 - Vórtices de Görtler que aparecem em seções transversais ao sentido preferencial do escoamento

FIGURA 3.1 - Divisão do espectro de energia cinética turbulenta para aplicação da SGE: as grandes escalas são estimadas diretamente, enquanto que um modelo de turbulência é aplicado, levando em conta o efeito das estruturas turbilhonares de pequena escala

FIGURA 3.2 - O domínio de escoamento é discretizado por um filtro de espessura $\Delta$ que captura as grandes escalas, mas que não retém as escalas sub-malha

FIGURA 3. 3 - A divisão das escalas ocorre na região inercial do espectro de energia cinética turbulenta. As grandes escalas podem ser estipuladas aproximadamente de acordo com geometrias características do escoamento. As escalas dissipativas podem ser estimadas a partir da equação (3.2)

FIGURA 3. 4 - Aplicação da filtragem sobre uma curva instantânea de uma variável genérica $(\varphi)$. O efeito da operação proporciona uma suavização da curva original ..........

FIGURA 3.5 - Representação de uma célula do domínio e das variáveis relevantes na operação de filtragem. Note-se que esta operação ocorre apenas dentro de cada célula discreta

FIGURA 3.6 - O filtro de Gauss leva em conta a influência da distância (atua como um peso) que cada elemento de volume está do centro da célula. Note-se que regiões fora da célula ainda são influenciadas

FIGURA 3.7 - Função filtro por volume: somente elementos de volume dentro da célula são relevantes, independentemente da sua distância ao centro da mesma 
FIGURA 3.8 - Na filtragem por volume as grandezas resultantes (filtradas) representam a média (no espaço) das grandezas instantâneas dentro de cada célula

FIGURA 3.9 - A fixação da escala de corte determina o nível de refinamento imposto à malha. No caso (a) a escala de corte foi fixada na região de grandes estruturas turbilhonares, constituindo uma alternativa muito grosseira. No caso (b) houve fixação na faixa inercial, constituindo uma alternativa intermediária. Finalmente o caso (c) demonstra a fixação de uma escala de corte próxima da faixa dissipativa. Esta última alternativa fornece menores erros numéricos, embora demande um custo computacional bastante elevado

FIGURA 4.1 - Discretização com células ortogonais: os limites do domínio são substituídos por formas recortadas

FIGURA 4.2 - Discretização de um domínio com geometria irregular, utilizando malha não-estruturada

FIGURA 4.3 - Tratamento de um domínio com geometria irregular, utilizando discretização coincidente com a fronteira

FIGURA 4.4 - No Método de Fronteira Imersa, o domínio real de escoamento é estendido para um domínio regular, discretizado por uma malha fixa e cartesiana (euleriana), acoplada a outra malha (lagrangeana) constituída por um conjunto de pontos que representam apenas a interface imersa

FIGURA 4.5 - Esquema de tensões elásticas que produzem a ligação entre os pontos lagrangeanos

FIGURA 4.6 -Representação tridimensional da fronteira imersa por um conjunto de pontos dispostos paralelamente. O traçado de linhas horizontais e verticais, a partir de cada ponto lagrangeano $\vec{x}_{k}=\left(x_{k}, y_{k}, z_{k}\right)$, determina os pontos 1 e 2 (espaçados de $\mathrm{dx}$ ), 3 e 4 (espaçados de dy) e 5 e 6 (espaçados de dz)

FIGURA 4.7 - Função de distribuição / interpolação utilizada no MFV

FIGURA 4.8 - Região de abrangência para interpolar velocidades e pressão no ponto auxiliar 4. Nota-se que as variáveis seguem um arranjo deslocado na malha euleriana. Este procedimento também é repetido para os demais pontos auxiliares

FIGURA 4.9 - A distribuição da força interfacial $(\vec{f})$ no corpo do escoamento provoca um campo de força resultante $(\vec{F})$ que faz a partícula de fluido reconhecer a fronteira sólida

FIGURA 5.1 - Malha deslocada nos casos 2D e 3D: as velocidades são armazenadas nas faces das células, enquanto que os escalares são armazenados no centro 
FIGURA 5.2 - Indexação das variáveis num arranjo deslocado tridimensional

FIGURA 5.3 - Esquema geral do Método de Passos Fracionados: somente após a solução da equação de Poisson é que são obtidos os campos finais de velocidade e pressão

FIGURA 5.4 - Esquema de decomposição, da matriz, na forma cheia, para o armazenamento esparso em três vetores. O uso deste esquema visa economizar memória computacional

FIGURA 5.5 - Algoritmo geral do PBiCGSTAB (retirado de BARRET et al., 1994) .....

FIGURA 5.6 - Multiplicação entre matriz e vetor utilizando o armazenamento esparso CRS (retirado de BARRET et al., 1994)

FIGURA 5.7 - Fluxos de massa de ressuspensão a partir do fundo de canais aluviais, atuando como condição de contorno para células adjacentes ao leito. O fluxo de massa é função da velocidade de cisalhamento e só ocorre quando condições cisalhantes críticas sobre o leito são superadas

FIGURA 5.8 - Comparação entre os critérios de erosão de Shields e das Figuras de Erosão

FIGURA 5.9 - (a) Esquema de sedimentação (para baixo $\left(\mathrm{V}_{1}\right)$ ) e escoamento da água (para cima $\left(\mathrm{V}_{2}\right)$ ); (b) Relação entre a área total ocupada pelas partículas e a área total do escoamento

FIGURA 5.10 - Ajuste da equação proposta aos dados experimentais de Tomkins et al. (2004) para sedimentação de areias

FIGURA 5.11 - Comparação da equação analítica proposta com relações empíricas e semi-empíricas

FIGURA 5.12 - (a) curvas analíticas ajustadas para sedimentação de areias com diferentes diâmetros; (b) variação dos parâmetros da equação analítica proposta com o diâmetro da partícula de areia

FIGURA 5.13 - Fluxos advectivos $(\dot{a})$ e difusivos $(\dot{d})$ de sedimentos nas faces das células adjacentes ao leito do canal

FIGURA 5.14 - Equivalência entre as malhas lagrangeana e euleriana. O ponto lagrangeano $\mathrm{k}$, onde é feita a análise de variação de cota, apresenta as mesmas coordenadas x e z (longitudinal e transversal) do centro da célula adjacente. Apenas é permitida a variação da cota $\mathrm{y}_{\mathrm{k}}$, a qual é calculada de acordo com os métodos descritos 
FIGURA 5.15 - Fluxograma resumo do código computacional

FIGURA 6.1 - Escoamento entre placas planas paralelas com domínio de escoamento estendido e parede inferior modelada pela malha lagrangeana

FIGURA 6.2 - Perfil de velocidade e campo de força euleriano no regime permanente ...

FIGURA 6.3 - Variação temporal do fator $\mathrm{L}_{2}$ para o escoamento entre placas paralelas

FIGURA 6.4 - Comparação entre perfis simulados e teóricos de velocidade e de tensão cisalhante

FIGURA 6.5 - Esquema do domínio real de escoamento estendido para o domínio de cálculo (retangular) com inserção da malha lagrangeana

FIGURA 6.6 - Variação do fator residual $\mathrm{L}_{2}$ com os níveis de tempo

FIGURA 6.7 - Evolução temporal dos vetores de velocidade. Destaque para a formação de estruturas turbilhonares de grande escala a jusante das cristas das dunas

FIGURA 6.8 - Evolução temporal das componentes horizontal e vertical de velocidade $[\mathrm{m} / \mathrm{s}]$

FIGURA 6.9 - Evolução temporal da vorticidade $[\mathrm{m} /(\mathrm{s} . \mathrm{m})]$ e das linhas de corrente.Percebe-se que os vales das dunas constituem regiões propensas a apresentar recirculações de fluido

FIGURA 6.10 - Estrutura turbilhonar de grande escala formada a jusante da crista de uma duna: comparação entre linhas de corrente instantâneas, simuladas neste trabalho, e visualizações experimentais de Rousseaux et al. (2004)

FIGURA 6.11 - Campos médios de vorticidade $[\mathrm{m} /(\mathrm{s} . \mathrm{m})]$ e pressão $\left[\mathrm{N} / \mathrm{m}^{2}\right]$. As estruturas turbilhonares de grande escala apresentam correlação espacial com os setores de baixa pressão. Todavia, a colisão dessas estruturas com as cristas das dunas acarreta setores de elevada pressão, imediatamente a montante das mesmas. As médias temporais foram calculadas sobre um intervalo de sessenta segundos

FIGURA 6.12 - Viscosidade sub-malha (adimensionalizada) na duna central do domínio. As maiores viscosidades turbulentas ocorrem onde os gradientes locais de velocidade são mais acentuados. Os vetores de velocidade representam médias temporais calculadas no decorrer de sessenta segundos

FIGURA 6.13 - Comparações entre os resultados da presente simulação $(\operatorname{Re}=8400)$ e as Simulações de Grandes Escalas sobre coordenadas curvilíneas $(\mathrm{Re}=2400)$, realizadas por Tseng e Ferziger (2004): (a) campos médios adimensionalizados de velocidade longitudinal $\left(\mathrm{u} / \mathrm{U}_{\mathrm{b}}\right)$; (b) campos médios adimensionalizados de velocidade vertical $\left(\mathrm{v} / \mathrm{U}_{\mathrm{b}}\right)$. Neste caso, $\lambda$ representa o comprimento de onda e A representa a amplitude da ondulação 
FIGURA 6.14 - Transformação do domínio real no domínio computacional estendido ...

FIGURA 6.15 - Variação do fator residual $\mathrm{L}_{2}$ com os níveis de tempo 166

FIGURA 6.16 - Evolução temporal da vorticidade [m/(s.m)](continua) 168

FIGURA 6.16 - Evolução temporal da vorticidade [m/(s.m)](conclusão)

FIGURA 6.17 - Campos instantâneos de velocidade e linhas de corrente correlatas. Verifica-se a formação de zonas de recirculação instantâneas e movimentos ascendentes a partir do fundo do canal (continua)

FIGURA 6.17 - Campos instantâneos de velocidade e linhas de corrente correlatas. Verifica-se a formação de zonas de recirculação instantâneas e movimentos ascendentes a partir do fundo do canal (conclusão)

FIGURA 6.18 - Distribuição instantânea $\left(\mathrm{t}^{+}=1.7\right)$ do coeficiente de difusão efetivo na duna central

FIGURA 6.19 - Evolução temporal da concentração de sedimentos em correlação com velocidades de cisalhamento e fluxos de ressus pensão no fundo do canal (continua) .......

FIGURA 6.19 - Evolução temporal da concentração de sedimentos em correlação com velocidades de cisalhamento e fluxos de ressuspensão no fundo do canal (conclusão) .....

FIGURA 6.20 - Perfis de concentração no vale central do domínio: percebe-se que as maiores concentrações de sedimentos são mantidas junto ao fundo do canal, fato que destaca a influência da velocidade de sedimentação

FIGURA 6.21 - Lançamento de sedimentos a jusante das cristas por estruturas turbilhonares de grande escala

FIGURA 6.22 - Lançamento de sedimentos na forma de estruturas tipo "cogumelo".

FIGURA 6.23 - Comparação qualitativa entre resultados instantâneos da presente simulação (com a equação de Advecção-Difusão) e a simulação realizada por Chang e Scotti (2003) (com a equação de Maxey-Riley). No caso (a) tem-se: $R e=8750$ (baseado na altura efetiva do canal), e sedimento com densidade de 2,65; No caso (b) tem-se $\mathrm{Re}=6500$ (baseado na altura do canal) e sedimento com densidade de 1,50

FIGURA 6.24 - Evolução temporal da forma de fundo, representada por deformações na malha lagrangeana

FIGURA 6.25 - Transformação do domínio de escoamento real para o domínio computacional, discretizado pelas malhas euleriana e lagrangeana 
FIGURA 6.26 - Distribuição dos pontos lagrangeanos ao longo do domínio computacional. Esses pontos possuem coordenadas fixas ao longo das direções longitudinal e transversal. Apenas a cota é totalmente independente da malha euleriana e pode variar livremente em decorrência dos eventuais processos de deposição e erosão estimados

FIGURA 6.27 - Condições de contorno: (a) para as componentes de velocidade; (b) para os termos de correção de pressão

FIGURA 6.28 - Condições de contorno para a equação de Advecção-Difusão (concentração de sedimentos)

FIGURA 6.29 - Esquema de distribuição dos pontos auxiliares a partir da interface imersa (croquis)

FIGURA 6.30 - Esquema (croquis) da região de interpolação para o ponto auxiliar 4: (a) vista lateral; (b) vista frontal. As regiões situadas fora do domínio e abaixo da interface (hachuras) não são aproveitadas

FIGURA 6.31 - Evolução temporal do fator residual $\mathrm{L}_{2}$

FIGURA 6.32 - Iso-superfícies instantâneas da componente longitudinal de velocidade $[\mathrm{m} / \mathrm{s}]$

FIGURA 6.33 - Iso-superfícies instantâneas da componente vertical de velocidade $[\mathrm{m} / \mathrm{s}]$

FIGURA 6.34 - Iso-superfícies instantâneas da componente transversal de velocidade $[\mathrm{m} / \mathrm{s}]$

FIGURA 6.35 - Vetores de velocidade tangentes ao plano longitudinal central (continua)

FIGURA 6.35 - Vetores de velocidade tangentes ao plano longitudinal central (conclusão)

FIGURA 6.36 - Visualização de movimentos transversais (continua)

FIGURA 6.36 - Visualização de movimentos transversais (conclusão)

FIGURA 6.37 - Vorticidade $\left(\omega_{Z}\right)$ em torno do eixo transversal $(Z)$ : Iso-superfícies e curvas de contorno instantâneas no plano que passa pelo eixo do canal

FIGURA 6.38 - (a)Iso-superfícies de viscosidade turbulenta sub-malha; (b) Planos transversais com contornos de difusividade efetiva (molecular + turbulenta sub-malha) ..

FIGURA 6.39 - Evolução temporal da concentração de sedimentos

FIGURA 6.40 - Campos instantâneos $\left(\mathrm{t}^{+}=20.70\right)$ de concentração de sedimentos. Representação de diferentes planos horizontais. A posição vertical de cada corte foi adimensionalizada como $\mathrm{h}^{+}=\mathrm{y} / \mathrm{H}$ 
FIGURA 6.41 - Lançamento de sedimentos por estruturas turbilhonares no plano vertical que passa pelo eixo do domínio de escoamento

FIGURA 6.42 - Evolução temporal da forma de fundo (continua)

FIGURA 6.42 - Evolução temporal da forma de fundo (conclusão) 


\section{Lista de Tabelas}

TABELA 2.1 - Algumas expressões para velocidade de sedimentação como função da concentração de partículas

TABELA 5.1 - Parâmetros calibrados com base nos dados experimentais de Tomkins et al. (2004) com truncamento de terceira ordem

TABELA 5.2 - Variação dos parâmetros da equação (5.50) com o diâmetro da partícula de areia em sedimentação 


\section{Lista de Abreviaturas e Siglas}

SND : $\quad$ Simulação Numérica Direta

$\kappa-\varepsilon: \quad$ Modelo de turbulência $\kappa-\varepsilon$

SGE: $\quad$ Simulação de Grandes Escalas

MFI: $\quad$ Método de Fronteira Imersa

MFV: $\quad$ Modelo Físico Virtual

$\mathrm{L}_{2}$ : $\quad$ Termo residual do Método de Fronteira Imersa

CRS: Armazenamento esparso tipo "compressed row storage"

PBiCGSTAB: Método dos gradientes bi-conjugados estabilizado e pré-condicionado

SOR: $\quad$ Método de sobre-relaxação sucessiva

BiCGSTAB: Método dos gradientes bi-conjugados estabilizado

BiCG: $\quad$ Método dos gradientes conjugados

2D: $\quad$ Referência a um escoamento bidimensional

3D: $\quad$ Referência a um escoamento tridimensional

ADV: $\quad$ Somatório dos termos advectivos

DIF: $\quad$ Somatório dos termos difusivos

SED: $\quad$ Termo de sedimentação

SUL: $\quad$ Referência ao termo localizado na face sul (inferior) da célula

NOR: Referência ao termo localizado na face norte (superior) da célula

DIR: Referência ao termo localizado na face direita (leste) da célula

ESQ: $\quad$ Referência ao termo localizado na face esquerda (oeste) da célula

ANT: $\quad$ Referência ao termo localizado na face anterior (dianteira) da célula

POS: $\quad$ Referência ao termo localizado na face posterior (traseira) da célula

AB2: $\quad$ Esquema de Adams-Bashforth de segunda ordem

AB4: $\quad$ Esquema de Adams-Bashforth de quarta ordem 


\section{Lista de Símbolos}

\section{LETRAS LATINAS}

$\mathrm{u}=$ componente de velocidade longitudinal $\left[\mathrm{LT}^{-1}\right]$;

$\mathrm{v}=$ componente de velocidade vertical $\left[\mathrm{LT}^{-1}\right]$;

$\mathrm{W}=$ componente de velocidade transversal $\left[\mathrm{LT}^{-1}\right]$;

$\mathrm{P}=$ pressão $\left[\mathrm{ML}^{-1} \mathrm{~T}^{-2}\right]$

$\mathrm{x}, \mathrm{y}, \mathrm{z}=$ coordenadas nas direções longitudinal, vertical e transversal, respectivamente [L];

$\mathrm{t}=$ tempo $[\mathrm{T}]$;

$D=$ diâmetro médio do sedimento [L];

$\mathrm{D}=$ coeficiente de difusão molecular do sedimento $\left[\mathrm{L}^{2} \mathrm{~T}^{-1}\right]$;

$\mathrm{c}=$ concentração de sedimentos $\left[\mathrm{ML}^{-3}\right]$;

$\mathrm{W}_{\mathrm{s}}=$ velocidade de sedimentação $\left[\mathrm{LT}^{-1}\right]$;

$\mathrm{u} *=$ velocidade de cisalhamento $\left[\mathrm{LT}^{-1}\right]$;

$\mathrm{D}_{\mathrm{sm}}=$ difusividade turbulenta sub-malha do escoamento $\left[\mathrm{L}^{2} \mathrm{~T}^{-1}\right]$;

$\mathrm{D}_{\mathrm{EF}}=$ difusividade efetiva do escoamento $\left[\mathrm{L}^{2} \mathrm{~T}^{-1}\right]$;

$\vec{x}=$ vetor posição $[\mathrm{L}]$;

$\vec{V}=$ vetor velocidade $\left[\mathrm{LT}^{-1}\right]$;

$\mathrm{u}_{\mathrm{i}}=$ velocidade na direção $\mathrm{i}\left[\mathrm{LT}^{-1}\right]$;

$\mathrm{x}_{\mathrm{i}}=$ coordenada na direção i $[\mathrm{L}]$;

$\vec{f}=$ vetor densidade de força lagrangeana $\left[\mathrm{MLT}^{-2}\right]$;

$\vec{F}=$ vetor campo de força euleriano $\left[\mathrm{MLT}^{-2}\right]$;

$\dot{f}_{\text {RESS }}=$ fluxo de ressuspensão de sedimentos $\left[\mathrm{ML}^{-2} \mathrm{~T}^{-1}\right]$;

$\dot{a}=$ fluxo advectivo de massa de sedimentos $\left[\mathrm{ML}^{-2} \mathrm{~T}^{-1}\right]$;

$\dot{d}=$ fluxo difusivo de massa de sedimentos $\left[\mathrm{ML}^{-2} \mathrm{~T}^{-1}\right]$;

$\dot{d}_{R E S}=$ fluxo resultante de massa de sedimento na célula adjacente ao leito $\left[\mathrm{ML}^{-2} \mathrm{~T}^{-1}\right]$;

$\ell=$ escala de comprimento da estrutura turbilhonar $[\mathrm{L}]$;

$\mathrm{L}=$ escala de comprimento das grandes estruturas turbilhonares [L];

$\ell_{D}=$ comprimento característico das escalas dissipativas [L];

$k=$ número de onda; 
$\mathrm{k}=$ energia cinética turbulenta $\left[\mathrm{L}^{2} \mathrm{~T}^{-2}\right]$;

Re = número de Reynolds;

\section{LETRAS GREGAS}

$\rho=$ massa específica do fluido $\left[\mathrm{ML}^{-3}\right]$;

$\rho_{\mathrm{s}}=$ massa específica do sedimento $\left[\mathrm{ML}^{-3}\right]$;

$\mu=$ viscosidade dinâmica do fluido $\left[\mathrm{ML}^{-1} \mathrm{~T}^{-1}\right]$;

$v=$ viscosidade cinemática do fluido $\left[\mathrm{L}^{2} \mathrm{~T}^{-1}\right]$;

$\mu_{\mathrm{sm}}=$ viscosidade turbulenta sub-malha do escoamento $\left[\mathrm{ML}^{-1} \mathrm{~T}^{-1}\right]$;

$\varepsilon=$ taxa de dissipação de energia cinética turbulenta $\left[\mathrm{ML}^{2} \mathrm{~T}^{-3}\right]$;

$\delta_{\mathrm{ij}}=$ delta de Kronecker;

$\lambda=$ porosidade dos depósitos de sedimento;

$\phi=$ concentração volumétrica de sedimentos;

$\Delta_{1}=$ variação da cota do ponto lagrangeano;

$\sigma_{\mathrm{c}}=$ número de Schmidt;

$\tau=$ escala de tempo dissipativa;

$\Delta=$ espessura do filtro.

\section{ÍNDICES}

$\mathrm{i}=$ posição vertical na matriz;

$\mathrm{j}=$ posição longitudinal na matriz;

$\mathrm{k}=$ posição transversal na matriz;

$\mathrm{k}$ = referência ao ponto lagrangeano;

$\mathrm{n}=$ nível de tempo;

$1,2,3,4,5,6=$ pontos auxiliares;

\section{OPERADORES MATEMÁTICOS}

$\nabla=$ operador nabla;

$\nabla^{2}=$ operador laplaciano;

$\partial=$ derivada parcial;

$\Delta$ = diferença finita;

“_ " = operador filtro; 


\section{Sumário}

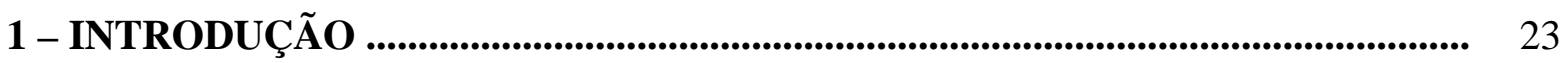

2 - REVISÃO BIBLIOGRÁFICA ….................................................................... 27

2.1 - TURBULÊNCIA NOS FLUIDOS ........................................................................ 27

2.1.1 - TENTATIVA DE DEFINIÇÃO ......................................................................... 27

2.1 .2 - CARACTERÍSTICAS _......................................................................... 28

2.1.2.1 - A imprediscibilidade (ou imprevisibilidade) ……………………………….... 28

2.1.2.2 - Dominância dos efeitos advectivos ................................................................ 29

2.1.2.3- Capacidade de mistura ................................................................................... 31

2.1.2.4- Vorticidade obrigatória …………………………..................................... 31

2.1.2.5 - Dissipação da turbulência ................................................................................ 32

2.1.2.6 - Multiplicidade de escalas ............................................................................. 32

2.1.3 - ESPECTRO DE ENERGIA CINÉTICA TURBULENTA .................................. 33

2.1.4 - AS EQUAÇÕES GOVERNANTES ............................................................. 38

2.1.5 - ASPECTOS DE MODELAGEM DA TURBULÊNCIA …................................. 40

2.1.5.1 - A Simulação Numérica Direta (SND) ……………………………………..... 41

2.1.5.2 - A Modelagem clássica da turbulência ............................................................... 44

2.1.5.3 - A Simulação de Grandes Escalas (SGE) …………………………………....... 47

2.2 - TRANSPORTE DE SEDIMENTOS ............................................................... 48

2.2.1 - CRITÉRIOS DE EROSÃO .......................................................................... 48

2.2.2 - GENERALIDADES SOBRE OS MODELOS CLÁSSICOS DE TRANSPORTE

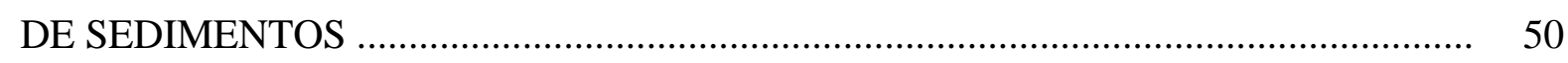

2.2.3 - ESTRUTURAS TURBULENTAS E TRANSPORTE DE SEDIMENTOS ......... 51

2.2.3.1- Turbilhões de grande escala ..................................................................... 52

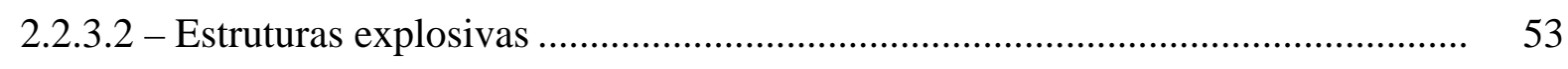

2.2.3.3 - Vórtices de Görtler ................................................................................... 56

2.2.4 - VELOCIDADE DE SEDIMENTAÇÃO ......................................................... 57

2.2.5 - EQUAÇÕES GOVERNANTES DO TRANSPORTE DE SEDIMENTOS ......... 59

2.2.5.1 - Equação de Maxey-Riley …………………………………………………... 60

2.2.5.2 - Equação de Adveç̧ão-Difusão .......................................................................... 64 
3 - SIMULAÇÃO DE GRANDES ESCALAS ................................................................ 66

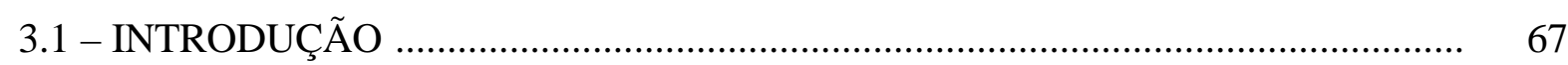

3.2 - ESTIMATIVA DA ESPESSURA DO FILTRO (DISCRETIZAÇÃO ESPACIAL

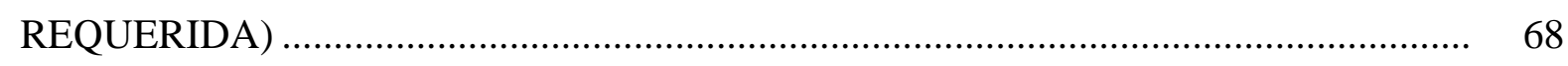

3.3 - A FILTRAGEM DAS EQUAÇÕES GOVERNANTES …...................................... 71

3.4 - EQUAÇÕES DE NAVIER-STOKES E DA CONTINUIDADE FILTRADAS ....... 76

3.5 - EQUAÇÃO DE ADVECÇÃO-DIFUSÃO FILTRADA …....................................... 79

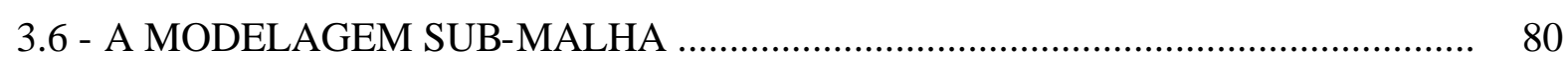

3.6.1 - MODELO SUB-MALHA DE SMAGORINSKY ……………………………... 80

3.6.1 - MODELO SUB-MALHA FUNÇÃO ESTRUTURA DE VELOCIDADE .......... 81

3.6.3 - AMORTECIMENTO PARA ESCOAMENTOS PARIETAIS ............................. 81

3.7 - ALGUNS ASPECTOS NUMÉRICOS ............................................................ 83

4 - MÉTODO DE FRONTEIRA IMERSA .......................................................... 86

4.1 - INTRODUÇÃO ...................................................................................... 86

4.2 - MÉTODO DE FRONTEIRA IMERSA - GENERALIDADES ….......................... 89

4.3 - TIPOS DE FRONTEIRAS IMERSAS ........................................................ 90

4.3.1 - INTERFACES ELASTICAMENTE DEFORMÁVEIS ...................................... 90

4.3.2 - INTERFACES ENTRE FLUIDOS IMISCÍVEIS _............................................. 92

4.3 .3 - INTERFACES SÓLIDAS _.......................................................................... 95

4.4 - MODELO FÍSICO VIRTUAL (MFV) ............................................................. 96

4.4.1 - INTRODUÇÃO ..................................................................................... 96

4.4.2 - CÁLCULO DA FORÇA LAGRANGEANA ………………………………..... 97

4.4.3 - ESPALHAMENTO DA FORÇA LAGRANGEANA ……………………….... 102

4.5 - APRECIAÇÕES FINAIS ............................................................................... 104

5 - METODOLOGIA ................................................................................. 105

5.1 - ARRANJO DAS VARIÁVEIS ..................................................................... 105

5.2 - TRATAMENTO NUMÉRICO DAS EQUAÇÕES FILTRADAS DE NAVIER-

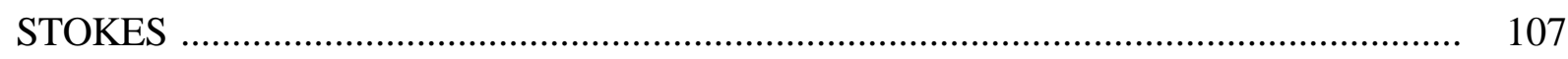

5.2 .1 - GENERALIDADES .................................................................................. 107

5.2.2 - AVANÇO TEMPORAL DAS VELOCIDADES ................................................ 108

5.2.2.1 - Esquema de Adams-Bashforth de segunda ordem ........................................... 108

5.2.2.2 - Esquema de Adams-Bashforth de quarta ordem .............................................. 109

5.2.3 - MODELAGEM SUB-MALHA …………………………………………..... 109 
5.2.3.2 - Modelo função estrutura de velocidade de segunda ordem.

5.2.4 - ESTIMATIVA DA VELOCIDADE DE CISALHAMENTO

5.3.1 - A ETAPA PREDITORA

5.3.2 - A ETAPA CORRETORA

5.4 - ASPECTOS DO TRATAMENTO NUMÉRICO DA EQUAÇÃO DE POISSON PARA OS TERMOS DE CORREÇÃO DE PRESSÃO

5.5 - MÉTODO DE GRADIENTES BI-CONJUGADOS ESTABILIZADO PRÉCONDICIONADO (PBiCGSTAB)

5.6 - TRATAMENTO NUMÉRICO DA EQUAÇÃO DE ADVECÇÃO-DIFUSÃO FILTRADA

5.7 - DESENVOLVIMENTOS ANALÍTICOS ACERCA DA VELOCIDADE DE SEDIMENTAÇÃO

5.7.1 - PRINCÍPIOS BÁSICOS

5.7.2 - VELOCIDADE DE SEDIMENTAÇÃO E ENERGIA CINÉTICA

5.7.2.1 - Velocidade de sedimentação para coeficiente de arrasto constante (menores concentrações volumétricas)

5.7.2.2 - Velocidade de sedimentação para coeficiente de arrasto variando com o inverso do número de Reynolds (maiores concentrações volumétricas)

5.7.3 - CALIBRAÇÃO DAS EQUAÇÕES PROPOSTAS

5.8 - ANÁLISE DA VARIAÇÃO DA FORMA DE FUNDO

5.9 - FLUXOGRAMA GLOBAL DE CÁLCULO

6 - RESULTADOS

6.1 - ESCOAMENTO ENTRE PLACAS PLANAS PARALELAS

6.2 - ESCOAMENTO SOBRE FORMA DE FUNDO ONDULADA

6.3 - SIMULAÇÃO DO TRANSPORTE DE SEDIMENTOS SOBRE FORMAS DE FUNDO ALUVIAIS (CASO BIDIMENSIONAL) 
FUNDO ALUVIAIS (CASO TRIDIMENSIONAL)

7 - CONCLUSÕES 204

REFERÊNCIAS 209

APÊNDICES

APÊNDICE A - DISCRETIZAÇÃO DAS EQUAÇÕES FILTRADAS DE NAVIERSTOKES (CASO TRIDIMENSIONAL)

A.1.1 - Componente das Equações de Navier-Stokes na direção longitudinal (direção x)

A.1.2 - Componente das Equações de Navier-Stokes na direção vertical (direção y) ......

A.1.3 - Componente das Equações de Navier-Stokes na direção transversal (direção z)..

APÊNDICE B - DISCRETIZAÇÃO DA EQUAÇÃO DE ADVECÇÃO-DIFUSÃO FILTRADA (CASO TRIDIMENSIONAL)

APÊNDICE C - DISCRETIZAÇÃO DAS EQUAÇÕES FILTRADAS DE NAVIERSTOKES (CASO BIDIMENSIONAL)

C.1.1 - Componente das Equações de Navier-Stokes na direção longitudinal (direção x) 226

C.1.2 - Componente das Equações de Navier-Stokes na direção vertical (direção y) ....... 228 APÊNDICE D - DISCRETIZAÇÃO DA EQUAÇÃO DE ADVECÇÃO-DIFUSÃO FILTRADA (CASO BIDIMENSIONAL) 


\section{Introdução}

Os processos erosivos, decorrentes da interação entre o escoamento e as paredes delimitantes dos corpos de água, tanto quanto o transporte de partículas por escoamentos turbulentos, instigam a argúcia de engenheiros e estudiosos na área da Hidráulica Fluvial. Tais processos ocorrem comumente em rios, canais de irrigação ou navegação, estuários, reservatórios e bacias de sedimentação. Por conseguinte, o projeto e a operação desses sistemas exigem da Engenharia conhecimentos mais incisivos a respeito do fenômeno de transporte de sedimentos. Os primeiros estudos relacionados à descrição física e matemática deste problema já somam cerca de cento e cinqüenta anos (Lei de Sedimentação de Stokes). A despeito disto, o entendimento detalhado do fenômeno é ainda incipiente. A maioria dos estudos realizados nesta área é amparada pelo empirismo, gerando formulações discutíveis quanto à sua universalidade. Note-se que não se efetua aqui uma crítica aos procedimentos empíricos, uma vez que os mesmos são fundamentais para que a pesquisa se mantenha junto à realidade. Apenas argumenta-se que a busca de um entendimento mais geral exige uma rediscussão dos conceitos em voga, no sentido de encontrar o caminho mais viável para uma representação mais adequada dos fenômenos de erosão e deposição.

O conhecimento razoavelmente recente das estruturas turbulentas que possuem relações mais diretas com a ressuspensão e o transporte de partículas trouxe nova diretriz às pesquisas. Apesar da complexidade dos movimentos turbulentos, essa frma de abordar o fenômeno atua como um estímulo a novas investigações nesta área. Porém, também se verifica a necessidade de descrever dois processos intricados, mesmo quando tratados isoladamente: a turbulência e o transporte de sedimentos. Mais do que isto, surge a necessidade de estabelecer vínculos quantificáveis entre esses dois fenômenos.

A aplicação da Segunda Lei de Newton e do Princípio da Conservação de Massa num volume de controle infinitesimal permite obter as equações diferenciais parciais exatas que governam os processos turbulentos. A equação que descreve a concentração de sedimentos ao 
longo de um escoamento é também obtida através da aplicação do Princípio da Conservação de Massa num volume de controle adequado. Dessa forma, a quantificação do processo de transporte de sedimentos exige a resolução das formulações que descrevem os campos de pressão e velocidade e das formulações que descrevem o transporte de uma grandeza escalar, neste caso, a concentração de sedimentos. A não linearidade inerente à formulação governante dos movimentos dos fluidos representa ainda um empecilho para a resolução analítica mais geral dos campos turbulentos. Como conseqüência, os campos escalares associados, cuja formulação costuma ser linear, também ficam sem solução. Fatores como estes condicionam os procedimentos de análise e conduzem à solução numérica das equações, a qual permite, através de artifícios convenientes, suplantar as dificuldades decorrentes das não-linearidades. Além disso, graças à disponibilidade dos modelos de turbulência, podem-se estimar os vários efeitos decorrentes da turbulência nos fluidos através de métodos numéricos aproximados. Dessa maneira, a simulação dos mecanismos de transporte de sedimentos também pode ser levada em conta no âmbito dos modelos de turbulência.

O presente trabalho teve por meta mais ampla a construção de um código computacional próprio, considerando equacionamentos que regem os fenômenos turbulentos e o transporte de partículas em canais. A despeito da razoável quantidade de códigos comerciais atualmente disponíveis, a pesquisa de novas formas de modelação constitui uma alternativa muito atraente. Primeiro, porque os programas comerciais são exageradamente caros, sendo que muitos deles carecem de renovações periódicas da sua licença. Segundo, porque tais programas possuem código fechado e faixas restritas de variação de parâmetros, impedindo que sejam testadas várias alternativas que muitas vezes podem ser necessárias para cada problema particular. Finalmente, só a pesquisa permite a avaliação de novas metodologias, sem as quais o estado de conhecimento permaneceria estacionário, restringindo-se apenas à aplicação dos referidos códigos comerciais. Descarta-se aqui, qualquer intenção de crítica a esses programas, visto que os mesmos são ferramentas poderosas para avaliações de casos práticos. Contudo, os códigos "fechados" podem constituir barreiras no estudo dos fundamentos de um fenômeno, onde, muitas vezes, se faz necessário o acoplamento de novas metodologias. Vale lembrar que os fenômenos físicos relacionados à sedimentação e ressuspensão ainda necessitam de formulações mais precisas que os vinculem à turbulência. Os códigos comerciais utilizam aproximações cuja validade não pode ser generalizada, o que destaca, portanto, a importância da investigação científica de novas alternativas.

Este texto está estruturado em sete capítulos, levando-se em conta esta Introdução, os quais permitem detalhar adequadamente os fundamentos teóricos do fenômeno estudado, das 
metodologias aplicadas, a ilustração dos resultados obtidos e as conclusões acerca dos mesmos. No Capítulo 2 realiza-se uma breve revisão acerca dos fenômenos de turbulência e de transporte de sedimentos, ora descrevendo os fenômenos isoladamente, ora buscando estabelecer convenientemente relações entre ambos. As equações governantes são apresentadas, fornecendo o embasamento dos capítulos seguintes. O Capítulo 3 é dedicado à Simulação de Grandes Escalas (SGE), metodologia utilizada no tratamento da turbulência. O Capítulo 4 descreve o Método de Fronteira Imersa (MFI) utilizado na modelagem da interface entre o escoamento e o fundo do canal. O Capítulo 5 resume os aspectos metodológicos da solução global do problema. O Capítulo 6 apresenta resultados obtidos, enquanto que o Capítulo 7 traz as conclusões a respeito do trabalho.

Vale aqui mencionar que o código computacional utilizado foi totalmente desenvolvido no presente trabalho de doutorado, desde o entendimento dos fenômenos físicos, inclusive com quantificações originais; passando pelo entendimento e aplicação das ferramentas numéricas, até a implantação e teste dos códigos criados. Além disso, é conveniente citar que duas metodologias das mais modernas na simulação de escoamentos foram aqui seguidas e devidamente adaptadas: a Simulação de Grandes Escalas e o Método de Fronteira Imersa. Este trabalho, portanto, engloba todas as partes do processo criativo e gerador de um código computacional, que deve apresentar algumas características mais adequadas ao estudo de transporte de sedimentos do que os atualmente existentes. Adicionado a isto, sempre há que se considerar que esta pesquisa constitui o início da obtenção de um produto cujos similares são importados, caros e, muitas vezes, apenas cedidos por um tempo determinado.

Os objetivos deste trabalho de pesquisa podem ser divididos em duas classes, representando metas principais e metas específicas (ou complementares). Assim, pode-se dizer que o objetivo primordial foi a construção de um código computacional que permitisse relacionar o transporte de sedimentos com as estruturas verificadas em escoamentos turbulentos. Para a consecução deste objetivo buscou-se inicialmente a compreensão física dos dois fenômenos, o que permitiu a aplicação adequada das equações governantes, na sua forma diferencial, para a obtenção de um detalhamento mais efetivo do escoamento. Ferramentas modernas da Mecânica dos Fluidos Computacional foram aplicadas e devidamente adaptadas, sendo ainda implementadas formulações originais decorrentes da análise física dos problemas. 
O objetivo primário demanda, naturalmente, a realização de tarefas que possuem objetivos específicos, os quais devem convergir para atingir uma meta global. Os objetivos específicos podem ser, assim, arrolados:

- Aplicação da Simulação de Grandes Escalas, acoplada a modelos sub-malha;

- Adaptação do Método de Fronteira Imersa com Modelo Físico Virtual na modelação do leito dos canais;

- Uso da equação de Advecção-Difusão para o transporte de sedimentos;

- Modelação da Velocidade de Sedimentação;

Neste trabalho procuroutse estudar os fenômenos relacionados ao transporte de partículas por caminhos não triviais, evitando, até quando se pôde, a aplicação de modelos essencialmente empíricos e, até mesmo, de modelos analíticos ou numéricos clássicos. Nesse sentido, buscourse observar o fenômeno de transporte de sedimentos a partir de um novo ponto de vista, de forma que não se incorresse em respostas já conhecidas, vinculadas às hipóteses e ferramentas tradicionais. O autor, enfim, considera que esta seja, talvez, a maior contribuição deste texto. 


\section{Revisão Bibliográfica}

Uma conveniente revisão é realizada neste capítulo, de forma a descrever as características e as equações fundamentais dos fenômenos de turbulência e transporte de sedimentos. Como há estreita relação entre os dois fenômenos, sendo que o primeiro condiciona mais fortemente o segundo, o autor julgou adequado dividir o capítulo em duas partes. Assim, a primeira parte é dedicada ao assunto turbulência nos fluidos, enquanto que a parte final engloba aspectos do transporte de sedimentos. Esta divisão, meramente didática, aponta conceitos que são utilizados nos capítulos posteriores sem, contudo, significar a desvinculação entre os dois temas. Muito pelo contrário, a relação entre ambos é destacada sempre que possível.

\section{1 - TURBULÊNCIA NOS FLUIDOS}

\subsection{1 - TENTATIVA DE DEFINIÇÃO}

Um escoamento pode ser entendido como turbulento se as grandezas que o caracterizam (velocidade, pressão e demais relevantes), apresentam instabilidades indicadas por valores instantâneos que variam, no espaço e no tempo, com características que "lembram" fenômenos caóticos. Todavia, a aparente aleatoriedade dos movimentos dos fluidos é uma questão discutível, uma vez que a aplicação do balanço de forças num volume infinitesimal de fluido redunda nas leis matemáticas exatas que governam seu movimento: as equações de Navier-Stokes. Isto vem indicar que o fenômeno pode ser descrito de forma determinística, em detrimento da concepção intuitiva de que os movimentos dos fluidos sejam aleatórios por completo.

Segundo Rodi (2000), a turbulência se relaciona com movimentos turbilhonares que, para elevados números de Reynolds, apresentam um grande espectro de dimensões e de 
velocidades. Com intuito de proporcionar uma definição mais objetiva do fenômeno, Lesieur (1997) aponta três propriedades fundamentais da turbulência: a imprediscibilidade, a elevada capacidade de mistura e a multiplicidade de escalas. Neste sentido, percebe-se a busca de características que possam ser consideradas comuns a todos os escoamentos turbulentos. Silveira Neto (2003) destaca que, no estado atual de conhecimento, qualquer tentativa de definição seria incompleta, sendo de mais valia caracterizar a turbulência em vez de defini-la. De fato, nota-se que, na ausência de uma definição geral de turbulência, a compreensão das suas características proporciona um melhor entendimento físico do fenômeno. O item seguinte comenta algumas características relevantes dos escoamentos turbulentos.

\subsection{2 - CARACTERÍSTICAS}

\subsubsection{1 - A imprediscibilidade (ou imprevisibilidade)}

De início, parece contraditória a idéia de não se poder prever um fenômeno que pode ser descrito por leis matemáticas exatas. Contudo, o termo imprediscibilidade (ou imprevisibilidade), quando aplicado a escoamentos turbulentos, está associado a duas conjunturas.

A primeira delas refere-se à incapacidade de reproduzir analiticamente, ou numericamente de forma exata, as condições iniciais e de contorno existentes em escoamentos de campo e, até mesmo, em escoamentos de laboratório. Assim, a capacidade de representar a rigorosa realidade das soluções das equações governantes torna-se restrita. Essas equações impõem que diferenças muito pequenas, nas condições iniciais, sejam amplificadas rapidamente pelas interações não lineares. Assim, quaisquer variações nas condições iniciais e de contorno determinam estados futuros diferentes nas previsões numéricas e experimentais. Assim, por exemplo, se duas partículas são lançadas, num escoamento turbulento, bem próximas uma da outra (situação inicial), as interações não lineares determinarão trajetórias cada vez mais distintas, para essas partículas, ao longo do tempo.

O segundo fator, que reforça a concepção de imprediscibilidade, é referente ao fato dos recursos computacionais disponíveis ainda serem insuficientes para capturar (simular) todas as estruturas turbulentas que surgem em escoamentos de campo e em grande parte dos experimentos em laboratório. As chamadas Simulações Numéricas Diretas (SND) das equações de Navier-Stokes ainda estão restritas a escoamentos simples e didáticos. O objetivo 
de simular problemas mais práticos impõe a necessidade de modelar os efeitos da turbulência. Sendo esta modelagem uma aproximação, será também uma fonte de erro.

\subsubsection{2 - Dominância dos efeitos advectivos}

Qualquer escoamento real pode ser entendido como a composição de dois mecanismos de transporte: advecção e difusão.

O transporte advectivo de quantidade de movimento força o escoamento a seguir uma direção preferencial, geralmente determinada por um fator externo, seja ele a injeção de fluido, gradiente de pressão ou diferenças de densidade. Este efeito aparece, nas equações governantes, como parcelas não lineares que atuam na geração de instabilidades e na amplificação das perturbações injetadas no escoamento. Assim, a questão da imprediscibilidade da turbulência está relacionada ao transporte advectivo de quantidade de movimento, o qual induz soluções bastante diferentes para condições de entrada quase próximas (conforme já mencionado).

O mecanismo difusivo, por sua vez, atua na tendência de equilibrar diferenças de quantidade de movimento entre as regiões do escoamento. Em outras palavras, procura distribuir a quantidade de movimento das regiões com elevada velocidade (relativa a um referencial) para setores de baixa velocidade (relativa a esse mesmo referencial). Os efeitos difusivos são responsáveis pela inibição e amortecimento das instabilidades.

A relação entre os efeitos advectivos e os efeitos difusivos é o parâmetro usualmente tomado para verificar se um escoamento é ou não turbulento, através de um critério numérico. É justamente assim que se define o número de Reynolds (Re). Quanto maiores forem os efeitos advectivos, maior será o grau de instabilidade e, portanto, provavelmente o escoamento apresentará maior grau de turbulência. Em contrapartida, quanto mais pronunciados forem os efeitos difusivos, maior será a inibição de instabilidades, fazendo com que o escoamento tenda a ser laminar (ver figura 2.1). 

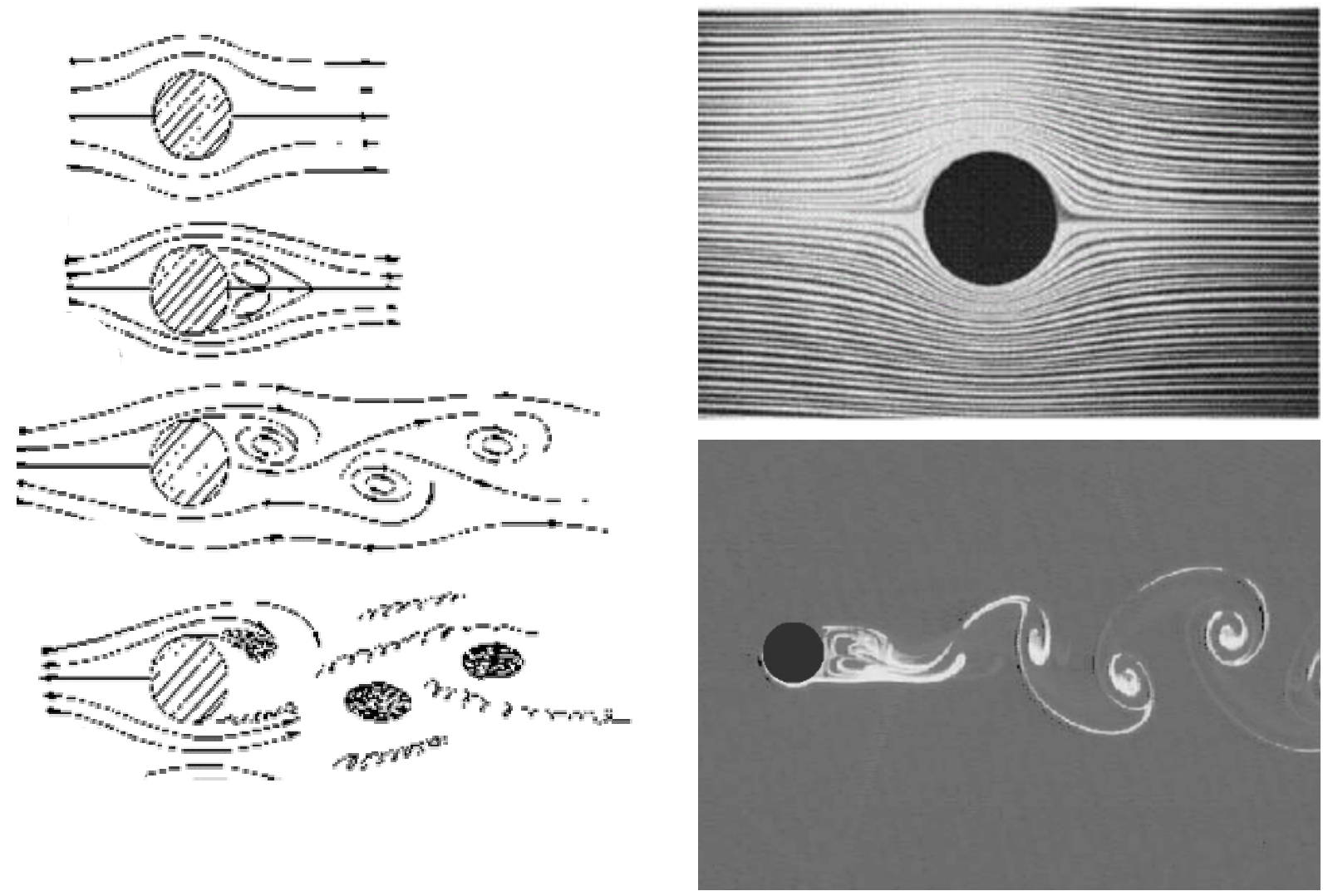

Figura 2.1 - Nos escoamentos laminares, as perturbações são inibidas até que seja atingida uma situação de equilíbrio. Nos escoamentos turbulentos qualquer perturbação injetada é amplificada, tornando o sistema naturalmente instável

Como um escoamento que apresenta elevados números de Reynolds é naturalmente instável, uma pequena perturbação irá gerar perturbações que se amplificam (devido aos efeitos não lineares). Assim, pelo balanço entre os efeitos advectivos e difusivos pode-se concluir que a turbulência é um fenômeno que ocorre quando o primeiro mecanismo é preponderante sobre o segundo. Tradicionalmente o número de Reynolds é definido como:

$$
\mathrm{Re}=\frac{\text { efeitos advectivos }}{\text { efeitos difusivos }}=\frac{\mathrm{U} \cdot \mathrm{L}}{?}
$$

Em que:

- $\mathrm{U}=$ velocidade característica do escoamento $\left[\mathrm{LT}^{-1}\right]$;

- $\mathrm{L}=$ dimensão característica do escoamento [L];

- $\quad v=$ viscosidade cinemática do fluido $\left[\mathrm{L}^{2} \mathrm{~T}^{-1}\right]$. 
A viscosidade, uma vez que foi definida e quantificada para fenômenos difusivos, torna-se o fator "físico" adequado para a descrição do amortecimento de instabilidades. O seu valor é, portanto, considerado relevante para "representar" os efeitos difusivos. Por outro lado, a velocidade, além de uma dimensão característica do domínio do escoamento, representam bem os efeitos advectivos, tendo em vista que a primeira impõe a direção preferencial, enquanto que a segunda sugere a ordem de grandeza das maiores estruturas turbilhonares.

\subsubsection{3- Capacidade de mistura}

Os escoamentos turbulentos são capazes de misturar quantidades (substâncias, sedimentos, energia, quantidade de movimento) de maneira mais rápida e eficaz do que os escoamentos laminares, nos quais prepondera a difusão molecular. Silveira Neto (2003) destaca que, no regime turbulento, a presença de flutuações térmicas e de concentração, além do transporte de parcelas de fluido para diferentes regiões, cria a ocorrência de fortes gradientes locais, trazendo maior eficácia ao processo de difusão. Nota-se assim que, embora sejam dominantes os efeitos advectivos, um escoamento turbulento também tem sua capacidade difusiva intensificada.

\subsubsection{4- Vorticidade obrigatória}

Um escoamento turbulento é obrigatoriamente rotacional, de forma que existe a tendência das parcelas de fluido girarem em torno de um ou vários eixos. Lesieur (1997) salienta que a presença de paredes impõe aos escoamentos regiões de velocidade nula que inevitavelmente irão produzir tendência de rotação, ou seja, vorticidade. A vorticidade gerada nessas regiões é ampliada pelo estiramento tridimensional de vórtices.

Os escoamentos turbulentos podem apresentar estruturas organizadas ou desorganizadas. Neste contexto torna-se conveniente a definição das chamadas estruturas coerentes. Estruturas coerentes são aquelas que apresentam certo grau de organização em relação a qualquer quantidade referente ao escoamento. Tais estruturas podem ocorrer na forma de turbilhões coerentes. Os maiores turbilhões que surgem num escoamento podem ser geralmente designados como coerentes, uma vez que conseguem manter sua forma definida por um tempo superior a um tempo característico (associado com a supressão da correlação de eventos subseqüentes) como, por exemplo, o seu tempo de rotação. Essas estruturas 
promovem a anisotropia do escoamento, uma vez que apresentam uma direção preferencial ditada pelo escoamento médio.

\subsubsection{5 - Dissipação da turbulência}

A presença dos efeitos viscosos impede que as instabilidades geradas num escoamento se prolonguem incessantemente. As maiores estruturas turbilhonares induzem movimentos de estruturas menores, as quais cedem energia, provocando movimentos de turbilhões menores ainda. Esta seqüência vigora até a formação de estruturas muito pequenas que são rapidamente inibidas pelo efeito da viscosidade do fluido. Assim, para se manter a turbulência em um escoamento é necessário o fornecimento contínuo de energia. $\mathrm{Na}$ falta desse fornecimento os efeitos da viscosidade dissipam toda a energia turbulenta de forma a estabilizar o escoamento. Tem-se, então, o chamado decaimento da turbulência.

\subsubsection{6 - Multiplicidade de escalas}

Um escoamento pode ser constituído por estruturas de dimensões variadas, desde as grandes escalas de comprimento, produzindo normalmente estruturas coerentes, até as pequenas escalas dissipativas. A multiplicidade de escalas induz à constatação de que turbilhões menores coexistem com turbilhões maiores (ver figura 2.2).

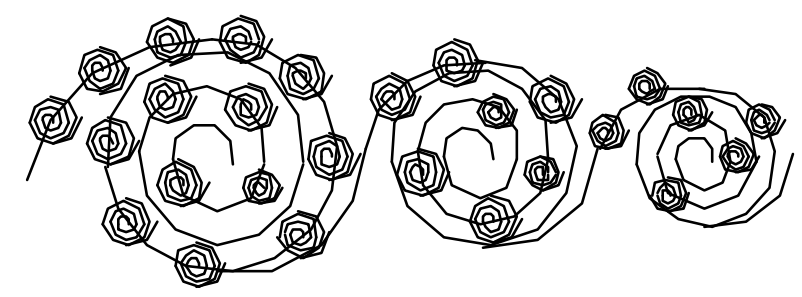

Figura 2 .2-As diversas escalas de turbulência podem coexistir, indicando a característica chamada de multiplicidade de escalas. Note-se que, numa simulação numérica, a captura de todas as escalas só é possível com uma discretização muito refinada

A concepção da coexistência de estruturas turbilhonares com várias escalas de comprimento é o princípio de diversas formas de modelagem de escoamentos turbulentos. A figura 2.2 sugere que a multiplicidade de escalas fornece noções interessantes a respeito do 
nível de discretização espacial em uma aproximação numérica e, conseqüentemente, da possibilidade de capturar estruturas mais grosseiras ou mais finas com esta discretização.

\subsection{3 - ESPECTRO DE ENERGIA CINÉTICA TURBULENTA}

As escalas de turbulência podem-se relacionar com a quantidade de energia cinética turbulenta contida nas diversas estruturas. Para um determinado escoamento, a relação de dependência entre o nível de energia cinética turbulenta e o tamanho das diversas estruturas turbilhonares é fornecida pelo espectro de energia, ilustrado pela figura 2.3.

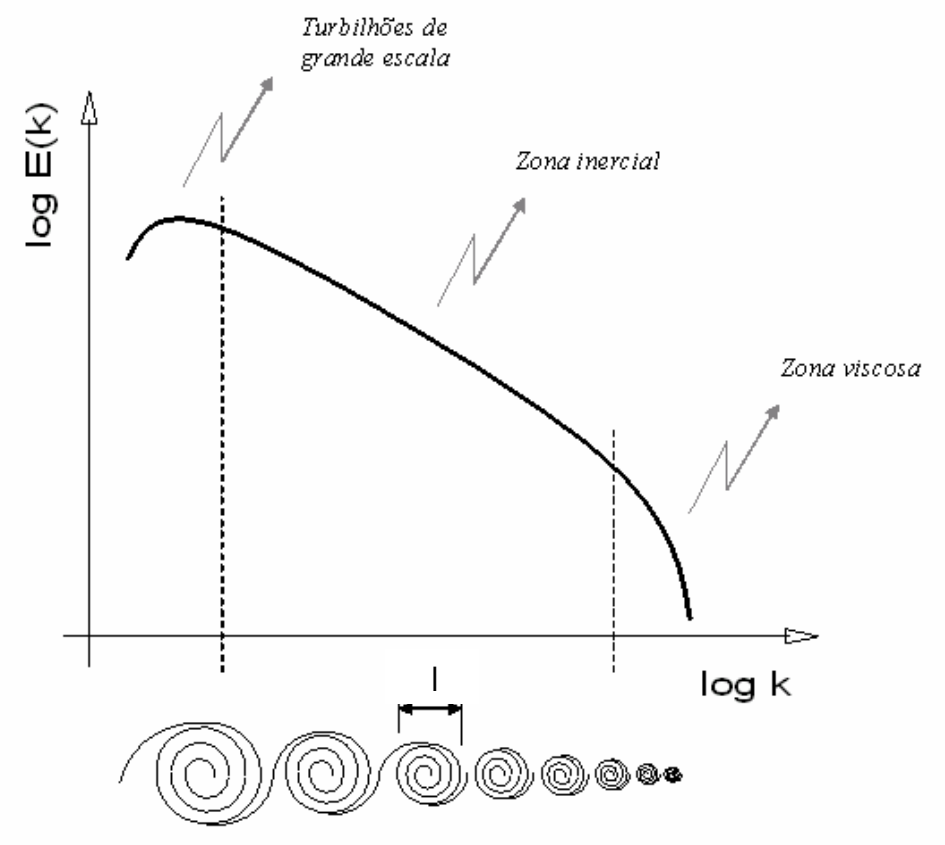

Figura 2.3 - O espectro de energia cinética turbulenta relaciona a escala de comprimento das estruturas turbulentas com o nível de energia que elas possuem

Na figura 2.3, o termo $\ell$ é definido como a escala de comprimento das estruturas turbulentas e $k \cong \frac{1}{\ell}$ é definido como o número de onda. O termo $E(k)$ representa o nível de energia contido nas diversas estruturas turbilhonares.

No estudo tradicional de turbulência, o espectro de energia é apresentado de modo a se identificar três regiões: a de grande escala, a inercial e a dissipativa. É necessário mencionar, entretanto, que para observar essas três regiões, algumas condições do escoamento turbulento devem ser satisfeitas. Ao longo do presente texto são tecidas algumas considerações quanto à observância dessas regiões em função do valor do número de Reynolds. 
A região de grande escala apresenta estruturas que contêm os maiores níveis de energia cinética turbulenta. Essa energia pode ser injetada no sistema, por exemplo, através da passagem do escoamento por alguma singularidade qualquer. As grandes estruturas turbilhonares, formadas justamente através dessa interação com o escoamento médio, são receptoras da energia turbulenta injetada e, por isso possuem escalas de comprimento relacionadas à geometria que as origina. Assim, por exemplo, o escoamento em torno de um obstáculo gera estruturas de grande escala cuja ordem de grandeza é aproximadamente equivalente à dimensão do obstáculo. Da mesma forma, um escoamento aluvial sobre uma duna gera estruturas vorticosas com dimensões similares à altura da crista dessa duna. As estruturas formadas nessa faixa do espectro apresentam, em geral, direção e forma bem definidas por um tempo superior ao seu tempo de rotação. Diante desse relativo grau de organização, as grandes escalas podem ser designadas como coerentes, conforme já foi previamente comentado. O tempo característico de duração de uma estrutura de grande escala $(t)$ pode ser estimado como:

$$
t=\frac{L}{U}
$$

Em que:

- $L=$ comprimento característico de um contorno físico que origina um turbilhão, ou escala de comprimento dos grandes turbilhões [L];

- $U=$ velocidade de transporte das grandes estruturas $\left[\mathrm{LT}^{-1}\right]$.

Note-se que a duração da estrutura turbulenta pode ser estimada a partir das características do domínio e do escoamento médio, uma vez que a velocidade $U$ pode ser tomada como a própria velocidade média do escoamento.

Na região inercial do espectro ocorre a transferência não linear de energia entre as diferentes escalas. As grandes estruturas turbulentas, na sua tendência de seguir a direção preferencial do escoamento, sofrem um processo de estiramento, gerando instabilidades que resultam na sua quebra e na distribuição da energia, formando estruturas menores. Este processo, comumente chamado de cascata de energia, se repete entre as diversas escalas, até que os efeitos viscosos se tornem suficientemente consideráveis para dissiparem a energia cinética (ver figura 2.4). A cascata de energia é dirigida preferencialmente no sentido das maiores para as menores escalas, ou seja da esquerda para a direita no espectro de energia. Isto, contudo, não representa uma regra rígida, pois alguns escoamentos - tipicamente aqueles 
dominados pela rotação - podem apresentar pequenos turbilhões que se agrupam em turbilhões maiores. Este último caso, por exemplo, denota que, embora em menor magnitude, também existe um sentido inverso de transmissão de energia.

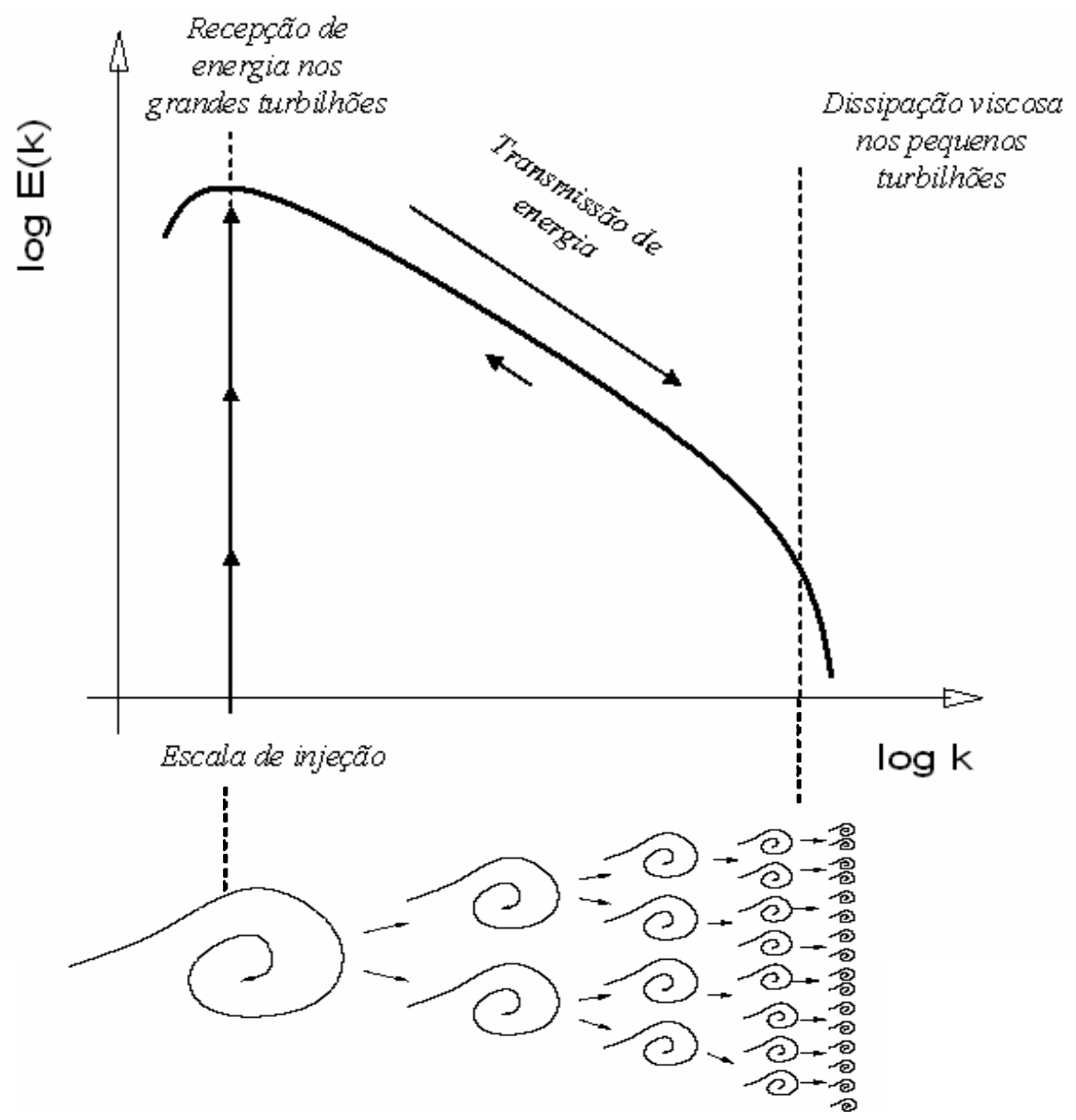

Figura 2.4 - Cascata de energia cinética turbulenta. A energia recebida pelas grandes estruturas turbilhonares é distribuída para as menores escalas, num sentido preferencial de transmissão, até que haja dissipação completa nas escalas viscosas

Lesieur (1997) destaca que a zona inercial pode ser considerada uma região de turbulência totalmente desenvolvida, onde os movimentos dos fluidos não são diretamente afetados pelas dimensões do domínio de escoamento, nem pelo efeito da viscosidade. O mesmo não pode ser dito para as estruturas de grande escala, confinadas pelas paredes nos escoamentos internos, nem para as escalas dissipativas, com duração e desenvolvimento limitados pelos efeitos viscosos. 
Na região inercial, o nível de energia cinética turbulenta contida nos turbilhões pode ser expresso pela lei de Kolmogorov, escrita como:

$$
E(k)=C_{k} \cdot \varepsilon^{\frac{2}{3}} \cdot k^{\frac{-5}{3}}
$$

Em que:

- $C_{k}=$ constante de proporcionalidade, com valores aceitos da ordem de 1,40;

- $\varepsilon=$ taxa de dissipação de energia cinética turbulenta $\left[\mathrm{ML}^{2} \mathrm{~T}^{-3}\right]$;

- $k \cong \frac{1}{\ell}\left[\mathrm{L}^{-1}\right]=$ número de onda;

- $\quad \ell=$ escala de comprimento [L].

A região dissipativa do espectro de energia é caracterizada pela predominância dos efeitos da viscosidade do fluido. Consiste das menores estruturas turbilhonares, com tempos de duração muito pequenos. Todavia, as escalas dissipativas ainda são consideradas bem maiores do que o caminho livre médio entre as moléculas de fluido, de forma que ainda se pode aplicar a hipótese de meio contínuo. As escalas (de espaço e tempo) dissipativas de Kolmogorov $\left(\ell_{d}\right.$ e $\tau$, respectivamente $)$ podem ser estimadas por:

$$
\begin{aligned}
& \ell_{\mathrm{d}}=\left(\frac{?^{3}}{\mathrm{e}}\right)^{\frac{1}{4}} \\
& \mathrm{t}=\left(\frac{?}{\mathrm{e}}\right)^{\frac{1}{2}}
\end{aligned}
$$

Para estruturas com escalas de comprimento menores que $\ell_{d}$, os efeitos viscosos passam a dominar os efeitos inerciais. Estruturas turbilhonares com escalas menores que $\ell_{d}$ mal conseguem se desenvolver, uma vez que são logo dissipadas. O seu tempo característico é muito pequeno.

A taxa de dissipação de energia cinética turbulenta pode enfim ser estimada, para escoamentos turbulentos completamente desenvolvidos, ao considerar a equivalência entre a dissipação viscosa e a taxa de injeção de energia turbulenta nas grandes escalas. Assim, podese calcular a taxa de dissipação a partir das características das grandes escalas, de acordo com:

$$
\varepsilon=\frac{U^{2}}{t}=\frac{U^{3}}{L}
$$


Isto indica que, embora a dissipação ocorra nas pequenas escalas, a quantidade de energia a ser dissipada é determinada pelas maiores estruturas turbilhonares. A relação entre as escalas dissipativas e as grandes escalas pode ser calculada combinando-se as equações (2.2) e (2.4) de forma que:

$$
\ell_{d}=\left[\frac{v^{3}}{\left(U^{3} / L\right.}\right]^{\frac{1}{4}}
$$

Esta expressão é equivalente à: $\left[\frac{L}{\ell_{d}}\right]^{3}=\left[\frac{U \cdot L}{v}\right]^{\frac{9}{4}}=\operatorname{Re}^{\frac{9}{4}}$

Uma conclusão interessante pode ser obtida a partir da equação (2.8): quanto mais turbulento for o escoamento (maior $R e$ ), maior será a largura do espectro de energia, ou seja, maior será a diferença entre as grandes escalas e as escalas dissipativas e, portanto, surgirá uma maior quantidade de estruturas com diferentes dimensões e tempos característicos. A existência da região inercial fica, dessa maneira, condicionada ao valor do número de Reynolds, de forma que escoamentos muito turbulentos terão espectros com ampla faixa inercial, ao passo que escoamentos laminares terão essa região pouco desenvolvida (ver figura 2.5).

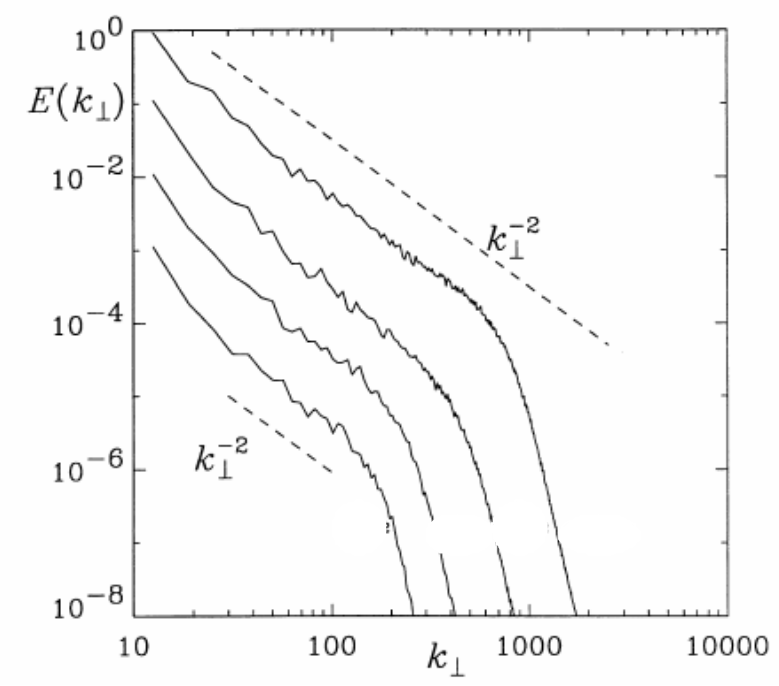

Figura 2.5 - Espectros de energia para diferentes números de Reynolds (retirado de BHATTACHARJEE e NO, 2001). Quanto mais o escoamento se aproxima de ser turbulento, maior é o número de escalas e, portanto, maior é a largura do espectro de energia 


\subsection{4 - AS EQUAÇÕES GOVERNANTES}

As equações de Navier-Stokes governam o transporte de quantidade de movimento em escoamentos e são obtidas a partir da aplicação da Segunda Lei de Newton num elemento infinitesimal de fluido, o qual se deforma em decorrência das tensões de cisalhamento. Schulz (2003) destaca que essas equações representam uma aproximação válida para uma grande variedade de escoamentos práticos, dentre eles, escoamentos em água e ar. Além disso, as equações de Navier-Stokes são suficientes para modelar escoamentos laminares ou turbulentos, em regimes permanente ou transiente. Em contrapartida, essa aproximação, ainda que derivada de princípios físicos clássicos, contém não linearidades que tornam a obtenção de uma solução analítica geral extremamente dificultosa. Assim, opta-se pela resolução numérica, que permite, através de artifícios convenientes, suplantar estas dificuldades.

As equações de Navier-Stokes descrevem o transporte de quantidade de movimento através de dois mecanismos já comentados em itens anteriores: advecção e difusão. Utilizando a notação tensorial essas equações podem ser escritas, na sua forma mais geral, como:

$$
\frac{\partial\left(\rho \cdot u_{i}\right)}{\partial t}+\frac{\partial\left(\rho \cdot u_{i} \cdot u_{j}\right)}{\partial x_{j}}=-\frac{\partial P}{\partial x_{i}}+\frac{\partial}{\partial x_{j}}\left[\mu \cdot\left(\frac{\partial u_{i}}{\partial x_{j}}+\frac{\partial u_{j}}{\partial x_{i}}\right)\right]+F_{i}
$$

Em que:

- $\quad u_{i}=$ velocidade instantânea na direção $i\left[\mathrm{LT}^{-1}\right]$;

- $\rho=$ massa específica do fluido $\left[\mathrm{ML}^{-3}\right]$;

- $\mu=$ viscosidade dinâmica do fluido $\left[\mathrm{ML}^{-1} \mathrm{~T}^{-1}\right]$;

- $P=$ pressão instantânea $\left[\mathrm{ML}^{-1} \mathrm{~T}^{-2}\right]$;

- $F_{i}=$ termo fonte de força atuante na direção $i\left[\mathrm{ML}^{-2} \mathrm{~T}^{-2}\right]$.

Em escoamentos incompressíveis (como na maioria dos casos dos escoamentos em água) a massa específica do fluido permanece invariante no tempo e no espaço, de forma que ela pode ser retirada das derivadas. Assim, a consideração de incompressibilidade redunda na seguinte forma para as equações de Navier-Stokes: 


$$
\rho \cdot \frac{\partial\left(u_{i}\right)}{\partial t}+\rho \cdot \frac{\partial\left(u_{i} \cdot u_{j}\right)}{\partial x_{j}}=-\frac{\partial P}{\partial x_{i}}+\frac{\partial}{\partial x_{j}}\left[\mu \cdot\left(\frac{\partial u_{i}}{\partial x_{j}}+\frac{\partial u_{j}}{\partial x_{i}}\right)\right]+F_{i}
$$

A equação (2.10) reproduz a forma tensorial primitiva das equações de Navier-Stokes para um escoamento incompressível. A parcela $\left\{\rho \cdot \frac{\partial\left(u_{\mathrm{i}} \cdot \mathrm{u}_{\mathrm{j}}\right)}{\partial \mathrm{x}_{\mathrm{j}}}\right\}$ representa o transporte advectivo de quantidade de movimento (por vezes denominada de aceleração advectiva), denotando os efeitos não lineares que geram instabilidades e amplificam as perturbações no escoamento. Assim, a questão da imprediscibilidade da turbulência está ligada a esta parcela que, como já foi mencionado, é a causa da existência de "soluções bastante diferentes" para condições de entrada bastante próximas. A parcela $\left\{\frac{\partial}{\partial \mathrm{x}_{\mathrm{j}}}\left[\mu \cdot\left(\frac{\partial u_{i}}{\partial x_{j}}+\frac{\partial u_{j}}{\partial x_{i}}\right)\right]\right\}$, por sua vez, representa o mecanismo de difusão, cuja tendência é amortecer e inibir a formação de instabilidades. Conforme foi comentado nos itens anteriores, esta parcela é responsável pela dissipação da turbulência.

A aplicação das equações de quantidade de movimento deve caminhar em conjunto com o uso da equação da Continuidade, de forma a suprir dois princípios físicos mútuos: Segunda Lei de Newton (reproduzida por Navier-Stokes) e Conservação de Massa (reproduzida pela Continuidade). A equação da Continuidade é descrita, por sua vez, na sua maneira mais geral, como:

$$
\frac{\partial \rho}{\partial t}+\frac{\partial(\rho \cdot u)}{\partial x_{i}}=0
$$

A equação (2.11) pode ser simplificada para escoamentos em fluidos incompressíveis, redundando em:

$$
\frac{\partial u_{i}}{\partial x_{i}}=0
$$

Note-se que as equações de Navier-Stokes, as quais foram obtidas pelo balanço de forças num volume elementar de fluido, referem-se a quantidades (velocidade e pressão) que 
representam médias espaciais nesse volume. Do ponto de vista matemático, esses volumes podem ser tão pequenos quanto se queira, desde que seja respeitada a hipótese de meio contínuo. Assim, podem-se obter campos de velocidade e pressão tão precisos quanto se deseja. Da mesma forma, ainda partindo de um ponto de vista teórico, os incrementos de tempo também podem ser "infinitamente pequenos", proporcionando o acompanhamento, com qualquer precisão, da evolução dos campos hidrodinâmicos. Lesieur (1997) comenta que, ao postular-se o princípio do determinismo de Newton para a turbulência, podem-se calcular campos de velocidade e pressão futuros a partir das equações governantes e dos campos atuais. Tudo isto vem indicar que a turbulência é um fenômeno determinístico, embora envolva com o tempo um caminho bastante complicado devido às interações não lineares. Finalmente, pode-se concluir que a discretização do domínio de escoamento em volumes de controle menores do que a escala dissipativa de Kolmogorov $\left(\ell_{d}\right)$ e passos de tempo da ordem desta escala $(\tau)$, permite calcular exatamente os fenômenos turbulentos. Todavia, conforme será comentado no item seguinte, ainda existem restrições computacionais para isto.

\subsection{5 - ASPECTOS DE MODELAGEM DA TURBULÊNCIA}

Sabe-se que as equações de Navier-Stokes tomadas na sua forma primitiva (conforme a equação (2.10)) são suficientes para modelar escoamentos em qualquer regime e para qualquer número de Reynolds. Vale aqui a ressalva óbvia de que se está falando estritamente de escoamentos Newtonianos ou Stokesianos, ou seja, de situações onde vale a proporcionalidade entre tensão e taxa de deformação (gradiente de velocidade). Qualquer generalização é válida apenas neste cenário da realidade. O problema é que o aumento do número de Reynolds amplia o espectro de energia do escoamento, fazendo surgir uma quantidade maior de escalas a serem resolvidas. Isto exige a alocação de uma malha e de um passo de tempo extremamente refinados de forma a capturar a menor escala do espectro, o que impõe custos computacionais inviáveis. São restrições como estas (nitidamente computacionais) que direcionam os experimentalistas numéricos à utilização de modelos de turbulência, os quais baseiam-se na hipótese de divisão das escalas. 


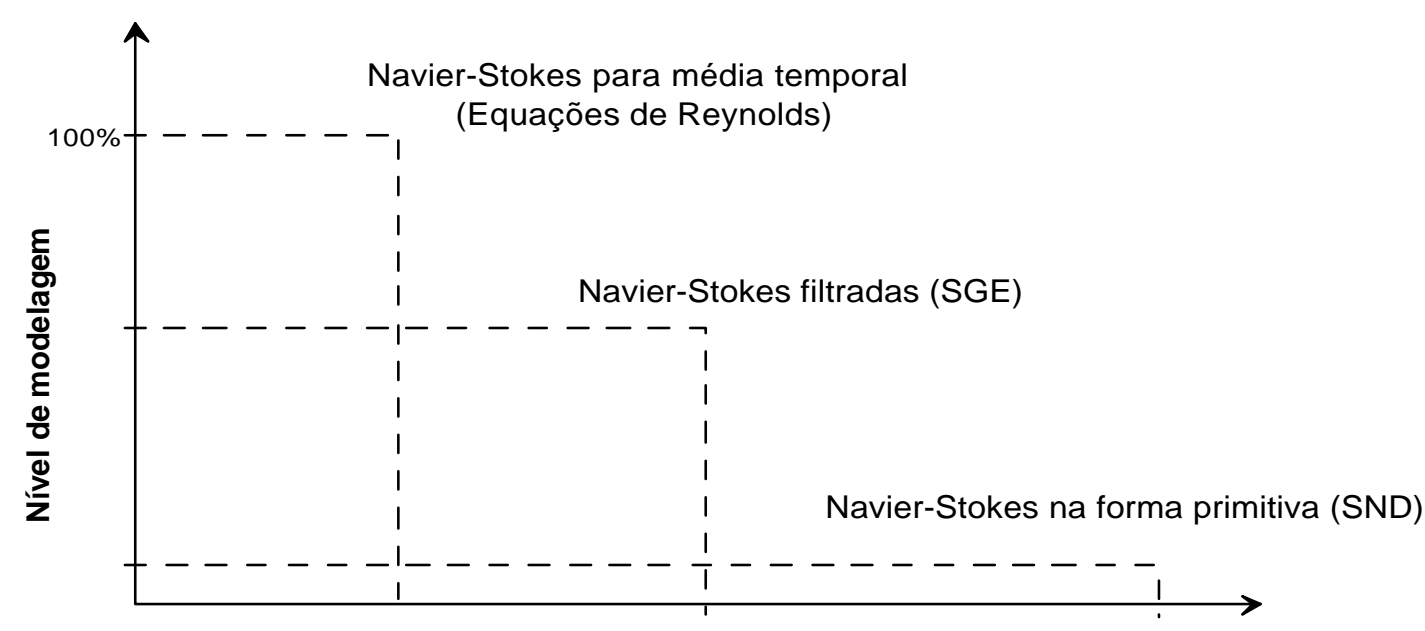

Nível de refinamento da malha

Figura 2.6 - Diagrama resumo sobre as diferentes formas de modelagem da turbulência

Atualmente, graças à disponibilidade dos modelos de turbulência, podem-se estimar vários efeitos no escoamento através de métodos numéricos aproximados. Paralelamente ao desenvolvimento dos modelos de turbulência, os avanços computacionais ocorridos nas últimas décadas permitiram análises mais minuciosas das hipóteses da turbulência e sua melhor utilização em casos práticos. Dessa forma, o tratamento teórico de problemas reais já pode ser alcançado com mais precisão. Em geral, atualmente podem-se distinguir três formas diferentes na modelagem de um escoamento turbulento, as quais são ilustradas pela figura 2.6. Vale mencionar que esta classificação é dinâmica, sempre se alterando, de acordo com as inovações tecnológicas, conceituais ou teóricas que emergem ao longo dos anos.

\subsubsection{1 - A Simulação Numérica Direta (SND)}

A forma talvez mais ideal de "modelagem" é a chamada Simulação Numérica Direta (SND). Na SND todas as escalas de turbulência (das coerentes até as dissipativas) são resolvidas. Isto equivale a calcular todo o espectro de energia cinética turbulenta, o que é feito através da resolução numérica das equações de Navier-Stokes na forma primitiva (conforme apresentado no item 2.1.5). A única modelagem imposta decorre das diferentes formas de discretização das equações governantes, no tempo e no espaço, além do tratamento das condições de contorno. 

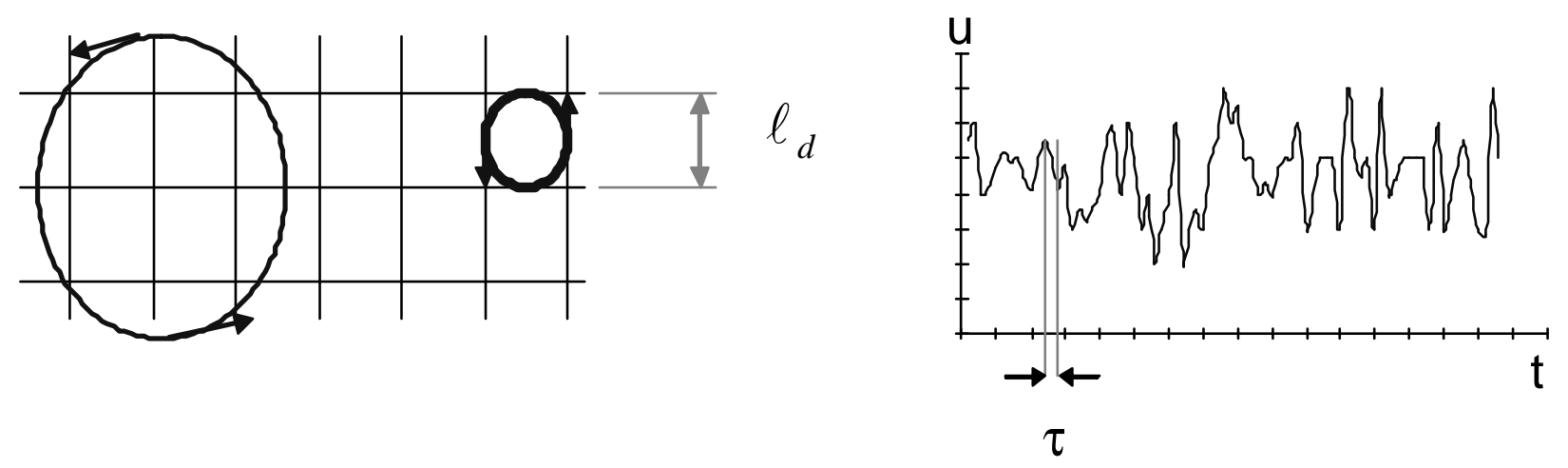

Figura 2.7 - Refinamentos espacial e temporal para a SND: as células devem ter, pelo menos, dimensões equivalentes às escalas dissipativas $\left(\ell_{d}\right)$ e os incrementos de tempo devem equivaler à duração destas escalas ( $\tau$ ). Estes dois aspectos permitem estimar numericamente campos de velocidade e pressão rigorosamente instantâneos

Pelo fato de uma SND capturar todas as escalas do escoamento, ela exige naturalmente um refinamento espacial e temporal rigoroso, de forma a reter as dimensões e o tempo característico das escalas dissipativas. Assim, se as menores escalas são capturadas, as maiores também fatalmente o serão. Os incrementos de tempo devem equivaler ao tempo característico das escalas dissipativas. Como estas escalas são destruídas rapidamente pelos efeitos viscosos, seu tempo de duração é ínfimo, de forma que os campos hidrodinâmicos obtidos podem ser considerados rigorosamente instantâneos. A figura 2.7 ilustra o nível de refinamento requerido para uma SND.

Como os intervalos de tempo são extremamente pequenos, a SND estima justamente as velocidades e pressões instantâneas do escoamento. A Simulação Numérica Direta, ao fornecer como produto final valores instantâneos, permite, pelo menos teoricamente, aproximar com muito mais exatidão, os campos reais de velocidade e pressão. Todavia, a severa discretização espacial e temporal esbarra em custos computacionais excessivos. Entenda-se aqui por custo computacional a memória requerida para armazenar as variáveis e o tempo físico de processamento dos cálculos.

O custo computacional pode ser analisado sob o ponto de vista dos graus de liberdade, associados ao número de vezes que a menor escala de turbulência deve ser resolvida ao longo do domínio do escoamento. De forma simples, trata-se do número de células em que o domínio de escoamento deve ser dividido para capturar todas as escalas. Por conseguinte, o número de graus de liberdade é uma medida do refinamento da malha para que se possa 
representar completamente um escoamento turbulento. O número de graus de liberdade $(\mathrm{Ngl})$, para escoamentos tridimensionais, pode ser calculado por:

$$
N g l=\left[\frac{L}{\ell_{D}}\right]^{3}=\mathrm{Re}^{\frac{9}{4}}
$$

Onde:

- $L=$ comprimento característico das grandes escalas [L];

- $\ell_{d}=$ comprimento característico das escalas dissipativas [L];

- $\quad \operatorname{Re}=\mathrm{U} \cdot \mathrm{L} / ?$

- $\mathrm{U}=$ velocidade média ao longo de uma seção transversal do escoamento [LT ${ }^{-1}$ ].

Note-se que o comprimento das grandes escalas (L) é equivalente a uma dimensão característica do escoamento. De fato, as grandes estruturas turbilhonares estão intimamente ligadas à geometria do domínio, uma vez que elas surgem por interações entre o fluido e os contornos. Vê-se que, quanto maior o número de Reynolds, maior é o nível de refinamento requerido, uma vez que a quantidade de escalas a serem resolvidas será maior (ver figura 2.8).

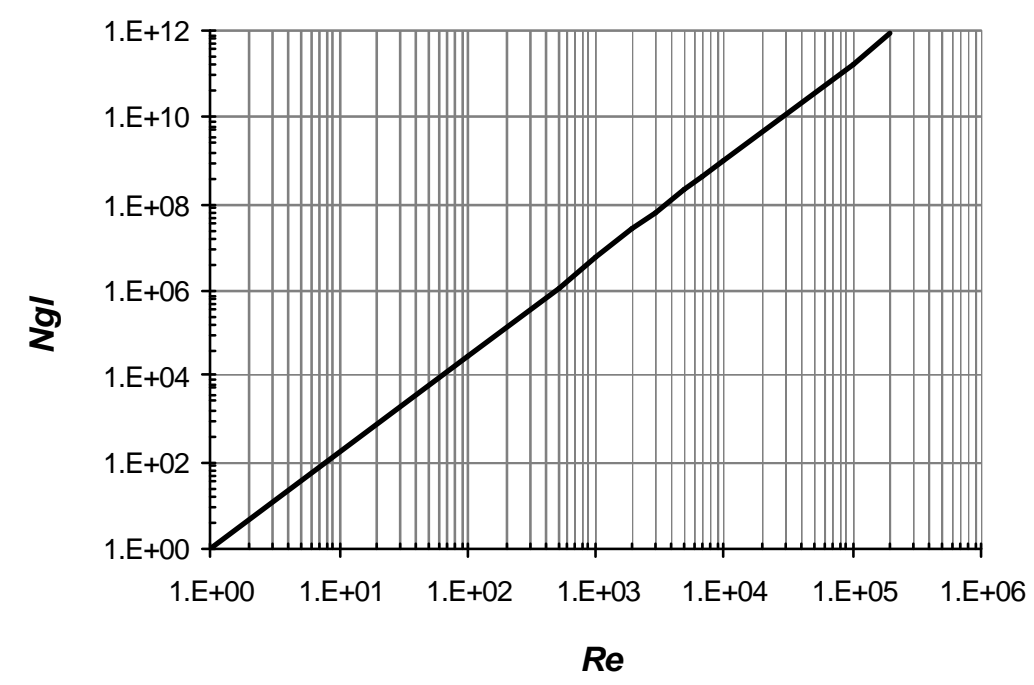

Figura 2.8 - Número de células (graus de liberdade) exigidas pela SND para diferentes números de Reynolds

A figura 2.8 fornece uma noção acerca da dificuldade de se aplicar a SND. Isto ocorre porque o grau de refinamento exigido é muito elevado para números de Reynolds moderados 
(grande parte ainda abaixo daqueles de muitos escoamentos de campo). Por isso, a SND atualmente se restringe a escoamentos "didáticos", para estudar a física da turbulência e permitir parâmetros comparativos para os outros modelos.

\subsubsection{2 - A Modelagem clássica da turbulência}

A forma clássica de modelagem da turbulência utiliza o princípio de separação de escalas. Nessa linha de pensamento, as escalas de turbulência são representadas pela média temporal (de velocidade e pressão) e pelas flutuações em torno dessas médias. Assim, a grandeza instantânea pode ser calculada como a soma da média mais a flutuação, de acordo com a aproximação estatística de Reynolds (ver figura 2.9).

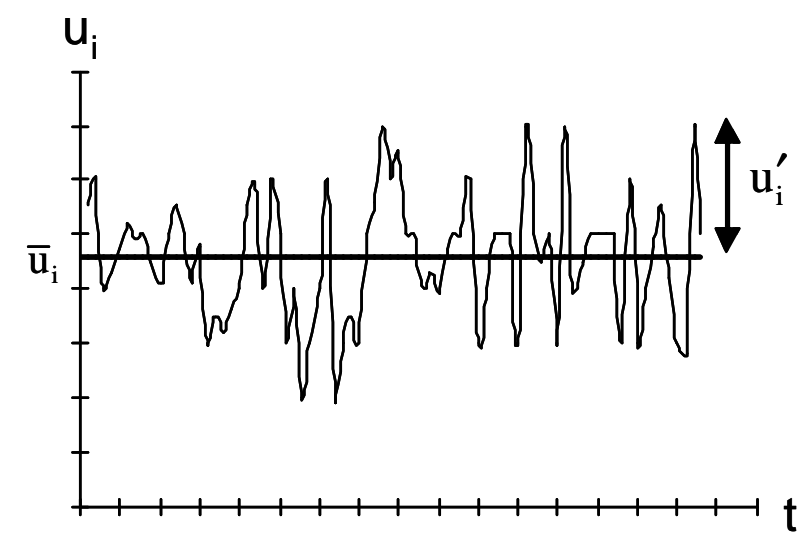

$$
\bar{u}_{i}=\lim _{\mathrm{T} ? \mathrm{~T}_{1}} \frac{1}{T} \int_{0}^{T} u_{i}(t) \cdot d t
$$

Figura 2.9 - Na modelagem clássica, uma grandeza instantânea, como por exemplo a velocidade, é dividida em duas escalas: a média mais a sua flutuação temporal $\left(u_{i}=\bar{u}_{i}+u_{i}{ }^{\prime}\right)$

Nos modelos clássicos, todo o espectro de energia é modelado, uma vez que não interessa a previsão do surgimento de estruturas turbulentas com diferentes escalas de comprimento, mas sim uma escala média única (de velocidade e pressão) que é o produto final dos cálculos.

A aplicação das hipóteses de Reynolds nas equações governantes (Navier-Stokes e Continuidade) e a integração dessas equações numa escala de tempo maior do que a escala dos movimentos turbulentos (dito tempo de relaxação) fornecem as equações da Continuidade e de Navier-Stokes para valores médios de velocidade e pressão, também ditas, na modelagem clássica, como equações de Reynolds: 


$$
\begin{aligned}
& \frac{\partial \overline{\mathrm{u}}_{\mathrm{i}}}{\partial \mathrm{x}_{\mathrm{i}}}=0 \\
& \rho \cdot \frac{\partial\left(\overline{\mathrm{u}}_{\mathrm{i}}\right)}{\partial \mathrm{t}}+\rho \cdot \frac{\partial\left(\overline{\mathrm{u}}_{\mathrm{i}} \cdot \overline{\mathrm{u}}_{\mathrm{j}}+\overline{\mathrm{u}_{\mathrm{i}}^{\prime} \cdot \mathrm{u}_{\mathrm{j}}^{\prime}}\right)}{\partial \mathrm{x}_{\mathrm{j}}}=-\frac{\partial \overline{\mathrm{P}}}{\partial \mathrm{x}_{\mathrm{i}}}+\frac{\partial}{\partial \mathrm{x}_{\mathrm{j}}}\left[\mu \cdot\left(\frac{\partial \overline{\mathrm{u}}_{\mathrm{i}}}{\partial \mathrm{x}_{\mathrm{j}}}+\frac{\partial \overline{\mathrm{u}}_{\mathrm{j}}}{\partial \mathrm{x}_{\mathrm{i}}}\right)\right]+\overline{\mathrm{F}}_{\mathrm{i}}
\end{aligned}
$$

Com a aplicação da média temporal sobre as equações primitivas de Navier-Stokes, essas evoluem e se diferenciam da sua forma primitiva apresentada no item 2.1.4 (equação (2.10)). Abre-se aqui o parêntese de que as barras sobre as variáveis indicam médias temporais. Em contrapartida, o aparecimento do tensor $\overline{u_{i}^{\prime} \cdot u_{j}^{\prime}}$ gera o problema de não fechamento (mais incógnitas do que equações). Apesar da sua origem se relacionar à parcela advectiva das equações de Navier-Stokes, o tensor $\overline{u_{i}^{\prime} \cdot u_{j}^{\prime}}$ possui características que se aproximam de uma natureza viscosa, o que justifica sua transposição para o segundo membro da equação. Esse artifício clássico já tem mais de um século de proposição, sendo a forma mais aceita para iniciar a modelação das parcelas não lineares das flutuações de velocidade. Tem-se, então:

$$
\rho \cdot \frac{\partial\left(\bar{u}_{i}\right)}{\partial t}+\rho \cdot \frac{\partial\left(\bar{u}_{i} \cdot \bar{u}_{j}\right)}{\partial x_{j}}=-\frac{\partial \bar{P}}{\partial x_{i}}+\frac{\partial}{\partial x_{j}}\left[\mu \cdot\left(\frac{\partial \bar{u}_{i}}{\partial x_{j}}+\frac{\partial \bar{u}_{j}}{\partial x_{i}}\right)-\overline{u_{i}^{\prime} \cdot u_{j}^{\prime}}\right]+\bar{F}_{i}
$$

As tensões atuantes no fluido, que com o artifício de transposição acima apresentam uma componente viscosa e outra turbulenta, são calculadas partindo-se do princípio de que as tensões turbulentas podem ser expressas como proporcionais aos gradientes das velocidades médias, de maneira análoga às tensões viscosas (hipótese de Boussinesq). Em outras palavras, contornou-se o problema advectivo "transformando-o" em um problema difusivo e adotando as aproximações que se mostraram historicamente válidas para a difusão molecular. Assim:

$$
\tau_{\mathrm{ij}}=-\rho \cdot \overline{\mathrm{u}_{\mathrm{i}}^{\prime} \cdot \mathrm{u}_{\mathrm{j}}^{\prime}}=\mu_{\mathrm{t}}\left(\frac{\partial \overline{\mathrm{u}}_{\mathrm{i}}}{\partial \mathrm{x}_{\mathrm{j}}}+\frac{\partial \overline{\mathrm{u}}_{\mathrm{j}}}{\partial \mathrm{x}_{\mathrm{i}}}\right)-\frac{2}{3} \rho \cdot \mathrm{k} \cdot \delta_{\mathrm{ij}}
$$


Em que:

- $\mathrm{k}=\frac{\overline{\mathrm{u}_{\mathrm{j}}^{\prime} \cdot \mathrm{u}_{\mathrm{j}}^{\prime}}}{2}=$ energia cinética turbulenta $\left[\mathrm{L}^{2} \mathrm{~T}^{-2}\right]$;

- $\quad \delta_{\mathrm{ij}}=$ delta de $\operatorname{Kronecker}(1$, se $i=j ; 0$, se $i ? j)$.

Esta hipótese introduz um novo parâmetro, a viscosidade turbulenta $\left(\mu_{\mathrm{t}}\right)$ que, ao contrário da viscosidade cinemática, não depende do fluido, mas sim da estrutura do escoamento. A substituição da equação (2.18) na equação (2.17) leva a uma feição mais tratável para as ditas equações de Reynolds, que evoluem para a seguinte forma:

$\rho \cdot \frac{\partial\left(\bar{u}_{i}\right)}{\partial t}+\rho \cdot \frac{\partial\left(\bar{u}_{i} \cdot \bar{u}_{j}\right)}{\partial x_{j}}=-\frac{\partial \bar{P}^{*}}{\partial x_{i}}+\frac{\partial}{\partial x_{j}}\left[\left(\mu+\mu_{t}\right) \cdot\left(\frac{\partial \bar{u}_{i}}{\partial x_{j}}+\frac{\partial \bar{u}_{j}}{\partial x_{i}}\right)\right]+\bar{F}_{i}$

Em que: $\overline{\mathrm{P}^{*}}=\overline{\mathrm{P}}+\frac{2}{3} \rho \cdot \mathrm{k}$

Note-se que a equação (2.19) apresenta uma forma muito semelhante à equação de Navier-Stokes primitiva (equação (2.10)). Há diferenças no significado físico das variáveis dependentes (que são médias temporais em vez de valores instantâneos) e no conceito de viscosidade turbulenta, que responde como um coeficiente difusivo adicional. O cálculo da viscosidade turbulenta é uma questão que precisa ser feita antes da resolução numérica das equações de Reynolds. A estimativa dessa viscosidade adicional é o objetivo final de metodologias clássicas como, por exemplo os modelos $k-\varepsilon, k-\omega$, tensões de Reynolds, Spalart-Allmaras, entre outros. Uma descrição mais detalhada dos modelos clássicos foge dos objetivos do presente texto. Para isto o autor indica a leitura de Rodi (2000), que faz uma revisão conveniente a respeito do "estado da arte" destes modelos.

O cálculo dos campos médios não aponta instabilidades típicas de campos instantâneos, uma vez que as flutuações de velocidade e pressão são atenuadas. Isto pode ser ilustrado pela figura 2.10 que destaca a diferença entre um campo de velocidade médio e outro instantâneo. 


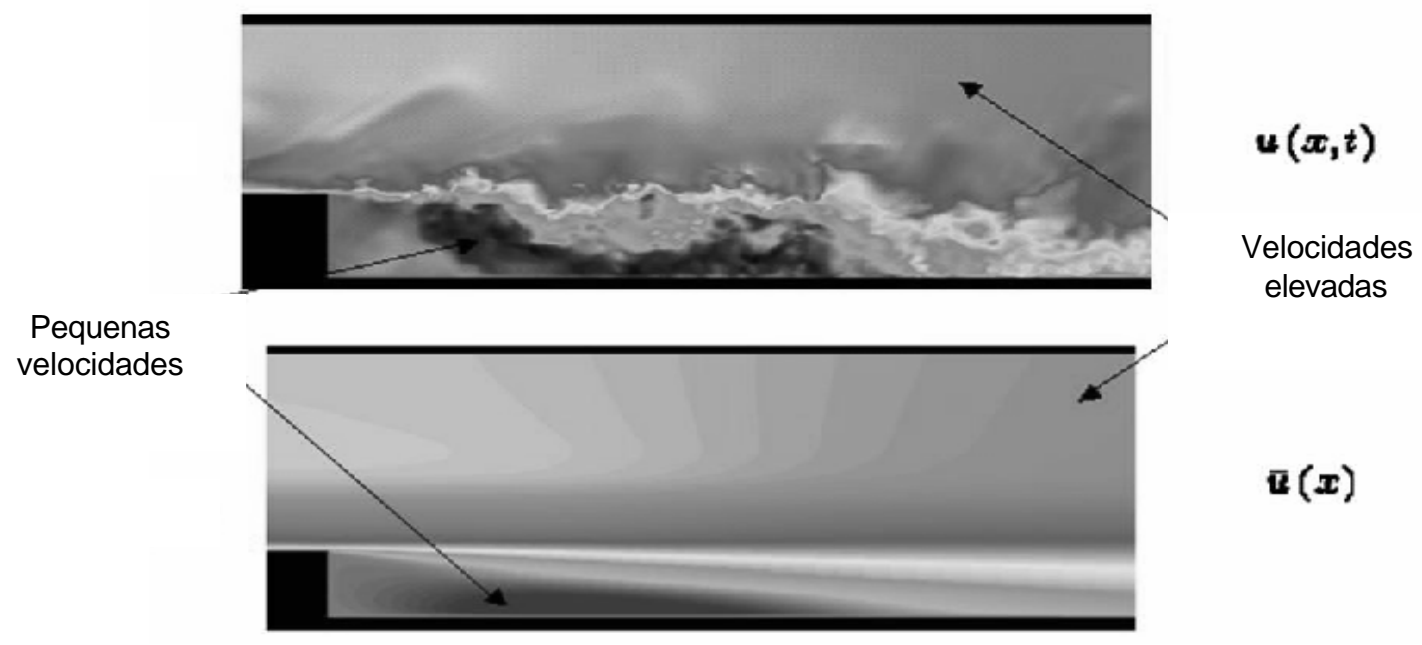

Figura 2.10 - Diferença entre campos de velocidade instantâneos e médios. A representação do escoamento apenas pela escala média temporal alivia as instabilidades

A grande vantagem da modelagem clássica é permitir a utilização de uma discretização mais grosseira, o que fatalmente diminui o custo computacional. Esta vantagem, todavia, esbarra na perda de precisão dos resultados que, vale novamente lembrar, representam médias temporais. Assim, como salienta Schulz (2003), picos de máximos ou vales de mínimos que podem ser relevantes e até mesmo críticos para determinado tipo de problema, são "disfarçados" pela média. A captura de movimentos turbulentos finos não é possível, uma vez que somente estruturas turbilhonares com grandes durações (como as coerentes) podem ser evidenciadas pelos cálculos.

\subsubsection{3 - A Simulação de Grandes Escalas (SGE)}

A busca de um entendimento mais físico dos escoamentos turbulentos sugere a aplicação da Simulação de Grandes Escalas (SGE). O princípio básico da SGE consiste na divisão do espectro de energia turbulenta em duas partes: grandes e pequenas escalas. Desta forma, as grandes escalas são resolvidas diretamente, enquanto que as pequenas escalas são modeladas. Assim, somente uma parte do espectro é modelada, permitindo (pelo menos em tese) a captura de estruturas turbulentas mais refinadas.

Este procedimento classifica a SGE como uma metodologia intermediária entre os modelos clássicos e a Simulação Numérica Direta. Por isto, tradicionalmente a SGE exige níveis de discretização mais rigorosos que a modelagem clássica. Por ser um assunto de 
fundamental importância no desenvolvimento deste trabalho, julgourse conveniente comentar, com mais detalhes, os aspectos da SGE, o que é feito no capítulo seguinte.

\section{2 - TRANSPORTE DE SEDIMENTOS}

\subsection{1 - CRITÉRIOS DE EROSÃO}

As primeiras tentativas de quantificar o transporte de sedimentos em leitos aluviais partiram da idéia de estabelecer condições matematicamente definidas, a partir das quais ocorre o início da movimentação das partículas. Desde as primeiras observações experimentais feitas por Shields (1936), muitos pesquisadores enfocaram a definição das condições críticas de escoamento, associadas com a instabilidade inicial e adicional suspensão das partículas de sedimento. De acordo com Graf (1970), o movimento inicial dos leitos de canais ou, mais comumente chamada de condição crítica de erosão, costuma ser explicada por três maneiras:

- Com critérios de velocidade crítica, considerando o impacto de parcelas de fluido nas partículas;

- Com critérios de cisalhamento, considerando o arrasto do escoamento nas partículas;

- Com critérios de força de suspensão, considerando diferenças de pressão devido ao gradiente de velocidade.

Os critérios baseados na tensão cisalhante no leito ganharam apreciável destaque na literatura e, até os dias atuais, critérios, como o de Shields, são bastante utilizados na avaliação das condições iniciais de suspensão de sedimentos (ver, por exemplo, ZEDLER e STREET, 2001; CHANG e SCOTTI, 2003). Van Rijn (1984a) ressalta que, quando a velocidade de cisalhamento no leito $\left(u_{*}\right)$ supera levemente a velocidade crítica (valor limite para início de movimento), ocorrem movimentos de deslizamento e rolamento das partículas sobre o fundo do canal; quando $u *$ cresce, esses movimentos dão lugar a saltos e, eventualmente, quando $u *$ supera a velocidade de sedimentação da partícula, esta pode ser elevada até um nível onde as forças inerciais verticais (derivadas da turbulência do 
escoamento) superam o peso submerso do sedimento, gerando um estado de suspensão. A figura 2.11 ilustra uma série de critérios apoiados na condição de cisalhamento junto ao leito.

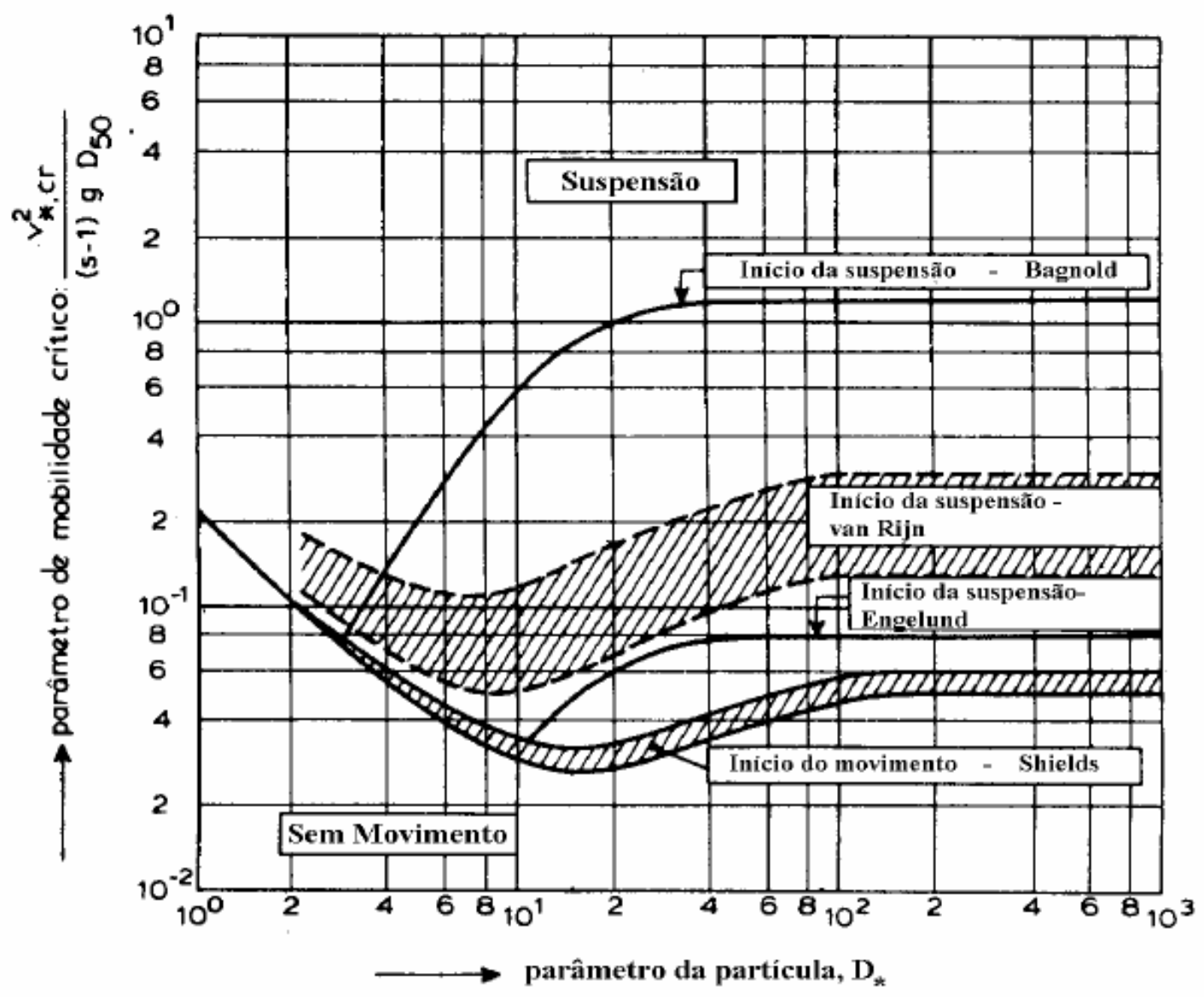

Figura 2.11 - Critérios para suspensão incipiente de sedimentos baseados nas condições de cisalhamento junto ao leito dos canais (retirado de VAN RIJN, 1984)

A figura 2.11 relaciona os seguintes parâmetros:

- Parâmetro adimensional de mobilidade : $\frac{\mathrm{u}_{*}{ }^{2}}{(\mathrm{~s}-1) \cdot \mathrm{g} \cdot \mathrm{d}_{50}}$;

- Parâmetro adimensional da partícula: $\mathrm{d}_{*}=\mathrm{d}_{50} \cdot\left[\frac{(\mathrm{s}-1) \cdot \mathrm{g}}{\mathrm{v}^{2}}\right]^{1 / 3}$;

- $\quad \mathrm{d}_{50}=$ diâmetro médio das partículas que compõem o leito de um canal [L];

- $s=\rho_{s} / \rho=$ densidade relativa entre o sedimento e o fluido;

- $\mathrm{g}=$ aceleração da gravidade $\left[\mathrm{LT}^{-2}\right]$; 
- $\quad v=$ viscosidade cinemática do fluido $\left[\mathrm{L}^{2} \mathrm{~T}^{-1}\right]$.

\subsection{2 - GENERALIDADES SOBRE OS MODELOS CLÁSSICOS DE TRANSPORTE DE SEDIMENTOS}

Paralelamente ao desenvolvimento dos critérios de suspensão (ou de erosão), conforme discutido no item anterior, surgiu o ensejo de quantificar a contribuição do leito em relação aos sedimentos transportados pelo escoamento. Os modelos ditos clássicos surgiram a partir de meados do século passado e incorporam observações experimentais intensas, informações relacionadas basicamente ao escoamento médio e considerável trabalho estocástico. Tais modelos seguem a tendência de dividir a profundidade do escoamento em duas regiões, onde predominam isoladamente o transporte de fundo e o transporte em suspensão. Nesse sentido, cada tipo de transporte é avaliado por equações próprias, sendo que a sobreposição dos seus resultados fornece a carga total de sedimentos transportada pelo escoamento.

Dentre os modelos clássicos mais notáveis, destacam-se, entre outros, os de Einstein (1942, 1950) para transporte de fundo e suspensão, além do modelo de Van Rijn (1984b) para transporte em suspensão. Apesar desses modelos ainda serem largamente empregados (geralmente para estimativas em escoamentos de campo, como rios, reservatórios, etc.), eles não podem ser considerados universais, uma vez que são fortemente amparados pelo empirismo e incorporam apenas brandamente as informações acerca da mecânica da turbulência. Note-se que, neste ponto, reside uma justificativa ainda plausível para a aplicação desses modelos em escoamentos com escalas de campo, uma vez que os custos computacionais oriundos da discretização desses domínios são ainda elevados para um tratamento numérico mais refinado.

Todavia, os modelos clássicos de transporte de sedimentos vêm perdendo espaço no tocante à aplicação geral, à medida que os avanços no entendimento das estruturas turbulentas contribuem para uma melhor caracterização e descrição do fenômeno. Não se questiona, evidentemente, a relevante carga conceitual que os modelos clássicos introduziram na área, nem a sua conveniência didática. Como em muitos aspectos da turbulência, os conceitos sobrevivem às aplicações generalizadas (um exemplo é o comprimento de mistura, cujo conceito permanece, apesar de os cálculos, na atualidade, prescindirem de sua quantificação). Nas seções seguintes destacam-se algumas das estruturas turbulentas que são determinantes para a dinâmica dos sedimentos em canais. 


\subsection{3 - ESTRUTURAS TURBULENTAS E TRANSPORTE DE SEDIMENTOS}

De acordo com o que foi discutido no item anterior, várias conclusões a respeito do transporte de sedimentos não podem ser aplicadas universalmente, uma vez que não incorporam conhecimentos a respeito da turbulência. Assim, apesar da grande quantidade de pesquisas relacionadas ao estudo do transporte de sedimentos, o estado geral do conhecimento deste fenômeno é ainda relativamente incipiente.

Sutherland (1967) desenvolveu o que talvez tenha sido o estudo pioneiro que relacionou o efeito da turbulência no transporte de sedimentos. Observações dos movimentos das partículas levaram-no a considerar que o início e a suspensão das mesmas são causados por estruturas turbilhonares que desfazem a sub-camada viscosa e atuam diretamente sobre o leito do canal. Sua hipótese de transporte fundamenta-se na idéia de movimentos "explosivos", descobertos simultaneamente por Kline et al. (1967). Este conceito é consistente com a terminologia atual dos movimentos de ejeções e varreduras. Embora sem resolver o problema da interação entre o fluido e a partícula, Sutherland enfatizou que os sedimentos não podem ser suspensos sem a presença de flutuações turbulentas adjacentes e dirigidas diretamente ao leito do canal. Outras valiosas pesquisas de transporte de sedimentos, onde a turbulência assume papel fundamental, foram descritas por Grass (1983), Sumer (1986) e outros. Observações laboratoriais de estruturas turbulentas coerentes, nos escoamentos em canais, têm revelado a importância da turbulência na erosão e suspensão das partículas de sedimentos (GARCIA et al., 1995, 1996). Estas observações indicaram claramente que a suspensão incipiente das partículas está associada com estruturas turbulentas coerentes ao longo da parede de fundo do canal. Assim, o conhecimento de estruturas coerentes guarda fortes relações com o mecanismo de transporte de sedimentos. Estruturas coerentes de grande escala contêm a maior parte da energia turbulenta, causando um impacto significativo no transporte de partículas suspensas.

Nas regiões distantes das paredes, a turbulência também exerce influência na manutenção de sedimentos em suspensão. Assim, quando a velocidade de sedimentação é sobrepujada por velocidades instantâneas locais ascendentes, a partícula se mantém em suspensão no corpo do escoamento. Essas correntes ascendentes podem decorrer tanto de estruturas turbilhonares de grande, quanto de pequena escala, sendo o seu grau de influência dependente das dimensões e da densidade da partícula. 


\subsubsection{1- Turbilhões de grande escala}

Notadamente, os turbilhões de grande escala surgem em camadas cisalhantes dos escoamentos, ou seja, em regiões onde o gradiente de velocidade é elevado. A figura 2.12 ilustra a presença desses turbilhões entre duas regiões de velocidades bastante distintas. A natureza dessas estruturas está ligada ao comportamento dos campos de base de velocidade que, nessas camadas, são inflexionais.

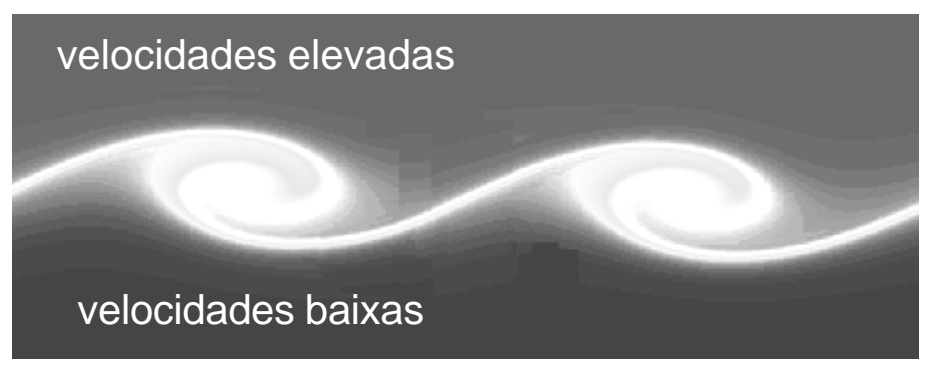

Figura 2.12 - Estruturas turbilhonares de origem cisalhante entre duas regiões de velocidades distintas

Os turbilhões de origem cisalhante representam um mecanismo fundamental para o transporte de sedimentos em canais aluviais. Estes domínios são geralmente caracterizados por fundos ondulados (ondulações, dunas ou anti-dunas). A presença das ondulações faz surgir duas regiões com velocidades de ordens de grandezas distintas, além de separar a camada limite nas suas cristas. Isto estabelece uma camada cisalhante livre, ao longo da qual há a formação de grandes turbilhões (ver figura 2.13). Chang e Scotti (2003), realizaram Simulações Numéricas Diretas (SND) em canais com fundos ondulados, comprovando a preponderância dessas estruturas turbilhonares no lançamento de partículas em direção ao corpo principal do escoamento.

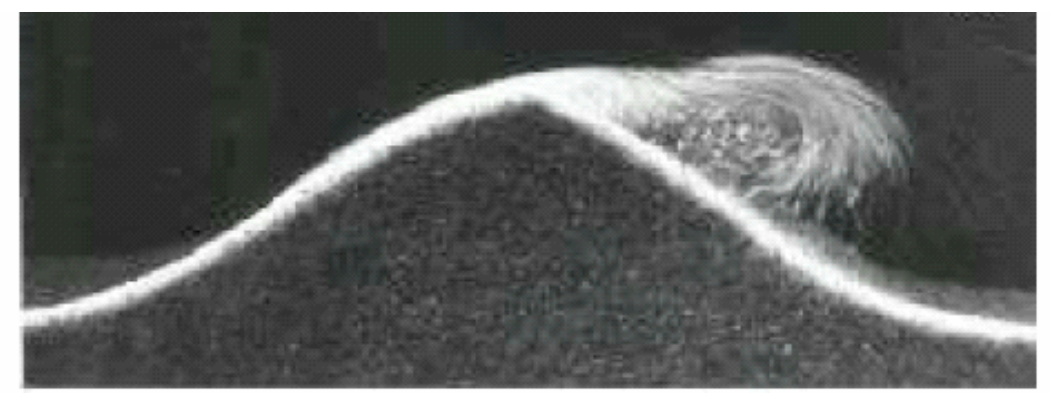

Figura 2.13 - Surgimento de turbilhões de grande escala com origem cisalhante a jusante das cristas de uma duna 
É interessante notar que, em canais naturais, a origem de estruturas desta espécie requer a existência de uma superfície convexa, uma vez que o desprendimento dos vórtices ocorre a partir das cristas das ondulações.

\subsubsection{2 - Estruturas explosivas}

As estruturas turbulentas explosivas surgem nas adjacências das paredes $y^{+}=100$, $y^{+}=y \cdot u_{*} / v$ ). Ao contrário dos movimentos turbilhonares descritos no item anterior, a origem e evolução inicial destas estruturas ocorre na sub-camada viscosa, o que faz com que o efeito da viscosidade do fluido seja preponderante para esta evolução. O surgimento de instabilidades de origem viscosa, originadas a partir de filamentos de fluido de baixa velocidade, que culminam em turbulência tridimensional, representa um caso típico de transição à turbulência e que está intimamente ligado a fenômeno de "explosão". Para descrições mais detalhadas, ver Lesieur (1997) e Silveira Neto (2003).

As figuras 2.14 e 2.15 ilustram o mecanismo que redunda nas estruturas explosivas. Visualizações do escoamento, feitas com injeção de bolhas de hidrogênio, têm revelado a presença de regiões de baixa velocidade na sub-camada viscosa. Tais visualizações acusam a presença de filamentos de fluido de comportamento laminar, os quais, devido à ação da viscosidade, sofrem pequenas oscilações características das instabilidades de TollmienSchlichting (TS). Essas perturbações são amplificadas, gerando oscilações de maior amplitude e perpendiculares à parede, as quais originam instabilidades "grampo de cabelo" ou "ferradura". Tais instabilidades são determinadas por filamentos de fluido que giram em sentido contrário ao do escoamento (dito contra-rotativos). A referida rotação determina uma tendência de erguer a crista do filamento em direção ao corpo do escoamento e de manter os vales próximos ao fundo (ver figura 2.14 (c)). Esses mecanismos geram estiramento e posterior ruptura do filamento, ocasionando as explosões que lançam parcelas consideráveis de fluido (e, neste caso, também de sedimentos) em direção ao corpo principal do escoamento (ejeção). A última ejeção é seguida imediatamente por um efeito de varredura, causada por porções de fluido com elevada quantidade de movimento que tomam a direção da parede do canal. Localmente, uma súbita variação nas flutuações das velocidades longitudinal e transversal é observada. Este cenário é típico de escoamentos sobre placas planas ou convexas. 
(a)

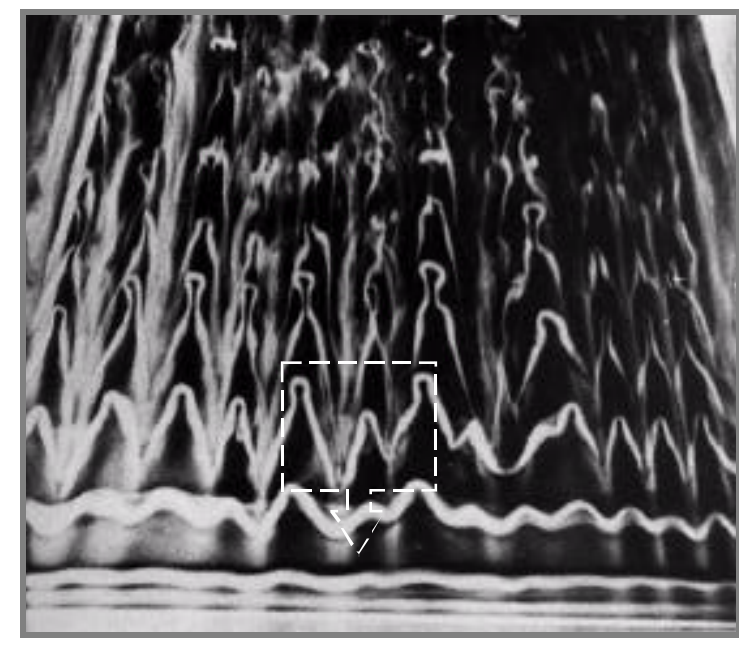

(b)

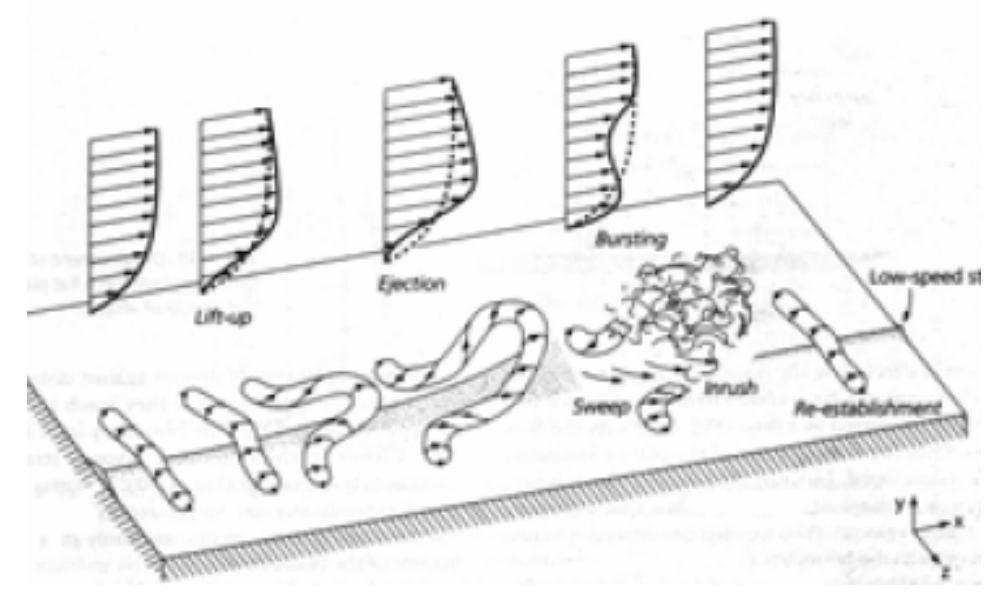

(c)

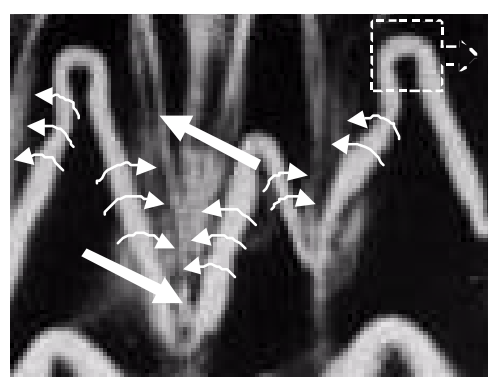

Figura 2.14-Origem das estruturas explosivas que ocorrem sobre o fundo de canais (retirado de SILVEIRA NETO, 2003): (a) vista frontal; (b) esquema de vista longitudinal; (c) vista ampliada

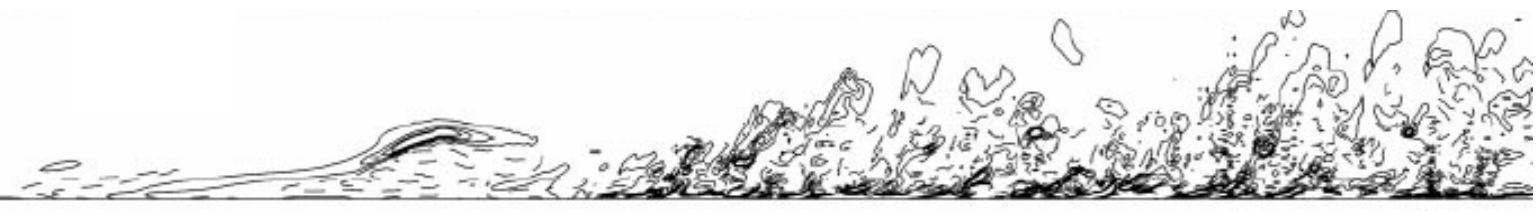

Figura 2.15 - Desenvolvimento longitudinal de estruturas explosivas sobre um fundo plano (retirado de PIOMELLI, 1999)

Assim, a transferência de partículas próximas às paredes é também condicionada por estruturas coerentes explosivas que controlam o ciclo de regeneração da turbulência. Uma série de experimentos (KAFTORI et al., 1995 a,b; GYR e SCHMID, 1997; SECHET e LE GUENNEC, 1999) demonstram que tanto o processo de ressuspensão quanto o processo de deposição de sedimentos podem ser controlados pelas "explosões turbulentas". Dessa forma, 
o comportamento das partículas apresenta correlação com o movimento destas estruturas que causam, basicamente, três tipos de efeitos:

- surgimento de depósitos em regiões de baixa velocidade próximas às paredes;

- disponibilidade de condições para ressuspensão de partículas do leito para o corpo principal do escoamento, através das ejeções;

- favorecimento ao processo de deposição, pelo arrasto de partículas suspensas no escoamento em direção ao fundo do canal, através das varreduras.

A figura 2.16 ilustra este mecanismo de transporte de sedimentos obtido através de uma série de observações experimentais.
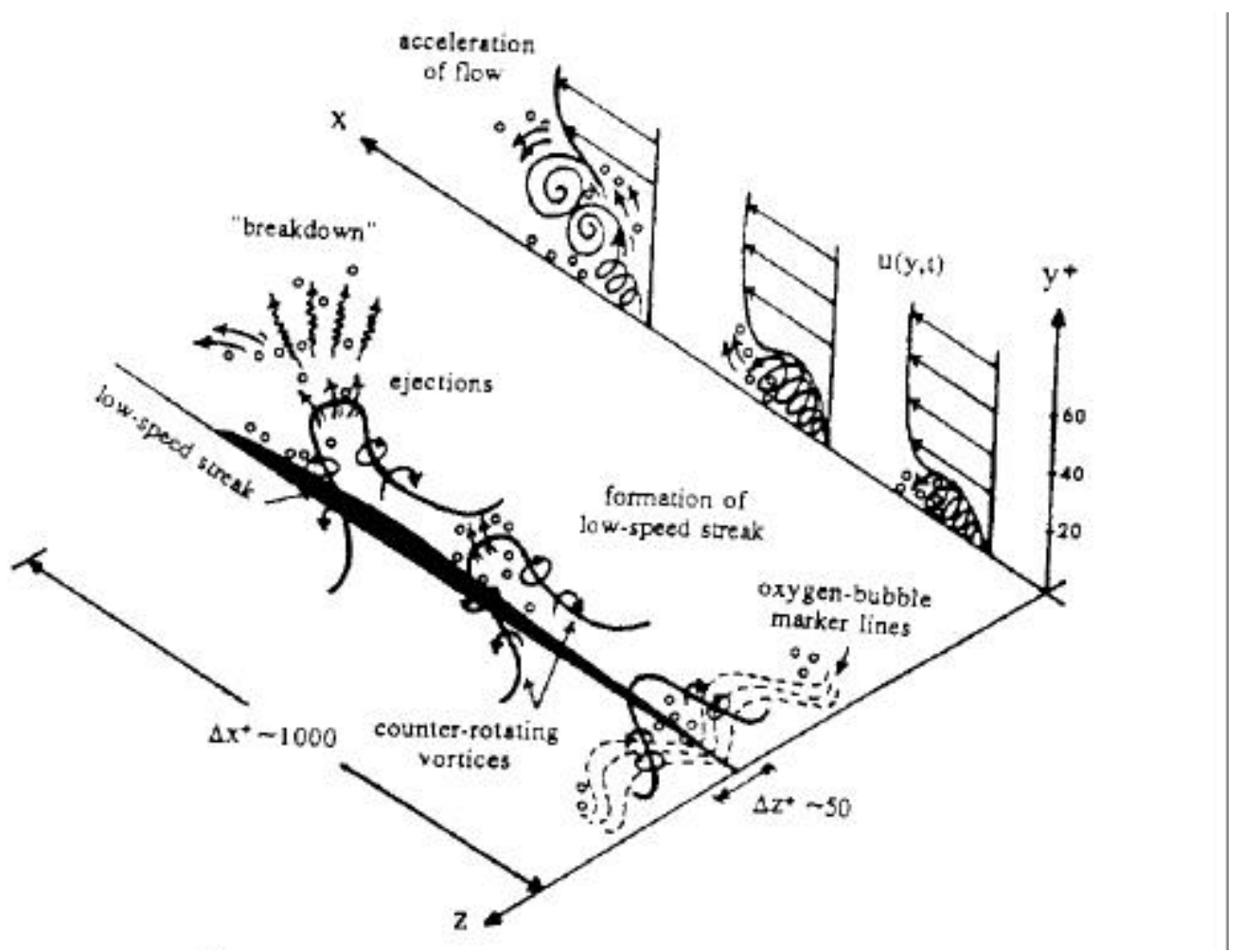

Figura 2.16-Mecanismo de suspensão de sedimento do leito de um canal (retirado de RASHDI et al., 1990) 


\subsubsection{3 - Vórtices de Görtler}

Adicionalmente, podem aqui ser mencionados os vórtices de Görtler, que são estruturas secundárias (transversais ao escoamento principal e originadas por flutuações de velocidade), os quais ocorrem em escoamentos sobre superfícies côncavas (ver figura 2.17). Sua origem está relacionada à força centrífuga atuante nas parcelas de fluido que escoam próximas a essas regiões.

A importância dos vórtices de Görtler para o transporte de partículas, segundo destacam as Simulações de Grandes Escalas (SGE) de Zedler e Street (2001), está no fato dessas estruturas estarem associadas a regiões do escoamento com elevadas velocidades verticais, sejam elas positivas ou negativas. Recorrendo ao caso dos escoamentos aluviais, onde as formas de fundo em geral são onduladas, Chang e Scotti (2003), através de Simulações Numéricas Diretas (SND), verificaram que os vórtices de Görtler são formados preferencialmente nos aclives das dunas. A estrutura das correntes secundárias de Görtler pode ser ilustrada pela figura 2.18.

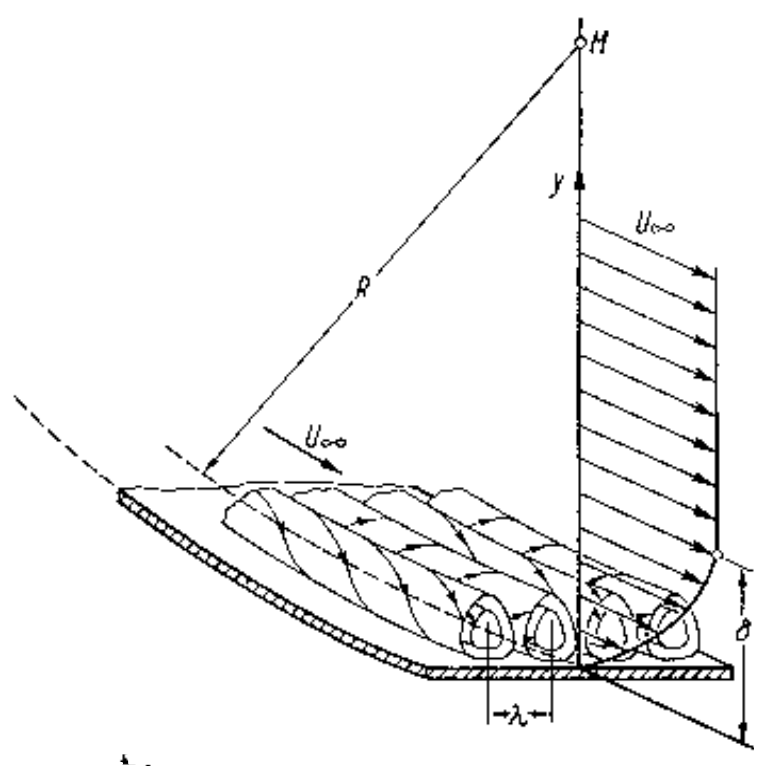

Figura 2.17 - Esquema dos vórtices de Görtler sobre uma superfície côncava (retirado de SILVEIRA NETO, 2003) 


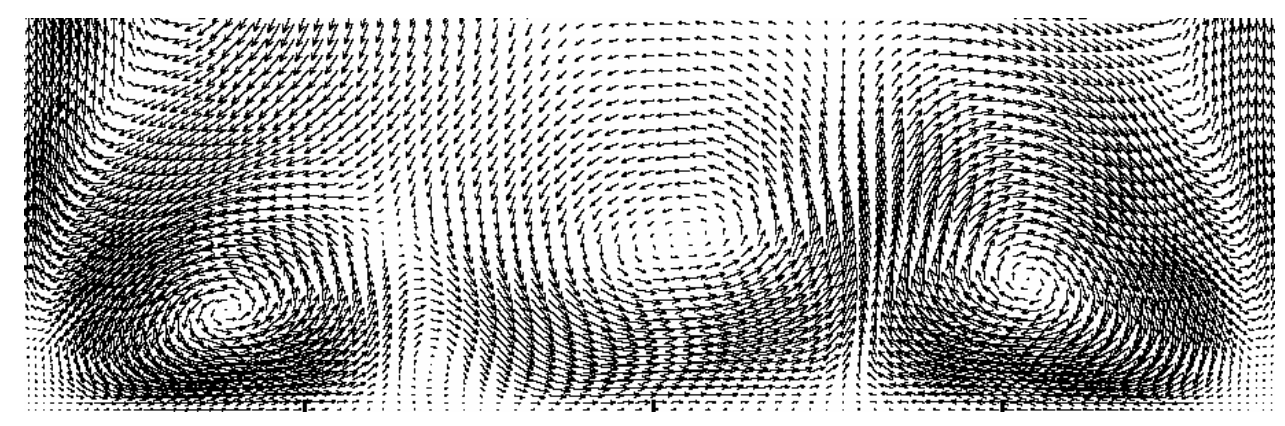

Figura 2.18 - Vórtices de Görtler que aparecem em seções transversais ao sentido preferencial do escoamento

\subsection{4 - VELOCIDADE DE SEDIMENTAÇÃO}

A velocidade de sedimentação das partículas atua como uma das variáveis fundamentais no transporte de sedimentos. Para sedimentos densos ou de grande diâmetro, a velocidade de queda consegue superar as correntes turbulentas ascendentes, determinando um estado de sedimentação dominante. Em contrapartida, sedimentos pouco densos ou de pequeno diâmetro podem ser levados pela massa líquida por grandes distâncias, o que determina um estado de suspensão. Por isto a avaliação correta da velocidade de sedimentação das partículas é importante na modelagem de processos de sedimentaçãoressuspensão.

Para partículas isoladas, ou suspensões muito dispersas (baixas concentrações de sedimentos), a velocidade de sedimentação pode ser obtida, com precisão, através do balanço das forças gravitacionais, de empuxo e de arrasto em uma única partícula. Esta análise redunda na chamada Lei de Stokes, que é expressa pela equação:

$$
w_{o}=\frac{2 \cdot g \cdot(d / 2)^{2} \cdot\left(\rho_{s}-\rho\right)}{9 \cdot \mu}
$$

Em que:

- $w_{o}=$ velocidade terminal de sedimentação $\left[\mathrm{LT}^{-1}\right]$;

- $g=$ aceleração da gravidade $\left[\mathrm{LT}^{-2}\right]$;

- $d=$ diâmetro da partícula [L];

- $\rho_{s}=$ massa específica do sedimento $\left[\mathrm{ML}^{-3}\right]$; 
- $\rho=$ massa específica do fluido $\left[\mathrm{ML}^{-3}\right]$;

- $\mu=$ viscosidade dinâmica do fluido $\left[\mathrm{ML}^{-1} \mathrm{~T}^{-1}\right]$.

Experimentos com elevada concentração em suspensão revelam uma substancial redução da velocidade de sedimentação devido à presença de partículas adjacentes. Este assunto tem sido tema de uma série de investigações empíricas e semi-empíricas (RICHARDSON e ZAKI, 1954; VAN RIJN, 1984; entre outros) e também de investigações analíticas devidamente ratificadas por dados experimentais (BALDOCK et al. , 2004; SCHULZ e ALAMY FILHO, 2005; entre outros). Diante disso, a tabela 2.1 relaciona uma série de expressões encontradas na literatura.

Tabela 2.1 - Algumas expressões para velocidade de sedimentação como função da concentração de partículas

\begin{tabular}{ll}
\hline \hline Hawksley (1951): & $w_{s}=w_{o} \cdot \xi(1-\phi)^{2} \cdot \exp \left(\frac{-k_{1} \cdot \phi}{1-k_{2} \cdot \phi}\right)$ \\
\hline Zaki (1954): & $w_{s}=w_{o} \cdot(1-\phi)^{\alpha}$ \\
\hline Happel e Brenner (1965): & $w_{s}=w_{o} \cdot \frac{3-9 \phi / 2+9 \phi^{5} / 2-3 \phi^{6}}{3+2 \phi^{5}}$ \\
\hline Merkel (1971): & $w_{s}=w_{o} \cdot(1-\phi)^{1,41}$ \\
\hline van Rijn (1984): & $w_{s}=w_{o} \cdot(1-\phi)^{4}$ \\
\hline \hline
\end{tabular}

Na tabela 2.1, podem-se definir:

- $\quad w_{s}=$ velocidade de sedimentação (como função da concentração de partículas) [LT ${ }^{-1}$ ];

- $\xi=1$ (eventos sem floculação) e 2/3 (eventos com floculação);

- $\mathrm{k}_{1}=5 / 2$ para esferas;

- $\mathrm{k}_{2}=39 / 64$

- $\alpha=$ coeficiente entre 2,35 e 4,65 . 
O adimensional $\phi$ é definido como a concentração volumétrica de partículas, matematicamente descrita por:

$\phi=\frac{\text { Volume de sedim entos }}{\text { Volume Total }}=\frac{c}{\rho_{s}}, \quad$ onde $c$ é a concentração de sedimentos $\left[\mathrm{ML}^{-3}\right]$

Apesar do grande número de equações existentes, não se tem observado que uma única relação universal entre a velocidade de sedimentação e a concentração volumétrica de sedimentos satisfaça a todas as experimentações. Diante disso, este trabalho destacou a utilidade de se desenvolver uma formulação que permitisse cobrir uma vasta gama de cenários de sedimentação, tais como as variações de concentrações, materiais e diâmetros. Assim, desenvolvimentos analíticos baseados na quantificação da energia cinética no processo de sedimentação redundaram numa formulação teórica interessante, a qual, por conveniência, será detalhada em capítulo posterior.

\subsection{5 - EQUAÇÕES GOVERNANTES DO TRANSPORTE DE SEDIMENTOS}

A modelagem do transporte de sedimentos em escoamentos turbulentos utiliza dois conjuntos distintos de equações, um para o fluido e outro para o sedimento. Conforme já foi comentado, são as equações de Navier-Stokes que governam o escoamento dos fluidos, permitindo avaliar os campos de velocidade e pressão. Segundo o grau de modelagem adotada (lembrar os três tipos classificados na primeira parte deste capítulo), estas equações assumem formas ligeiramente distintas. A adoção de cada grau de modelagem é determinada pelo tipo de informação que se deseja obter no escoamento.

Ainda que haja um consenso quanto à modelagem do movimento do fluido (neste caso, com a nossa atual matriz de conhecimentos, não se pode prescindir das equações de Navier-Stokes e da Continuidade), a literatura destaca duas formas, um tanto distintas, para equacionar o transporte de sedimentos. A primeira delas procura descrever a trajetória das partículas, enquanto que a outra procura descrever a sua distribuição espacial e temporal quantificável em termos das concentrações no escoamento. As seções seguintes procuram tecer comentários a respeito dessas situações distintas e de suas equações governantes. 


\subsubsection{1 - Equação de Maxey-Riley}

A aplicação da Segunda Lei de Newton ao movimento individual de uma partícula de sedimento origina a equação de Maxey-Riley, a qual permite calcular a posição de partículas lançadas num determinado escoamento. A união das posições para diversos instantes de tempo permite que sejam traçadas as trajetórias individuais. Para isto, torna-se conveniente sintetizar algumas forças atuantes numa partícula imersa em um escoamento. Assim:

- Força gravitacional: decorrente do peso da partícula;

- Força de empuxo: decorrente da ação do fluido na partícula;

- Força de arrasto: decorrente do gradiente de pressão entre os bordos de ataque (frontal) e traseiro da partícula e também decorrente do cisalhamento exercido pelo fluido sobre a partícula;

- Força de suspensão decorrente da superposição de dois efeitos:

1. Efeito de Saffman: promove a suspensão da partícula em função do gradiente de velocidade local (cisalhamento);

2. Efeito de Magnus: promove a suspensão da partícula em função da sua tendência de rotação.

Apesar do princípio físico rígido (Segunda Lei de Newton) que rege a equação de Maxey-Riley, sua aplicação ainda é cercada por considerações que decorrem da falta de conhecimento preciso a respeito das forças atuantes na partícula. De fato, as quantificações dos efeitos de arrasto e de suspensão dependem de coeficientes empíricos. Além disso, percebe-se que a literatura demonstra incertezas quanto à relevância dos efeitos de cisalhamento e de rotação na força de suspensão. Van Rijn (1984a) considerou que o efeito da força de Magnus (devido à rotação das partículas) é uma ordem de grandeza menor que a força de Saffman (devido ao cisalhamento). Assim, segundo van Rijn, mesmo para escoamentos turbulentos, a força devido ao cisalhamento é a principal causadora da suspensão do sedimento. Isto fez com que esse autor desconsiderasse a força de Magnus na sua análise. Outros autores como White e Shulz (1977) examinaram a força de arrasto e a força de Magnus, concluindo que esta última é de grande relevância. Já os estudos de Murphy e Aguirre (1985) mostraram que a força de Magnus pode ser desprezada. A ausência de um 
consenso geral, quanto aos coeficientes e aos efeitos a serem considerados, resulta em equações de Maxey-Riley ligeiramente diferentes.

Wang e Squires (1996), por exemplo, realizaram Simulações de Grandes Escalas (SGE) para partículas dispersas num canal vertical. Dessa forma, foram utilizadas as equações filtradas de Navier-Stokes para o fluido e uma equação de Maxey-Riley para o sedimento, a qual assume a seguinte forma tensorial:

$\frac{d V_{i}}{d t}=\frac{-\rho}{\rho_{s}} \cdot \frac{3}{4} \cdot C_{D} \cdot \frac{|\vec{V}-\vec{u}|}{d} \cdot\left(V_{i}-u_{i}\right)+f_{i}$

Em que:

- $\quad i=$ direções 1 (longitudinal), 2 e 3 (transversais);

- $V_{i}=$ velocidade da partícula na direção $i\left[\mathrm{LT}^{-1}\right]$;

- $u_{i}=$ velocidade do fluido na direção $i\left[\mathrm{LT}^{-1}\right]$;

- $\rho=$ massa específica do fluido $\left[\mathrm{ML}^{-3}\right]$;

- $\rho_{s}=$ massa específica do sedimento $\left[\mathrm{ML}^{-3}\right]$;

- $d=$ diâmetro da partícula [L];

- $C_{D}=\frac{24}{\operatorname{Re}_{s}} \cdot\left[1+0,15 \cdot \operatorname{Re}_{s}^{0,687}\right]$;

- $\operatorname{Re}_{s}=\frac{\mathrm{d} \cdot|\overrightarrow{\mathrm{u}}-\overrightarrow{\mathrm{V}}|}{?}$

- $f_{i}=-\frac{0,343 \cdot(d / 2)}{\tau} \cdot \frac{d u_{1} / d x_{2}}{\left|d u_{1} / d x_{2}\right|} \cdot\left[\frac{1}{\operatorname{Re}_{\tau} \mid}\left|\frac{d u_{1}}{d x_{2}}\right|\right]^{\frac{1}{2}} \cdot \delta_{i 2}=$ força de suspensão;

- $\tau^{+}=$tempo constante de Stokes $=2 \frac{\rho}{\rho_{s}}\left(\frac{d^{+}}{2}\right)^{2} / 9$;

- $\delta_{\mathrm{i} 2}=$ delta de $\operatorname{Kronecker}(1$, se $\mathrm{i}=2 ; 0$, se i?2);

- $\operatorname{Re}_{\tau}=\frac{\mathrm{u}_{*} \cdot \mathrm{d}}{?} ;$

- $\quad \mathrm{u}_{*}=$ velocidade de cisalhamento $\left[\mathrm{LT}^{-1}\right]$;

- $\delta=$ metade da largura do canal [L]. 
Note-se que os autores consideraram, na composição da equação de Maxey-Riley, apenas as forças de arrasto e de suspensão, sendo este último composto pelo efeito de Saffman, exclusivamente.

Marchioli e Soldati (2002), por sua vez, realizaram Simulações Numéricas Diretas (SND) para transporte de partículas num canal, aplicando as equações de Navier-Stokes, na forma primitiva para o fluido, e novamente uma equação de Maxey-Riley para o sedimento. A equação de Maxey-Riley, utilizada por esses autores, na forma vetorial, pode ser escrita como:

$\frac{d \vec{V}}{d t}=\frac{C_{D}}{\tau_{s}} \cdot(\vec{u}-\vec{V})+\left(1-\frac{\rho}{\rho_{s}}\right) \cdot \vec{g}-\xi(e) \cdot \frac{6,46 \cdot d}{12 \pi} \cdot \frac{\left|\partial u_{x} / \partial z\right|^{\frac{1}{2}}}{\tau_{s}} \cdot\left(V_{x}-u_{x}\right) \cdot \vec{k}$

Em que:

- $\mathrm{x}=$ direção longitudinal do escoamento;

- $\quad \mathrm{z}=$ direção transversal (normal às paredes);

- $\tau_{\mathrm{s}}=$ tempo de relaxação da partícula $\left(\tau_{s}=d^{2} \cdot \rho_{s} /(18 \mu)\right.$;

- $\vec{k}=$ vetor unitário na direção z;

- $\xi(e)=$ fator de correção.

O fator de correção $\xi(e)$ leva em conta situações onde as diferenças entre as velocidades da partícula e do fluido são muito grandes. Assim, de acordo com Mc Laughlin (1991), $\xi(e)$ pode ser calculado como:

$$
\begin{cases}\xi(e)=\frac{1}{K} \cdot\left[-32 \pi^{2} e^{5} \cdot \ln \left(e^{-2}\right)\right] & , \text { para } e=0,025 \\ \xi(e)=\frac{1}{K} \cdot\left[1,418 \cdot \operatorname{arctg}\left(2,8 \cdot e^{2,44}\right)\right] & , \text { para } 0,025<e=20 \\ \xi(e)=\frac{1}{K} \cdot\left(K-0,6463 \cdot e^{-2}\right) & , \text { para } e>20\end{cases}
$$

Em que:

- $\mathrm{K}=2,225$; 
- $\quad e=\left|\frac{\partial u_{x}^{+}}{\partial z^{+}}\right|^{0,5} \cdot \frac{d^{+}}{\operatorname{Re}_{s}}$

- $z^{+}=z \cdot u_{*} /$,

- $u_{x}^{+}=u_{x} / u_{*}$.

Outra variante da equação de Maxey-Riley é apresentada por Chang e Scotti (2003), porém levando em consideração uma massa de partícula adicional devido ao envolvimento do grão por uma fina camada de fluido. De uma maneira geral, as simulações apresentadas na literatura não consideram o efeito de Magnus na força de suspensão.

A integração da equação de Maxey-Riley (formulações nos moldes das equações (2.23) e (2.24)) é feita numericamente e fornece as trajetórias individuais das partículas. Uma condição inicial, utilizada por Marchioli e Soldati (2002), consiste em impor velocidades iguais entre a partícula e o fluido quando essas são liberadas no escoamento. Outro aspecto numérico interessante é que nem sempre (ou na maioria das vezes) a posição da partícula coincide com as regiões do domínio onde as velocidades do fluido são conhecidas (geralmente nas faces das células, quando é utilizado um esquema deslocado). Isto revela a necessidade de interpolar as velocidades do fluido de forma a obter seu valor nos pontos coincidentes com a posição da partícula.

Os efeitos de ejeção e varredura sobre a movimentação das partículas são observados através de simulações com a equação de Maxey-Riley, uma vez que esta permite estimar para quais novas posições uma partícula individual de sedimento será levada pelo escoamento. Contudo, a equação prevê comedidamente a interação (colisões) entre as diferentes partículas, o que levaria a grandes dificuldades de implementação. De fato, as simulações com MaxeyRiley são feitas liberando um número finito de partículas no escoamento de forma que as concentrações são mantidas pequenas. Este procedimento não é o mais adequado (e nem o mais geral) para avaliar concentrações de partículas num escoamento. Isto atua como um fator limitante para aplicação deste equacionamento em escoamentos fluviais, onde não se pode quantificar (ou nem mesmo medir) o número de partículas dispersas. Nestes casos a avaliação das concentrações é mais representativa. Além dessa limitação, deve-se também levar em conta os aspectos "incertos" e empíricos a respeito da consideração das forças atuantes nas partículas e seus respectivos coeficientes. 


\subsubsection{2 - Equação de Advecção-Difusão}

A necessidade de quantificar a concentração de sedimentos suspensos em um escoamento, induz a uma segunda forma de modelar o transporte de partículas, o que é feito através da equação de Advecção-Difusão. O princípio físico que rege essa equação é o da Conservação de Massa. A equação de Advecção-Difusão apresenta grande generalidade, podendo ser aplicada para qualquer grandeza escalar transportada pelo escoamento. No caso do transporte de sedimentos, surge um termo fonte de sedimentação, de forma que a equação governante pode ser escrita como:

$$
\frac{\partial c}{\partial t}+u_{i} \frac{\partial c}{\partial x_{i}}=\frac{\partial}{\partial x_{i}}\left(D_{i} \frac{\partial c}{\partial x_{i}}\right)+\frac{\partial\left(w_{s} \cdot c\right)}{\partial x_{3}}
$$

Em que:

- $\quad i=1,2,3$ (direções longitudinal (1) e vertical (3));

- $c=$ concentração de sedimentos $\left[\mathrm{ML}^{-3}\right]$;

- $D_{i}=$ coeficiente de difusão molecular do sedimento $\left[\mathrm{L}^{2} \mathrm{~T}^{-1}\right]$;

- $w_{s}=$ velocidade de sedimentação da partícula $\left[\mathrm{LT}^{-1}\right]$.

Da mesma forma que para as equações de Navier-Stokes, a equação (2.26) representa a forma primitiva da Advecção-Difusão, permitindo o cálculo de concentrações instantâneas. Nas simulações com modelos clássicos ou com as equações filtradas, as formas assumidas pela equação de Advecção-Difusão são semelhantes, ainda que as variáveis tenham significados físicos diferentes. Assim, tanto para a modelagem clássica, quanto para a $S G E$, a equação de Advecção-Difusão pode assumir a seguinte forma, com a introdução de um coeficiente de difusão turbulenta adicional:

$$
\frac{\partial \bar{c}}{\partial t}+\bar{u}_{i} \frac{\partial \bar{c}}{\partial x_{i}}=\frac{\partial}{\partial x_{i}}\left(\left(D_{i}+D_{t}\right) \frac{\partial \bar{c}}{\partial x_{i}}\right)+\frac{\partial\left(w_{s} \cdot \bar{c}\right)}{\partial x_{3}}
$$

Onde:

- Para a modelagem clássica:

1. $\bar{c}, \bar{u}_{i}=$ representam médias temporais da concentração e das velocidades; 
2. $\mathrm{D}_{\mathrm{t}}=$ difusividade turbulenta $\left[\mathrm{L}^{2} \mathrm{~T}^{-1}\right]$.

- Para a $S G E$ :

1. $\bar{c}, \bar{u}_{i}=$ representam concentrações e velocidades filtradas no espaço;

2. $\mathrm{D}_{\mathrm{t}}=$ difusividade turbulenta sub-malha $\left[\mathrm{L}^{2} \mathrm{~T}^{-1}\right]$.

Um dos entraves à utilização da equação de Advecção-Difusão, destacado por Chang e Scotti (2003), consiste na determinação da difusividade turbulenta $\left(D_{t}\right)$, sendo este valor muitas vezes considerado como igual ao da viscosidade cinemática turbulenta $\left(v_{t}\right)$. Isto pode subestimar ou superestimar as concentrações. Assim, a difusividade turbulenta pode geralmente ser relacionada à viscosidade turbulenta como $D_{t}=v_{t} / \sigma_{c}$. O valor de $\sigma_{\mathrm{c}}$ (dito número de Schmidt) é geralmente considerado unitário, o que gera a restrição comentada por Chang e Scotti (2003). Existem, todavia, relações empíricas para estimar uma forma de variação deste coeficiente (COLEMAN, 1970). Assim:

$$
\sigma_{c}=\frac{1}{1+2 \cdot\left(\frac{w_{s}}{u_{*}}\right)^{2}} \quad, \text { para } 0,1<\frac{w_{s}}{u_{*}}<1
$$

Confrontadas as duas formas de equacionar o transporte de sedimentos (Maxey-Riley e Equação de Advecção-Difusão), o autor deste trabalho considera que esta última pode fornecer resultados mais interessantes, além de servir como base para futura aplicação da metodologia em escoamentos fluviais. 


\section{Simulação de Grandes Escalas}

As simulações com modelos clássicos de turbulência são freqüentemente suficientes para a resolução de problemas práticos de Engenharia Civil. Nesses casos, o objetivo é a quantificação média dos efeitos da turbulência, uma vez que as flutuações instantâneas são pouco significativas dentro dos grandes horizontes de projeto requeridos pelas obras hidráulicas. A utilização da modelagem clássica, todavia, não captura informações mais detalhadas acerca do movimento dos fluidos, as quais são perdidas na aplicação da média temporal. Da mesma forma, a determinação de grandezas médias pode ocultar casos particulares extremos que, dependendo do tipo de problema, podem ser importantes.

Segundo Piller (1997), os modelos clássicos descrevem a influência da turbulência sobre as características médias do escoamento, sem, contudo, descrever seus detalhes. As Simulações Numéricas Diretas (SND), embora descrevam exatamente as estruturas turbulentas, possuem distante expectativa de aplicação para escoamentos práticos. Assim, percebe-se claramente que ainda existe uma distância, entre os modelos clássicos e as simulações diretas, no que diz respeito à capacidade de capturar detalhes refinados da turbulência para escoamentos de campo, como os fluviais, por exemplo.

A metodologia da Simulação de Grandes Escalas (SGE) se posiciona de forma intermediária entre a SND e a modelagem clássica, permitindo compreender fisicamente a dinâmica da turbulência nos fluidos. Conforme mencionado, problemas aplicativos podem necessitar de maiores graus de detalhamento, o que ocorre quando tecnologias dispendiosas estão em jogo (reatores nucleares, problemas de vibrações em estruturas hidráulicas estratégicas, como hidrelétricas ou plataformas de perfuração de petróleo, entre outras) Além disso, na SGE aplicações para números de Reynolds mais elevados podem ser viáveis, o que permite justificar o aumento gradativo observado em seu uso. 


\section{1 - INTRODUÇÃO}

As estruturas turbilhonares de grande escala são produzidas por interações com o escoamento médio e, por isto, dependem das condições de contorno impostas ao problema. Como o escoamento médio apresenta direção e sentido preferenciais, estas características são também impostas aos turbilhões maiores, acarretando uma condição de anisotropia da turbulência. A despeito disto e, decorrente da dissipação de energia cinética turbulenta, os turbilhões menores perdem esta imposição direcional, tendendo à turbulência isotrópica. De fato, os pequenos turbilhões são altamente susceptíveis ao efeito da viscosidade do fluido e não conseguem manter uma direção bem definida, pois são logo dissipados. Estes dois efeitos proporcionam (o que é comumente chamado na literatura) a isotropia local da turbulência, ou seja, a turbulência pode ser considerada isotrópica apenas nas pequenas escalas.

Conforme já mencionadas no capítulo anterior, as limitações computacionais ainda existentes impossibilitam a aplicação da SND para resolução de estruturas turbulentas muito finas (de pequena escala). Todavia, esta restrição não atinge a estimativa das maiores escalas que, geralmente, são objeto de maior interesse por conter informações acerca da geração e transmissão de energia turbulenta. De fato, o cálculo das maiores escalas de turbulência, pela própria anisotropia vinculada à direção principal do escoamento, é um problema fundamentalmente dependente do tempo e do espaço, exigindo a resolução das equações de Navier-Stokes. Os turbilhões de pequena escala, por apresentarem características isotrópicas e independentes das condições de contorno, podem ser mais facilmente parametrizados.

A idéia que orienta a Simulação de Grandes Escalas (SGE) baseia-se na discretização do domínio de escoamento para resolver escalas maiores de turbulência (escalas filtradas) e na utilização de um modelo para aproximar as escalas menores (escalas sub-malha). Assim, de acordo com a figura 3.1, apenas uma parte do espectro de energia turbulenta é modelada.

A divisão entre grandes escalas e escalas sub-malha, característica da SGE, não determina que cada parte seja resolvida por um conjunto de equações separadamente. Assim, apesar do conceito físico diferente, como nas equações médias de Reynolds, há introdução de tensores adicionais que são objetos de modelação. As equações de Navier-Stokes primitivas passam a ser as equações de Navier-Stokes filtradas (com o modelo intrínseco) cuja resolução numérica fornece os campos filtrados de velocidade e pressão. As discussões acerca do equacionamento são discutidas adiante. Por ora é conveniente ater-se aos princípios e às etapas cronológicas de modelagem. 


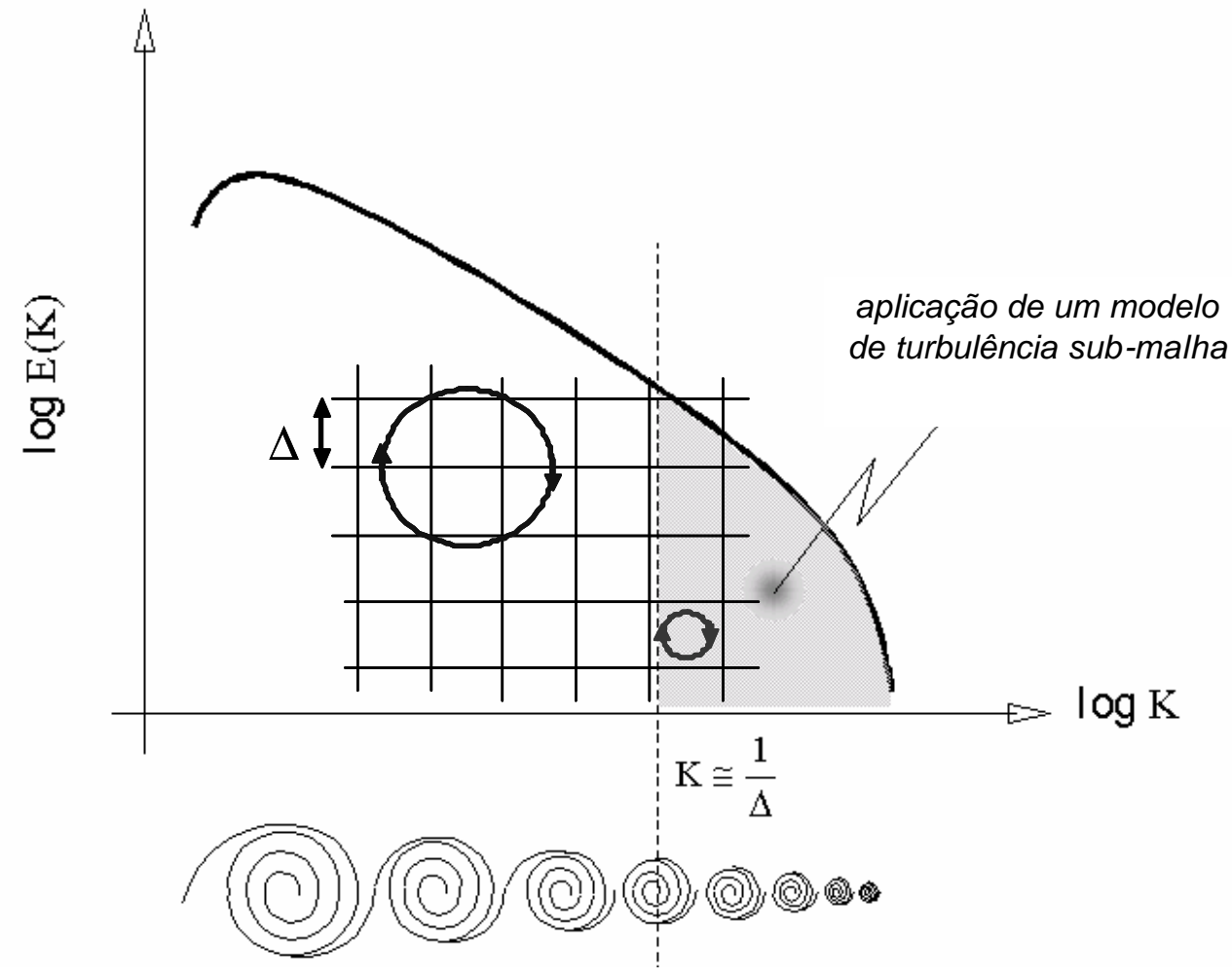

Figura 3.1 - Divisão do espectro de energia cinética turbulenta para aplicação da SGE : as grandes escalas são estimadas diretamente, enquanto que um modelo de turbulência é aplicado, levando em conta o efeito das estruturas turbilhonares de pequena escala

\section{2 - ESTIMATIVA DA ESPESSURA DO FILTRO (DISCRETIZAÇÃO ESPACIAL REQUERIDA)}

Enquanto a modelagem clássica realiza uma divisão temporal de escalas (médias temporais e flutuações em torno dessas médias), a SGE utiliza uma divisão espacial (ou geométrica). Isto quer dizer que a separação ocorre em relação às dimensões das estruturas turbilhonares, delimitando, conforme já comentado, as grandes escalas e as escalas sub-malha. A imposição do limite de corte (o que é grande ou pequena escala?) é feita através da aplicação de um filtro de espessura $\Delta$ fixada pelo modelador. $O$ filtro representa a discretização espacial do domínio de escoamento, atuando apenas na retenção das estruturas classificadas como de grande escala (ver figura 3. 2).

A questão que surge é: como estimar a espessura do filtro, ou seja, como determinar o limite entre as escalas resolvidas e as escalas sub-malha? Note-se que o espectro de energia cinética turbulenta é construído em função da variável $k$ que representa o número de onda ou 
freqüência espacial da estrutura turbilhonar. O número de onda de corte pode se relacionar com a espessura do filtro da seguinte maneira: $k_{c} \cong 1 / \Delta$. Assim, pode-se localizar onde é feita a divisão no espectro. Contudo, o espectro de energia turbulenta depende de cada tipo de escoamento. Não existem espectros prontos ou disponíveis. Pelo contrário, estes são construídos a partir de simulações numéricas ou a partir de experimentos conduzidos para um escoamento em particular. É mais prático estimar diretamente a espessura do filtro $(\Delta)$ para depois estimar o número de onda de corte $\left(k_{c}\right)$.

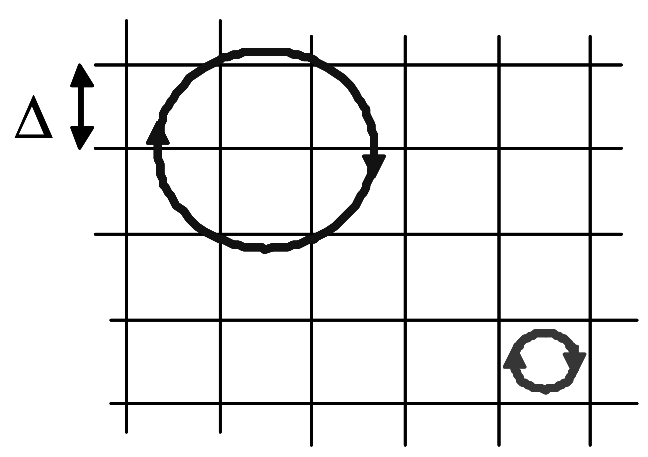

Filtro espacial

Figura 3.2 - O domínio de escoamento é discretizado por um filtro de espessura $\Delta$ que captura as grandes escalas, mas que não retém as escalas sub-malha

A análise do espectro de energia turbulenta demonstra intuitivamente que quanto maior o valor de $k$ (quanto mais refinado for o filtro), menor é a região a ser modelada. Isto conduz a resultados mais precisos, uma vez que a SGE se aproxima da SND. De fato, a modelagem das pequenas estruturas turbulentas, dita modelagem sub-malha, baseia-se na hipótese de isotropia para as pequenas escalas (como é apresentado adiante). A utilização de elevados números de onda de corte aproxima esta tendência. Em contrapartida, quando se estipula baixos números de onda de corte (quanto mais grosseiro for o filtro), pode-se cair em graves contrastes, modelando parcelas com alto grau de anisotropia como se fossem isotrópicas!

$\mathrm{Na}$ prática a escolha do comprimento característico do filtro é feita por tentativas. Todavia, existem parâmetros aproximados para estimar uma região viável. Tais parâmetros baseiam-se no número de Reynolds, de acordo com a expressão utilizada para calcular o número de graus de liberdade, aqui convenientemente reescrita como: 


$$
\left[\frac{L}{\ell_{D}}\right]^{3}=R e^{\frac{9}{4}}
$$

Notadamente é possível estipular uma dimensão característica para as maiores escalas $(L)$, uma vez que elas apresentam a mesma ordem de grandeza de uma singularidade geométrica que perturba o escoamento. Este elemento geométrico pode ser, por exemplo, um obstáculo ou a altura de uma duna. A partir dessa primeira estimativa, uma noção de grandeza da escala dissipativa pode ser fornecida por:

$$
\ell_{D}=L / \operatorname{Re}^{\frac{3}{4}}
$$

A figura 3. 3 ilustra a faixa do espectro onde a escala de corte pode ser aplicada.
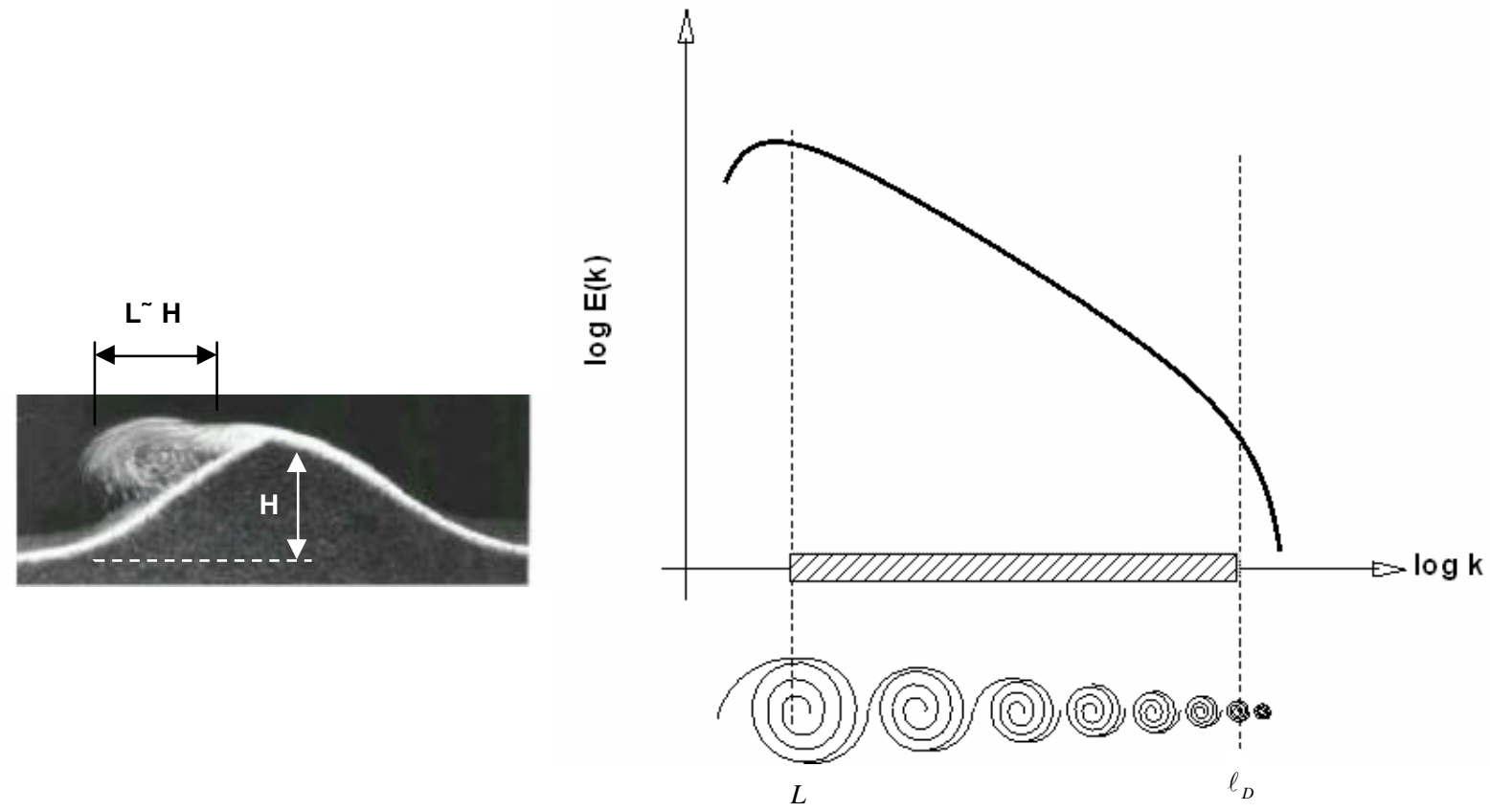

Figura 3. 3- A divisão das escalas ocorre na região inercial do espectro de energia cinética turbulenta. As grandes escalas podem ser estipuladas aproximadamente de acordo com geometrias características do escoamento. As escalas dissipativas podem ser estimadas a partir da equação (3.2)

A primeira impressão, ao analisar a figura 3.3, é que a estimativa descrita acima não foi muito perspicaz, afinal o corte pode ser aplicado na maior parte do espectro! Isto é mais 
acentuado com o aumento do número de Reynolds, uma vez que o espectro de energia tornase mais largo, fazendo surgir uma vasta faixa inercial. Na verdade, deve-se adequar a disponibilidade computacional ao grau de precisão desejado. Quanto mais próximo de $\ell_{D}$ for a escala de corte, mais preciso será o resultado, porém mais refinada deve ser a malha. Partindo do outro extremo, se o corte for feito próximo das grandes escalas, o refinamento da malha torna-se mais grosseiro em detrimento dos resultados que, no mínimo, são dotados de imprecisão. A adoção de escalas de corte com ordens de grandeza muito superiores a $\ell_{D}$ pode levar a resultados que divergem, destruindo a solução numérica. De fato isto ocorre porque o modelo atribui como isotrópica uma escala que pode ser altamente anisotrópica.

A melhor alternativa é adotar escalas de corte gradativamente maiores do que $\ell_{D}$, adequando-se a isto os recursos computacionais existentes (armazenamento e tempo de processamento).

\section{3 - A FILTRAGEM DAS EQUAÇÕES GOVERNANTES}

Após a seleção do filtro, ou seja, após a discretização do domínio de escoamento, automaticamente já é aplicada a filtragem implícita sobre as equações. Este procedimento suaviza as curvas de variação instantânea, seja ela de velocidade, pressão, concentração, etc. Ainda que os resultados filtrados não sejam rigorosamente instantâneos (pois não se trata de uma SND), eles podem ser considerados próximos (ver figura 3.4).

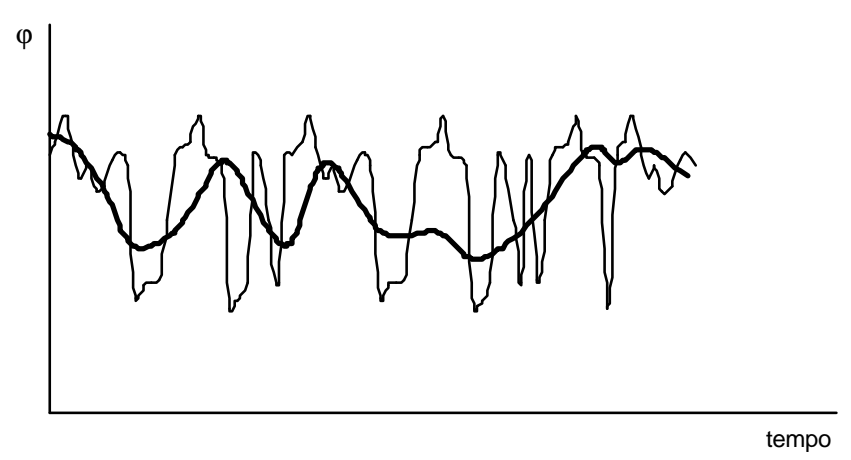

Figura 3. 4 - Aplicação da filtragem sobre uma curva instantânea de uma variável genérica $(\varphi)$ ). $O$ efeito da operação proporciona uma suavização da curva original 
De acordo com Wang e Squires (1996), os resultados da SGE (filtrados) podem ser considerados como resultados equivalentes aos instantâneos, obtidos por experimentos. Isto ocorre porque:

- As escalas filtradas são similares à precisão das medições experimentais;

- As diferenças decorrem dos erros (ruídos) provindos do modelo sub-malha;

- A modelagem apenas das escalas menores conduz a erros menos significativos, pois o sentido de transferência de energia cinética turbulenta é preferencialmente das grandes para as menores estruturas turbilhonares, e não o contrário.

A operação de filtragem pode ser matematicamente definida como a integral de convolução entre a função a ser filtrada (velocidade, pressão, concentração, temperatura, etc.) e uma função filtro a ser definida, de acordo com a expressão abaixo.

$$
\bar{\varphi}(\vec{x}, t)=\int_{V} G\left(\vec{x}-\vec{x}^{\prime}\right) \cdot \varphi\left(\vec{x}^{\prime}, t\right) \cdot d \vec{x}^{\prime}
$$

Em que:

- $\varphi$ = variável a ser filtrada (velocidade, pressão, concentração, temperatura, etc.);

- $\bar{\varphi}=$ valor filtrado da variável $\varphi$;

- $G=$ função filtro.

A grandeza instantânea é assim representada pela soma do seu valor filtrado e do seu valor residual (sub-malha):

$$
\varphi=\bar{\varphi}+\varphi^{\prime}
$$

Note-se que, na SGE, as barras superiores indicam que os valores são filtrados e não médias temporais como ocorre nos modelos clássicos. Mas falta ainda definir alguns termos da equação (3.3). A integral de convolução é aplicada sobre um domínio $V$ que é referente ao volume de cada célula da malha. Note-se então, que a filtragem é realizada dentro de cada elemento discreto (célula) da malha. A figura 3.5 ilustra o domínio sobre o qual é aplicada a filtragem. 


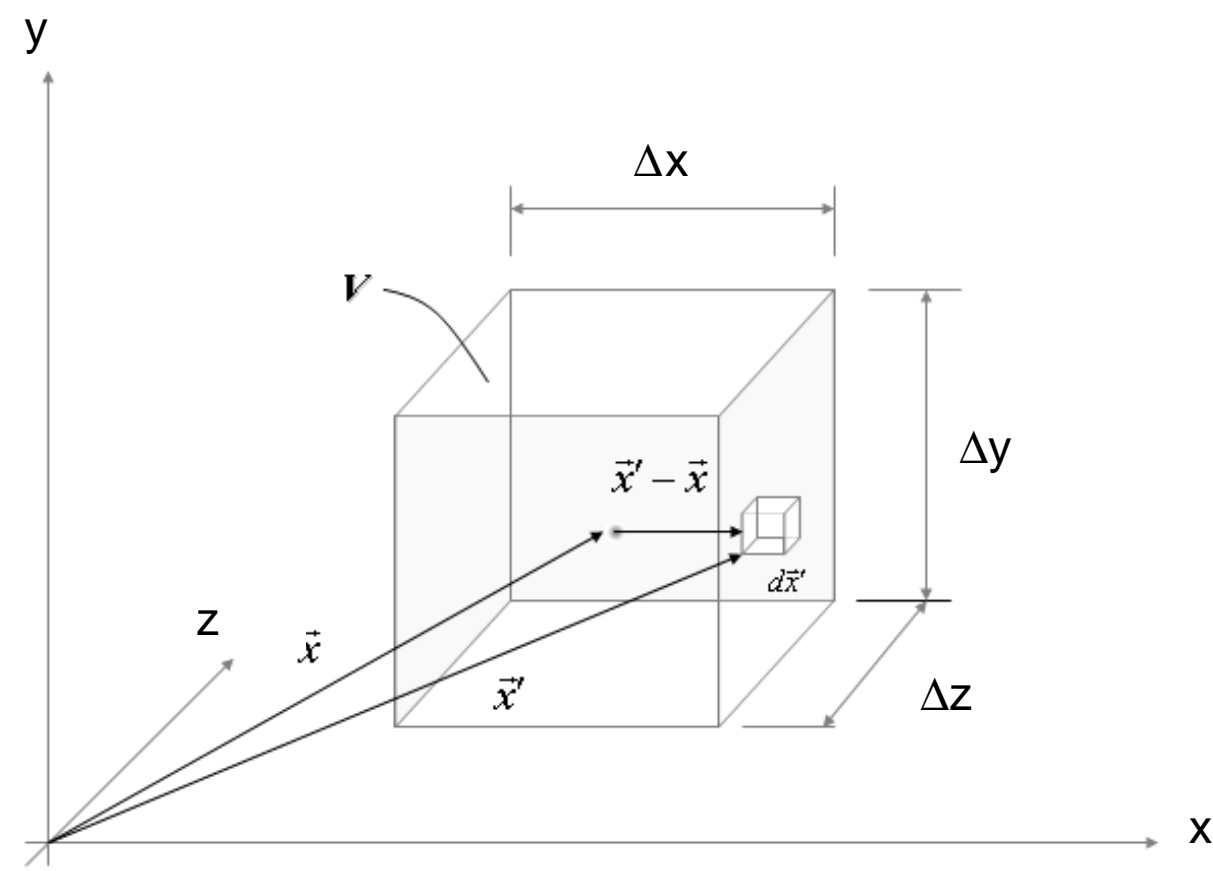

Figura 3.5 - Representação de uma célula do domínio e das variáveis relevantes na operação de filtragem. Note-se que esta operação ocorre apenas dentro de cada célula discreta

De acordo com a figura 3.5, a variável $\vec{x}$ representa um vetor de posição dentro do domínio. Assim:

- $\quad \vec{x}=$ posição referente ao centro da célula;

- $\quad \vec{x}^{\prime}=$ posição de um elemento de volume $d \vec{x}^{\prime}$ que pode estar tanto dentro como fora da célula;

- $V=$ volume da célula. Pode referir-se à área da célula para simulações bidimensionais.

A função filtro $(G)$ é uma função do vetor $\vec{x}^{\prime}-\vec{x}$ que exprime a distância que cada um dos elementos de volume $d \vec{x}^{\prime}$ está do centro da célula. Diante disto, a literatura destaca vários tipos de funções filtro, sendo a filtragem de Gauss e a filtragem por volume as mais difundidas.

Os filtros de Gauss podem ser escritos como: 
$G_{i}\left(x_{i}-x_{i}^{\prime}\right)=\left(\frac{6}{\pi \cdot \Delta_{i}}\right)^{\frac{1}{2}} \cdot \exp \left[\frac{-6 \cdot\left(x_{i}-x_{i}^{\prime}\right)^{2}}{\Delta_{i}^{2}}\right]$

Em que:

- $\quad \mathrm{i}=$ direções de aplicação da filtragem $(\mathrm{i}=1,2,3)$;

- $\Delta_{i}=$ espessura do filtro (dimensão da célula) na direção i.

A figura 3.6 ilustra uma curva obtida pela função de Gauss. A operação de filtragem faz uma integração (ver equação (3.3)), dentro da célula, de cada produto $G \cdot \varphi$, de forma que o resultado final exprime a grandeza filtrada $(\bar{\varphi})$.

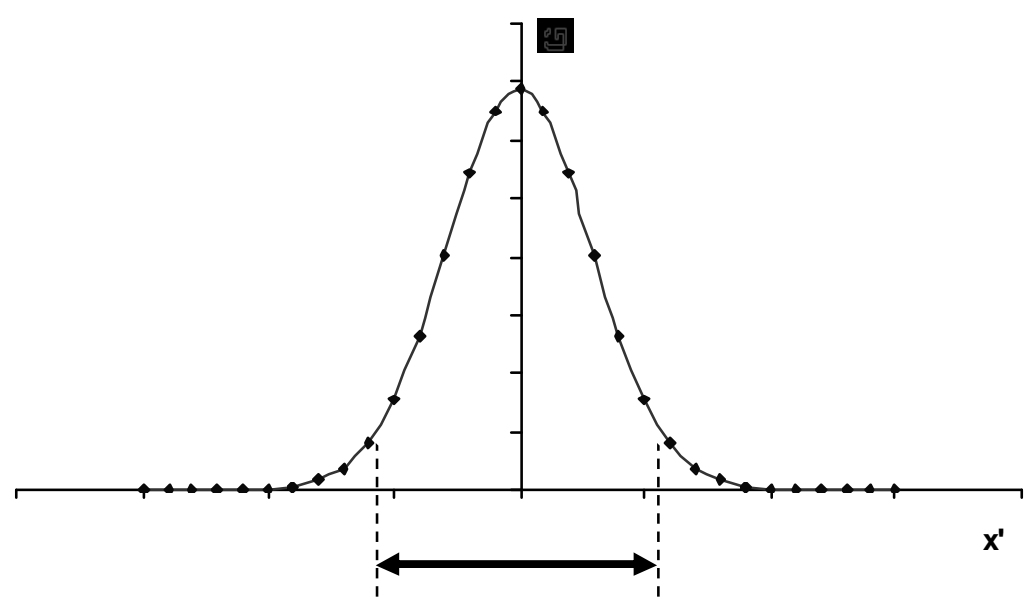

$\Delta$

Figura 3.6 - O filtro de Gauss leva em conta a influência da distância (atua como um peso) que cada elemento de volume está do centro da célula. Note-se que regiões fora da célula ainda são influenciadas

Outro tipo de formulação, talvez bem mais utilizada, é a função filtro por volume. Esta aplicação leva em conta somente elementos de volume dentro de cada célula e despreza a influência daqueles que estão em células adjacentes. O filtro por volume é definido como:

$$
G\left(x_{i}-x_{i}^{\prime}\right)= \begin{cases}\frac{1}{V} & \text { para }\left|x_{i}-x_{i}^{\prime}\right| \leq \frac{1}{2} \Delta \\ 0 & \text { para }\left|x_{i}-x_{i}\right|>\frac{1}{2} \Delta\end{cases}
$$


Com a definição expressa pela equação (3.6) a aplicação da função filtro por volume resulta na curva tipo "cartola" ilustrada pela figura 3.7.

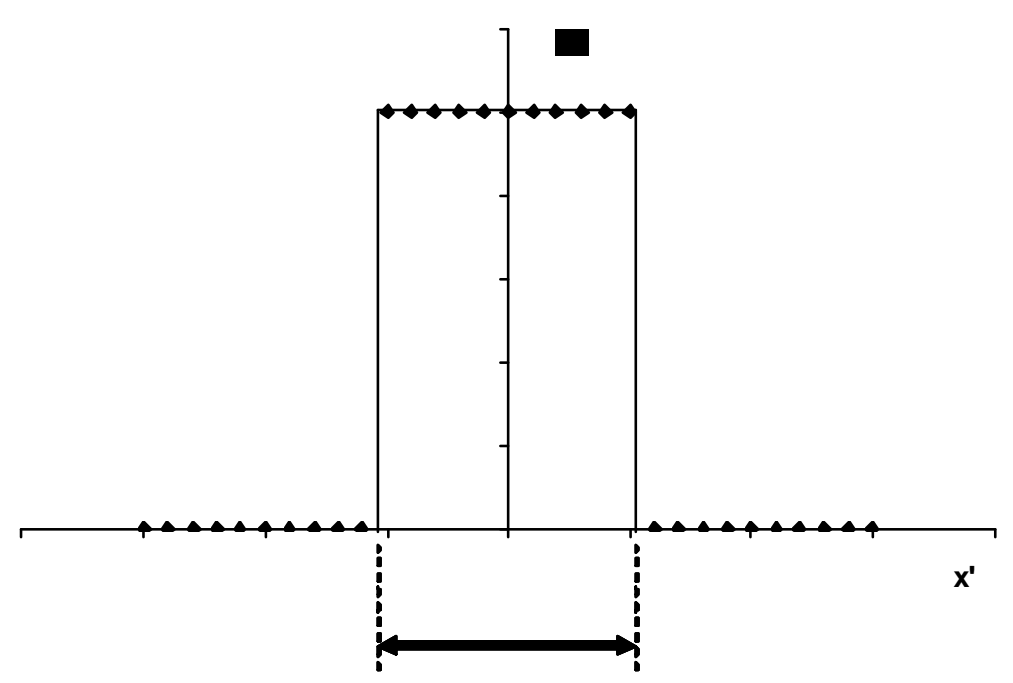

$\Delta$

Figura 3.7 - Função filtro por volume: somente elementos de volume dentro da célula são relevantes, independentemente da sua distância ao centro da mesma

A utilização da função filtro por volume leva a uma interpretação física mais perceptível, além de facilitar o processo de discretização das equações governantes. Assim, a variável filtrada representa a média espacial de todos os seus valores instantâneos dentro da célula. De acordo com a definição de filtragem (equação(3. 3)):

- Considerando a região interna de cada célula:

$$
\bar{\varphi}=\int_{V} \frac{1}{V} \cdot \varphi \cdot d x^{\prime}=\frac{1}{V} \cdot \int_{V} \varphi \cdot d x^{\prime} \equiv \frac{\sum\left(\varphi \cdot d x^{\prime}\right)}{\sum d x^{\prime}}
$$

- Considerando regiões fora da célula:

$$
\bar{\varphi}=\int_{V} 0 \cdot \varphi \cdot d x^{\prime}=0
$$


O esquema ilustrado pela figura 3.8 demonstra a distribuição de velocidade filtrada ao longo de células vizinhas.

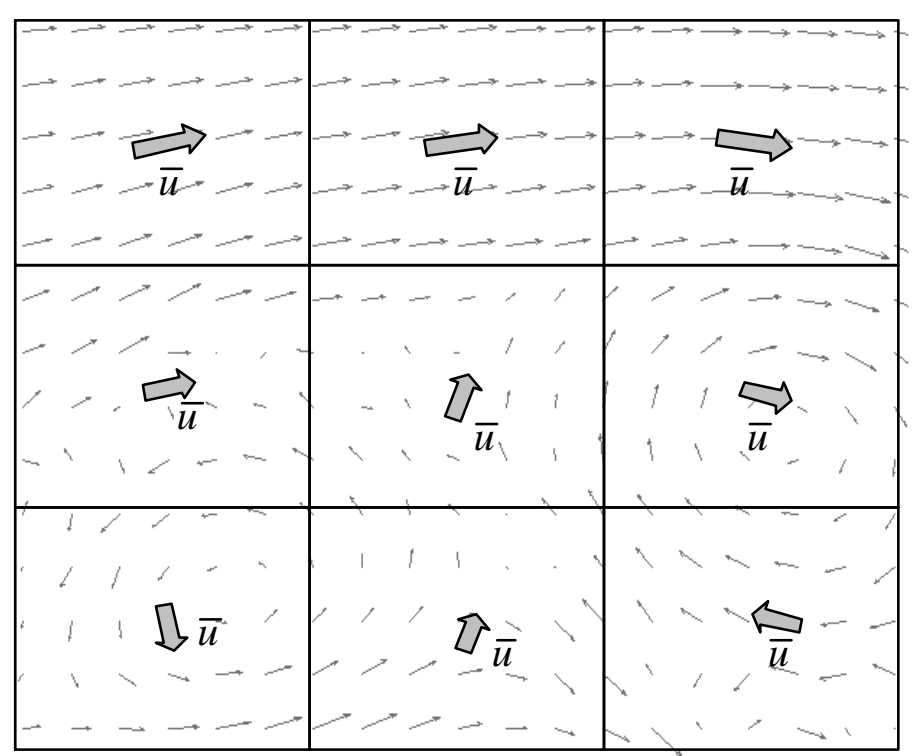

Figura 3.8 - Na filtragem por volume as grandezas resultantes (filtradas) representam a média (no espaço) das grandezas instantâneas dentro de cada célula

\section{4 - EQUAÇÕES DE NAVIER-STOKES E DA CONTINUIDADE FILTRADAS}

Após a revisão sobre os procedimentos de filtragem, torna-se conveniente apresentar as equações de Navier-Stokes e da Continuidade filtradas, uma vez que sua resolução numérica é o objetivo final da SGE. Os campos de velocidade e pressão obtidos a partir dessas equações representam conjuntos filtrados. A aplicação da filtragem por volume, por exemplo, redundará em campos cujos valores individuais representam a média no espaço de cada célula.

As equações governantes filtradas (independentemente da função filtro aplicada) são expressas por:

$\rho \frac{\partial \bar{u}_{i}}{\partial t}+\rho \frac{\partial\left(\bar{u}_{i} \cdot \bar{u}_{j}\right)}{\partial x_{j}}=-\frac{\partial \bar{p}}{\partial x_{i}}+\frac{\partial}{\partial x_{j}}\left[\mu \cdot\left(\frac{\partial \bar{u}_{i}}{\partial x_{j}}+\frac{\partial \bar{u}_{j}}{\partial x_{i}}\right)-\tau_{i j}+C_{i j}+L_{i j}\right]$

(Navier-Stokes filtrada) 


$$
\frac{\partial \bar{u}_{i}}{\partial x_{i}}=0
$$

(Continuidade filtrada)

Em que:

- $\tau_{\mathrm{ij}}=\overline{u_{i}^{\prime} \cdot u_{j}^{\prime}}=$ tensor de Reynolds de sub-malha;

- $\mathrm{C}_{\mathrm{ij}}=\overline{u_{i}^{\prime} \cdot \bar{u}_{j}}+\overline{\bar{u}_{i} \cdot u_{j}^{\prime}}=$ tensor cruzado;

- $\mathrm{L}_{\mathrm{ij}}=\overline{\bar{u}_{i} \cdot \bar{u}_{j}}-\bar{u}_{i} \cdot \bar{u}_{j}=$ tensor de Leonard.

Note-se que, como nos modelos clássicos, há o surgimento de tensores adicionais que provocam o não fechamento das equações filtradas. No caso da SGE surgem três tensores adicionais porque $\overline{\bar{u}_{i} \cdot u_{j}^{\prime}} \neq 0$ e $\overline{\bar{u}}_{i} \neq \bar{u}_{i}$. Assim, há a necessidade de se obter expressões para calcular essas novas variáveis.

A soma dos tensores cruzado e de Leonard pode ser modelada, segundo Findikakis e Street (1979), como:

$$
C_{i j}+L_{i j} \cong \frac{\Delta_{k}}{12} \cdot \frac{\partial \bar{u}_{i}}{\partial x_{k}} \cdot \frac{\partial \bar{u}_{j}}{\partial x_{k}} \quad \mathrm{k}=1,2,3
$$

O tensor de Reynolds (sub-malha) pode também ser modelado pela hipótese de Boussinesq, de maneira semelhante aos modelos clássicos:

$$
\tau_{i j}=\mu_{s m}\left(\frac{\partial \bar{u}_{i}}{\partial x_{j}}+\frac{\partial \bar{u}_{j}}{\partial x_{i}}\right)-\frac{2}{3} \rho \cdot k \cdot \delta_{i j}
$$

Em que:

- $\mu_{s m}=$ viscosidade turbulenta sub-malha;

- $\mathrm{k}=$ energia cinética turbulenta (como definida nos modelos clássicos);

- $\delta_{\mathrm{ij}}=$ delta de $\operatorname{Kronecker}\left(\delta_{\mathrm{ij}}=1\right.$, se $\mathrm{i}=\mathrm{j} ; \delta_{\mathrm{ij}}=0$, se i?j $)$.

Note-se que aqui também é adotada uma viscosidade turbulenta, mas sempre deve-se lembrar que seu significado físico é diferente daquela considerada nos modelos clássicos. A 
viscosidade turbulenta sub-malha, assim como o tensor de Reynolds, modela a influência das pequenas escalas de turbulência nas equações filtradas de Navier-Stokes.

De acordo com Shaanan et al. (1975), citado por Silveira Neto (2003), os tensores cruzado e de Leonard podem ser desprezados se forem utilizados esquemas advectivos de discretização de até $2^{\mathrm{a}}$ ordem. Assim:

- $\mathrm{L}_{\mathrm{ij}} \sim 0$ e $\mathrm{C}_{\mathrm{ij}} \sim 0$ para esquemas advectivos de até $2^{\mathrm{a}}$ ordem;

- $\mathrm{L}_{\mathrm{ij}}$ ? 0 e $\mathrm{C}_{\mathrm{ij}}$ ? 0 para ordens maiores que 2 e para métodos espectrais.

Silveira Neto et al. (1993) mostraram que, para esquemas de até $3^{\mathrm{a}}$ ordem observam-se as desigualdades:

- $\mathrm{L}_{\mathrm{ij}}<<\tau_{\mathrm{ij}}$

- $\mathrm{C}_{\mathrm{ij}}<<\tau_{\mathrm{ij}}$;

Assim, a utilização de esquemas de até $3^{\mathrm{a}}$ ordem (o que já é bastante satisfatório), permite simplificar a equação (3.7), a qual evolui para:

$\rho \frac{\partial \bar{u}_{i}}{\partial t}+\rho \frac{\partial\left(\bar{u}_{i} \cdot \bar{u}_{j}\right)}{\partial x_{j}}=-\frac{\partial \bar{p}}{\partial x_{i}}+\frac{\partial}{\partial x_{j}}\left[\mu \cdot\left(\frac{\partial \bar{u}_{i}}{\partial x_{j}}+\frac{\partial \bar{u}_{j}}{\partial x_{i}}\right)-t_{i j}\right]$

A substituição da equação (3.10) na equação (3.11) produz a forma filtrada mais tratável e encontrada na literatura:

$\rho \frac{\partial \overline{\mathrm{u}}_{\mathrm{i}}}{\partial \mathrm{t}}+\rho \frac{\partial\left(\overline{\mathrm{u}}_{\mathrm{i}} \cdot \overline{\mathrm{u}}_{\mathrm{j}}\right)}{\partial \mathrm{x}_{\mathrm{j}}}=-\frac{\partial \overline{\mathrm{p}}^{*}}{\partial \mathrm{x}_{\mathrm{i}}}+\frac{\partial}{\partial \mathrm{x}_{\mathrm{j}}}\left[\left(\mu+\mu_{\mathrm{sm}}\right) \cdot\left(\frac{\partial \overline{\mathrm{u}}_{\mathrm{i}}}{\partial \mathrm{x}_{\mathrm{j}}}+\frac{\partial \overline{\mathrm{u}}_{\mathrm{j}}}{\partial \mathrm{x}_{\mathrm{i}}}\right)\right]$

Onde: $\quad \bar{p}^{*}=\bar{p}+\frac{2}{3} \cdot \rho \cdot k=$ pressão modificada.

Assim, uma questão fundamental está na forma de estimar a viscosidade turbulenta sub-malha. Como modelar este termo e levar em conta os efeitos das pequenas estruturas turbilhonares na solução filtrada final? De fato, a estimativa de $\mu_{s m}$ tem sido uma fonte recente de vários estudos em SGE. Os procedimentos aplicados no cálculo desta variável são denominados modelagem sub-malha. A modelagem sub-malha é discutida adiante. Por ora é 
interessante apresentar outra equação governante de interesse: a equação de AdvecçãoDifusão filtrada.

\section{5 - EQUAÇÃO DE ADVECÇÃO-DIFUSÃO FILTRADA}

A obtenção da forma filtrada da equação de Advecção-Difusão é feita de maneira análoga ao caso das equações de quantidade de movimento. Novamente aparecem três variáveis adicionais que são chamadas de fluxo turbulento. Assim, a aplicação da operação de filtragem sobre a equação da concentração de sedimentos (Advecção-Difusão) produz:

$$
\frac{\partial \overline{\mathrm{c}}}{\partial \mathrm{t}}+\frac{\partial\left(\overline{\mathrm{u}}_{\mathrm{i}} \cdot \overline{\mathrm{c}}\right)}{\partial \mathrm{x}_{\mathrm{i}}}=\frac{\partial}{\partial \mathrm{x}_{\mathrm{i}}}\left[\mathrm{D} \cdot \frac{\partial \overline{\mathrm{c}}}{\partial \mathrm{x}_{\mathrm{i}}}-\left(\theta_{\mathrm{i}}+\mathrm{C}_{\theta \mathrm{i}}+\mathrm{L}_{\theta \mathrm{i}}\right)\right]+w_{s} \frac{\partial \bar{c}}{\partial x_{3}}
$$

Em que:

- $\theta_{\mathrm{i}}=\overline{\mathrm{u}_{\mathrm{i}}^{\prime} \cdot \mathrm{c}^{\prime}}=$ fluxo turbulento sub-malha;

- $\mathrm{C}_{\theta \mathrm{i}}=\overline{\mathrm{u}_{\mathrm{i}}^{\prime} \cdot \mathrm{c}^{\prime}}+\overline{\overline{\mathrm{u}}_{\mathrm{i}} \cdot \mathrm{c}^{\prime}}=$ fluxo turbulento cruzado;

- $\mathrm{L}_{\theta \mathrm{i}}=\overline{\overline{\mathrm{u}}}_{\mathrm{i}} \cdot \overline{\mathrm{c}}-\overline{\mathrm{u}}_{\mathrm{i}} \cdot \overline{\mathrm{c}}=$ fluxo turbulento de Leonard.

A adoção de esquemas de discretização espacial de até $2^{\mathrm{a}}$ ordem permite eliminar da equação filtrada os fluxos cruzado e de Leonard. Assim, o fluxo sub-malha passa a ser a única variável adicional a ser modelada. Sua estimativa, assim como nas equações que governam o transporte de fluido, pode ser feita através da hipótese de difusividade turbulenta sub-malha, de forma que:

$$
\theta_{i}=-D_{s m} \cdot\left(\frac{\partial \bar{c}}{\partial x_{i}}\right)
$$

Onde: $\mathrm{D}_{\mathrm{sm}}=$ difusividade turbulenta sub- malha $\left[\mathrm{L}^{2} \mathrm{~T}^{-1}\right]$.

Assim, a equação filtrada de Advecção-Difusão assume, finalmente, a seguinte forma:

$$
\frac{\partial \bar{c}}{\partial t}+\frac{\partial\left(\bar{u}_{i} \cdot \bar{c}\right)}{\partial x_{i}}=\frac{\partial}{\partial x_{i}}\left[\left(D+D_{s m}\right) \cdot \frac{\partial \bar{c}}{\partial x_{i}}\right]+w_{s} \frac{\partial \bar{c}}{\partial x_{3}}
$$




\section{6 - A MODELAGEM SUB-MALHA}

Como foi comentado anteriormente, é a modelagem sub-malha que permite embutir, nas equações filtradas, o efeito das pequenas escalas turbulentas, as quais não foram retidas pelo filtro. Atualmente é possível dividir a modelagem sub-malha em dois grupos:

- Modelos baseados em taxas de deformação (gradientes de velocidade) (Modelo de Smagorinsky e Modelo Dinâmico);

- Modelos baseados na diferença de velocidade entre pontos adjacentes (Modelo Função Estrutura de Velocidade).

\subsection{1 - MODELO SUB-MALHA DE SMAGORINSKY}

A metodologia mais utilizada no cálculo da viscosidade turbulenta sub-malha consiste no modelo de Smagorinsky. A hipótese base sugerida por Smagorinsky refere-se ao equilíbrio local para as pequenas escalas. Isto quer dizer que a produção e a dissipação de tensões turbulentas se equivalem nas escalas sub-malha. A viscosidade turbulenta sub-malha pode ser calculada por uma formulação, tipo comprimento de mistura, escrita como:

$$
\mu_{s m}=\rho \cdot\left(C_{s} \cdot \Delta\right)^{2} \cdot \sqrt{2 \cdot \overline{S_{i j} \bar{S}_{i j}}}
$$

Em que:

- $\mathrm{C}_{\mathrm{s}}=$ constante de Smagorinsky;

- $\Delta=$ espessura (global) do filtro [L];

- $\bar{S}_{i j}=\frac{1}{2} \cdot\left(\frac{\partial \bar{u}_{i}}{\partial x_{j}}+\frac{\partial \bar{u}_{j}}{\partial x_{i}}\right)$

A constante de Smagorinsky $\left(C_{s}\right)$ pode assumir valores positivos, na faixa de 0,1 a 1/3. $\mathrm{O}$ valor $\mathrm{C}_{\mathrm{s}}=0,18$ é comumente encontrado na literatura. Um dos avanços na modelagem sub-malha, o Modelo Dinâmico (GERMANO et al., 1991), baseia-se no Modelo de Smagorinsky, permitindo avaliar a referida "constante" em cada posição e para cada nível de 
tempo. Para maiores detalhes acerca do Modelo Dinâmico recomenda-se a leitura de Lesieur e Métais (1996), Silveira Neto (2003), entre outros.

A espessura global do filtro pode ser calculada a partir das espessuras individuais (dimensões da célula), em cada direção, pela média geométrica das dimensões da célula. Assim, em três dimensões: $\Delta=[d x \cdot d y \cdot d z]^{1 / 3}$. E, no caso bidimensional: $\Delta=[d x \cdot d y]^{1 / 2}$.

\subsection{1 - MODELO SUB-MALHA FUNÇÃO ESTRUTURA DE VELOCIDADE}

A modelagem Função Estrutura de Velocidade (MÉTAIS e LESIEUR, 1991) permite calcular a viscosidade de sub-malha através de diferenças entre os vetores de velocidade de células vizinhas. Assim como no Modelo de Smagorinsky, esta metodologia apóia-se na hipótese de turbulência completamente desenvolvida. A viscosidade sub-malha pode ser calculada como:

$$
\mu_{s m}=\rho \cdot 0,104 \cdot C_{K}^{-\frac{3}{2}} \cdot \Delta \cdot \sqrt{\bar{F}_{2}(\vec{x}, t)}
$$

Em que:

- $C_{K}=$ constante de Kolmogorov $\cong 1,40$;

- $\bar{F}_{2}(\vec{x}, t)=$ função estrutura de velocidade de segunda ordem.

A função estrutura de velocidade é dependente da posição e do tempo e pode ser calculada como:

$$
\bar{F}_{2}(\vec{x}, t)=\overline{|\vec{u}(\vec{x}+\vec{r}, t)-\overrightarrow{\vec{u}}(\vec{x}, t)|^{2}} \quad \text {, sendo que }|\vec{r}|=\Delta
$$

Convém mais uma vez lembrar que as barras sobrepostas às velocidades indicam que essas grandezas são filtradas. A média espacial determinada pela equação (3.18) é normalmente feita entre células adjacentes, sugerindo, em três dimensões, uma formulação que envolve seis pontos (seis células com faces comuns). De maneira semelhante, no caso bidimensional, a média é feita em torno de quatro células com faces comuns.

\subsection{3 - AMORTECIMENTO PARA ESCOAMENTOS PARIETAIS}


A modelagem sub-malha apresenta um fator um tanto intrigante. Nas paredes, a viscosidade turbulenta sub-malha deve ser nula, uma vez que esta região está dentro da subcamada viscosa. Entretanto, experimentos numéricos não revelam valores nulos nas paredes.

Os Modelos de Smagorinsky e Função Estrutura de Velocidade apresentam relativa imprecisão nas proximidades das paredes, pois baseiam-se na hipótese de turbulência completamente desenvolvida, a qual não é rigorosamente válida para essas regiões. Este problema pode ser evitado através da utilização do Modelo Dinâmico, por exemplo. O Modelo Dinâmico permite a simulação de escoamentos em transição à turbulência e pode levar à estimativa de viscosidades negativas, indicando o processo inverso de transmissão de energia (das pequenas para as grandes escalas). Assim, o processo inverso ("back-scatter") também pode ser verificado lançando-se mão do Modelo Dinâmico. Todavia, a utilização de viscosidades turbulentas negativas pode gerar instabilidade ao código computacional, reforçando os termos advectivos que, conforme já foi comentado, são propagadores de instabilidades. Esta questão pode ser evitada em termos de implementação, anulando-se eventuais valores negativos de viscosidade.

Para contornar, ou pelo menos aliviar, esta limitação, aos Modelos de Smagorinsky e Função Estrutura de Velocidade, é comumente adicionada uma função de amortecimento, de forma a diminuir a viscosidade turbulenta sub-malha à medida que a célula se aproxima da parede. A função de amortecimento pode ser diretamente multiplicada ao valor da viscosidade e é escrita da seguinte forma:

$$
f_{w}=\left(1-\exp \left[\frac{-y^{+}}{A}\right]\right)^{2} \quad, \text { com } 0 \leq f_{w} \leq 1
$$

Em que:

- $A=25$;

- $\mathrm{y}^{+}=\frac{y \cdot u_{*}}{\mu / \rho}=$ menor distância adimensional à parede.

A equação (3.19) representa o amortecimento de van Driest, contudo outras funções exponenciais semelhantes podem ser aplicadas.

Note-se que, ao utilizar o amortecimento de van Driest já se incorporou o valor de uma segunda constante ao modelo, ou seja, a constante $A=25$. Assim, sucessivos refinamentos podem trazer a necessidade de mais constantes na formulação. 


\section{7 - ALGUNS ASPECTOS NUMÉRICOS}

A aplicação da SGE demanda alguns cuidados numéricos especiais. O primeiro deles surge antes mesmo do manuseio das equações filtradas e refere-se à escolha da escala de corte (espessura do filtro ou discretização espacial requerida). Este aspecto, que já foi comentado dentro deste capítulo, ainda assim deve ser mais uma vez destacado. De acordo com Souza (2003), a frequiência até a qual as escalas são diretamente resolvidas (determinada pela malha utilizada) deve estar o mais próximo possível das escalas dissipativas ou, pelo menos na região inercial do espectro de energia (ver figura 3.9).
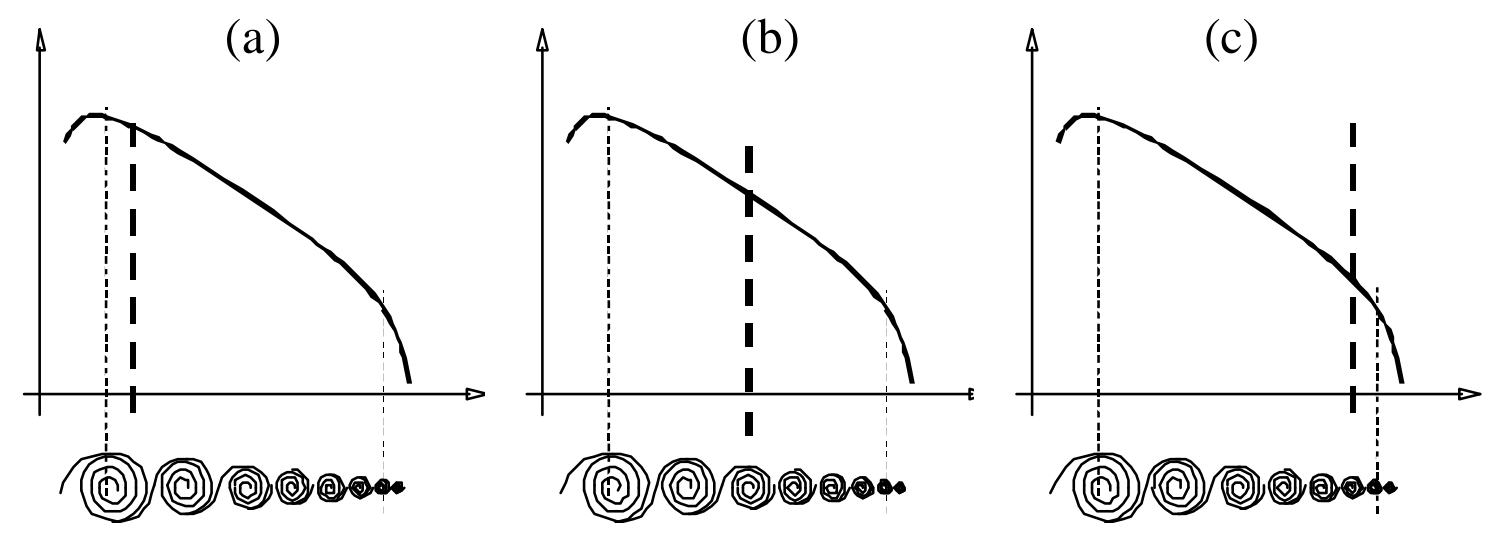

Figura 3.9 - A fixação da escala de corte determina o nível de refinamento imposto à malha. No caso (a) a escala de corte foi fixada na região de grandes estruturas turbilhonares, constituindo uma alternativa muito grosseira. No caso (b) houve fixação na faixa inercial, constituindo uma alternativa intermediária. Finalmente o caso (c) demonstra a fixação de uma escala de corte próxima da faixa dissipativa. Esta última alternativa fornece menores erros numéricos, embora demande um custo computacional bastante elevado

A fixação de escalas de corte próximas da região de grande escala (região de injeção de energia turbulenta) permite a utilização de malhas mais grosseiras, mas pode levar a resultados numéricos inconsistentes. Por outro lado, a fixação do corte próximo das escalas dissipativas aumenta substancialmente o custo computacional. 
Os incrementos de tempo exigidos pela SGE são pequenos, embora muito distantes do severo refinamento de uma SND. De fato, uma melhor descrição das estruturas turbulentas requer passos de tempo pequenos sem os quais muita informação acerca do movimento dos fluidos seria perdida. Não é raro encontrar passos de tempo da ordem de $10^{-4}$ segundos para números de Reynolds de aproximadamente $10^{5}$.

Segundo Souza (2003), na maioria das vezes os métodos explícitos de acoplamento pressão-velocidade são estáveis para o passo de tempo exigido. Dessa forma não há necessidade de adotar métodos implícitos, o que aumentaria o custo computacional sem grandes benefícios para a precisão dos resultados. Grande parte das simulações utiliza métodos explícitos de avanço temporal como Runge-Kutta e Adams-Bashforth de $2^{\mathrm{a}}$ a $4^{\mathrm{a}}$ ordens. Assim, para SGE e SND, recomenda-se que o avanço nos níveis de tempo seja de $2^{\mathrm{a}}$ a $4^{\mathrm{a}}$ ordens. Dentre estes métodos, os de Adams-Bashforth merecem destaque por sua vasta aplicação em simulações SGE, além de proporcionar baixo custo computacional.

Esquemas explícitos de avanço temporal de segunda ordem (como Adams-Bashforth) utilizam a informação (campos de velocidade) em dois instantes ( $n-1$ e $n$ ) para atualizar os campos no instante $(n+1)$. Este esquema, quando aplicado às parcelas advectivas e difusivas das equações filtradas de Navier-Stokes, pode ser descrito como:

$$
\begin{aligned}
& \rho \frac{\overline{\mathrm{u}}_{\mathrm{i}}^{*}-\overline{\mathrm{u}}_{\mathrm{i}}^{\mathrm{n}}}{? \mathrm{t}}=\frac{3}{2} \cdot\left\{-\left(\rho \frac{\partial\left(\overline{\mathrm{u}}_{\mathrm{j}} \cdot \overline{\mathrm{u}}_{\mathrm{i}}\right)}{\partial \mathrm{x}_{\mathrm{j}}}\right)+\frac{\partial}{\partial \mathrm{x}_{\mathrm{j}}}\left(\left(\mu+\mu_{\mathrm{sm}}\right)\left(\frac{\partial \overline{\mathrm{u}}_{\mathrm{i}}}{\partial \mathrm{x}_{\mathrm{j}}}+\frac{\partial \overline{\mathrm{u}}_{\mathrm{j}}}{\partial \mathrm{x}_{\mathrm{i}}}\right)\right)\right\}^{\mathrm{n}}+ \\
& -\frac{1}{2} \cdot\left\{-\left(\rho \frac{\partial\left(\overline{\mathrm{u}}_{\mathrm{j}} \cdot \overline{\mathrm{u}}_{\mathrm{i}}\right)}{\partial \mathrm{x}_{\mathrm{j}}}\right)+\frac{\partial}{\partial \mathrm{x}_{\mathrm{j}}}\left(\left(\mu+\mu_{\mathrm{sm}}\right)\left(\frac{\partial \overline{\mathrm{u}}_{\mathrm{i}}}{\partial \mathrm{x}_{\mathrm{j}}}+\frac{\partial \overline{\mathrm{u}}_{\mathrm{j}}}{\partial \mathrm{x}_{\mathrm{i}}}\right)\right)\right\}^{\mathrm{n}-1}-\frac{\partial \overline{\mathrm{p}}^{\mathrm{n}}}{\partial \mathrm{x}_{\mathrm{i}}}
\end{aligned}
$$

Note-se que há a imposição de um peso (3/2) para o instante atual (n) e (-1/2) para o instante anterior $(n-1)$.

$\mathrm{Na}$ discretização espacial dos termos advectivos e difusivos da equação (3.20), preferem-se os esquemas de diferenças centrais porque estes são pouco dissipativos e conservam energia. A maior parte das simulações SGE utiliza diferenças centrais de segunda ordem no tratamento destas parcelas. De acordo com Souza (2003), citando Ferziger e Peric (1999), é melhor utilizar um esquema centrado de segunda ordem do que esquemas "upwind" de ordem superior, uma vez que estes últimos não são conservativos. 
Outro detalhe numérico interessante consiste no tratamento das parcelas advectivas. Estas derivadas devem ser discretizadas na forma divergente, conforme descreve a equação (3.21):

$$
\operatorname{Adv}_{\mathrm{i}}=\rho \frac{\partial\left(\overline{\mathrm{u}}_{\mathrm{i}} \cdot \overline{\mathrm{u}}_{\mathrm{j}}\right)}{\partial \mathrm{x}_{\mathrm{j}}}
$$

Ainda segundo Souza (2003), a forma divergente para os termos advectivos é utilizada na SGE por ser conservativa, para esquemas centrados de segunda ordem, nas aplicações em diferenças finitas sobre malhas deslocadas.

A aplicação de esquemas temporais e espaciais de $2^{\mathrm{a}}$ ordem (ou qualquer ordem superior) produz resultados mais acurados para passos de tempo e malhas bem refinadas. A utilização destes esquemas em malhas grosseiras não é recomendada, uma vez que informações distantes influenciam as soluções calculadas para um determinado instante ou local do domínio.

Com a utilização da modelagem sub-malha pode-se destacar mais uma vantagem da SGE, no seu estágio atual de desenvolvimento, sobre as diversas metodologias de modelagem clássica. Enquanto estas últimas necessitam de um considerável número de constantes empíricas, a primeira necessita apenas de uma, quando são utilizados modelos como o de Smagorinsky ou Função estrutura de Velocidade, ou de nenhuma constante quando é utilizado o modelo Dinâmico. Evidentemente a definição do número das constantes decorre da definição da viscosidade turbulenta e da viscosidade sub-malha. Por exemplo, no modelo clássico $\mathrm{k}-\varepsilon$, a definição da viscosidade turbulenta implica no uso de duas variáveis turbulentas, a energia cinética e a sua taxa de dissipação, que necessitam, cada qual, de uma equação de transporte adicional, as quais envolvem as constantes tradicionais (modelo de duas equações). No caso da viscosidade sub-malha, tem-se o equivalente àquilo que na literatura de turbulência se denominou de um "modelo de zero equações", uma vez que não são utilizadas variáveis adicionais. Os resultados até o momento obtidos na literatura mostram que essa forma de abordagem é altamente adequada. 


\section{Método de Fronteira Imersa}

Neste capítulo resumem-se os aspectos mais relevantes de uma metodologia utilizada na simulação de escoamentos sobre geometrias complexas. No caso deste trabalho, essas singularidades são representadas pelas formas de fundo do canal, æs quais podem assumir conformações das mais variadas, dependendo dos processos de erosão-deposição verificados. Os itens seguintes descrevem e justificam o uso do Método de Fronteira Imersa, uma técnica que vem se firmando como bastante adequada para o tratamento de escoamentos sobre geometrias diversas.

\section{1 - INTRODUÇÃO}

Uma das dificuldades existentes no tratamento de problemas reais através de métodos numéricos consiste na discretização do domínio de escoamento, o qual habitualmente assume formas irregulares. Isto impõe a necessidade de utilizar células de discretização que envolvam adequadamente o domínio estudado. Uma das formas de contornar este problema consiste na discretização com células ortogonais, aproximando o contorno real com um contorno recortado, conforme ilustra a figura 4.1.
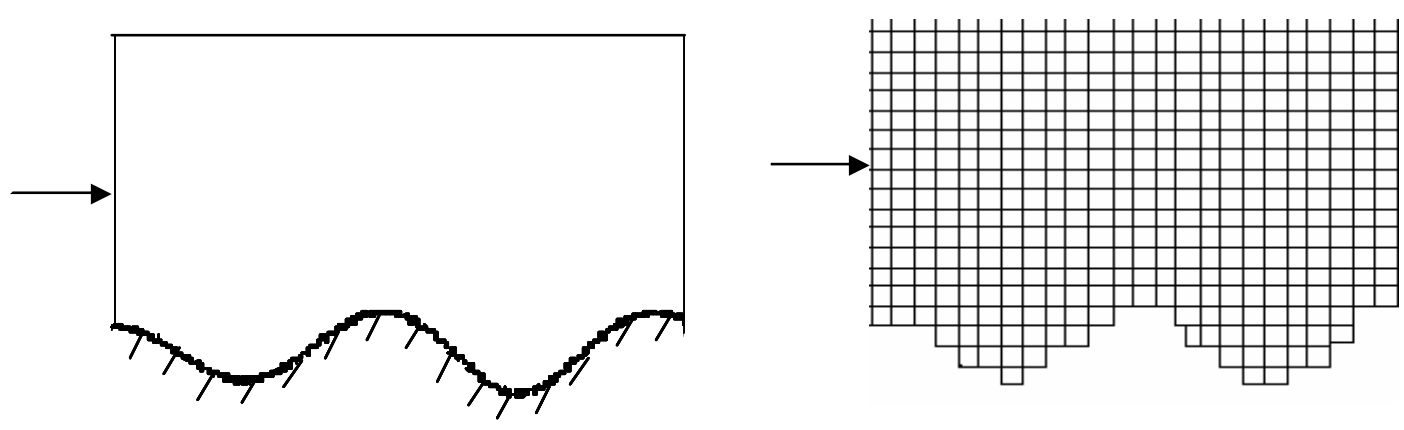

Figura 4.1 - Discretização com células ortogonais: os limites do domínio são substituídos por formas recortadas 
Esse tipo de discretização é ainda bastante utilizado, tendo, contudo, algumas desvantagens. Uma delas consiste na alteração imposta à geometria real que delimita o domínio. Para reduzir essa limitação, é necessário utilizar uma discretização local bem refinada, de forma a diminuir ao máximo a diferença entre o domínio de cálculo (discretizado) e o domínio real. Outra dificuldade consiste no tratamento particular da grande quantidade de "células de quina" que surgem dentro do domínio. Células adjacentes às quinas podem ter diferentes condições de contorno para as velocidades quando tratadas isoladamente. Segundo Fortuna (2000), apesar destas dificuldades serem contornáveis, elas introduzem uma complexidade adicional aos cálculos, uma vez que existe a necessidade de alterar o valor das velocidades no contorno, dependendo de qual célula está sendo tratada. Outrossim, o número de células numa determinada direção deixa de ser fixo, introduzindo mais um empecilho aos cálculos.

Grandes esforços para o desenvolvimento de métodos mais robustos para tratamento de geometrias irregulares foram demandados a partir da década de 70 do século passado. Dentre esses métodos destacam-se a utilização de malhas não estruturadas e a discretização coincidente com a fronteira.

A discretização por malhas não estruturadas, conforme ilustra a figura 4.2, apresenta a vantagem de ser adaptativa. Isto possibilita concentrar os nós em regiões de interesse. Todavia, segundo destaca Maliska (1995), cada nó pode ter um diferente número de vizinhos, fato que impõe a dificuldade de estabelecer uma regra de ordenação entre os pontos. Assim, estabelecer um sistema de coordenadas nestes casos é uma tarefa bastante árdua. Além disso, as malhas não estruturadas, em função da vizinhança variável dos nós, redundam em matrizes de banda variável cuja montagem também é trabalhosa.

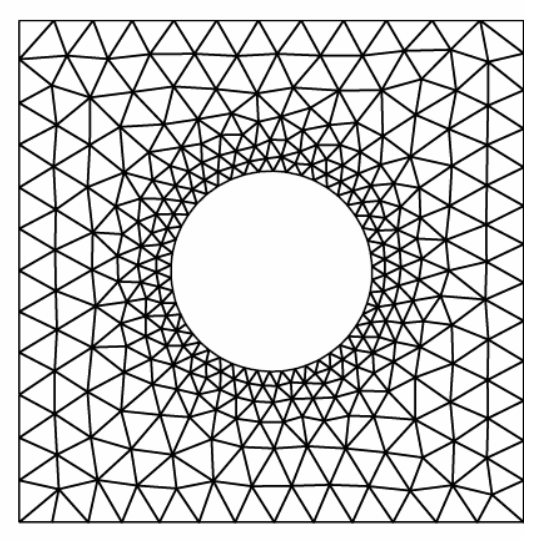

Figura 4.2 - Discretização de um domínio com geometria irregular, utilizando malha não-estruturada 
A discretização coincidente com a fronteira, conforme ilustra a figura 4.3, pode apresentar a vantagem de ser estruturada. Neste caso, como cada célula tem um mesmo número de vizinhos, torna-se possível estabelecer uma regra de ordenação, o que possibilita o estabelecimento de um sistema de coordenadas. Assim as matrizes resultantes desse tipo de discretização apresentam banda fixa e, conseqüentemente, uma implementação mais facilitada.

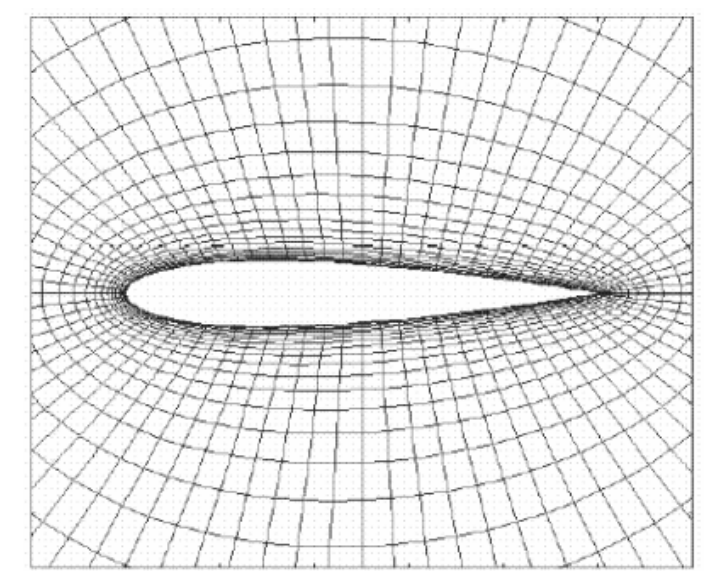

Figura 4.3 - Tratamento de um domínio com geometria irregular, utilizando discretização coincidente com a fronteira

Apesar da aptidão de ordenação das células, a discretização coincidente com a fronteira necessita gerar um sistema de coordenadas generalizadas curvilíneas. Além disso, as equações governantes devem ser transformadas para esse novo sistema, fato que envolve um algebrismo vetorial considerável, acarretando inevitável aumento do custo computacional.

Domínios, onde os contornos podem ter formas transientes, como o caso do fundo de canais aluviais, requerem que o procedimento de geração de malha seja repetido para cada nível de tempo (remalhagem). A remalhagem pode ser global ou local, mas é sempre necessária, de forma a ajustar a discretização à nova conformação do domínio. Este fator, além de complicar a implementação, também incorre num aumento do custo computacional.

Uma concisa avaliação dos métodos descritos neste item permite concluir que, a despeito das suas vantagens, existem dificuldades de implementação computacional para cada um deles. Tais dificuldades são refletidas no dispêndio de memória e de tempo de processamento. Fatores como estes induziram os pesquisadores à busca de uma metodologia alternativa para tratamento das geometrias complexas: o Método de Fronteira Imersa. 


\section{2 - MÉTODO DE FRONTEIRA IMERSA - GENERALIDADES}

De acordo com o item anterior, os métodos tradicionais de discretização de domínios apresentam certa morosidade em termos de implementação e custo computacional geralmente elevado. Tais características comuns podem ser basicamente atribuídas à necessidade sucessiva de remalhagem do domínio, além da necessidade de introduzir um novo sistema de coordenadas generalizadas. Conforme já mencionado, estes empecilhos incentivaram o desenvolvimento do Método de Fronteira Imersa.

O Método de Fronteira Imersa foi desenvolvido por Peskin (1977), visando simular o escoamento de sangue no interior do coração. No seu modelo, as paredes dos músculos foram tratadas como um conjunto de filamentos elásticos, trançados em espiral, e imersos no fluido. Apesar dessa origem, a metodologia se estendeu para tratar também outros tipos de interfaces como aquelas entre fluidos diferentes e imiscíveis, além de interfaces sólidas.

O Método de Fronteira Imersa estende um domínio de geometria irregular para um domínio de geometria retangular. A discretização é feita por dois tipos de malha, uma ortogonal que cobre todo o domínio (malha euleriana) e outra, formada por um conjunto de pontos, que representa apenas a interface delimitante do contorno (malha lagrangeana). A figura 4.4 ilustra um domínio de escoamento com interface imersa.

A interface delineada pela malha lagrangeana pode representar tanto o limite entre regiões ocupadas por dois fluidos diferentes, como também interfaces elásticas ou sólidas. Exceto no primeiro caso, todo o domínio é simulado como se bsse ocupado por um único fluido. As condições de contorno na interface são impostas virtualmente através de um campo de força que é aplicado ao escoamento. Este campo de força altera o vetor velocidade das partículas de fluido, quando essas se aproximam da interface imersa. Assim, o fundamento básico do Método de Fronteira Imersa consiste na estimativa de um termo fonte de força que sugere a reação da interface sobre o fluido. Esse termo fonte é adicionado às equações de Navier-Stokes, forçando a condição de não deslizamento sobre a interface. Isto induz que a velocidade de um elemento de fluido situado sobre a interface seja igual à própria velocidade da interface. Assim, as equações de Navier-Stokes podem ser escritas como:

$$
\rho \frac{\partial u_{i}}{\partial t}+\rho \frac{\partial\left(u_{j} \cdot u_{i}\right)}{\partial x_{j}}=-\frac{\partial P}{\partial x_{i}}+\frac{\partial}{\partial x_{j}}\left[\mu \cdot\left(\frac{\partial u_{i}}{\partial x_{j}}+\frac{\partial u_{j}}{\partial x_{i}}\right)\right]+F_{i}
$$


Em que:

- $F_{i}==$ campo de força, na direção $i$, aplicado ao escoamento (força euleriana) $\left[\mathrm{ML}^{-2} \mathrm{~T}^{-2}\right]$.

A possibilidade de manter o domínio discretizado por uma malha fixa e ortogonal confere um atrativo considerável na aplicação do Método de Fronteira Imersa. Esta idéia é ainda mais acentuada para casos onde as fronteiras se alteram com o tempo. Nestes casos, apenas a posição de cada ponto da malha lagrangeana é alterada e não há, portanto, nenhuma necessidade de modificar a malha euleriana, a qual é construída apenas uma vez.

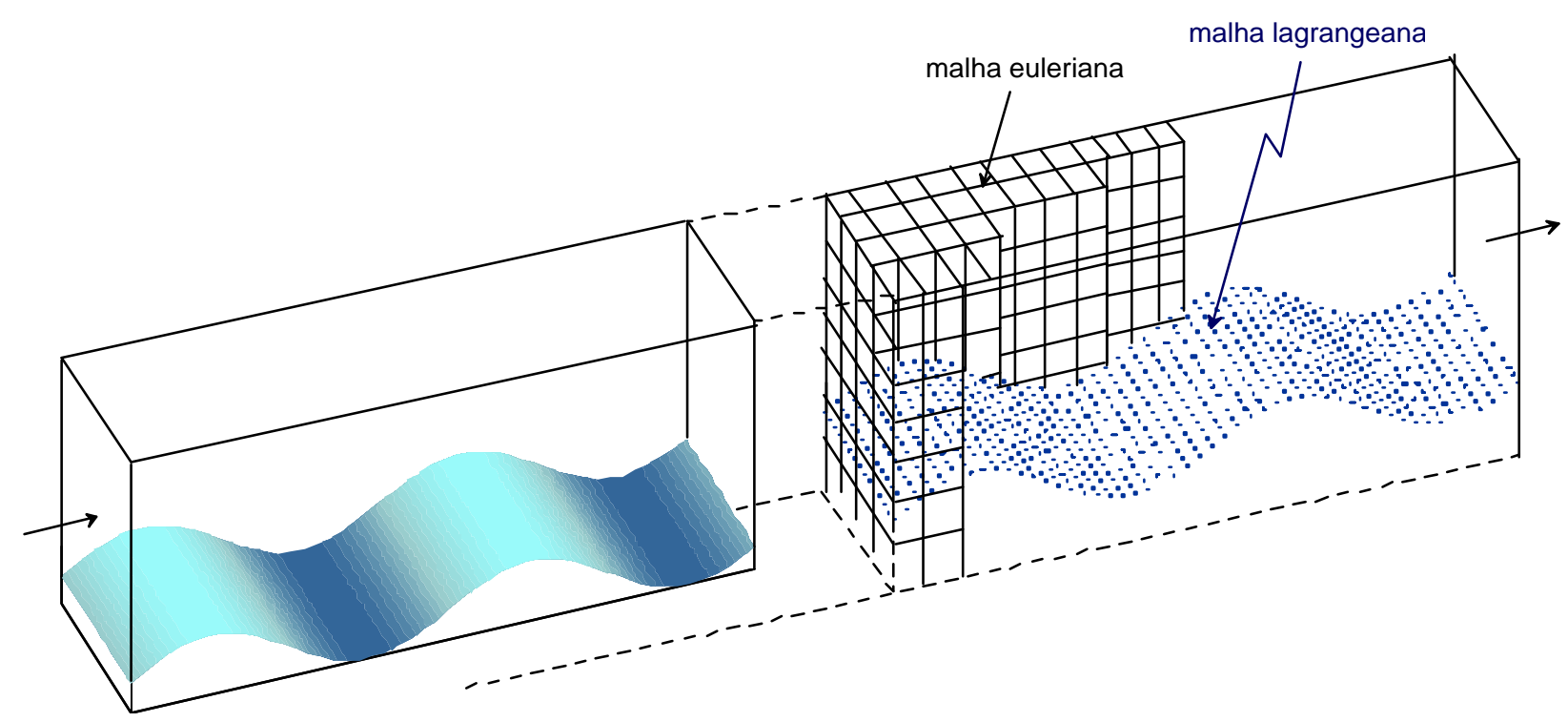

Figura 4.4 - No Método de Fronteira Imersa, o domínio real de escoamento é estendido para um domínio regular, discretizado por uma malha fixa e cartesiana (euleriana), acoplada a outra malha (lagrangeana) constituída por um conjunto de pontos que representam apenas a interface imersa

A diferença básica entre as diversas metodologias de Fronteira Imersa consiste na determinação da força sobre os pontos interfaciais (dita força lagrangeana) e na forma de disseminar esta força sobre o escoamento (gerando a força euleriana). Assim, existem diferentes procedimentos para diferentes tipos de interfaces.

\section{3 - TIPOS DE FRONTEIRAS IMERSAS}

\subsection{1 - INTERFACES ELASTICAMENTE DEFORMÁVEIS}


De acordo com os comentários da seção anterior, a aplicação pioneira do Método de Fronteira Imersa (PESKIN, 1977) utilizou um conjunto de fibras trançadas para simular as paredes do coração. Nessa aplicação, os pontos isolados que formam a interface (pontos lagrangeanos) são unidos entre si por forças, as quais permitem uma certa deformação elástica da interface. A figura 4.5 vem elucidar melhor este cenário.

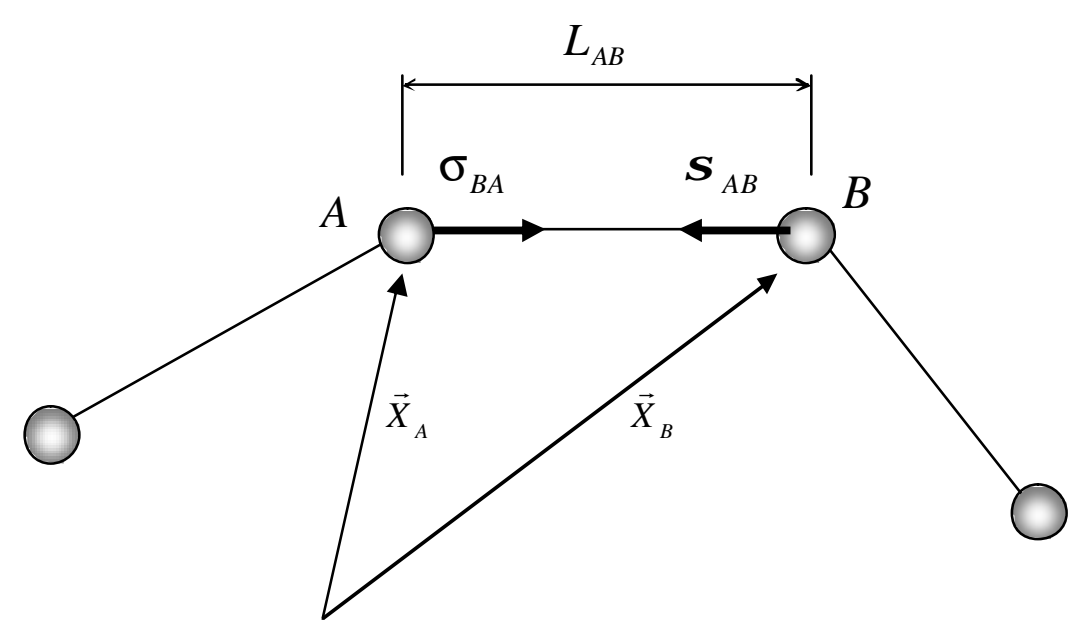

Figura 4.5 - Esquema de tensões elásticas que produzem a ligação entre os pontos lagrangeanos

Seguindo o esquema da figura 4.5, a força lagrangeana pode ser calculada em cada ponto discreto da interface como:

$$
\overrightarrow{\mathrm{f}}_{\mathrm{A}}=\frac{1}{\mathrm{~N}} \cdot \sum_{\substack{\mathrm{B}=1 \\ \mathrm{~B} \neq \mathrm{A}}}^{\mathrm{N}} \overrightarrow{\mathrm{\sigma}}_{\mathrm{AB}} \cdot \frac{\left(\overrightarrow{\mathrm{X}}_{\mathrm{B}}-\overrightarrow{\mathrm{X}}_{\mathrm{A}}\right)}{\mathrm{L}_{\mathrm{AB}}}
$$

Em que:

- $\mathrm{N}$ = número total de pontos lagrangeanos;

- $\vec{\sigma}_{\mathrm{AB}}=$ tensão elástica atuante entre dois pontos da interface $\left[\mathrm{ML}^{-1} \mathrm{~T}^{-2}\right]$;

- $\mathrm{L}_{\mathrm{AB}}=$ distância entre dois pontos da malha lagrangeana [L];

- $\quad \overrightarrow{\mathrm{X}}=(\mathrm{x}, \mathrm{y}, \mathrm{z})=$ vetor posição de cada ponto.

Note-se que o termo $\left(\vec{X}_{B}-\vec{X}_{A}\right) / L_{A B}$ nada mais é do que o vetor unitário na direção do segmento que une os dois pontos da interface.

$\mathrm{Na}$ prática, calculam-se as componentes direcionais dos vetores. Dessa forma, a equação (4. 2) pode ser decomposta, utilizando o caso tridimensional, nas equações seguintes: 


$$
\left\{\begin{array}{l}
\overrightarrow{\mathrm{f}}_{\mathrm{xA}}=\frac{1}{\mathrm{~N}} \cdot \sum_{\substack{\mathrm{B}=1 \\
\mathrm{~B} \neq \mathrm{A}}}^{\mathrm{N}} \vec{\sigma}_{\mathrm{xA}} \cdot \frac{\left(\mathrm{x}_{\mathrm{B}}-\mathrm{x}_{\mathrm{A}}\right)}{\mathrm{L}_{\mathrm{AB}}} \\
\overrightarrow{\mathrm{f}}_{\mathrm{yA}}=\frac{1}{\mathrm{~N}} \cdot \sum_{\substack{\mathrm{B}=1 \\
\mathrm{~B} \neq \mathrm{A}}}^{\mathrm{N}} \vec{\sigma}_{\mathrm{yA}} \cdot \frac{\left(\mathrm{y}_{\mathrm{B}}-\mathrm{y}_{\mathrm{A}}\right)}{\mathrm{L}_{\mathrm{AB}}} \\
\overrightarrow{\mathrm{f}}_{\mathrm{zA}}=\frac{1}{\mathrm{~N}} \cdot \sum_{\substack{\mathrm{B}=1 \\
\mathrm{~B} \neq \mathrm{A}}}^{\mathrm{N}} \vec{\sigma}_{\mathrm{zA}} \cdot \frac{\left(\mathrm{z}_{\mathrm{B}}-\mathrm{z}_{\mathrm{A}}\right)}{\mathrm{L}_{\mathrm{AB}}}
\end{array}\right.
$$

A tensão elástica $\left(\vec{\sigma}_{\mathrm{AB}}\right)$ é geralmente calculada como função da distância entre os pontos lagrangeanos $\left(\mathrm{L}_{\mathrm{AB}}\right)$. Maiores detalhes podem ser encontrados em Peskin (1977), Lim e Peskin (2004), entre outros. Após ter sido calculada, a força interfacial $\left(\vec{f}_{A}\right)$ é espalhada no interior do domínio de escoamento, gerando o campo de força aplicado sobre o fluido (campo de força euleriano).

Este tipo de simulação encontra maiores aplicações na área biotecnológica, permitindo modelar, além de paredes musculares, células que se movimentam com flagelos ou células amebianas, etc.

\subsection{2 - INTERFACES ENTRE FLUIDOS IMISCÍVEIS}

Embora a origem do Método de Fronteira Imersa esteja ligada à simulação de fibras elásticas, esta metodologia foi estendida para outros tipos de interfaces. No caso de escoamentos multifásicos com diferentes fluidos, a força lagrangeana depende de um coeficiente de tensão interfacial e também de algumas propriedades geométricas da interface, conforme descreve a equação (4.4):

$$
\overrightarrow{\mathrm{f}}\left(\overrightarrow{\mathrm{X}}_{\mathrm{k}}\right)=\sigma \cdot \kappa\left(\overrightarrow{\mathrm{X}}_{\mathrm{k}}\right) \cdot \overrightarrow{\mathrm{n}}\left(\overrightarrow{\mathrm{X}}_{\mathrm{k}}\right)
$$

Onde:

- $\overrightarrow{\mathrm{X}}_{\mathrm{k}}=\left(\mathrm{x}_{\mathrm{k}}, \mathrm{y}_{\mathrm{k}}, \mathrm{z}_{\mathrm{k}}\right)=$ vetor posição dos pontos lagrangeanos;

- $\sigma=$ coeficiente de tensão interfacial $\left[\mathrm{MT}^{2}\right]$;

- $\kappa\left(\overrightarrow{\mathrm{X}}_{\mathrm{k}}\right)=$ curvatura da interface no ponto $\overrightarrow{\mathrm{X}}_{\mathrm{k}}\left[\mathrm{L}^{-1}\right]$;

- $\overrightarrow{\mathrm{n}}\left(\overrightarrow{\mathrm{X}}_{\mathrm{k}}\right)=$ vetor normal à interface no ponto $\overrightarrow{\mathrm{X}}_{\mathrm{k}}$. 
Como no caso anterior, o que se faz na prática é calcular as componentes direcionais da força lagrangeana, de forma que a equação (4.4), para o caso tridimensional, pode ser decomposta em:

$$
\left\{\begin{array}{l}
\vec{f}_{x}\left(\vec{X}_{k}\right)=\sigma \cdot \kappa\left(\vec{X}_{k}\right) \cdot n_{x}\left(\vec{X}_{k}\right) \\
\vec{f}_{y}\left(\vec{X}_{k}\right)=\sigma \cdot \kappa\left(\vec{X}_{k}\right) \cdot n_{y}\left(\vec{X}_{k}\right) \\
\vec{f}_{z}\left(\vec{X}_{k}\right)=\sigma \cdot \kappa\left(\vec{X}_{k}\right) \cdot n_{z}\left(\vec{X}_{k}\right)
\end{array}\right.
$$

Não se pode perder de vista que a idéia básica do Método de Fronteira Imersa é simular todo o domínio estendido como se estivesse ocupado por um único fluido. Todavia, no caso de interfaces entre fluidos diferentes, propriedades como massa específica e viscosidade não podem ser tomadas indiscriminadamente como se fossem apenas à da fase contínua. Isto ocorre porque as diferentes fases (contínua e dispersa) geralmente apresentam diferenças vultosas nessas propriedades. Assim, segundo propõem Unverdi e Tryggvason (1992), a massa específica e a viscosidade podem ser inseridas nas equações de Navier-Stokes da seguinte forma:

$$
\left\{\begin{array}{l}
\rho=\rho_{o}+\left(\rho_{1}-\rho_{o}\right) \cdot I \\
\mu=\mu_{o}+\left(\mu_{1}-\mu_{o}\right) \cdot I
\end{array}\right.
$$

Onde:

- $\quad \rho$ e $\mu$ são, respectivamente, a massa específica e a viscosidade dinâmica a serem embutidas nas equações governantes;

- índices 0 e 1 representam, respectivamente, a fase contínua e a fase dispersa;

- $\quad$ é uma função dita indicadora, cujo valor varia de 0 a 1.

O objetivo da função indicadora ( $($ ) é assinalar a posição de cada fase. Assim, se $I=0$, dominam as propriedades da fase contínua. No entanto, se $I=1$, as propriedades da fase dispersa são dominantes (ver equação (4.6)). A função indicadora pode ser calculada como: 
$\nabla^{2} I(\vec{X}, t)=\nabla G(\vec{X}, t)$ onde: $\vec{X}=$ posição de um ponto qualquer dentro do domínio

A decomposição da equação (4.7) em três dimensões leva a:

$$
\frac{\partial^{2} I}{\partial x^{2}}+\frac{\partial^{2} I}{\partial y^{2}}+\frac{\partial^{2} I}{\partial z^{2}}=\frac{\partial G(x, t)}{\partial x}+\frac{\partial G(y, t)}{\partial y}+\frac{\partial G(z, t)}{\partial z}
$$

Finalmente a função $G(\vec{X}, t)$ pode ser calculada como:

$$
G(\vec{X}, t)=\sum_{k=1}^{N} D\left(\vec{X}-\vec{X}_{k}\right) \cdot \vec{n}\left(\vec{X}_{k}\right) \cdot \Delta s\left(\vec{X}_{k}\right)
$$

Em que:

- $\quad N$ = número de pontos lagrangeanos;

- $D\left(\vec{X}-\vec{X}_{k}\right)=$ função de intepolação / distribuição (a ser definida, por conveniência, na seção seguinte);

- $\vec{n}\left(\vec{X}_{k}\right)=$ vetor normal à interface no ponto $\vec{X}_{k}$;

- $\Delta s\left(\vec{X}_{k}\right)=$ distância entre dois pontos lagrangeanos consecutivos.

Note-se que a equação (4.9), quando desmembrada nas três direções, gera:

$$
\left\{\begin{array}{l}
G(x, t)=\sum_{k=1}^{N} D\left(x-x_{k}\right) \cdot n_{x}\left(\vec{X}_{k}\right) \cdot \Delta s\left(\vec{X}_{k}\right) \\
G(y, t)=\sum_{k=1}^{N} D\left(y-y_{k}\right) \cdot n_{y}\left(\vec{X}_{k}\right) \cdot \Delta s\left(\vec{X}_{k}\right) \\
G(z, t)=\sum_{k=1}^{N} D\left(z-z_{k}\right) \cdot n_{z}\left(\vec{X}_{k}\right) \cdot \Delta s\left(\vec{X}_{k}\right)
\end{array}\right.
$$

Em suma, a metodologia descrita resumidamente neste item permite simular virtualmente escoamentos multifásicos, entre diferentes tipos de fluido, como se fosse o escoamento de um fluido único. Nesse caso, destacam-se alguns aspectos importantes como a introdução do campo de força nas equações de Navier-Stokes e o cálculo das propriedades das fases, as quais necessitam da determinação das posições assinaladas pela função indicadora. 
Maiores detalhes sobre esses procedimentos podem ser encontrados em Unverdi e Tryggvason (1992), Lima e Silva (2002), entre outros.

\subsection{3 - INTERFACES SÓLIDAS}

No que diz respeito à simulação de interfaces sólidas, a literatura apresenta diferentes metodologias inseridas dentro do Método de Fronteira Imersa. Relacionando as semelhanças entre cada uma delas, podem-se destacar aquelas que utilizam constantes ajustáveis, os modelos de reconstrução local e os modelos que disseminam a força interfacial no interior do escoamento. Fronteiras sólidas são aquelas em que os pontos discretos estão rigidamente interligados. Isto, contudo, não impede o possível caráter transiente dessas interfaces, as quais podem apresentar conformações diferentes para cada nível de tempo.

Modelos com constantes "ad-hoc" (GOLDSTEIN et al., 1993; SAIKI e BIRINGEN, 1996) calculam a força interfacial por meio de uma função que anula a diferença de velocidades entre a fronteira e as parcelas de fluido que estão sobre esta interface. Assim, surge a tendência de impor a condição de não-deslizamento. Em geral, duas constantes são utilizadas como pesos nessa função. Essas constantes são ajustadas de forma a contribuir com a estabilidade e a convergência da solução.

Os modelos de reconstrução local (TSENG e FERZIGER, 2003) dividem o domínio de cálculo em duas regiões: o domínio físico ou região externa à interface e o domínio das células fictícias. Nesse contexto, células fictícias são células situadas em regiões onde não há escoamento (dentro da fronteira) e cortadas parcialmente pela interface imersa. Assim, o campo de força a ser embutido nas equações de Navier-Stokes é calculado apenas nessas células. Um esquema de reconstrução local da solução (extrapolação) permite estimar qual seria o valor assumido pela velocidade e pressão, dentro da célula fictícia através dos valores das células vizinhas no domínio físico, além da condição de contorno sobre a interface, a qual é conhecida. Um modelo semelhante a este último foi apresentado por Ye et al. (1999). Essa metodologia mapeia as regiões de fluido cortadas pela interface, de forma a determinar células trapezoidais externas, onde é aplicado o campo de força. Note-se que estes dois últimos modelos perdem uma certa regalia do Método de Fronteira Imersa, que é justamente a possibilidade de tratar todo o domínio como se estivesse ocupado por um único fluido. De fato, a necessidade de dividir o domínio em regiões que estão fora e regiões que estão dentro da interface é um complicador a mais na implementação dos cálculos. 
Diante desse complicador, os modelos que primeiro calculam a força sobre os pontos da interface (pontos lagrangeanos) e depois disseminam essa força para todo o domínio de escoamento, possuem uma implementação mais direta ou, no mínimo, sem muitos entraves. Além do mais, tais metodologias seguem a idéia original de Peskin (1977). Dentre esses modelos está o Modelo Físico Virtual (MFV), utilizado neste trabalho e que, por isto, é comentado com mais minúcias na seção seguinte.

\section{4 - MODELO FÍSICO VIRTUAL (MFV)}

\subsection{1 - INTRODUÇÃO}

O Modelo Físico Virtual (MFV) (LIMA e SILVA, 2002; LIMA e SILVA et al., 2003) é uma metodologia para calcular a força sobre os pontos discretos de uma fronteira sólida (dita força interfacial ou lagrangeana). A caracterização da força interfacial, conforme foi comentado anteriormente, representa a diferença primordial entre as diversas metodologias de Fronteira Imersa. Sua estimativa difere segundo o tipo de interface a ser considerada (interfaces sólidas, entre fluidos diferentes, etc.) e também na forma de aplicar a força interfacial sobre o escoamento. O Modelo Físico Virtual utiliza o espalhamento da força interfacial sobre o interior do escoamento. Assim, o campo de força $\left(F_{i}\right)$, também dito campo de força euleriano, é aplicado nas proximidades da fronteira imersa, tendo seu valor atenuado à medida que a distância à interface aumenta.

Com a finalidade de trazer mais clareza às descrições, vale a pena reescrever aqui a equação governante do escoamento (Navier-Stokes) (equação(4.1)):

$$
\rho \frac{\partial u_{i}}{\partial t}+\rho \frac{\partial\left(u_{j} \cdot u_{i}\right)}{\partial x_{j}}=-\frac{\partial P}{\partial x_{i}}+\frac{\partial}{\partial x_{j}}\left[\mu \cdot\left(\frac{\partial u_{i}}{\partial x_{j}}+\frac{\partial u_{j}}{\partial x_{i}}\right)\right]+F_{i}
$$

Trata-se da forma tensorial das equações de Navier-Stokes, onde os índices ( $i$ e $j$ ) variam de acordo com as direções do espaço. O campo de força euleriano é o responsável por representar de maneira virtual uma geometria presente no escoamento. Assim, uma partícula de fluido sob o efeito de um campo $\left(F_{i}\right)$ deve ter seu vetor velocidade alterado de modo que o escoamento contorne e reconheça essa singularidade. 


\subsection{2 - CÁLCULO DA FORÇA LAGRANGEANA}

No MFV, a força interfacial é calculada diretamente a partir da aplicação das equações de Navier-Stokes sobre uma partícula de fluido situada sobre a interface, de acordo com:

$$
f_{i}\left(\vec{x}_{k}, t\right)=? \frac{\partial u_{\mathrm{i}}\left(\vec{x}_{k}, t\right)}{\partial t}+? \frac{\partial}{\partial x_{j}}\left[u_{\mathrm{j}}\left(\vec{x}_{k}\right) \cdot u_{\mathrm{i}}\left(\vec{x}_{k}\right)\right]-\mu \frac{\partial}{\partial x_{j}}\left[\frac{\partial u_{\mathrm{i}}\left(\vec{x}_{k}, t\right)}{\partial x_{j}}\right]+\frac{\partial P\left(\vec{x}_{k}, t\right)}{\partial x_{i}}
$$

Onde:

- $\quad \vec{x}_{k}=$ posição de um ponto $k$ situado sobre a malha lagrangeana;

- $? \frac{\partial u_{\mathrm{i}}\left(\vec{x}_{k}, t\right)}{\partial t}=$ componente de aceleração da força lagrangeana $\left[\mathrm{ML}^{-2} \mathrm{~T}^{-2}\right]$;

- $? \frac{\partial}{\partial x_{j}}\left[u_{\mathrm{j}}\left(\vec{x}_{k}\right) \cdot u_{\mathrm{i}}\left(\vec{x}_{k}\right)\right]=$ componente inercial da força lagrangeana $\left[\mathrm{ML}^{-2} \mathrm{~T}^{-2}\right]$;

- $-\mu \frac{\partial}{\partial x_{j}}\left[\frac{\partial u_{\mathrm{i}}\left(\vec{x}_{k}, t\right)}{\partial x_{j}}\right]=$ componente viscosa da força lagrangeana $\left[\mathrm{ML}^{-2} \mathrm{~T}^{-2}\right] ;$

- $\frac{\partial P\left(\vec{x}_{k}, t\right)}{\partial x_{i}}=$ componente de pressão da força lagrangeana $\left[\mathrm{ML}^{-2} \mathrm{~T}^{-2}\right]$;

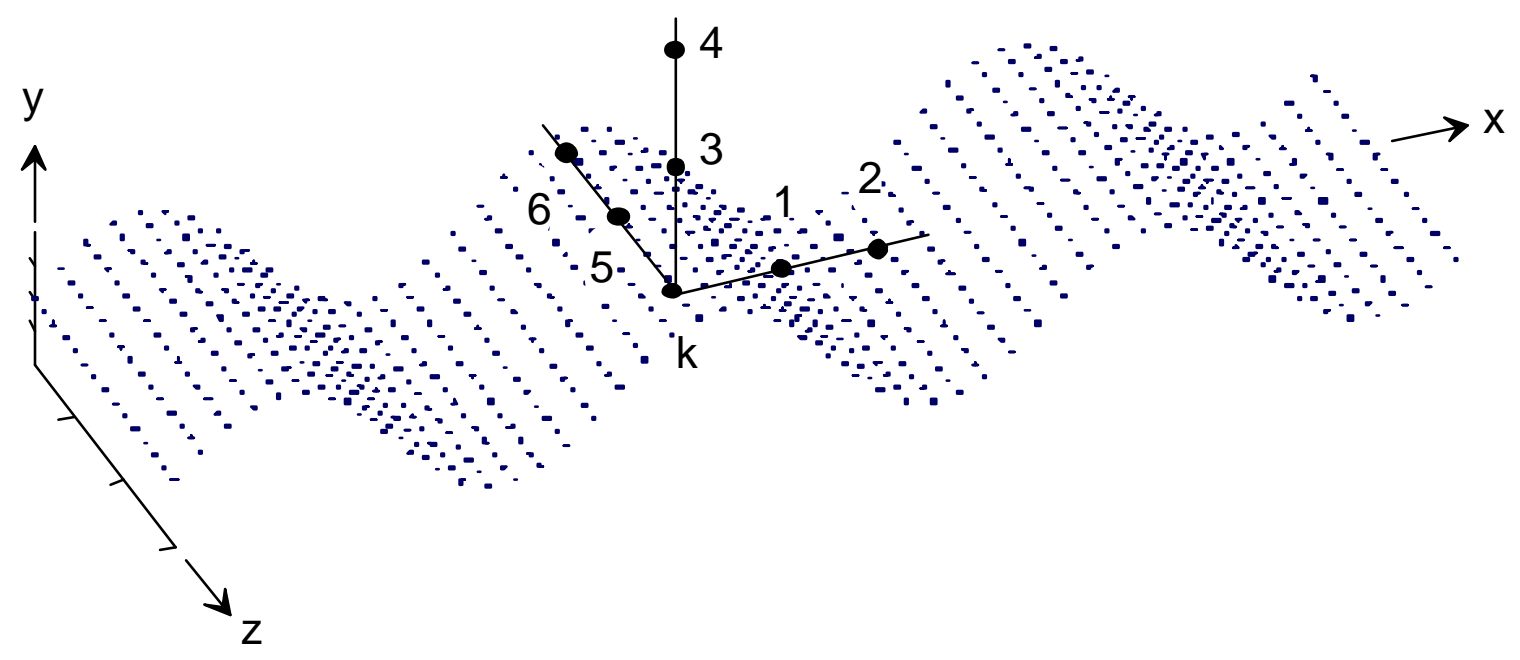

Figura 4.6-Representação tridimensional da fronteira imersa por um conjunto de pontos dispostos paralelamente. $O$ traçado de linhas horizontais $e$ verticais, a partir de cada ponto lagrangeano $\vec{x}_{k}=\left(x_{k}, y_{k}, z_{k}\right)$, determina os pontos 1 e 2 (espaçados de dx), 3 e 4 (espaçados de dy) e 5 e 6 (espaçados de dz) 
Note-se que o cálculo da força lagrangeana é feito separadamente para cada ponto da interface. O primeiro passo para estimar as várias parcelas de força lagrangeana consiste na fixação de pontos auxiliares a partir da fronteira, conforme ilustra a figura 4.6.

É conveniente citar que os pontos auxiliares estão sempre situados na região de interesse do escoamento, ou seja, na região que se deseja simular. Os valores de velocidade e pressão nesses pontos, em geral, não são conhecidos, mas podem ser obtidos, a partir das células vizinhas, com o auxílio de uma função de distribuição/interpolação Assim:

$$
\begin{aligned}
& \vec{V}\left(\vec{x}_{i}\right)=\sum_{j} D\left(\vec{x}_{j}-\vec{x}_{i}\right) \cdot \vec{V}\left(\vec{x}_{j}\right) \cdot d x \cdot d y \cdot d z \\
& P\left(\vec{x}_{i}\right)=\sum_{j} D\left(\vec{x}_{j}-\vec{x}_{i}\right) \cdot P\left(\vec{x}_{j}\right) \cdot d x \cdot d y \cdot d z \quad \text { com } i=1,2,3,4,5,6 \text { e } k
\end{aligned}
$$

Em que:

- $j$ = ponto da malha euleriana onde a grandeza (velocidade ou pressão) é conhecida;

- $\quad d x, d y, d z=$ dimensões das células eulerianas [L].

No caso da simulação de um problema bidimensional, a direção transversal é desconsiderada, de forma que os pontos auxiliares somente são fixados nas direções longitudinal (pontos 1 e 2) e vertical (pontos 3 e 4).

A equação (4.12) foi escrita na notação vetorial para evitar confusões com os índices. Seguindo o esquema tridimensional, ela pode ser reescrita, desmembrando suas componentes direcionais como:

$$
\left\{\begin{array}{l}
u\left(\vec{x}_{i}\right)=\sum_{j} D\left(x_{j}-x_{i}\right) \cdot u\left(x_{j}\right) \cdot d x \cdot d y \cdot d z \\
v\left(\vec{x}_{i}\right)=\sum_{j} D\left(y_{j}-y_{i}\right) \cdot v\left(x_{j}\right) \cdot d x \cdot d y \cdot d z \\
w\left(\vec{x}_{i}\right)=\sum_{j} D\left(z_{j}-z_{i}\right) \cdot w\left(x_{j}\right) \cdot d x \cdot d y \cdot d z
\end{array}\right.
$$

A função de distribuição/interpolação, segundo a proposta de Peskin (1977), modificada por Juric (1996), é definida como: 


$$
D=\frac{f\left(\frac{x_{k}-x_{j}}{d x}\right) \cdot f\left(\frac{y_{k}-y_{j}}{d y}\right) \cdot f\left(\frac{z_{k}-z_{j}}{d z}\right)}{d x \cdot d y \cdot d z}
$$

$$
f(r)=\left\{\begin{array}{ccc}
\frac{3-2 \cdot|r|+\sqrt{1+4 \cdot|r|-4 \cdot|r|^{2}}}{8} & \text { se } \quad|r| \leq 1 \\
\frac{5-2 \cdot|r|-\sqrt{-7+12 \cdot|r|-4 \cdot|r|^{2}}}{8} & \text { se } 1<|r| \leq 2 \\
0 & \text { se } \quad|r|>2
\end{array}\right.
$$

De acordo com a definição da equação (4.16), a interpolação abrange uma distância de, no máximo, duas malhas do ponto considerado, uma vez que o valor da função (D) é anulado para distâncias maiores. Isto pode ser explicado porque a região de abrangência da função (D) deve ser finita de forma a manter razoável o custo computacional do Método de Fronteira Imersa. Sem essa consideração, haveria contribuição de muitos pontos, tornando o dispêndio computacional proibitivo. A figura 4.7 ilustra o comportamento dessa função.

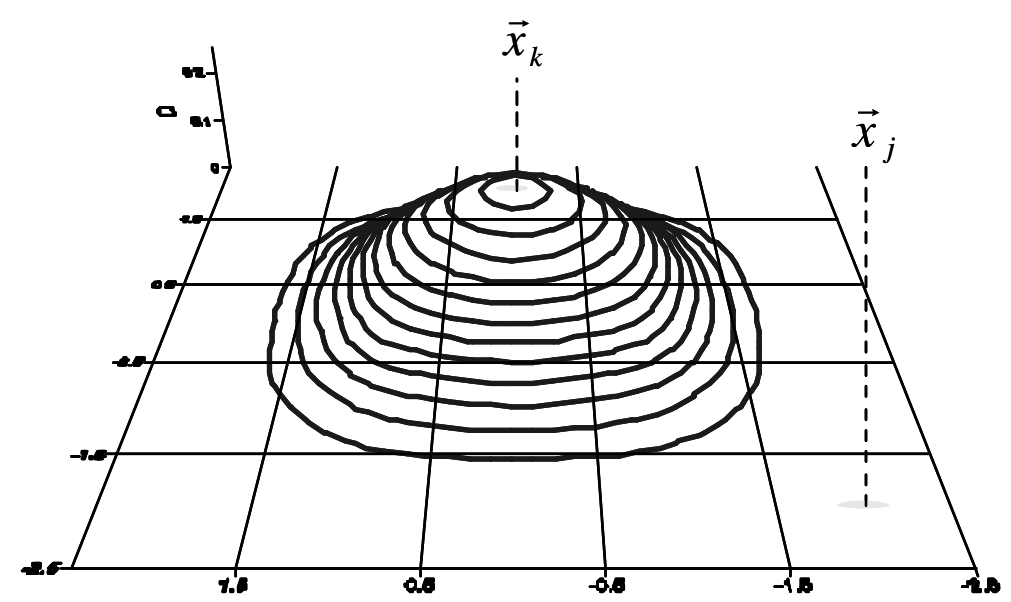

Figura 4.7 - Função de distribuição / interpolação utilizada no MFV 
É conveniente citar que a função (D) permite transferir quantidades entre as malhas euleriana e lagrangeana. Aqui ela atua como uma função de interpolação, no item seguinte ela atuará com o objetivo de distribuir a força lagrangeana para fora da interface.
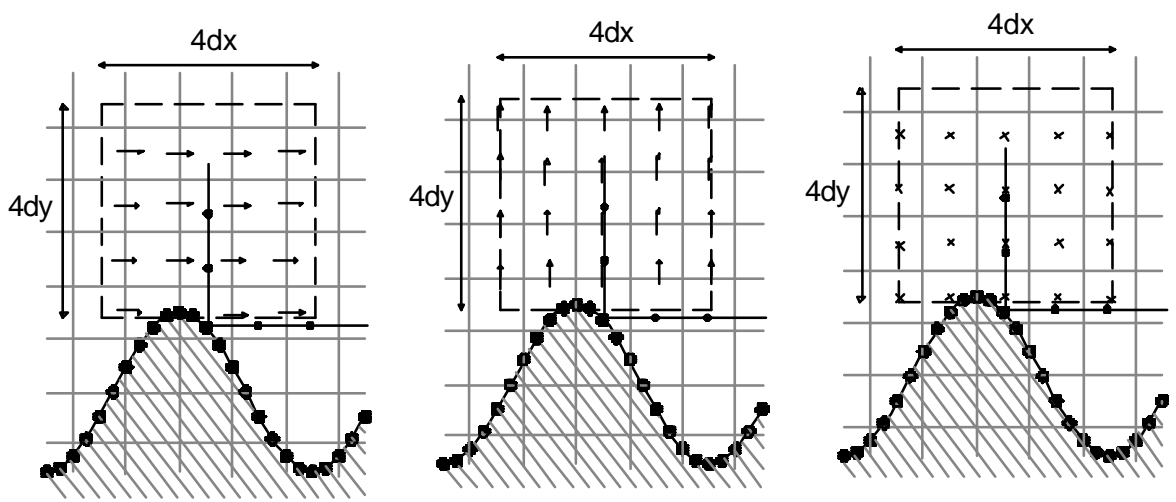

Figura 4.8 - Região de abrangência para interpolar velocidades e pressão no ponto auxiliar 4. Notase que as variáveis seguem um arranjo deslocado na malha euleriana. Este procedimento também é repetido para os demais pontos auxiliares

Um procedimento conveniente para fixar a região de interpolação, conforme descrito por Lima e Silva (2002), consiste em alocar um cubo centrado em cada ponto auxiliar, de acordo com a figura 4.8. Nos casos bidimensionais esse cubo é substituído por um quadrado. Assim, somente os pontos dentro dessa região são contribuintes. Esse processo tira proveito da definição da função de distribuição $(D)$, que estipula uma contribuição de pontos distantes até duas malhas, e auxilia na redução do custo computacional.

A interpolação de velocidades e pressão para os pontos auxiliares possui uma particularidade: somente são aproveitados os pontos da zona de abrangência que estão na região de interesse do escoamento. Esta restrição, contudo, não atinge o procedimento de interpolação de velocidades para os pontos lagrangeanos, uma vez que tanto regiões acima quanto abaixo da interface podem ser contribuintes.

Calculadas as velocidades e pressões nos pontos auxiliares $(1,2,3,4,5$ e 6$)$ e também no ponto lagrangeano $(k)$, juntam-se os elementos para estimar as derivadas que compõem cada parcela de força da equação (4.11), reescrita aqui por conveniência:

$$
f_{i}\left(\vec{x}_{k}, t\right)=? \frac{\partial u_{i}\left(\vec{x}_{k}, t\right)}{\partial t}+? \frac{\partial}{\partial x_{j}}\left[u_{j}\left(\vec{x}_{k}\right) \cdot u_{i}\left(\vec{x}_{k}\right)\right]-\mu \frac{\partial}{\partial x_{j}}\left[\frac{\partial u_{i}\left(\vec{x}_{k}, t\right)}{\partial x_{j}}\right]+\frac{\partial P\left(\vec{x}_{k}, t\right)}{\partial x_{i}}
$$


As derivadas espaciais que constituem as parcelas da equação acima são calculadas através de polinômios de Lagrange. Assim, representando as variáveis a serem derivadas por uma grandeza genérica $\varphi$, obtém-se para casos tridimensionais:

$$
\begin{aligned}
& \frac{\partial f\left(\vec{x}_{k}\right)}{\partial x}=\frac{\left(x_{k}-x_{2}\right)}{\left(x_{1}-x_{2}\right) \cdot\left(x_{1}-x_{k}\right)} \cdot f^{+}+\frac{\left(x_{k}-x_{1}\right)}{\left(x_{2}-x_{1}\right) \cdot\left(x_{2}-x_{k}\right)} \cdot f_{2}+\frac{\left(x_{k}-x_{1}\right) \cdot\left(x_{k}-x_{2}\right)}{\left(x_{k}-x_{1}\right) \cdot\left(x_{k}-x_{2}\right)} \cdot f_{k} \\
& \frac{\partial f\left(\vec{x}_{k}\right)}{\partial y}=\frac{\left(y_{k}-y_{4}\right)}{\left(y_{3}-y_{4}\right) \cdot\left(y_{3}-y_{k}\right)} \cdot f_{3}+\frac{\left(y_{k}-y_{3}\right)}{\left(y_{4}-y_{3}\right) \cdot\left(y_{4}-y_{k}\right)} \cdot f_{4}+\frac{\left(y_{k}-y_{3}\right) \cdot\left(y_{k}-y_{4}\right)}{\left(y_{k}-y_{3}\right) \cdot\left(y_{k}-y_{4}\right)} \cdot \varphi_{k} \\
& \frac{\partial f\left(\vec{x}_{k}\right)}{\partial z}=\frac{\left(z_{k}-z_{6}\right)}{\left(z_{5}-z_{6}\right) \cdot\left(z_{5}-z_{k}\right.} \cdot f_{5}+\frac{\left(z_{k}-z_{5}\right)}{\left(z_{6}-z_{5}\right) \cdot\left(z_{6}-z_{k}\right)} \cdot f_{6}+\frac{\left(z_{k}-z_{5}\right) \cdot\left(z_{k}-z_{6}\right)}{\left(z_{k}-z_{5}\right) \cdot\left(z_{k}-z_{6}\right)} \cdot \varphi_{k}
\end{aligned}
$$

E, para as derivadas de segunda ordem:

$$
\begin{aligned}
& \frac{\partial^{2} f\left(\vec{x}_{k}\right)}{\partial x^{2}}=\frac{2 \cdot f_{1}}{\left(x_{1}-x_{2}\right) \cdot\left(x_{1}-x_{k}\right)}+\frac{2 \cdot f_{2}}{\left(x_{2}-x_{1}\right) \cdot\left(x_{2}-x_{k}\right)}+\frac{2 \cdot f_{k}}{\left(x_{k}-x_{1}\right) \cdot\left(x_{k}-x_{2}\right)} \\
& \frac{\partial^{2} f\left(\vec{x}_{k}\right)}{\partial y^{2}}=\frac{2 \cdot f_{3}}{\left(y_{3}-y_{4}\right) \cdot\left(y_{3}-y_{k}\right)}+\frac{2 \cdot f_{4}}{\left(y_{4}-y_{3}\right) \cdot\left(y_{4}-y_{k}\right)}+\frac{2 \cdot f_{k}}{\left(y_{k}-y_{3}\right) \cdot\left(y_{k}-y_{4}\right)} \\
& \frac{\partial^{2} f\left(\vec{x}_{k}\right)}{\partial z^{2}}=\frac{2 \cdot f_{5}}{\left(y_{5}-y_{6}\right) \cdot\left(y_{5}-y_{6}\right)}+\frac{2 \cdot f_{6}}{\left(y_{6}-y_{5}\right) \cdot\left(y_{6}-y_{k}\right)}+\frac{2 \cdot f_{k}}{\left(y_{k}-y_{5}\right) \cdot\left(y_{k}-y_{6}\right)}
\end{aligned}
$$

Em que:

- $\vec{x}_{k}=\left(x_{k}, y_{k}, z_{k}\right)=$ coordenadas dos pontos lagrangeanos [L];

- $\left(x_{i}, y_{i}, z_{i}\right)=$ coordenadas dos pontos auxiliares $(i=1,2,3,4,5,6)[\mathrm{L}]$.

A derivada temporal pode ser diretamente estimada por: 


$$
\frac{\partial \varphi}{\partial t}=\frac{\varphi_{k}-\varphi_{f k}}{\Delta t}
$$

Na equação (4.19), a variável $\varphi_{k}$ representa a componente de velocidade da interface. Se a interface for fixa, por exemplo, seu valor é anulado.

As equações (4.11) a (4.19), descritas neste item, permitem calcular a força interfacial para cada ponto da malha lagrangeana. O próximo passo consiste na disseminação dessa força para dentro do domínio de cálculo. Vale lembrar que esses procedimentos, embora sejam escritos aqui para simulações tridimensionais, também podem ser aplicados para casos bidimensionais, apenas desconsiderando a direção transversal do escoamento.

\subsection{3 - ESPALHAMENTO DA FORÇA LAGRANGEANA}

Após ser calculada ao longo da malha lagrangeana, a força interfacial $(\vec{f})$ é distribuída no escoamento, conforme ilustra a figura 4.9, originando um campo de força euleriano $(\vec{F})$ que atua sobre as partículas de fluido vizinhas da fronteira. Assim, a força atuante nas proximidades da interface pode ser calculada por:

$$
\vec{F}=\vec{F}\left(\vec{x}_{j}\right)=\sum_{k} D\left(\vec{x}_{j}-\vec{x}_{k}\right) \cdot \vec{f}\left(\vec{x}_{k}\right) \cdot d s^{n}
$$

Em que:

- $\vec{x}_{j}=$ posição do ponto $j$ na malha euleriana [L];

- $d s=$ distância média entre pontos lagrangeanos $\vec{x}_{k}$ adjacentes [L];

- $n=$ número de dimensões do problema (2 ou 3).

Outra alternativa, possível nos casos tridimensionais, consiste em substituir o elemento $d s^{n}$, no espalhamento da força interfacial (equação (4.20)), pelo produto entre um elemento de área $d A$ e um elemento de distância $d l$. Assim, a equação (4.20) pode ser adaptada como:

$$
\vec{F}=\vec{F}\left(\vec{x}_{j}\right)=\sum_{k} D\left(\vec{x}_{j}-\vec{x}_{k}\right) \cdot \vec{f}\left(\vec{x}_{k}\right) \cdot d A \cdot d l
$$

Em que: 
- $d l=$ distância (ao longo da longitudinal) entre pontos lagrangeanos adjacentes [L];

- $d A=\frac{d x}{2} \cdot \frac{d z}{2}=$ elemento de área no plano definido pelas direções longitudinal $(X) \mathrm{e}$ transversal $(Z)\left[\mathrm{L}^{2}\right]$.

Essas equações, ligeiramente diferentes, decorrem da experimentação numérica, sendo que a equação (4.21) foi explorada neste trabalho.

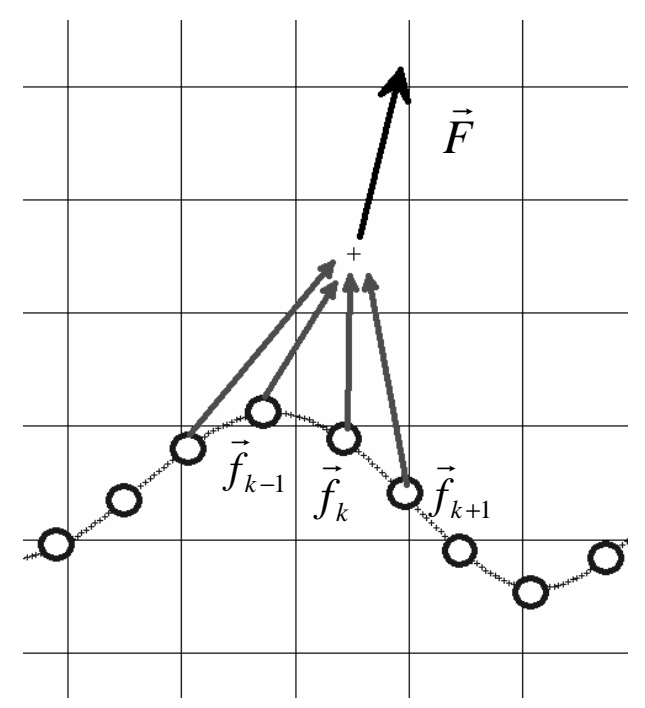

Figura 4.9 - A distribuição da força interfacial $(\vec{f})$ no corpo do escoamento provoca um campo de força resultante $(\vec{F})$ que faz a partícula de fluido reconhecer a fronteira sólida

A decomposição da equação vetorial (equação (4.21)), no caso tridimensional, leva à expressão abaixo que permite o cálculo das componentes do campo de força euleriano.

$$
\left\{\begin{array}{c}
F_{x}=\sum_{k} D\left(x_{j}-x_{k}\right) \cdot f_{x}\left(\vec{x}_{j}\right) \cdot d A \cdot d l \\
F_{y}=\sum_{k} D\left(y_{j}-y_{k}\right) \cdot f_{y}\left(\vec{x}_{j}\right) \cdot d A \cdot d l \\
F_{z}=\sum_{k} D\left(z_{j}-z_{k}\right) \cdot f_{z}\left(\vec{x}_{j}\right) \cdot d A \cdot d l
\end{array}\right.
$$


Para simulações bidimensionais, recomenda-se o uso da equação (4.20), que decomposta pode ser escrita como:

$$
\left\{\begin{array}{l}
F_{x}=\sum_{k} D\left(x_{j}-x_{k}\right) \cdot f_{x}\left(\vec{x}_{j}\right) \cdot d l^{2} \\
F_{y}=\sum_{k} D\left(y_{j}-y_{k}\right) \cdot f_{y}\left(\vec{x}_{j}\right) \cdot d s^{2}
\end{array}\right.
$$

Em que: $d s$ é a distância média entre dois pontos lagrangeanos na direção longitudinal [L].

\section{5 - APRECIAÇÕES FINAIS}

O Método de Fronteira Imersa vem sendo paulatinamente mais utilizado no cálculo de escoamentos em torno de geometrias diversas. De fato, a alternativa de manter o domínio discretizado por uma malha ortogonal e fixa é altamente atraente diante dos dificultosos métodos tradicionais de geração de malha.

O presente trabalho incorpora esta metodologia, utilizando o Modelo Físico Virtual. Neste caso, vale lembrar que as conformações de fundo dos canais, devido aos fenômenos de erosão e deposição, são transientes e variadas. Lembra-se que alguns aspectos sem quantificação definitiva estão unidos nesse problema de interface sólido-líquido:

- A velocidade de sedimentação, que foi modelada a partir de equacionamento original para conjuntos de partículas;

- O posicionamento da fronteira a partir dos fenômenos de sedimentação e ressuspensão, atuando concomitantemente.

Pelas características do fenômeno tratado, no qual os depósitos de fundo apresentam formas onduladas e variáveis, o Método de Fronteira Imersa constituiu, desde o início dos trabalhos, uma alternativa instigante. 


\section{Metodologia}

Neste capítulo estão agrupados os aspectos principais relacionados ao tratamento numérico das equações governantes, além da descrição dos métodos de solução das mesmas. Aqui também são apresentados alguns desenvolvimentos teóricos que conduziram a formulações importantes para o problema de transporte de sedimentos. Algumas dessas formulações apresentam natureza analítica, enquanto que outras são numéricas na sua essência, conforme está detalhado na leitura que se segue.

Todas as equações foram discretizadas pelo Método de Diferenças Finitas. De acordo com Maliska (1995), a Mecânica dos Fluidos Computacional tem utilizado este método desde o seu início. Nessas circunstâncias, os pesquisadores se concentraram fortemente na tentativa de dominar as não linearidades decorrentes dos termos advectivos. Concomitantemente, a Engenharia de Estruturas explorava o Método de Elementos Finitos, buscando a solução para distribuição interna de tensões, problema esse de caráter difusivo. Este fato permite explicar porque, até os dias atuais, o Método de Diferenças Finitas tem se acolhido melhor na comunidade que estuda os movimentos dos fluidos, mesmo depois de serem introduzidas, em Elementos Finitos, técnicas para tratar as referidas não linearidades. Ainda que, posteriormente, tenha surgido a técnica de Volumes Finitos, a qual foi largamente utilizada nas décadas de 1980 e 1990, percebe-se, por uma breve revisão da literatura recente, um retorno perceptível ao Método de Diferenças Finitas na simulação de escoamentos diversos.

O código computacional foi escrito na linguagem Fortran Power Station 4.0 e reuniu, assim, as diversas metodologias específicas descritas a seguir.

\section{1 - ARRANJO DAS VARIÁVEIS}

O arranjo de variáveis mais elementar, utilizado nos cálculos por Diferenças Finitas, consiste no esquema co-localizado. Nesse caso, todas as incógnitas são armazenadas em um mesmo ponto (nó). Assim, nas aproximações numéricas das equações de Navier-Stokes, a 
utilização de malhas co-localizadas produz o armazenamento dos valores de velocidade e pressão em um mesmo ponto. Segundo alguns autores como Patankar (1980), esse tipo de arranjo tem apresentado o inconveniente de fornecer campos espaciais oscilatórios de pressão. Isto decorre das diferentes vizinhanças contribuintes ao cálculo dos termos que compõem as equações, gerando quatro grupos de equações desacopladas entre si. Tal empecilho surge porque os grupos não apresentam pontos comuns na malha. $\mathrm{O}$ efeito potencial desse desacoplamento é a geração, ao longo do domínio, dos já mencionados campos oscilatórios de pressão, fisicamente incorretos.

Diante disso, buscou-se modificar a posição em que cada variável é armazenada, em vez de fixá-las num mesmo ponto. Malhas desse tipo, onde as variáveis estão armazenadas em diferentes posições, são chamadas na literatura de malhas deslocadas ("staggered grid"). De acordo com Fortuna (2000), essa malha tem se tornado um padrão no cálculo de escoamentos incompressíveis. Nesse caso, cada nó é representado por uma célula, conforme ilustra a figura 5.1 .
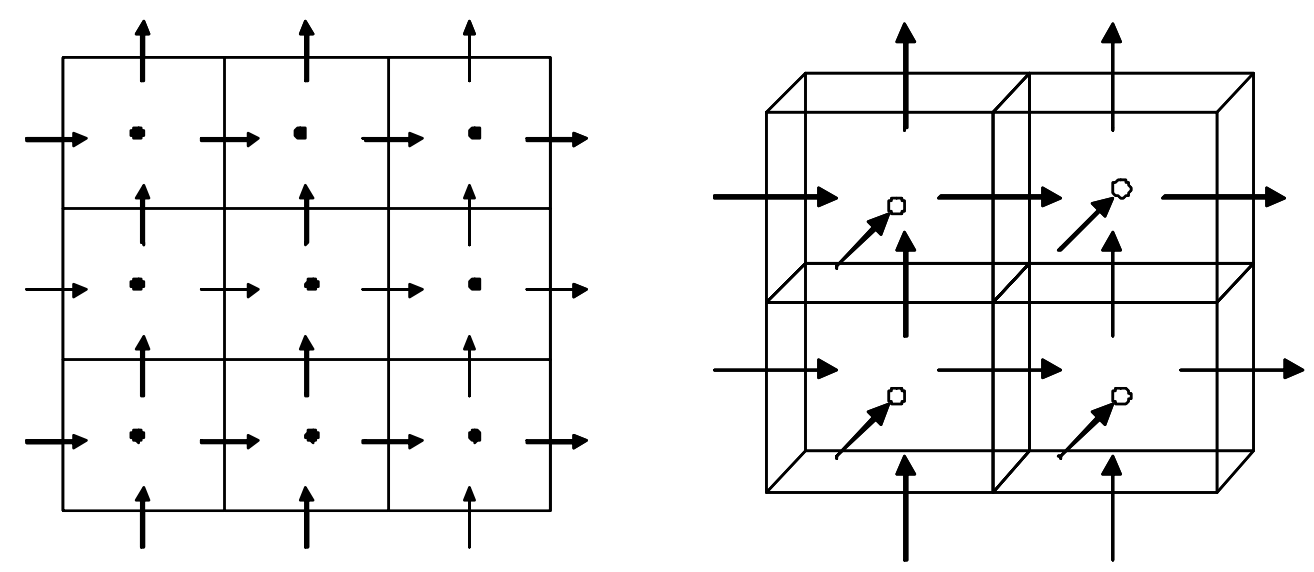

Figura 5.1 - Malha deslocada nos casos 2D e 3D: as velocidades são armazenadas nas faces das células, enquanto que os escalares são armazenados no centro

As condições de armazenamento de variáveis em cada célula são as seguintes:

- Escalares tais como pressão, concentração e viscosidade efetiva: armazenados no centro da célula;

- Componentes de velocidade: armazenadas nas faces laterais;

- Vorticidade e campo de força euleriano: armazenados no centro das células. 
Diante do arranjo deslocado, é conveniente estipular uma regra de ordenação (indexação) para as variáveis, permitindo seu armazenamento matricial. Essa indexação é fixada, por convenção, de acordo com a ilustração da figura 5.2 (para casos tridimensionais). Note-se que uma variável genérica $(\varphi)$ foi utilizada para representar as propriedades armazenadas no centro das células (pressão, viscosidade de sub-malha, concentração, etc.).

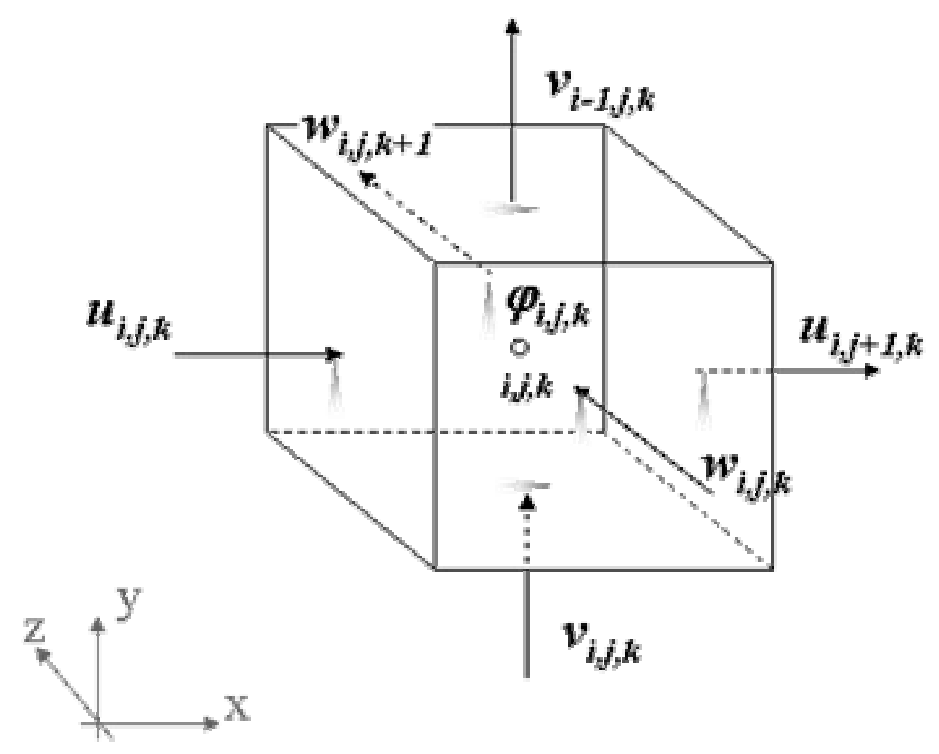

Figura 5.2 - Indexação das variáveis num arranjo deslocado tridimensional

Assim, as velocidades que entram na célula recebem a mesma indexação desse elemento discreto, ou seja, $i, j$ (em duas dimensões) e $i, j, k$ (em três dimensões). A partir dessas propriedades, fixadas pela malha deslocada, foi baseado todo o processo de discretização das equações e indexação das variáveis.

\section{2 - TRATAMENTO NUMÉRICO DAS EQUAÇÕES FILTRADAS DE NAVIER-STOKES}

\subsection{1 - GENERALIDADES}

A partir do tratamento numérico, as equações diferenciais de quantidade de movimento são transformadas em relações algébricas passíveis de resolução. Assim, a pressão 
e as velocidades são calculadas para cada célula discreta, tomando por base uma malha deslocada, conforme descrito no item anterior.

No capítulo dedicado à Simulação de Grandes Escalas, as velocidades e a pressão aparecem, nas equações filtradas, com barras sobrepostas. De acordo com o que também foi feito no capítulo subseqüente, sobre o Método de Fronteira Imersa, essas barras serão aqui suprimidas por uma simples que stão de legibilidade. Todavia, deve-se ter em mente que todas as variáveis aqui apresentadas constituem grandezas filtradas.

As derivadas espaciais foram discretizadas por Diferenças Centrais de segunda ordem. As vantagens deste esquema espacial estão relacionadas à sua capacidade de conservar energia, conforme está descrito no capítulo dedicado à Simulação de Grandes Escalas. A discretização das componentes direcionais das equações de Navier-Stokes apresenta uma grande quantidade de parcelas que o autor julgou por bem apresentá-las no Apêndice, no final dete trabalho. As derivadas temporais seguiram esquemas explícitos de Adams-Bashforth de segunda ou quarta ordem. Para facilitar o entendimento dos itens seguintes, convém, de início, reescrever as equações filtradas de Navier-Stokes na sua forma completa, ou seja, com o termo fonte de força euleriana e com a viscosidade turbulenta sub-malha adicional. Assim:

$\rho \frac{\partial u_{i}}{\partial t}+\rho \frac{\partial\left(u_{j} \cdot u_{i}\right)}{\partial x_{j}}=-\frac{\partial P}{\partial x_{i}}+\frac{\partial}{\partial x_{j}}\left[\left(\mu+\mu_{s m}\right) \cdot\left(\frac{\partial u_{i}}{\partial x_{j}}+\frac{\partial u_{j}}{\partial x_{i}}\right)\right]+F_{i}$

\subsection{2 - AVANÇO TEMPORAL DAS VELOCIDADES}

\subsubsection{1 - Esquema de Adams-Bashforth de segunda ordem}

O esquema de Adams-Bashforth de segunda ordem utiliza informações em dois níveis de tempo (o atual e o anterior) para calcular as velocidades no nível de tempo seguinte. Dessa maneira, as três componentes de velocidade são calculadas como: 


$$
\begin{aligned}
& u_{i, j+1, k}{ }^{n+1}=u_{i, j+1, k}{ }^{n}+\frac{\Delta t}{\rho} \cdot\left\{\frac{3}{2} \cdot[-A D V+D I F]^{n}-\frac{1}{2} \cdot[-A D V+D I F]^{n-1}\right\}-\left(\frac{\partial P}{\partial x}\right)^{n}+F_{x}{ }^{n} \\
& v_{i-1, j, k}{ }^{n+1}=v_{i-1, j, k}{ }^{n}+\frac{\Delta t}{\rho} \cdot\left\{\frac{3}{2} \cdot[-A D V+D I F]^{n}-\frac{1}{2} \cdot[-A D V+D I F]^{n-1}\right\}-\left(\frac{\partial P}{\partial y}\right)^{n}+F_{y}{ }^{n} \\
& w_{i, j, k+1}{ }^{n+1}=w_{i, j, k+1}{ }^{n}+\frac{\Delta t}{\rho} \cdot\left\{\frac{3}{2} \cdot[-A D V+D I F]^{n}-\frac{1}{2} \cdot[-A D V+D I F]^{n-1}\right\}-\left(\frac{\partial P}{\partial z}\right)^{n}+F_{z}{ }^{n}
\end{aligned}
$$

Em que: ADV corresponde à soma das parcelas advectivas e DIF corresponde à soma das parcelas difusivas, para cada componente direcional das equações filtradas de Navier-Stokes.

\subsubsection{2 - Esquema de Adams-Bashforth de quarta ordem}

Este esquema é semelhante ao anterior, uma vez que utiliza pesos para os diversos níveis de tempo anteriores. A diferença é que, neste caso, são utilizados quatro níveis de tempo (o atual e mais três anteriores). Assim, as componentes de velocidade são calculadas como:

$$
\begin{aligned}
& u_{i, j+1, k}^{n+1}=u_{i, j+1, k}^{n}+\frac{\Delta t}{\rho} \cdot\left\{\begin{array}{l}
\frac{55}{24} \cdot[-A D V+D I F]^{n}-\frac{59}{24} \cdot[-A D V+D I F]^{n-1}+ \\
+\frac{37}{24} \cdot[-A D V+D I F]^{n-2}-\frac{9}{24} \cdot[-A D V+D I F]^{n-3}
\end{array}\right\}-\left(\frac{\partial P}{\partial x}\right)^{n}+F_{x}^{n} \\
& \mathrm{v}_{\mathrm{i}-1, \mathrm{j}, \mathrm{k}}^{\mathrm{n}+1}=\mathrm{v}_{\mathrm{i}-1, \mathrm{j}, \mathrm{k}}{ }^{\mathrm{n}}+\frac{\Delta \mathrm{t}}{\rho} \cdot\left\{\begin{array}{l}
\frac{55}{24} \cdot[-\mathrm{ADV}+\mathrm{DIF}]^{\mathrm{n}}-\frac{59}{24} \cdot[-\mathrm{ADV}+\mathrm{DIF}]^{\mathrm{n}-1}+ \\
+\frac{37}{24} \cdot[-\mathrm{ADV}+\mathrm{DIF}]^{\mathrm{n}-2}-\frac{9}{24} \cdot[-\mathrm{ADV}+\mathrm{DIF}]^{\mathrm{n}-3}
\end{array}\right\}-\left(\frac{\partial \mathrm{P}}{\partial \mathrm{y}}\right)^{\mathrm{n}}+\mathrm{F}_{\mathrm{y}}{ }^{\mathrm{n}} \\
& \mathrm{w}_{\mathrm{i}, \mathrm{j}, \mathrm{k}+1}{ }^{\mathrm{n}+1}=\mathrm{w}_{\mathrm{i}, \mathrm{j}, \mathrm{k}+1}{ }^{\mathrm{n}}+\frac{\Delta \mathrm{t}}{\rho} \cdot\left\{\begin{array}{l}
\frac{55}{24} \cdot[-\mathrm{ADV}+\mathrm{DIF}]^{\mathrm{n}}-\frac{59}{24} \cdot[-\mathrm{ADV}+\mathrm{DIF}]^{\mathrm{n}-1}+ \\
+\frac{37}{24} \cdot[-\mathrm{ADV}+\mathrm{DIF}]^{\mathrm{n}-2}-\frac{9}{24} \cdot[-\mathrm{ADV}+\mathrm{DIF}]^{\mathrm{n}-3}
\end{array}\right\}-\left(\frac{\partial \mathrm{P}}{\partial \mathrm{z}}\right)^{\mathrm{n}}+\mathrm{F}_{\mathrm{z}}^{\mathrm{n}}
\end{aligned}
$$


Note-se que o custo computacional dos esquemas de quarta ordem é maior em relação aos esquemas de ordem inferior. Em contrapartida o "histórico" do escoamento é melhor aproveitado.

\subsection{3 - MODELAGEM SUB-MALHA}

\subsubsection{1 - Modelo de Smagorinsky}

Este modelo baseia-se nas taxas de deformação (gradientes de velocidade) para calcular a viscosidade turbulenta sub-malha. Assim, de acordo com o Modelo de Smagorinsky:

$$
\mu_{s m}=\rho \cdot C_{s}^{2} \cdot \Delta^{2} \cdot \sqrt{2 \cdot \bar{S}_{i j} \cdot \bar{S}_{i j}}
$$

Em que:

- $\overline{\mathrm{S}}_{\mathrm{ij}}=\frac{1}{2} \cdot\left(\frac{\partial \mathrm{u}_{\mathrm{i}}}{\partial \mathrm{x}_{\mathrm{j}}}+\frac{\partial \mathrm{u}_{\mathrm{j}}}{\partial \mathrm{x}_{\mathrm{i}}}\right)$

- $\Delta=$ espessura do filtro [L];

- $\quad$ Cs = constante de Smagorinsky $(0,1$ a 0,33$)$.

A espessura global do filtro é comumente calculada pela média geométrica dos lados da célula de discretização. Assim, numa formulação mais geral, espessura global do filtro pode ser calculada da seguinte forma:

$$
\Delta=\left(\prod_{\mathrm{i}=1}^{\mathrm{N}} \Delta \mathrm{x}_{\mathrm{i}}\right)^{\frac{1}{\mathrm{~N}}} \quad \text { onde: } \mathrm{N} \text { é o número de dimensões do problema }
$$

Note-se que o cálculo da viscosidade sub-malha requer a determinação dos gradientes de velocidade, os quais podem ser obtidos de forma discreta sobre os pontos centrais das células. Recorrendo à equação (5.4), uma atenção especial deve ser dada à decomposição 
do tensor $\overline{\mathrm{S}}_{\mathrm{ij}}=\frac{1}{2} \cdot\left(\frac{\partial \mathrm{u}_{\mathrm{i}}}{\partial \mathrm{x}_{\mathrm{j}}}+\frac{\partial \mathrm{u}_{\mathrm{j}}}{\partial \mathrm{x}_{\mathrm{i}}}\right)$. Com a finalidade de evitar confusão quanto aos índices $(i$ e j), é oportuno descrever cada decomposição. Dessa forma:

- $\overline{\mathrm{S}}_{11}=\frac{1}{2} \cdot\left(\frac{\partial \mathrm{u}_{1}}{\partial \mathrm{x}_{1}}+\frac{\partial \mathrm{u}_{1}}{\partial \mathrm{x}_{1}}\right)=\frac{\partial \mathrm{u}_{1}}{\partial \mathrm{x}_{1}}=\frac{\partial \mathrm{u}}{\partial \mathrm{x}}$

- $\bar{S}_{22}=\frac{1}{2} \cdot\left(\frac{\partial \mathrm{u}_{2}}{\partial \mathrm{x}_{2}}+\frac{\partial \mathrm{u}_{2}}{\partial \mathrm{x}_{2}}\right)=\frac{\partial \mathrm{u}_{2}}{\partial \mathrm{x}_{2}}=\frac{\partial \mathrm{v}}{\partial \mathrm{y}}$

- $\overline{\mathrm{S}}_{33}=\frac{1}{2} \cdot\left(\frac{\partial \mathrm{u}_{3}}{\partial \mathrm{x}_{3}}+\frac{\partial \mathrm{u}_{3}}{\partial \mathrm{x}_{3}}\right)=\frac{\partial \mathrm{u}_{3}}{\partial \mathrm{x}_{3}}=\frac{\partial \mathrm{w}}{\partial \mathrm{z}}$

- $\overline{\mathrm{S}}_{12}=\frac{1}{2} \cdot\left(\frac{\partial \mathrm{u}_{2}}{\partial \mathrm{x}_{1}}+\frac{\partial \mathrm{u}_{1}}{\partial \mathrm{x}_{2}}\right)=\frac{1}{2} \cdot\left(\frac{\partial \mathrm{v}}{\partial \mathrm{x}}+\frac{\partial \mathrm{u}}{\partial \mathrm{y}}\right)=\overline{\mathrm{S}}_{21}$

- $\overline{\mathrm{S}}_{13}=\frac{1}{2} \cdot\left(\frac{\partial \mathrm{u}_{3}}{\partial \mathrm{x}_{1}}+\frac{\partial \mathrm{u}_{1}}{\partial \mathrm{x}_{3}}\right)=\frac{1}{2} \cdot\left(\frac{\partial \mathrm{w}}{\partial \mathrm{x}}+\frac{\partial \mathrm{u}}{\partial \mathrm{z}}\right)=\overline{\mathrm{S}}_{31}$

- $\overline{\mathrm{S}}_{23}=\frac{1}{2} \cdot\left(\frac{\partial \mathrm{u}_{3}}{\partial \mathrm{x}_{2}}+\frac{\partial \mathrm{u}_{2}}{\partial \mathrm{x}_{3}}\right)=\frac{1}{2} \cdot\left(\frac{\partial \mathrm{w}}{\partial \mathrm{y}}+\frac{\partial \mathrm{v}}{\partial \mathrm{z}}\right)=\overline{\mathrm{S}}_{32}$

Assim, a viscosidade de sub-malha é finalmente expressa por:

$\mu_{s m}=\rho \cdot\left(C_{s} \cdot \Delta\right)^{2} \cdot \sqrt{2 \cdot\left(\bar{S}_{11}^{2}+\bar{S}_{22}^{2}+2 \bar{S}_{12}^{2}\right)} \quad$ (para casos bidimensionais)

$\left.\mu_{s m}=\rho \cdot\left(C_{s} \cdot \Delta\right)^{2} \cdot \sqrt{2 \cdot\left(\bar{S}_{11}^{2}+\bar{S}_{22}{ }^{2}+\bar{S}_{33}{ }^{2}+2 \bar{S}_{12}{ }^{2}+2 \bar{S}_{13}{ }^{2}+2 \bar{S}_{23}{ }^{2}\right.}\right)$ (para casos tridimensionais)

Finalmente, os gradientes de velocidade, necessários para avaliar a equação (5.6), podem ser escritos, de forma discreta, como:

- $\frac{\partial \mathrm{u}}{\partial \mathrm{x}}=\frac{\mathrm{u}_{\mathrm{i}, \mathrm{j}+1, \mathrm{k}}-\mathrm{u}_{\mathrm{i}, \mathrm{j}, \mathrm{k}}}{\Delta \mathrm{x}}$

- $\frac{\partial v}{\partial y}=\frac{v_{i-1, j, k}-v_{i, j, k}}{\Delta y}$

- $\frac{\partial \mathrm{w}}{\partial \mathrm{z}}=\frac{\mathrm{w}_{\mathrm{i}, \mathrm{j}, \mathrm{k}+1}-\mathrm{w}_{\mathrm{i}, \mathrm{j}, \mathrm{k}}}{\Delta \mathrm{z}}$ 
- $\frac{\partial \mathrm{w}}{\partial \mathrm{x}}=\frac{1 / 4\left(\mathrm{w}_{\mathrm{i}, \mathrm{j}, \mathrm{k}}+\mathrm{w}_{\mathrm{i}, \mathrm{j}, \mathrm{k}+1}+\mathrm{w}_{\mathrm{i}, \mathrm{j}+1, \mathrm{k}+1}+\mathrm{w}_{\mathrm{i}, \mathrm{j}+1, \mathrm{k}}\right)-1 / 4\left(\mathrm{w}_{\mathrm{i}, \mathrm{j}, \mathrm{k}}+\mathrm{w}_{\mathrm{i}, \mathrm{j}, \mathrm{k}+1}+\mathrm{w}_{\mathrm{i}, \mathrm{j}-1, \mathrm{k}+1}+\mathrm{w}_{\mathrm{i}, \mathrm{j}-1, \mathrm{k}}\right)}{\Delta \mathrm{x}}$

- $\frac{\partial \mathrm{u}}{\partial \mathrm{z}}=\frac{1 / 4\left(\mathrm{u}_{\mathrm{i}, \mathrm{j}, \mathrm{k}}+\mathrm{u}_{\mathrm{i}, \mathrm{j}+1, \mathrm{k}}+\mathrm{u}_{\mathrm{i}, \mathrm{j}+1, \mathrm{k}+1}+\mathrm{u}_{\mathrm{i}, \mathrm{j}, \mathrm{k}+1}\right)-1 / 4\left(\mathrm{u}_{\mathrm{i}, \mathrm{j}, \mathrm{k}}+\mathrm{u}_{\mathrm{i}, \mathrm{j}+1, \mathrm{k}}+\mathrm{u}_{\mathrm{i}, \mathrm{j}+1, \mathrm{k}-1}+\mathrm{u}_{\mathrm{i}, \mathrm{j}, \mathrm{k}-1}\right)}{\Delta \mathrm{z}}$

- $\frac{\partial w}{\partial y}=\frac{1 / 4\left(w_{i, j, k}+w_{i-1, j, k}+w_{i-1, j, k+1}+w_{i, j, k+1}\right)-1 / 4\left(w_{i, j, k}+w_{i, j, k+1}+w_{i+1, j, k+1}+w_{i+1, j, k}\right)}{\Delta y}$

- $\frac{\partial \mathrm{v}}{\partial \mathrm{z}}=\frac{1 / 4\left(\mathrm{v}_{\mathrm{i}, \mathrm{j}, \mathrm{k}}+\mathrm{v}_{\mathrm{i}-1, \mathrm{j}, \mathrm{k}}+\mathrm{v}_{\mathrm{i}-1, \mathrm{j}, \mathrm{k}+1}+\mathrm{v}_{\mathrm{i}, \mathrm{j}, \mathrm{k}+1}\right)-1 / 4\left(\mathrm{v}_{\mathrm{i}, \mathrm{j}, \mathrm{k}}+\mathrm{v}_{\mathrm{i}, \mathrm{j}, \mathrm{k}-1}+\mathrm{v}_{\mathrm{i}-1, \mathrm{j}, \mathrm{k}-1}+\mathrm{v}_{\mathrm{i}-1, \mathrm{j}, \mathrm{k}}\right)}{\Delta \mathrm{z}}$

- $\frac{\partial \mathrm{u}}{\partial \mathrm{y}}=\frac{1 / 4\left(\mathrm{u}_{\mathrm{i}, \mathrm{j}, \mathrm{k}}+\mathrm{u}_{\mathrm{i}, \mathrm{j}+1, \mathrm{k}}+\mathrm{u}_{\mathrm{i}-1, \mathrm{j}, \mathrm{k}}+\mathrm{u}_{\mathrm{i}-1, \mathrm{j}+1, \mathrm{k}}\right)-1 / 4\left(\mathrm{u}_{\mathrm{i}, \mathrm{j}, \mathrm{k}}+\mathrm{u}_{\mathrm{i}, \mathrm{j}+1, \mathrm{k}}+\mathrm{u}_{\mathrm{i}+1, \mathrm{j}, \mathrm{k}}+\mathrm{u}_{\mathrm{i}+1, \mathrm{j}+1, \mathrm{k}}\right)}{\Delta \mathrm{y}}$

- $\frac{\partial v}{\partial x}=\frac{1 / 4\left(v_{i, j, k}+v_{i-1, j, k}+v_{i-1, j+1, k}+v_{i, j+1, k}\right)-1 / 4\left(v_{i, j, k}+v_{i, j-1, k}+v_{i-1, j-1, k}+v_{i-1, j, k}\right)}{\Delta x}$

Notadamente, nos casos bidimensionais, a direção transversal é desconsiderada. Vale, mais uma vez lembrar, que a viscosidade de sub-malha é armazenada no centro da célula. Por isso as derivadas são também avaliadas nessa posição.

\subsubsection{2 - Modelo função estrutura de velocidade de segunda ordem}

Conforme já foi descrito no capítulo dedicado à Simulação de Grandes Escalas, a viscosidade turbulenta sub-malha pode ser calculada, pelo Modelo Função Estrutura de Velocidade, através das diferenças de velocidade entre células vizinhas. Assim:

$\mu_{\mathrm{sm}}=\rho \cdot 0,104 \cdot \mathrm{C}_{\mathrm{K}}^{-\frac{3}{2}} \cdot \Delta \cdot \sqrt{\overline{\mathrm{F}_{2}}(\overrightarrow{\mathrm{x}}, \Delta, \mathrm{t})}$

Em que, relembrando:

- $\mathrm{C}_{\mathrm{K}}=$ constante de Kolmogorov $\cong 1,40$;

- $\overline{\mathrm{F}}_{2}(\overrightarrow{\mathrm{x}}, \Delta, \mathrm{t})=\overline{|\overrightarrow{\mathrm{u}}(\overrightarrow{\mathrm{x}}+\overrightarrow{\mathrm{r}}, \mathrm{t})-\overrightarrow{\mathrm{u}}(\overrightarrow{\mathrm{x}}, \mathrm{t})|^{2}} \quad$,com $|\overrightarrow{\mathrm{r}}|=\Delta$. 
A barra utilizada no cálculo de $\overline{\mathrm{F}}_{2}(\overrightarrow{\mathrm{x}}, \Delta, \mathrm{t})$ indica uma média espacial realizada entre as células adjacentes (seis células no caso tridimensional e quatro células no caso bidimensional).

Como, segundo convenção, a viscosidade de sub-malha é determinada no centro das células, é também interessante trabalhar com velocidades centradas. De forma discreta, tais velocidades podem ser simplesmente calculadas pela média dos valores nas faces, de acordo com:

- $\mathrm{uc}_{\mathrm{i}, \mathrm{j}, \mathrm{k}}=\frac{1}{2} \cdot\left(\mathrm{u}_{\mathrm{i}, \mathrm{j}+1, \mathrm{k}}+\mathrm{u}_{\mathrm{i}, \mathrm{j}, \mathrm{k}}\right)$

- $\quad \mathrm{vc}_{\mathrm{i}, \mathrm{j}, \mathrm{k}}=\frac{1}{2} \cdot\left(\mathrm{v}_{\mathrm{i}-1, \mathrm{j}, \mathrm{k}}+\mathrm{v}_{\mathrm{i}, \mathrm{j}, \mathrm{k}}\right)$

- $\quad \mathrm{wc}_{\mathrm{i}, \mathrm{j}, \mathrm{k}}=\frac{1}{2} \cdot\left(\mathrm{w}_{\mathrm{i}, \mathrm{j}, \mathrm{k}+1}+\mathrm{w}_{\mathrm{i}, \mathrm{j}, \mathrm{k}}\right)$

O próximo passo consiste em calcular o módulo das diferenças de velocidades entre as seis células adjacentes. Assim:

- $|\overrightarrow{\mathrm{u}}|_{\mathrm{DIR}}=\left[\left(\mathrm{uc}_{\mathrm{i}, \mathrm{j}+1, \mathrm{k}}-\mathrm{uc}_{\mathrm{i}, \mathrm{j}, \mathrm{k}}\right)^{2}+\left(\mathrm{vc}_{\mathrm{i}, \mathrm{j}+1, \mathrm{k}}-\mathrm{vc}_{\mathrm{i}, \mathrm{j}, \mathrm{k}}\right)^{2}+\left(\mathrm{wc}_{\mathrm{i}, \mathrm{j}+1, \mathrm{k}}-\mathrm{wc}_{\mathrm{i}, \mathrm{j}, \mathrm{k}}\right)^{2}\right]^{1 / 2}$

- $|\overrightarrow{\mathrm{u}}|_{\mathrm{ESQ}}=\left[\left(\mathrm{uc}_{\mathrm{i}, \mathrm{j}-1, \mathrm{k}}-\mathrm{uc}_{\mathrm{i}, \mathrm{j}, \mathrm{k}}\right)^{2}+\left(\mathrm{vc}_{\mathrm{i}, \mathrm{j}-1, \mathrm{k}}-\mathrm{vc}_{\mathrm{i}, \mathrm{j}, \mathrm{k}}\right)^{2}+\left(\mathrm{wc}_{\mathrm{i}, \mathrm{j}-1, \mathrm{k}}-\mathrm{wc}_{\mathrm{i}, \mathrm{j}, \mathrm{k}}\right)^{2}\right]^{1 / 2}$

- $|\overrightarrow{\mathrm{u}}|_{\mathrm{NOR}}=\left[\left(\mathrm{uc}_{\mathrm{i}-1, \mathrm{j}, \mathrm{k}}-\mathrm{uc}_{\mathrm{i}, \mathrm{j}, \mathrm{k}}\right)^{2}+\left(\mathrm{vc}_{\mathrm{i}-1, \mathrm{j}, \mathrm{k}}-\mathrm{vc}_{\mathrm{i}, \mathrm{j}, \mathrm{k}}\right)^{2}+\left(\mathrm{wc}_{\mathrm{i}-1, \mathrm{j}, \mathrm{k}}-\mathrm{wc}_{\mathrm{i}, \mathrm{j}, \mathrm{k}}\right)^{2}\right]^{1 / 2}$

- $|\overrightarrow{\mathrm{u}}|_{\mathrm{sUL}}=\left[\left(\mathrm{uc}_{\mathrm{i}+1, \mathrm{j}, \mathrm{k}}-\mathrm{uc}_{\mathrm{i}, \mathrm{j}, \mathrm{k}}\right)^{2}+\left(\mathrm{vc}_{\mathrm{i}+1, \mathrm{j}, \mathrm{k}}-\mathrm{vc}_{\mathrm{i}, \mathrm{j}, \mathrm{k}}\right)^{2}+\left(\mathrm{wc}_{\mathrm{i}+1, \mathrm{j}, \mathrm{k}}-\mathrm{wc}_{\mathrm{i}, \mathrm{j}, \mathrm{k}}\right)^{2}\right]^{1 / 2}$

- $|\overrightarrow{\mathrm{u}}|_{\mathrm{POS}}=\left[\left(\mathrm{uc}_{\mathrm{i}, \mathrm{j}, \mathrm{k}+1}-\mathrm{uc}_{\mathrm{i}, \mathrm{j}, \mathrm{k}}\right)^{2}+\left(\mathrm{vc}_{\mathrm{i}, \mathrm{j}, \mathrm{k}+1}-\mathrm{vc}_{\mathrm{i}, \mathrm{j}, \mathrm{k}}\right)^{2}+\left(\mathrm{wc}_{\mathrm{i}, \mathrm{j}, \mathrm{k}+1}-\mathrm{wc}_{\mathrm{i}, \mathrm{j}, \mathrm{k}}\right)^{2}\right]^{1 / 2}$

- $|\overrightarrow{\mathrm{u}}|_{\mathrm{ANT}}=\left[\left(\mathrm{uc}_{\mathrm{i}, \mathrm{j}, \mathrm{k}-1}-\mathrm{uc}_{\mathrm{i}, \mathrm{j}, \mathrm{k}}\right)^{2}+\left(\mathrm{vc}_{\mathrm{i}, \mathrm{j}, \mathrm{k}-1}-\mathrm{vc}_{\mathrm{i}, \mathrm{j}, \mathrm{k}}\right)^{2}+\left(\mathrm{wc}_{\mathrm{i}, \mathrm{j}, \mathrm{k}-1}-\mathrm{wc}_{\mathrm{i}, \mathrm{j}, \mathrm{k}}\right)^{2}\right]^{1 / 2}$

Dessa forma, finalmente pode-se aplicar a média espacial, de forma que a função estrutura de velocidade de segunda ordem pode ser calculada como:

$$
\begin{aligned}
& \bar{F}_{2}(\vec{x}, \Delta, t)=\frac{1}{4} \cdot\left[|\vec{u}|_{D I R}^{2}+|\vec{u}|_{E S Q}^{2}+|\vec{u}|_{N O R}^{2}+|\vec{u}|_{S U L}^{2}\right] \quad \text { (para casos bidimensionais) } \\
& \left.\bar{F}_{2}(\vec{x}, \Delta, t)=\left.\frac{1}{6} \cdot|| \vec{u}\right|_{D I R} ^{2}+|\vec{u}|_{E S Q}^{2}+|\vec{u}|_{N O R}^{2}+|\vec{u}|_{S U L}^{2}+|\vec{u}|_{\text {POS }}^{2}+|\vec{u}|_{A N T}^{2}\right] \quad \text { (para casos tridimensionais) }
\end{aligned}
$$


Ao final deste procedimento, a viscosidade sub-malha é normalmente calculada, para cada célula do domínio, substituindo o valor discreto de $\overline{\mathrm{F}}_{2}(\overrightarrow{\mathrm{x}}, \Delta, \mathrm{t})$ na equação (5.7).

É conveniente comentar que o Modelo Função Estrutura de Velocidade tem implementação relativamente direta e um custo computacional semelhante ao do modelo de Smagorinsky.

\subsection{4 - ESTIMATIVA DA VELOCIDADE DE CISALHAMENTO}

É importante comentar, como uma breve recordação, que a utilização de funções de amortecimento, na estimativa da viscosidade sub-malha, é uma alternativa interessante para escoamentos limitados por paredes. A função de amortecimento é multiplicada ao valor da viscosidade sub-malha, reduzindo seu valor quanto menor for a distância adimensional $\left(d^{+}=u_{*} \cdot d /(\mu / \rho)\right)$ da célula à parede. Assim, a velocidade de cisalhamento é uma grandeza necessária no cálculo do amortecimento da viscosidade. Além disso, conforme será discutido adiante, condições cisalhantes sobre leitos aluviais podem gerar efeitos de ressuspensão de sedimentos. Essas duas análises justificam o cálculo da velocidade de cisalhamento, feito para paredes de fundo (leito).

A velocidade de cisalhamento pode ser obtida a partir da função de transferência $(D)$ discutida no capítulo anterior. Assim, velocidades em pontos situados até duas malhas acima do leito concorrem para a obtenção de um valor de velocidade que é extrapolado sobre a malha lagrangeana. Com isto, as células situadas mais próximas do leito contribuem com maior peso na extrapolação dos valores de velocidade. O valor, extrapolado sobre a interface imersa, é atribuído como a velocidade de cisalhamento. É conveniente salientar que, neste caso, apenas a região de interesse do escoamento (ou seja, acima da malha lagrangeana) deve ser contribuinte para a interpolação. Dessa maneira, vale a pena adaptar a formulação que, para a velocidade de cisalhamento, pode ser escrita como:

$$
u_{*}\left(\vec{x}_{k}\right)=\sum_{j} D\left(\vec{x}_{j}-\vec{x}_{k}\right) \cdot u\left(\vec{x}_{j}\right) \cdot d x \cdot d y \cdot d z
$$

Em que:

- $j$ = ponto da malha euleriana onde a velocidade é conhecida;

- $k=$ ponto sobre a malha lagrangeana; 
- $\quad D=$ função de transferência, conforme definida no capítulo anterior;

- $\quad d x, d y, d z=$ dimensões das células eulerianas [L].

Embora o uso da equação (5.9) não seja uma alternativa convencional, seus resultados têm se revelado mais profícuos, no caso de uma simulação numérica computacional, do que a aplicação da Lei da Viscosidade de Newton (onde há a necessidade de uma discretização muito refinada próxima do fundo do canal) e também mais consitentes do que o manuseio de leis de parede (onde o empirismo inerente aproveita muito pouco as informações já obtidas acerca do escoamento).

\section{3 - MÉTODO DE PASSOS FRACIONADOS}

O Método de Passos Fracionados constitui um procedimento numérico para acoplamento entre pressão e velocidade. A sua função é resolver numericamente as equações de Navier-Stokes e da Continuidade, realizando seu acoplamento de modo a fornecer campos finais de velocidade e pressão.

Este capítulo destaca o Método de Passos Fracionados por este ser o mais largamente utilizado pelos simuladores em SGE e, portanto, também aplicado neste trabalho. Como grande parte dos métodos de solução numérica das equações de Navier-Stokes, o princípio básico é o da resolução em dois passos, um preditor e outro corretor.

Num procedimento explícito, a etapa preditora é direta, utilizando as derivadas discretizadas, como foi visto na seção anterior. Um campo fictício (não corrigido) de velocidades é obtido a partir de campos tomados em instantes anteriores. A etapa corretora, por sua vez, garante a conservação de massa através da resolução de uma equação de Poisson para os termos de correção de pressão. Após a aplicação dessas duas etapas, novos campos (reais) de velocidade e pressão são obtidos. Este procedimento caminha em marcha temporal, ou seja, os campos finais, para um determinado instante, atuam como campos iniciais para o instante seguinte. Cada etapa dos Passos Fracionados é discutida adiante. 


\subsection{1 - A ETAPA PREDITORA}

Esta etapa utiliza as equações de Navier-Stokes filtradas para calcular uma primeira aproximação para o campo de velocidades (campo predito $\mathrm{u}^{*}$ ). Para um avanço temporal explícito, de segunda ordem tipo Adams-Bashforth, por exemplo, tem-se que:

$$
\rho \frac{u_{i}^{*}-u_{i}^{n}}{? t}=\frac{3}{2} \cdot\left\{-\left(\rho \frac{\partial\left(u_{j} \cdot u_{i}\right)}{\partial x_{j}}\right)+\frac{\partial}{\partial x_{j}}\left(\mu\left(\frac{\partial u_{i}}{\partial x_{j}}+\frac{\partial u_{j}}{\partial x_{i}}\right)\right)\right\}^{n}-\frac{1}{2} \cdot\left\{-\left(\rho \frac{\partial\left(u_{j} \cdot u_{i}\right)}{\partial x_{j}}\right)+\frac{\partial}{\partial x_{j}}\left(\mu\left(\frac{\partial u_{i}}{\partial x_{j}}+\frac{\partial u_{j}}{\partial x_{i}}\right)\right)\right\}^{n-1}-\frac{\partial p^{n}}{\partial x_{i}}+F_{i}^{n}
$$

A equação (5.10) é válida para qualquer tipo de modelagem da turbulência, pois representa um esquema geral de avanço no tempo (no caso, Adams-Bashforth de $2^{\mathrm{a}}$ ordem). $\mathrm{O}$ princípio também é o mesmo para outros esquemas de avanço temporal. Note-se que aqui, seguindo a tendência das seções anteriores, as barras que indicam serem as variáveis grandezas filtradas foram suprimidas do texto por simples questão de legibilidade.

Uma vez que o esquema descrito pela equação (5.10) é explícito, todas as variáveis já são conhecidas, pois representam campos de velocidade e pressão já calculados. Dessa forma, o campo predito $\left(u_{i}^{*}\right)$ pode ser facilmente calculado. Note-se que a etapa preditora é relativamente rápida, uma vez que se está lidando com um avanço temporal explícito. Cuidados especiais devem ser tomados no que se refere ao incremento de tempo (controle de "time-step") e no tratamento adequado dos contornos de velocidade e pressão.

\subsection{2 - A ETAPA CORRETORA}

Uma vez obtidos os campos fictícios (preditos) de velocidade $\left(u_{i}^{*}\right)$, é preciso garantir que a conservação de massa seja satisfeita no domínio de escoamento. Os campos preditos, por si só, não garantem esse princípio (a equação da Continuidade não é satisfeita). Isto ocorre porque a etapa preditora baseia-se unicamente na aplicação das equações de Navier-Stokes. Assim, os campos fictícios de velocidade devem ser corrigidos e este é o objetivo do passo corretor. Conforme foi comentado no prelúdio desta seção, deve-se resolver uma equação de Poisson para os termos de correção de pressão e depois corrigir os campos hidrodinâmicos. Em síntese, a etapa corretora dos Passos Fracionados é ilustrada pela figura 5.3. 
Campos de velocidade não corrigidos $\left(u_{i}^{*}\right)$

Campos de pressão no instante atual $\left(P^{n}\right)$
Solução da equação de Poisson para $p^{\prime}$
Campos hidrodinâmicos finais corrigidos $\left(P^{n+1}, u_{i}^{n+1}\right)$

Figura 5.3 - Esquema geral do Método de Passos Fracionados: somente após a solução da equação de Poisson é que são obtidos os campos finais de velocidade e pressão

Em vez de apresentar diretamente a equação de Poisson, é conveniente demonstrar como se chegou a essa expressão. Dessa maneira, parte-se de duas formas da equação (5.10), uma com tratamento explícito da pressão e outra com tratamento implícito da pressão:

$$
\left\{\begin{array}{l}
\rho \frac{\mathrm{u}_{\mathrm{i}}^{*}-\mathrm{u}_{\mathrm{i}}^{\mathrm{n}}}{? \mathrm{t}}=\frac{3}{2} \cdot\{-\mathrm{ADV}+\mathrm{DIF}\}^{\mathrm{n}}-\frac{1}{2} \cdot\{-\mathrm{ADV}+\mathrm{DIF}\}^{\mathrm{n}-1}-\frac{\partial \mathrm{P}^{\mathrm{n}}}{\partial \mathrm{x}_{\mathrm{i}}}+\mathrm{F}_{\mathrm{i}}^{\mathrm{n}} \\
\rho \frac{\mathrm{u}_{\mathrm{i}}^{\mathrm{n}+1}-\mathrm{u}_{\mathrm{i}}^{\mathrm{n}}}{? \mathrm{t}}=\frac{3}{2} \cdot\{-\mathrm{ADV}+\mathrm{DIF}\}^{\mathrm{n}}-\frac{1}{2} \cdot\{-\mathrm{ADV}+\mathrm{DIF}\}^{\mathrm{n}-1}-\frac{\partial \mathrm{P}^{\mathrm{n}+1}}{\partial \mathrm{x}_{\mathrm{i}}}+\mathrm{F}_{\mathrm{i}}^{\mathrm{n}}
\end{array}\right.
$$

Em que:

- $\mathrm{ADV}=$ termo advectivo $=\left\{\rho\left(\frac{\partial\left(\mathrm{u}_{\mathrm{j}} \cdot \mathrm{u}_{\mathrm{i}}\right)}{\partial \mathrm{x}_{\mathrm{j}}}\right)\right\}$

- $\quad$ DIF $=$ termo difusivo $=\left\{\frac{\partial}{\partial x_{j}}\left(\left(\mu+\mu_{\mathrm{sm}}\right)\left(\frac{\partial \mathrm{u}_{\mathrm{i}}}{\partial \mathrm{x}_{\mathrm{j}}}+\frac{\partial \mathrm{u}_{\mathrm{j}}}{\partial \mathrm{x}_{\mathrm{i}}}\right)\right)\right\}$

Fazendo a diferença entre as duas expressões, tem-se que:

$$
\rho \frac{u_{i}^{*}-u^{n+1}}{\Delta t}=\frac{\partial\left[P^{n+1}-P^{n}\right]}{\partial x_{i}} \Rightarrow \frac{u_{i}^{*}-u^{n+1}}{\Delta t}=\frac{1}{\rho} \frac{\partial\left[p^{\prime}\right]}{\partial x_{i}}
$$

Daí: $\quad \mathrm{u}_{\mathrm{i}}^{\mathrm{n}+1}=\mathrm{u}_{\mathrm{i}}^{*}-\frac{\Delta \mathrm{t}}{\rho} \frac{\partial \mathrm{p}^{\prime}}{\partial \mathrm{x}_{\mathrm{i}}}$ 
A equação (5.12) permite calcular o campo de velocidade final. Mas ainda não se dispõe do valor de p' (correção de pressão). Contudo, a demonstração ainda não está terminada, pois há a necessidade de se chegar à equação de Poisson. Assim, aplicando o operador divergente $\left(\frac{\partial}{\partial \mathrm{x}_{\mathrm{i}}}\right)$ na equação (5.11) obtém-se:

$\frac{\partial}{\partial x_{i}}\left(\frac{u_{i}^{*}-u_{i}^{n+1}}{\Delta t}\right)=\frac{\partial}{\partial x_{i}}\left(\frac{1}{\rho} \frac{\partial p^{\prime}}{\partial x_{i}}\right) \Rightarrow \frac{\frac{\partial}{\partial x_{i}} u_{i}^{n+1}-\frac{\partial}{\partial x_{i}} u_{i}^{*}}{\Delta t}=-\frac{1}{\rho} \cdot \frac{\partial p^{\prime}}{\partial x_{i} \partial x_{i}}$

$\frac{\partial u_{i}^{n+1}}{\partial x_{i}}=0 \quad$ (Continuidade $)$

E, finalmente : $\quad \frac{\partial^{2} \mathrm{p}^{\prime}}{\partial \mathrm{x}_{\mathrm{i}} \partial \mathrm{x}_{\mathrm{i}}}=\frac{\rho}{\Delta \mathrm{t}} \cdot \frac{\partial \mathrm{u}_{\mathrm{i}}^{*}}{\partial \mathrm{x}_{\mathrm{i}}} \quad$ (equação de Poisson para p')

Note-se que a equação de Poisson representa um sistema linear cuja resolução fornece os termos de correção de pressão (p'). A solução desse sistema corresponde a uma das partes mais dispendiosas do processo de acoplamento pressão-velocidade e, conseqüentemente de todo o código computacional. Segundo Souza (2003), é de fundamental importância a seleção de um método robusto de solução de sistemas lineares. Esta alternativa permite economizar tempos consideráveis de processamento.

Uma vantagem terminante do Método de Passos Fracionados, decorrente da própria dedução do método, é a garantia de baixos resíduos da Continuidade $\left(\frac{\partial \mathrm{u}_{\mathrm{i}}^{\mathrm{n}+1}}{\partial \mathrm{x}_{\mathrm{i}}} \cong 0\right)$ logo após a solução do sistema. Isto permite uma marcha temporal mais rápida, ou seja, uma passagem direta para o próximo nível de tempo.

Adiante comenta-se sobre o Método dos Gradientes Bi-conjugados Estabilizado Précondicionado (PBiCGSTAB), utilizado neste trabalho para a solução do sistema linear. Por ora, é conveniente resumir, de uma maneira estruturada, os procedimentos dos Passos Fracionados: 
- Campos atuais conhecidos : $u_{i}^{n}, P^{n}$;

- Passo preditor por qualquer esquema de avanço temporal. Aqui utiliza-se AdamsBashforth de segunda ordem:

$$
\begin{aligned}
& \rho \frac{u_{i}^{*}-u_{i}^{n}}{? t}=\frac{3}{2} \cdot\left\{-\left(\rho \frac{\partial\left(u_{j} \cdot u_{i}\right)}{\partial x_{j}}\right)+\frac{\partial}{\partial x_{j}}\left(\left(\mu+\mu_{s m}\right)\left(\frac{\partial u_{i}}{\partial x_{j}}+\frac{\partial u_{j}}{\partial x_{i}}\right)\right)\right\}^{n} \\
& -\frac{1}{2} \cdot\left\{-\left(\rho \frac{\partial\left(u_{j} \cdot u_{i}\right)}{\partial x_{j}}\right)+\frac{\partial}{\partial x_{j}}\left(\left(\mu+\mu_{s m}\right)\left(\frac{\partial u_{i}}{\partial x_{j}}+\frac{\partial u_{j}}{\partial x_{i}}\right)\right)\right\}^{n-1}-\frac{\partial P^{n}}{\partial x_{i}}+F_{i}^{n}
\end{aligned}
$$

- Do passo preditor extraem-se os campos de velocidade não corrigidos: $u_{i}^{*}$;

- Passo corretor indica o cálculo dos termos p' pela equação de Poisson:

$$
\frac{\partial^{2} \mathrm{p}^{\prime}}{\partial \mathrm{x}_{\mathrm{i}} \partial \mathrm{x}_{\mathrm{i}}}=\frac{\rho}{\Delta \mathrm{t}} \cdot \frac{\partial \mathrm{u}_{\mathrm{i}}^{*}}{\partial \mathrm{x}_{\mathrm{i}}} \stackrel{\text { Sistema linear }}{\longrightarrow} \mathrm{p}^{\prime}
$$

- Correçãa de pressão: $P^{n+1}=P^{n}+p^{\prime}$;

- Correção de velocidades: $\mathrm{u}_{\mathrm{i}}^{\mathrm{n}+1}=\mathrm{u}_{\mathrm{i}}^{*}-\frac{\Delta \mathrm{t}}{\rho} \frac{\partial \mathrm{p}^{\prime}}{\partial \mathrm{x}_{\mathrm{i}}}$

- Verificação da Continuidade: $\frac{\partial u_{i}}{\partial x_{i}} \rightarrow 0$;

- Próximo nível de tempo, tomando como valores iniciais os campos de pressão e velocidade acima calculados.

\section{4 - ASPECTOS DO TRATAMENTO NUMÉRICO DA EQUAÇÃO DE POISSON PARA OS TERMOS DE CORREÇÃO DE PRESSÃO}


Com a apresentação dos procedimentos de solução das equações governantes do escoamento, pelo Método de Passos Fracionados, é fácil perceber que o foco principal dessa metodologia está na forma de resolver o sistema fornecido pela equação de Poisson. Conforme também já foi comentado na seção anterior, este trabalho utiliza o Método dos Gradientes Bi-conjugados Estabilizado Pré-condicionado (PBiCGSTAB), o qual é detalhado na seção seguinte. Esse método utiliza a forma matricial $A \cdot X=B$, ou seja, determina o vetor de soluções (X), através da matriz de coeficientes (A) e de um vetor de resultados (B) (termo fonte). Nesse caso, a matriz (A) é formada pelos coeficientes da equação de Poisson discretizada por Diferenças Finitas; o vetor (X) corresponde aos termos de correção de pressão (p'), incógnitas de cada célula do domínio; e,finalmente, o termo fonte (B) é um vetor formado pelos valores de $\frac{\rho}{\Delta t} \cdot \frac{\partial u_{i}^{*}}{\partial x_{i}}$, os quais decorrem do passo preditor e já devem, pois, ser conhecidos.

Para isto, é interessante discretizar a equação de Poisson, o que permite notar mais claramente o sistema linear. A discretização é feita sobre o centro da célula (lembrar que a pressão é um escalar e, por isto, armazenada no centro).

A equação de Poisson (equação (5.13)), para termos de correção de pressão, é escrita, no caso tridimensional, como:

$$
\frac{\partial^{2} p^{\prime}}{\partial x^{2}}+\frac{\partial^{2} p^{\prime}}{\partial y^{2}}+\frac{\partial^{2} p^{\prime}}{\partial z^{2}}=\frac{\rho}{\Delta t} \cdot\left[\frac{\partial u^{*}}{\partial x}+\frac{\partial v^{*}}{\partial y}+\frac{\partial w^{*}}{\partial z}\right]
$$

A discretização da equação (5.14), por Diferenças Finitas, leva a:

$$
\begin{aligned}
& \frac{p_{i, j-1, k}^{\prime}-2 \cdot p_{i, j, k}^{\prime}+p_{i, j+1, k}^{\prime}}{\Delta x^{2}}+\frac{p_{i-1, j, k}^{\prime}-2 \cdot p_{i, j, k}^{\prime}+p_{i+1, j, k}^{\prime}}{\Delta y^{2}}+\frac{p_{i, j, k-1}^{\prime}-2 \cdot p_{i, j, k}^{\prime}+p_{i, j, k+1}^{\prime}}{\Delta z^{2}}= \\
& =\frac{\rho}{\Delta t} \cdot\left[\frac{u_{i, j+1, k}^{*}-u^{*}{ }_{i, j, k}}{\Delta x}+\frac{v_{i-1, j, k}^{*}-v^{*}{ }_{i, j, k}}{\Delta y}+\frac{v^{*}{ }_{i, j, k+1}-v_{i, j, k}^{*}}{\Delta z}\right]
\end{aligned}
$$

O segundo membro da equação (5.15) provém do passo preditor, sendo, portanto, conhecido. Rearranjando os termos pode-se escrever de uma maneira mais geral: 


$$
\begin{aligned}
& c x \cdot p_{i, j-1, k}^{\prime}+c x \cdot p_{i, j+1, k}^{\prime}+c y \cdot p_{i-1, j, k}^{\prime}+c y \cdot p_{i+1, j, k}^{\prime}+c z \cdot p_{i, j, k-1}^{\prime}+c z \cdot p_{i, j, k+1}^{\prime}+c \cdot p_{i, j}^{\prime}= \\
& =\frac{\rho}{\Delta t} \cdot\left[\frac{u^{*}{ }_{i, j+1, k}-u_{i, j, k}^{*}}{\Delta x}+\frac{v^{*}{ }_{i-1, j, k}-v^{*}{ }_{i, j, k}}{\Delta y}+\frac{v_{i, j, k+1}^{*}-v^{*}{ }_{i, j, k}}{\Delta z}\right]
\end{aligned}
$$

Em que:

- $\mathrm{cx}=1 / \Delta \mathrm{x}^{2}$;

- $\quad c y=1 / \Delta y^{2}$

- $\mathrm{cz}=1 / \Delta \mathrm{z}^{2}$

- $c=-2 \cdot\left[1 / \Delta x^{2}+1 / \Delta y^{2}+1 / \Delta z^{2}\right]=-2 \cdot(c x+c y+c z)$.

Da equação (5.16) pode-se notar mais claramente o sistema linear, onde o segundo membro compõe o termo fonte e os termos de correção de pressão compõem o vetor de incógnitas. Essa equação deve receber tratamentos especiais nos contornos, por isso convém destacar aqui os tipos de contornos mais freqüentemente utilizados neste trabalho:

- Entrada com velocidade prescrita:

$$
\frac{\partial p^{\prime}}{\partial x}=0 ? \quad p_{i, j-1, k}^{\prime}=p_{i, j, k}^{\prime}
$$

- Saída com condições de derivadas normais de velocidade nulas (Neumann):

$$
p_{i, j+1, k}^{\prime}=0
$$

- Face superior ou inferior com fronteira de simetria (ou parede fixa):

$$
\frac{\partial p^{\prime}}{\partial y}=0 ? \quad p_{i-1, j, k}^{\prime}=p_{i, j, k}^{\prime} \text { (na lateral superior), ou } p_{i+1, j, k}^{\prime}=p_{i, j, k}^{\prime} \text { (na lateral inferior); }
$$

- Laterais com fronteira de simetria (ou parede fixa):

$$
\frac{\partial p^{\prime}}{\partial z}=0 ? \quad p_{i, j, k-1}^{\prime}=p_{i, j, k}^{\prime}(\text { na lateral direita }) \text {, ou } p_{i, j, k+1}^{\prime}=p_{i, j, k}^{\prime} \text { (na lateral esquerda). }
$$

Não se pode perder de vista que o domínio estendido do escoamento (também dito domínio computacional) é um prisma retangular (com entrada, saída e laterais). A forma de fundo é imposta virtualmente através do campo de força da fronteira imersa. 
A montagem do sistema linear (equação (5.16)) na forma matricial indica que a matriz de coeficientes $(c, c x, c y, c z)$ é esparsa tipo banda, o que é típico das discretizações por Diferenças Finitas com malhas estruturadas. Note-se que, no caso tridimensional, a matriz possui sete diagonais com elementos não nulos. As matrizes tipo banda são compostas por um número finito de diagonais não nulas, sendo uma delas a diagonal principal. Os elementos fora dessas diagonais são todos nulos, denotando o caráter esparso da matriz.

A construção da matriz de coeficientes é uma operação trabalhosa que exige atenção especial para as células adjacentes aos contornos. Essas células apresentam, na equação de Poisson, coeficientes representados pela soma de dois ou três valores (outros coeficientes) que dependem da condição de contorno nas suas adjacências.

A montagem da matriz na forma cheia tem uma séria limitação. Toma-se, por exemplo, uma malha com $N_{i} \times N_{j} \times N_{k}$ células que irá redundar numa matriz com $\left(N_{i} \times N_{j} \times N_{k}\right)^{2}$ elementos. Como o grau de precisão dos resultados está ligado ao nível de discretização da malha, principalmente em SGE, percebe-se que esta forma de montagem exige um grande espaço para armazenar a matriz. Muitas vezes (ou na maioria delas), os computadores individuais não possuem essa capacidade de armazenamento.

Todavia, nota-se que a matriz apresenta um alto grau de esparsidade (a maioria dos elementos é nula) e, portanto, seria um desperdício de espaço armazenar todos os seus elementos (inclusive os nulos). Isto destaca a importância de se armazenar somente os valores diferentes de zero, tirando proveito da esparsidade da matriz, uma vez que a economia de memória é muito grande. A este procedimento dá-se o nome de armazenamento esparso da matriz.

Dentre os vários métodos de armazenamento esparso, foi utilizado o "Compressed Row Storage" (CRS). O CRS decompõe uma matriz (A) (no nosso caso a matriz de coeficientes) em três vetores, conforme ilustra a figura 6.4. A função de cada um desses vetores é a seguinte:

- vetor val ( ): armazena todos os elementos não nulos da matriz, sendo, portanto, um vetor de números reais. Sua ordenação é dada por uma varredura nas linhas da matriz;

- vetor col_ind ( ): guarda os índices das colunas de cada elemento do vetor val ( ). É um vetor de elementos inteiros;

- vetor row_ptr( ): guarda a locação, no vetor val ( ), do elemento não nulo que inicia cada linha da matriz cheia. É também um vetor de elementos inteiros. 


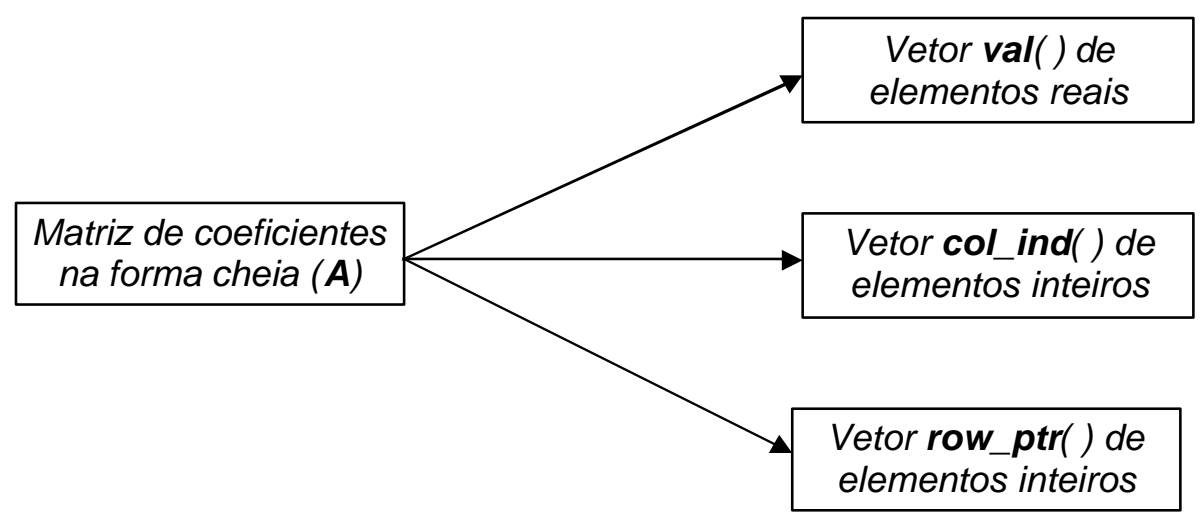

Figura 5.4 - Esquema de decomposição, da matriz, na forma cheia, para o armazenamento esparso em três vetores. O uso deste esquema visa economizar memória computacional

Assim, sendo $n=N_{i} \cdot N_{j} \cdot N_{k}$ o número total de células do domínio (que determina o número de linhas ou coluna da matriz) e $m$ o número de elementos não nulos, o espaço requerido pelo CRS é de $(2 \cdot m+n+1)$ locações. Isto representa uma considerável economia em relação às $\left(n^{2}\right)$ posições requeridas se a matriz fosse tratada na forma cheia.

Para maiores detalhes acerca do armazenamento CRS, além de outras técnicas de armazenamento esparso, recomenda-se a leitura de Barret et al. (1994).

\section{5 - MÉTODO DE GRADIENTES BI-CONJUGADOS ESTABILIZADO PRÉ-CONDICIONADO (PBiCGSTAB)}

O Método de Gradientes Bi-conjugados Estabilizado Pré-condiconado (PBiCGSTAB) é a ferramenta utilizada neste trabalho para a solução do sistema linear. De forma resumida, seu objetivo é a obtenção do vetor que guarda os termos de correção de pressão (p'). De maneira diferente dos métodos dito estacionários (como Gauss-Seidel ou SOR), os métodos de gradientes baseiam-se em direções de busca que variam a cada iteração. Assim, estes são procedimentos não estacionários, uma vez que os cálculos envolvem informações que se alteram de acordo com as iterações (procedimento dinâmico). A função dos vetores de busca é determinar direções e sentidos que minimizem os resíduos do sistema $A \cdot X=B$, onde, vale lembrar, o vetor X, incógnita do problema, armazena os termos de correção de pressão (p').

O PBiCGSTAB apresenta, em relação ao seu precursor BiCG (Método de Gradientes Conjugados), uma convergência mais regular, razão pela qual foi utilizado neste trabalho. 
Além disso, a matriz obtida da equação de Poisson não é exatamente simétrica, fato que restringe a aplicação do BiCG. Outra diferença, concernente ao algoritmo de solução, está na não necessidade de transpor a matriz, uma vez que somente são necessárias duas operações de multiplicação matriz x vetor.

Com o objetivo de acelerar a convergência do método, freqüentemente é também inserida uma operação de pré-condicionamento. $O$ pré-condicionamento adiciona às operações do PBiCGSTAB uma matriz de estrutura bastante semelhante à matriz de coeficientes (A), porém mais próxima da identidade. Isto ocorre porque os métodos de gradientes trabalham melhor para matrizes bem condicionadas (próximas da identidade). Nesse sentido, foi utilizado o esquema de Point-Jacobi, onde os elementos da matriz de précondicionamento (M) são obtidos a partir da matriz A, da seguinte forma:

$M_{i, j}= \begin{cases}A_{i, j} & \text { se } i=j \\ 0 & \text { se } i ? j\end{cases}$

onde: $\mathrm{M}_{\mathrm{i}, \mathrm{j}}$ e $\mathrm{A}_{\mathrm{i}, \mathrm{j}}$ são elementos de $\boldsymbol{M}$ e $\boldsymbol{A}$, respectivamente

Finalmente, tem-se um Método de Gradientes Bi-conjugados Estabilizado Précondicionado (PBiCGSTAB), cujo algoritmo é fornecido pela figura 5.5.

Convém ressaltar que é necessário adaptar o código, ilustrado pela figura 5.5, aos procedimentos de armazenamento esparso da matriz de coeficientes (A). Essa adaptação somente aparece nos produtos entre matriz e vetor. Tomando, como exemplo, uma matriz (A) - armazenada em três vetores como no método CRS - e um vetor $(\mathrm{X})$, o produto $A \cdot X=Y$ pode ser descrito pelo algoritmo da figura 5.6. 
Calcular $r^{(0)}=B-A \cdot X^{(0)}$ para um vetor inicial $X^{(0)}$ qualquer

Escolher um vetor $\tilde{r}^{(0)}$ (por exemplo, $\tilde{r}=r^{(0)}$ )

Para $i=1,2, \ldots$

$\rho_{i-1}=\tilde{r}^{T} \cdot r^{(i-1)}$

Se $\rho_{i-1}=0$, o método falha

Se $i=1$,

$p^{(i)}=r^{(i-1)}$

Senão,

$\beta_{i-1}=\left(\rho_{i-1} / \rho_{i-2}\right) \cdot\left(\alpha_{i-1} / \bar{\sigma}_{i-1}\right)$

$p^{(i)}=r^{(i-1)}+\beta_{i-1} \cdot\left(p^{(i-1)}-\bar{\omega}_{i-1} \cdot v^{(i-1)}\right)$

Fim Se.

Resolver $M \cdot \tilde{p}=p^{(i)}$

$v^{(i)}=A \cdot \tilde{p}$

$\alpha_{i}=\rho_{i-1} / \tilde{r}^{T} v^{(i)}$

$s=r^{(i-1)}-\alpha_{i} v^{(i)}$

Verificar a norma de $s$; se for pequena, faça $X^{(i)}=X^{(i-1)}+\alpha_{i} \cdot \tilde{p}$ e encerre o procedimento

Resolver $M \cdot \tilde{s}=s$

$t=A \cdot \tilde{s}$

$\bar{\sigma}_{i}=t^{T} s / t^{T} t$

$X^{(i)}=X^{(i-1)}+\alpha_{i} \cdot \tilde{p}+\bar{\varpi}_{i} \cdot \tilde{s}$

$r^{(i)}=s-\bar{\sigma}_{i} \cdot t$

Verificar a convergência; continuar se necessário

Para continuar é preciso que $\bar{\varpi}_{i} \neq 0$

Fim

Figura 5.5 - Algoritmo geral do PBiCGSTAB (retirado de BARRET et al., 1994)

$$
\begin{aligned}
& \text { Para } i=1, \ldots, n \\
& Y(i)=0 \\
& \text { Para } j=\text { row_ptr }(i), \ldots, r o w \_p t r(i+1)-1 \\
& \quad Y(i)=Y(i)+\operatorname{val}(j) . X(\text { col_ind }(j)) \\
& \text { Fim }
\end{aligned}
$$

Fim

Figura 5.6 - Multiplicação entre matriz e vetor utilizando o armazenamento esparso CRS (retirado de BARRET et al., 1994) 


\section{6 - TRATAMENTO NUMÉRICO DA EQUAÇÃO DE ADVECÇÃO- DIFUSÃO FILTRADA}

Conforme já foi discutido, em capítulo anterior, a equação de Advecção-Difusão foi utilizada, neste trabalho, para modelar o transporte de sedimentos pelo escoamento. Por isso, é conveniente reescrevê-la aqui como:

$$
\frac{\partial c}{\partial t}+u_{i} \frac{\partial c}{\partial x_{i}}=\frac{\partial}{\partial x_{i}}\left(D_{E F} \frac{\partial c}{\partial x_{i}}\right)+\frac{\partial\left(w_{s} \cdot c\right)}{\partial x_{3}}
$$

Onde $D_{E F}$ é o coeficiente de difusão efetivo, decorrente da soma dos coeficientes de difusão molecular e turbulento sub-malha. Seu valor é normalmente relacionado ao valor da viscosidade efetiva, de acordo com:

$$
D_{E F}=\Phi \cdot\left(\mu+\mu_{s m}\right) /\left(\rho \cdot \sigma_{c}\right)
$$

O número de Schmidt $\left(\sigma_{\mathrm{c}}\right)$ é geralmente tomado como unitário (ZEDLER e STREET, 2001), mas existem formas empíricas para estimar sua variação, conforme descrito no capítulo de Revisão Bibliográfica. $O$ fator $\Phi$ incorpora efeitos de interferência das partículas de sedimento no escoamento. Ambos os fatores podem ser calculados como:

$$
\begin{aligned}
& \sigma_{c}=\left[1+2 \cdot\left(\frac{w_{s}}{u_{*}}\right)^{2}\right]^{-1}, \text { para } 0,1<w_{s} / u_{*}<1 \\
& \Phi=1+\left(\frac{c}{0,65 \cdot \rho_{s}}\right)^{0,8}-2 \cdot\left(\frac{c}{0,65 \cdot \rho_{s}}\right)^{0,4}
\end{aligned}
$$

Em que:

- $w_{s}=$ velocidade de sedimentação da partícula $\left[\mathrm{LT}^{-1}\right]$;

- $u_{*}=$ velocidade de cisalhamento $\left[\mathrm{LT}^{-1}\right]$;

- $\rho_{s}=$ massa específica do sedimento $\left[\mathrm{ML}^{-3}\right]$. 
Vale lembrar que a utilização da Simulação de Grandes Escalas (SGE), denota que as velocidades e concentrações são grandezas filtradas, escritas aqui sem as barras superiores por razões já explicadas.

O tratamento numérico da equação de Advecção-Difusão também foi feito por Diferenças Finitas aplicadas sobre malhas deslocadas (assim, as concentrações são armazenadas no centro das células). Como no caso das equações de Navier-Stokes, seguem-se esquemas espaciais de segunda ordem, cujas parcelas discretas são apresentadas detalhadamente no Apêndice desta obra.

Para o avanço temporal foi utilizado o esquema de Adams-Bashforth de segunda ordem. Dessa forma:

$$
c_{i, j, k}^{n+1}=c_{i, j, k}{ }^{n}+\Delta t \cdot\left\{\frac{3}{2} \cdot[-A D V+D I F+S E D]^{n}-\frac{1}{2} \cdot[-A D V+D I F+S E D]^{n-1}\right\}
$$

Em que:

- $A D V=$ soma das parcelas de transporte advectivo $=\frac{\partial(\mathrm{u} \cdot \mathrm{c})}{\partial \mathrm{x}}+\frac{\partial(\mathrm{v} \cdot \mathrm{c})}{\partial \mathrm{y}}+\frac{\partial(\mathrm{w} \cdot \mathrm{c})}{\partial \mathrm{z}}$;

- $D I F=$ soma das parcelas de transporte difusivo $=\frac{\partial}{\partial x}\left(D_{\mathrm{EF}} \frac{\partial \mathrm{c}}{\partial \mathrm{x}}\right)+\frac{\partial}{\partial \mathrm{y}}\left(\mathrm{D}_{\mathrm{EF}} \frac{\partial \mathrm{c}}{\partial \mathrm{y}}\right)+\frac{\partial}{\partial \mathrm{z}}\left(\mathrm{D}_{\mathrm{EF}} \frac{\partial \mathrm{c}}{\partial \mathrm{z}}\right)$

- $S E D=$ parcela de sedimentação $=\frac{\partial\left(\mathrm{w}_{\mathrm{s}} \cdot \mathrm{c}\right)}{\partial \mathrm{y}}$.

Ainda que a solução numérica da equação de Advecção-Difusão seja relativamente direta, alguns aspectos peculiares, relacionados às condições de contorno de fundo, devem ser observados. Isto ocorre porque eventuais condições cisalhantes sobre o leito dos canais podem motivar a ressuspensão de sedimentos. Nessas condições, o leito atua como uma fonte de sedimentos que alimenta a equação de Advecção-Difusão. Convém comentar que, quando velocidades de cisalhamento locais superam a condição crítica, existe um fluxo vertical de sedimentos, a partir do fundo do canal, no sentido do interior do escoamento. Esse fluxo de massa adicional atua como uma condição de contorno para a face inferior das células adjacentes ao leito. Quando as velocidades de cisalhamento locais são inferiores à condição crítica, logicamente este fluxo de massa não existe (ver figura 5.7). 

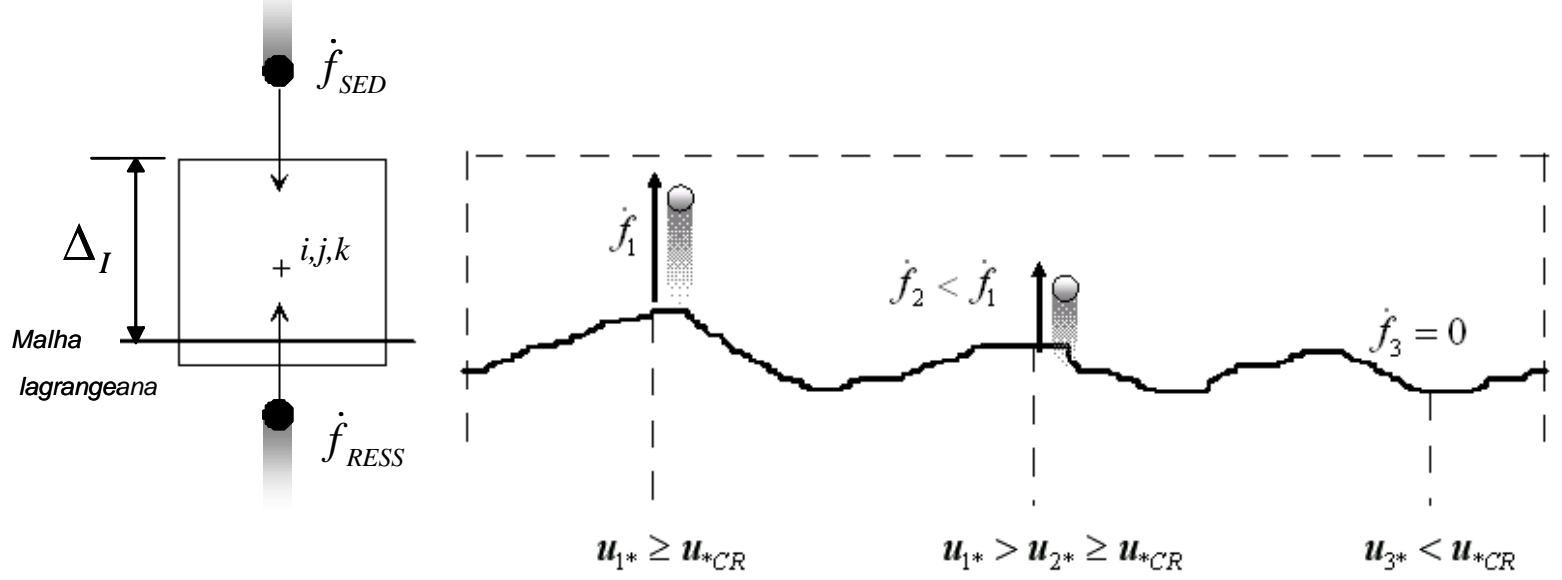

Figura 5.7 - Fluxos de massa de ressuspensão a partir do fundo de canais aluviais, atuando como condição de contorno para células adjacentes ao leito. O fluxo de massa é função da velocidade de cisalhamento e só ocorre quando condições cisalhantes críticas sobre o leito são superadas

Verificada a existência de um fluxo (local) de massa de ressuspensão, o mesmo é embutido na parcela de sedimentação da equação de Advecção-Difusão. Assim, seguindo o esquema da figura 5.7, esta parcela pode ser calculada, para células adjacentes ao leito (representado pela malha lagrangeana), como:

$$
\left.\frac{\partial\left(w_{s} \cdot c\right)}{\partial y}\right|_{i, j, k}=\frac{\dot{f}_{S E D}-\dot{f}_{R E S S}}{\Delta_{I}}
$$

Em que:

- $\quad \dot{f}_{S E D}=\left.w_{s} \cdot c\right|_{i, j, k}$

- $\quad \dot{f}_{R E S S}=\dot{f}_{R E S S}\left(u_{*}\right)=$ fluxo de massa de ressuspensão $\left[\mathrm{ML}^{-2} \mathrm{~T}^{-1}\right]$;

- $\Delta_{I}=\left(y_{i, j, k}+\Delta y\right)-y_{k}$, segundo ilustra a figura $5.7[\mathrm{~L}]$.

As formas de estimar $\dot{f}_{R E S S}$, além das condições críticas de ressuspensão, são discutidas a seguir.

Dentre os vários critérios de erosão, que exprimem condições de ressuspensão iminente, foi utilizada neste trabalho a teoria das Figuras de Erosão (BORGES e SARAIVA, 1980). Essa teoria permite explicitar uma velocidade crítica de cisalhamento, a partir da qual existe a saltação de partículas inicialmente espalhadas sobre uma superfície (maiores detalhes 
podem ser encontrados em SCHULZ, 2003). O critério das Figuras de Erosão é baseado em observações experimentais, as quais produziram as seguintes relações:

$$
\begin{aligned}
& F r_{c r}=\frac{\rho}{\rho_{S}} \cdot \frac{u_{*}{ }_{c r}^{2}}{g \cdot D}=0,0180 \cdot\left(\operatorname{Re}_{* c r}\right)^{-0,432} \\
& u_{* c r}=0.192 \cdot\left(\frac{\rho_{s} \cdot g}{\rho}\right)^{0.411} \cdot D^{0.234} \cdot v^{0.178}
\end{aligned}
$$

Em que:

- $F r_{c r}=$ número de Froude crítico para saltação;

- $\quad u * c r=$ velocidade de cisalhamento para iminência de saltação $\left[\mathrm{LT}^{-1}\right]$;

- $\operatorname{Re}_{*}=u_{*} \cdot D / v=$ número de Reynolds da partícula de sedimento;

- $\rho_{\mathrm{s}}=$ massa específica do sedimento $\left[\mathrm{ML}^{-3}\right]$;

- $\rho=$ massa específica do fluido $\left[\mathrm{ML}^{-3}\right]$;

- $\quad v=$ viscosidade cinemática do fluido $\left[\mathrm{L}^{2} \mathrm{~T}^{-1}\right]$;

- $D=$ diâmetro médio dos sedimentos [L].

O critério das Figuras de Erosão pode ser comparado com outros, como o de Shields, por exemplo (ver figura 5.8). Ele indica haver saltação a velocidades de cisalhamento menores que as de Shields. 
$M_{*}=u_{* C R}^{2} /\left[\left(\rho_{s} / \rho-1\right) \cdot g \cdot D\right]$

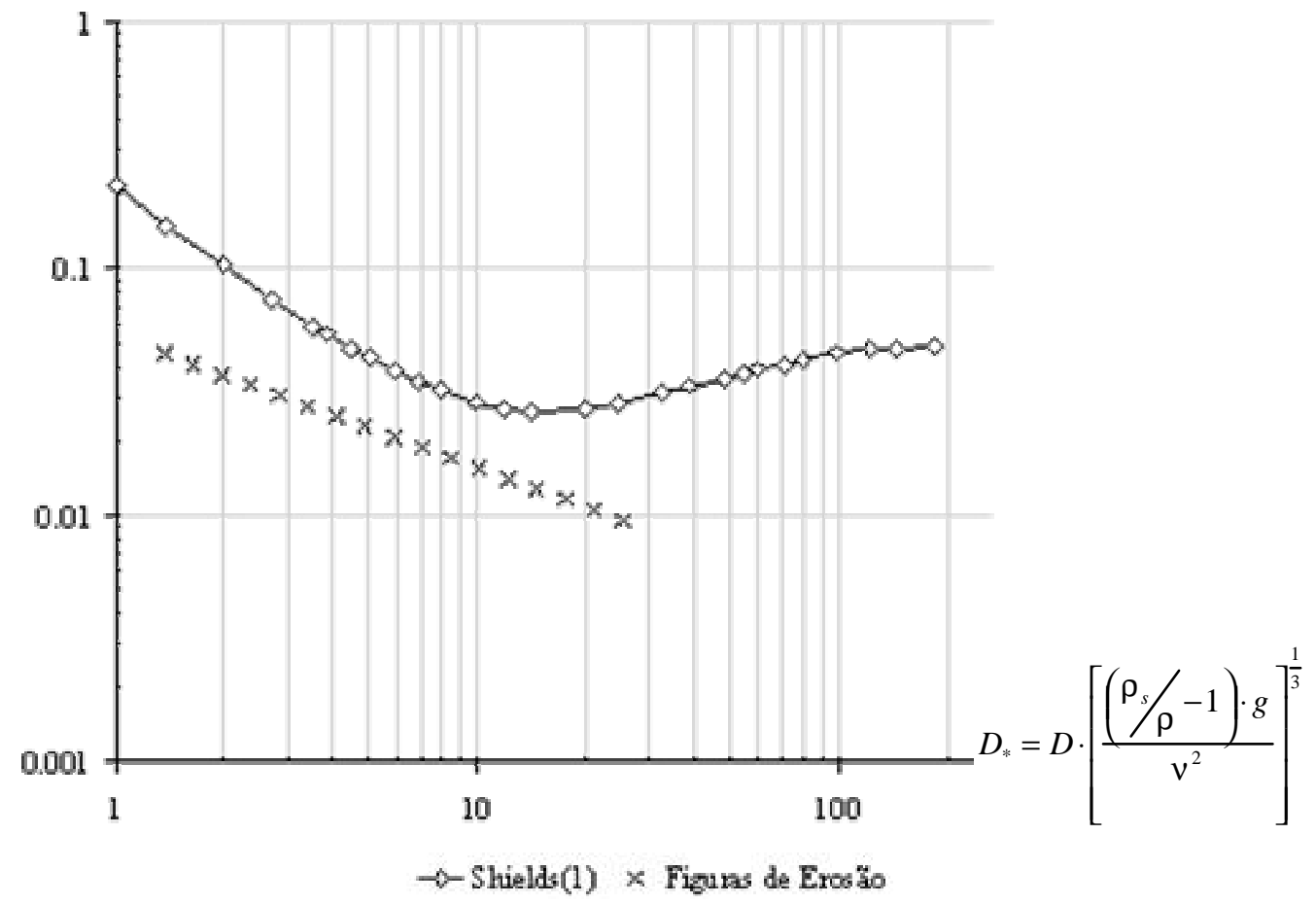

Figura 5.8 - Comparação entre os critérios de erosão de Shields e das Figuras de Erosão

É possível enumerar algumas expressões, todas de cunho empírico, que permitem estimar o fluxo de massa de ressuspensão a partir de condições cisalhantes. A formulação de VAN RIJN (1984) foi utilizada neste trabalho, uma vez que alcançou larga propagação na literatura (ver, por exemplo, ZEDLER e STREET, 2001; TROUW e WILLIAMS, 2000; entre outros). A seguir destacam-se algumas dessas formulações:

- Van Rijn (1984):

$$
\dot{f}_{\text {RESS }}=0,00033 \cdot D_{*}^{0,3} \cdot T^{1,5} \cdot \rho_{s} \cdot\left[\frac{\rho_{s}-\rho}{\rho} \cdot g \cdot D\right]^{\frac{1}{2}}
$$

Em que: $T=\frac{u_{*}^{2}-u_{* c r}^{2}}{u_{* c r}^{2}} \quad$ e $\quad D_{*}=\left(\frac{\rho_{s}-\rho}{\rho} \cdot \frac{g}{v^{2}}\right)^{\frac{1}{3}}$

- Nakagawa e Tsujimoto (1980): 


$$
\dot{f}_{\text {RESS }}=\alpha \cdot \rho_{s} \cdot\left[\frac{\rho_{s}-\rho}{\rho} \cdot g \cdot D\right]^{\frac{1}{2}} \cdot\left(1-\frac{0,035}{\theta}\right)^{3} \cdot \theta
$$

Onde: $\alpha=0,02$ ( $\mathrm{p} /$ esferas)

$$
\theta=\frac{u_{*}^{2}}{\left(\frac{\rho_{s}-\rho}{\rho} \cdot g \cdot D\right)}
$$

- Fernandez Luque (1974):

$$
\dot{f}_{\text {RESS }}=\alpha \cdot \rho_{s} \cdot\left[\frac{\rho_{s}-\rho}{\rho} \cdot g \cdot D\right]^{\frac{1}{2}} \cdot\left(\theta-\theta_{c r}\right)^{1,5} \cdot d x \cdot d z
$$

$$
\text { Onde: } \alpha=0,02(\mathrm{p} / \text { esferas }) \quad \quad \quad \quad \quad \theta_{c r}=\frac{u_{* r}{ }^{2}}{\left(\frac{\rho_{s}-\rho}{\rho} \cdot g \cdot D\right)}
$$

\section{7 - DESENVOLVIMENTOS ANALÍTICOS ACERCA DA VELOCIDADE DE SEDIMENTAÇÃO}

De uma forma resumida, sabe-se que a velocidade de sedimentação, além do diâmetro das partículas, está relacionada com a sua concentração no fluido. Conforme já foi visto em capítulo anterior, muitas equações e conceitos adequados existem na literatura, relacionando essas variáveis, bem como outros parâmetros do sistema fluido-partícula. Entretanto, não há uma aceitação geral de que uma única solução, com bases suficientemente amparadas em princípios físicos e utilizável em uma ampla faixa de concentrações e velocidades, tenha sido atingida. No presente desenvolvimento são utilizados alguns conceitos e relações básicas na construção de uma equação para a velocidade de sedimentação. De uma maneira geral, partese da quantificação da energia cinética no processo de sedimentação. 
O presente estudo se fundamenta em manuscritos de Schulz (1992, cedidos como informação pessoal), que foram rediscutidos amplamente e reavaliados quanto à representação da realidade física.

Para evitar possíveis confusões entre variáveis e parâmetros, a velocidade de queda das partículas $\left(w_{s}\right)$ será tratada, neste item, como $V_{p}$.

\subsection{1 - PRINCÍPIOS BÁSICOS}

Para suspensões de partículas homogêneas e isotrópicas, pode-se definir uma grandeza, dita concentração volumétrica, pela seguinte relação:

$$
\begin{aligned}
\phi & =\frac{\text { Volume de Partículas }}{\text { Volume Total }}=\frac{\text { Área ocupada por Partículas }}{\text { Área Total }} \\
& =\frac{\text { Comprimento ocupado por partículas }}{\text { Comprimento Total }}
\end{aligned}
$$

Desta relação decorrem três equações inter-relacionadas. $\mathrm{O}$ volume total representa $\mathrm{O}$ volume do domínio de escoamento considerado. A área ocupada pelas partículas corresponde à área de interseção entre as partículas e um plano imaginário (um plano horizontal, por exemplo). O comprimento ocupado pelas partículas é o comprimento de interseção entre as partículas e uma linha imaginária. As três relações são iguais. Como consequiência, também vale a equação (5.29), que expressa o espaço livre entre as partículas em uma, duas e três dimensões:

$$
\begin{aligned}
& 1-\phi=\frac{\text { Volume de fluido livre }}{\text { Volume Total }}=\frac{\text { Área de fluido livre }}{\text { Área Total }} \\
& =\frac{\text { Comprimento de fluido livre }}{\text { Comprimento Total }}
\end{aligned}
$$


O espaço livre $(1-\phi)$ denota a distância adimensional aproximada entre partículas vizinhas.

Em escoamentos em torno de partículas isoladas define-se um coeficiente de arrasto, o qual permite calcular a força sobre uma partícula e, se isto for de interesse, a energia gasta no movimento. Contudo, em fenômenos de sedimentação com alta concentração de partículas, a dissipação de energia ocorre não em um ambiente amplo, porém em um ambie nte restrito pela presença de sedimentos. Pode-se então considerar uma analogia com um escoamento confinado, no qual as variáveis devem ser relacionadas com a concentração de partículas. A equação para a força de arrasto em torno de corpos quaisquer é descrita como:

$$
F_{A}=C_{D} \cdot \rho \cdot \frac{V^{2}}{2} \cdot A
$$

A energia consumida ao longo de um deslocamento $\mathrm{L}$ pode ser quantificada pelo trabalho realizado, na forma:

$$
\text { Energia consumida }=F_{A} \cdot L=C_{D} \cdot \rho \cdot \frac{V^{2}}{2} \cdot A \cdot L
$$

Observa-se que a perda de energia é proporcional à própria energia cinética, que aparece na equação através do fator $V^{2} / 2$, sendo $V$ a velocidade relativa entre a partícula e o fluido. Na equação (5.31), $L$ é o comprimento a ser vencido e $A$ a área definida pela projeção frontal do corpo considerado. Para esferas, $A=\pi \cdot D^{2} / 4$, onde $D$ é o diâmetro da esfera. $\mathrm{O}$ termo $C_{D}$ é denominado coeficiente de arrasto, podendo ser variável ou constante, dependendo das condições do movimento. É interessante observar que o deslocamento $L$, no caso de sedimentação, incorpora informações geométricas acerca da própria existência de partículas no meio, o que pode ser relacionado com a concentração volumétrica das mesmas.

Ao longo da sedimentação natural de partículas, quando não existem perdas, há conservação de energia mecânica, ou seja, a soma das energias potencial e cinética mantém-se constante. Nessa situação hipotética, em havendo contínua perda de energia potencial (queda de partículas), deve ocorrer, em princípio, um aumento contínuo da energia cinética 
(velocidade). Todavia, no caso da sedimentação de uma partícula em fluido viscoso real, esta atinge rapidamente a velocidade de queda constante (velocidade terminal). Isto implica que, a partir de então, não há mais conversão de energia potencial em energia cinética. Em outras palavras, toda a energia potencial é perdida. Quando partículas se movem em conjunto, além da perda de toda a energia potencial, os rearranjos geométricos entre as partículas (adensamento) impõem uma perda adicional de energia cinética, que se observa na real diminuição da velocidade de sedimentação.

Considerando a observação de que, ao longo da queda conjunta de partículas, há rearranjos geométricos (adensamento) que induzem perda de energia cinética, podem-se tecer alguns comentários quanto à quantificação dessa perda de energia. Considerando a informação da equação (5.31), pode-se inicialmente propor a seguinte relação:

$$
d E=w_{1} \cdot m \cdot V^{2} / 2 \cdot d(1-\phi) \cdot L
$$

Na equação acima, w é uma constante de proporcionalidade que envolve também a massa específica ( $\rho$ ) do fluido e o diâmetro (D) das partículas, ambas grandezas conhecidas; $m$ é a massa da partícula. Em outras palavras, uma variação infinitesimal da energia (E) do conjunto de partículas, decorrente de uma variação infinitesimal do volume disponível (1- $\phi)$, é proporcional à energia cinética do conjunto de partículas. Contudo, a equação (5.31) envolve ainda a informação da dimensão L, vinculada ao espaço livre a ser vencido. Considerando as relações descritas pelas equações (5.28) e (5.29), pode-se dizer que $L$ deve ser função de (1- $\phi)$, muito embora a forma dessa função permaneça desconhecida. Utilizando expansão em série de potências, pode-se dizer que:

$$
L=\sum_{i=0}^{\infty} \alpha_{i} \cdot(1-\phi)^{i}
$$

Os coeficientes $\alpha_{i}$ são desconhecidos. Dessa série decorre que a equação (5.33), para seguir a forma da equação (5.32), pode ser reescrita na forma: 


$$
d E=w_{1} \cdot \sum_{i=0}^{\infty} \alpha_{i} \cdot(1-\phi)^{i} \cdot \frac{m \cdot V^{2}}{2} \cdot d(1-\phi)
$$

A velocidade relativa entre partículas de fluido confunde-se com a própria velocidade de queda das partículas quando se tem uma partícula única ou uma concentração volumétrica muito baixa. Porém, quando há partículas próximas entre si, ocorre um retardo no movimento de cada uma, que se reflete no movimento do conjunto de partículas. Considerando a conservação de massa, o fluido movimenta-se em sentido contrário ao das partículas e a velocidade relativa (V) é a soma, em módulo, das velocidades do fluido e das partículas $\left(\mathrm{V}_{\mathrm{p}}\right)$. No cálculo da perda de energia, continua sendo necessária a velocidade relativa, mas é mais adequado, neste desenvolvimento, escrever a equação (5.34) em termos da velocidade das partículas $\left(\mathrm{V}_{\mathrm{p}}\right)$. A relação entre $\mathrm{V}$ e $\mathrm{V}_{\mathrm{p}}$ pode ser obtida através do princípio de conservação de massa.

Considerando somente deslocamentos verticais, o uso da conservação integral de massa, para partículas em sedimentação, leva a uma dependência linear entre a velocidade de sedimentação e a concentração volumétrica. Para obter essa relação, seguem-se os esquemas da figura 5.9 .

(a)

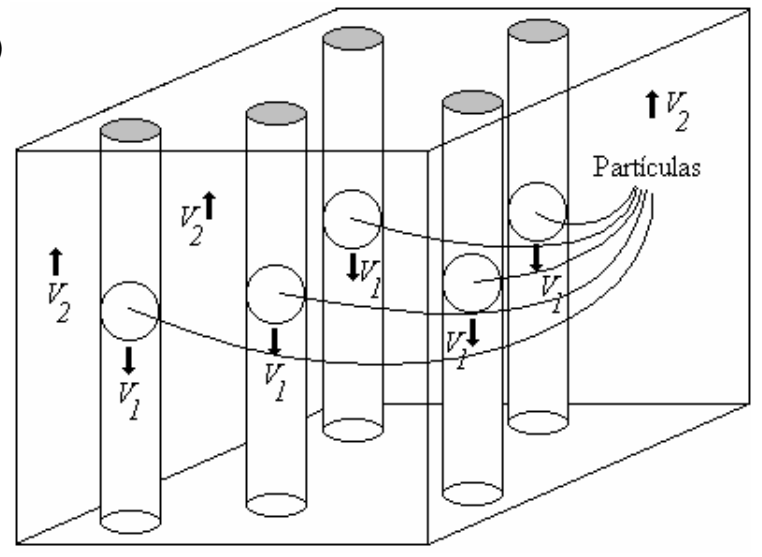

(b)

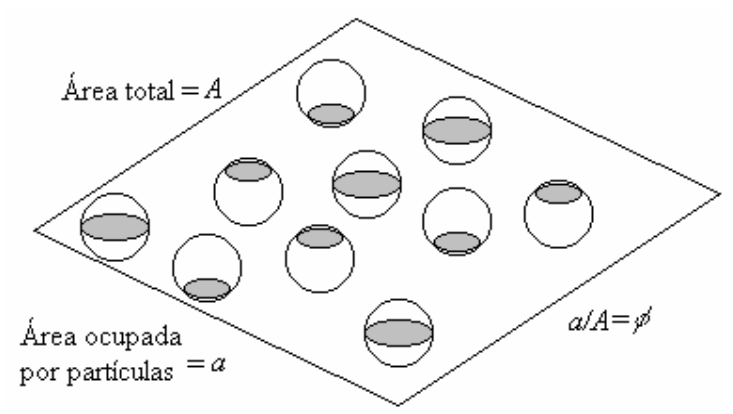

Figura 5.9 - (a) Esquema de sedimentação (para baixo $\left(V_{1}\right)$ ) e escoamento da água (para cima $\left.\left(V_{2}\right)\right)$; (b) Relação entre a área total ocupada pelas partículas e a área total do escoamento 
Da equação integral de conservação de massa e da equação (5.29):

$$
a V_{1}=A V_{2} \quad \text { ou } \quad \phi V_{1}=(1-\phi) V_{2}
$$

Em que:

- $\quad a$ = área ocupada pelas partículas;

- $\mathrm{A}=$ área total;

- $a / \mathrm{A}=\phi$.

A velocidade relativa, entre uma determinada partícula e o fluido, pode ser calculada pela Lei de Stokes $\left(\mathrm{V}_{\mathrm{o}}\right)$ (ver Revisão Bibliográfica). No presente caso, vale a seguinte relação:

$$
V_{o}=V_{1}+V_{2}
$$

Das equações $(5.35)$ e (5.36): $\quad V_{p}=V_{o} \cdot(1-\phi) \quad\left(\right.$ uma vez que $\left.\mathrm{V}_{1}=\mathrm{V}_{\mathrm{p}}\right)$

Assim, obtida a relação entre $\mathrm{V}$ e $\mathrm{V}_{\mathrm{p}}$, pode-se escrever a equação (5.34) em termos da velocidade da partícula, da seguinte forma:

$$
d E=w_{1} \cdot \frac{\sum_{i=0}^{\infty} \alpha_{i} \cdot(1-\phi)^{i}}{(1-\phi)^{2}} \cdot \frac{m \cdot V_{p}^{2}}{2} \cdot d(1-\phi)
$$

Contudo, a quantificação da energia consumida (trabalho realizado), feita pela equação (5.31), exige ainda o conhecimento do coeficiente de arrasto. Esse coeficiente assume valor constante para grandes valores do número de Reynolds $\left(V_{p} \cdot D / v\right)$, onde $v$ é a viscosidade cinemática do fluido. As maiores velocidades relativas são atingidas para as menores concentrações de partículas. Assim, caso se verifique a possibilidade de uso do coeficiente de arrasto constante, esta condição deverá ser válida para as menores concentrações de partículas. Por outro lado, o coeficiente de arrasto varia com o inverso do número de Reynolds quando este apresenta valores baixos (baixas velocidades), o que, na 
presente abordagem, é obtido para elevadas concentrações de partículas. Utilizando o fator $\mathrm{w}_{1}$ $\propto(V \cdot D)^{-1}$, considerando as equações (5.37) e (5.38), tem-se que:

$$
d E=w_{2} \cdot \frac{\sum_{i=1}^{\infty} \alpha_{i} \cdot(1-\phi)^{i}}{(1-\phi)^{2}} \cdot \frac{m \cdot V_{p}}{2} \cdot d(1-\phi)
$$

As formas das equações (5.38) e (5.39) diferem no expoente da velocidade. Evidentemente os coeficientes $\alpha_{i}$ também podem assumir valores diferentes. A equação (5.39) apresenta uma nova constante de proporcionalidade $\left(\mathrm{w}_{2}\right)$ que envolve o diâmetro das partículas e as propriedades físicas do fluido. Resumindo os desenvolvimentos deste item, a equação (5.38) é recomendada para baixas concentrações de partículas, enquanto que a equação (5.39) é recomendada para elevadas concentrações.

\subsection{2 - VELOCIDADE DE SEDIMENTAÇÃO E ENERGIA CINÉTICA}

O balanço de energia pode ser escrito, em função de $(1-\phi)$, como:

$$
\begin{aligned}
& E_{C}(1-\phi)+E_{P}(1-\phi)= \\
& =E_{C}(1-\phi-d(1-\phi))+E_{P}(1-\phi-d(1-\phi))+ \\
& +d E_{C}(1-\phi-d(1-\phi))+d E_{P}(1-\phi-d(1-\phi))
\end{aligned}
$$

$\mathrm{Na}$ equação acima, $E_{c}$ é a energia cinética e $E_{P}$ é a energia potencial. Como foi mencionado, a conversão de energia potencial em energia cinética implicaria em aumento de velocidade. Como isto não ocorre, toda a energia potencial é perdida e a equação (5.40) pode ser reescrita como:

$$
E_{C}(1-\phi)=E_{C}(1-\phi-d(1-\phi))+d E_{C}(1-\phi-d(1-\phi))
$$


Traduzindo em palavras, a energia cinética existente para a situação $(1-\phi)$ corresponde à energia que existia para a situação $(1-\phi-d(1-\phi))$ mais a variação de energia decorrente da variação do espaço livre $d(1-\phi)$. A soma das variações das energias cinética e potencial pode ser quantificada, matematicamente por:

$$
d E(1-\phi)=d E_{C}(1-\phi)+d E_{P}(1-\phi)
$$

A maneira mais simples de quantificar $\mathrm{dE}_{\mathrm{C}}$ e $\mathrm{dE}_{\mathrm{P}}$ separadamente é admitir que ambos sejam proporcionais a dE. Como na presente análise relaciona a energia cinética, basta admitir que:

$$
d E_{C}(1-\phi)=w_{3} \cdot d E(1-\phi)
$$

Note-se que w3 é uma constante de proporcionalidade.

\subsubsection{1 - Velocidade de sedimentação para coeficiente de arrasto constante (menores concentrações volumétricas)}

O manuseio das equações (5.38), (5.41) e (5.43) conduz à equação (5.44), na qual se utilizou $E_{C}(1-\phi)=\frac{m \cdot V_{p}^{2}(1-\phi)}{2}$ além das expansões em série de Taylor em torno de $(1-\phi)$, truncadas nos termos de primeira ordem:

$$
\begin{aligned}
& \frac{m V_{p}^{2}(1-\phi)}{2}=\left[\frac{m V_{p}^{2}(1-\phi)}{2}-\frac{d}{d(1-\phi)}\left(\frac{m V_{p}^{2}(1-\phi)}{2}\right) d(1-\phi)\right]+ \\
& \quad+\omega_{1} \omega_{3} \frac{\sum_{i=0}^{\infty} \alpha_{i}(1-\phi)^{i}}{(1-\phi)^{2}}\left[\frac{m V_{p}^{2}(1-\phi)}{2}-\frac{d}{d(1-\phi)}\left(\frac{m V_{p}^{2}(1-\phi)}{2}\right) d(1-\phi)\right] d(1-\phi)
\end{aligned}
$$


Os termos entre colchetes representam as expansões em série de Taylor mencionadas. Efetuando as simplificações possíveis e desconsiderando parcelas com produtos de termos infinitesimais, resulta:

$$
\frac{d V_{p}^{2}(1-\phi)}{V_{p}^{2}(1-\phi)}=w_{1} w_{3} \frac{\sum_{i=0}^{\infty} \alpha_{i}(1-\phi)^{i}}{(1-\phi)^{2}} d(1-\phi)
$$

Definindo novos coeficientes $\beta_{\mathrm{i}}$ como $\beta_{i}=w_{1} w_{3} \alpha_{i}$, pode-se apresentar a solução da equação (5.46) como:

$$
V_{p}=w_{4} \cdot e^{\left(-\frac{\beta_{o}}{2} \cdot \frac{\phi}{1-\phi}\right)} \cdot(1-\phi)^{\beta_{1} / 2} \cdot \prod_{i=2}^{\infty} e^{\left[\frac{\beta_{i}}{2}(1-\phi)^{i-1}\right]}
$$

$\mathrm{Na}$ equação acima, $w_{4}$ é uma nova constante de integração. A equação (5.47) é muito interessante para análises acerca do comportamento da velocidade de sedimentação. Por exemplo:

- Os expoentes dos diferentes fatores envolvem coeficientes que englobam características do meio fluido e o diâmetro das partículas, não sendo, portanto, valores numéricos universais;

- É possível cobrir todo o domínio sobre o qual $\phi$ varia, ou seja de 0 a 1 .

Trata-se, entretanto, de um produtório com infinitos termos. Para uma análise mais simplificada, convém truncar a solução nos termos de menor ordem e verificar o comportamento da resposta. A constante de integração $\left(\mathrm{w}_{4}\right)$ deve ser ajustada de forma a garantir a velocidade terminal $\left(\mathrm{V}_{\mathrm{o}}\right)$ para concentrações volumétricas nulas $(\phi=0)$. Seguindo esta proposta, os truncamentos de ordem zero e de ordem um, levam respectivamente a:

$$
\begin{aligned}
& V_{p} / V_{o}=e^{\left(-\frac{\beta_{o}}{2} \cdot \frac{\phi}{1-\phi}\right)} \\
& V_{p} / V_{o}=e^{\left(-\frac{\beta_{o}}{2} \cdot \frac{\phi}{1-\phi}\right)} \cdot(1-\phi)^{\beta_{1} / 2}
\end{aligned}
$$


Para truncamentos de ordem N, superiores a um, a equação (5.47) toma a seguinte forma genérica:

$$
\frac{V_{p}}{V_{o}}=e^{\left[-\left(\sum_{i=2}^{N} \frac{\beta_{i}}{2}\right)\right]} \cdot e^{\left[-\frac{\beta_{o}}{2} \cdot \frac{\phi}{1-\phi}\right]} \cdot(1-\phi)^{\frac{\beta_{1}}{2}} \cdot \prod_{i=2}^{N} e^{\left[\frac{\beta_{i}}{2}(1-\phi)^{i-1}\right]}
$$

5.7.2.2 - Velocidade de sedimentação para coeficiente de arrasto variando com o inverso do número de Reynolds (maiores concentrações volumétricas)

O manuseio das equações (5.39), (5.41) e (5.43) leva à equação (5.51), na qual novamente se utilizou $E_{C}(1-\phi)=\frac{m \cdot V_{p}^{2}(1-\phi)}{2}$ e a expansão em série de Taylor com truncamento de primeira ordem:

$$
\begin{aligned}
& \frac{m V_{p}^{2}(1-\phi)}{2}=\left[\frac{m V_{p}^{2}(1-\phi)}{2}-\frac{d}{d(1-\phi)}\left(\frac{m V_{p}^{2}(1-\phi)}{2}\right) d(1-\phi)\right]+ \\
& \quad+\omega_{2} \omega_{3} \frac{\sum_{i=1}^{\infty} \alpha_{i}(1-\phi)^{i}}{(1-\phi)^{2}}\left[\frac{m V_{p}(1-\phi)}{2}-\frac{d}{d(1-\phi)}\left(\frac{m V_{p}(1-\phi)}{2}\right) d(1-\phi)\right] d(1-\phi)
\end{aligned}
$$

Efetuando as simplificações possíveis e desconsiderando as parcelas com produtos de termos infinitesimais, resulta:

$$
d V_{p}(1-\phi)=\frac{w_{2} w_{3}}{2} \frac{\sum_{i=1}^{\infty} \alpha_{i}(1-\phi)^{i}}{(1-\phi)^{2}} \cdot d(1-\phi)
$$

Definindo novos coeficientes $\gamma_{i}=w_{2} w_{3} \alpha_{i} / 2$, a solução da equação (5.52) é:

$$
V_{p}=-\frac{\gamma_{o}}{1-\phi}+\gamma_{1} \cdot \ln (1-\phi)+\sum_{i=2}^{\infty} \gamma_{i} \cdot(1-\phi)^{i-1}+w_{5}
$$


Note-se que $\mathrm{w}_{5}$ é uma nova constante de integração. A equação (5.53) deve ser aplicável, segundo a hipótese, para $\phi$ ? 1, o que faz com que $w_{5}, \gamma_{0}$ e $\gamma_{1}$ se igualem a zero. Resta, portanto, um somatório de potências de $(1-\phi)$, de acordo com a seguinte equação:

$$
V_{p}=\sum_{i=2}^{\infty} \gamma_{i} \cdot(1-\phi)^{i-1}
$$

Na equação (5.54), as constantes ainda podem ser ajustadas (caso seja desejado) para representar a velocidade terminal $\left(\mathrm{V}_{\mathrm{o}}\right)$ para $\phi=0$. Embora elaborada para as maiores concentrações, ou seja $\phi$ ? 1, esta forma de abordagem pode cobrir continuamente toda a faixa de variação de $\phi$.

\subsection{3 - CALIBRAÇÃO DAS EQUAÇÕES PROPOSTAS}

Os desenvolvimentos analíticos descritos nos itens anteriores produziram duas formas explícitas (equações (5.50) e (5.54)) para quantificar a variação da velocidade de sedimentação com a concentração de partículas. Note-se ainda que a equação (5.54) é apenas recomendada para concentrações volumétricas tendendo ao limite máximo $(\phi$ ? 1). Diante desses fatos, torna-se muito oportuno e conveniente comparar a solução analític a fornecida pela equação (5.50) com dados experimentais e outras formulações empíricas e semiempíricas apresentadas na literatura.

Uma primeira análise utilizou dados experimentais de sedimentação de areias (TOMKINS et al., 2004), de forma a calibrar a equação proposta, além de verificar a ordem de truncamento que melhor se acomoda a esses dados. Os resultados desta análise são fornecidos pela figura 5.10. 


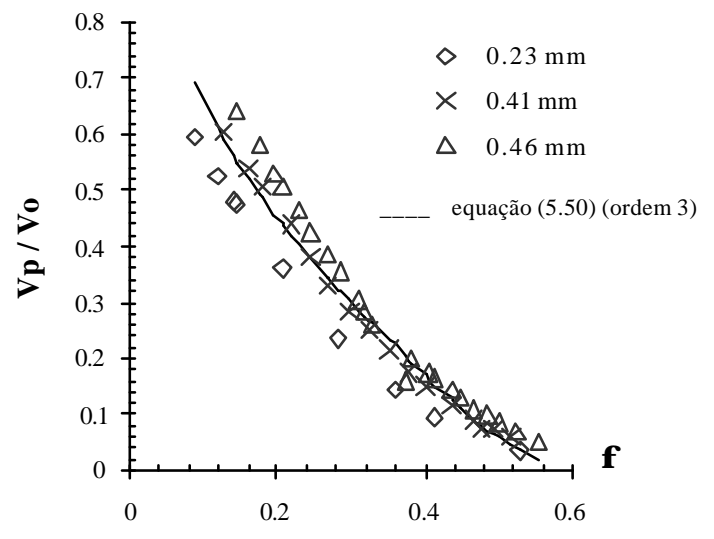

Figura 5.10 - Ajuste da equação proposta aos dados experimentais de Tomkins et al. (2004) para sedimentação de areias

Conforme ilustra a figura 5.10, a equação (5.50) se ajusta bem aos dados experimentais, bastando utilizar pequenas ordens de truncamento. $\mathrm{O}$ truncamento de terceira ordem conduziu ao melhor ajuste da curva. A tabela 5.1 fornece os valores dos parâmetros ajustados pela referida calibração.

Tabela 5.1 - Parâmetros calibrados com base nos dados experimentais de Tomkins et al. (2004) com truncamento de terceira ordem

\begin{tabular}{c|c}
\hline \hline$\beta_{\mathrm{o}}$ & 35,12583 \\
\hline$\beta_{1}$ & $-82,71052$ \\
\hline$\beta_{2}$ & 52,64647 \\
\hline$\beta_{3}$ & 2,07103 \\
\hline \hline
\end{tabular}

A curva obtida com os parâmetros ajustados também fornece boa concordância com formulações empíricas e semi-empíricas encontradas na literatura, conforme ilustra a figura 5.11 .

Ainda que as análises realizadas anteriormente conduzam a resultados ajustáveis aos experimentais, um estudo mais refinado pode ser conduzido, de forma a prever a variação dos parâmetros da equação proposta com o diâmetro das partículas (hipótese também apresentada 
na dedução analítica). Em estudo recente, Baldock et al. (2004) apresentaram resultados experimentais que confirmam essa hipótese.

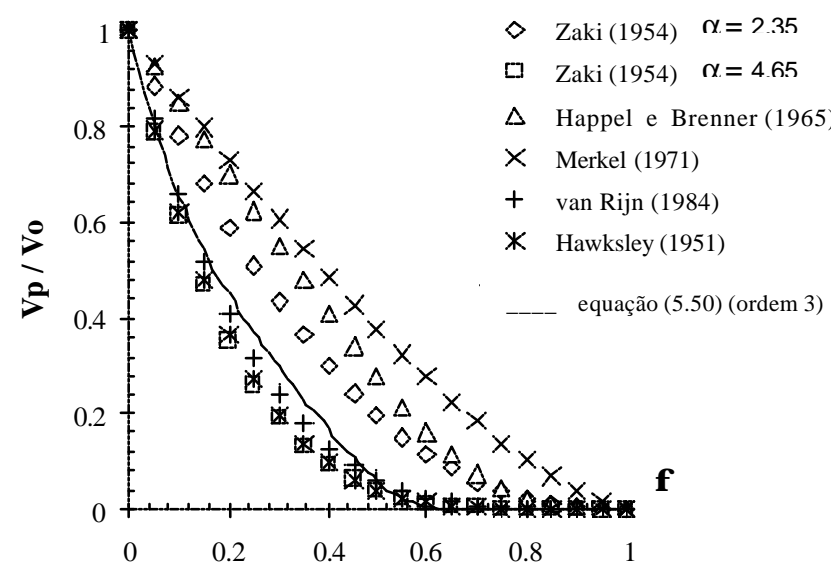

Figura 5.11 - Comparação da equação analítica proposta com relações empíricas e semiempíricas

(a)

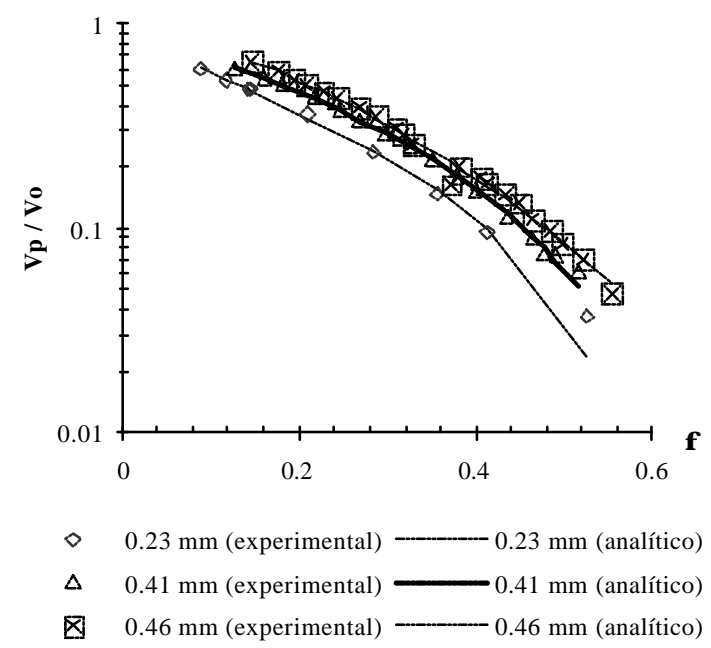

(b)

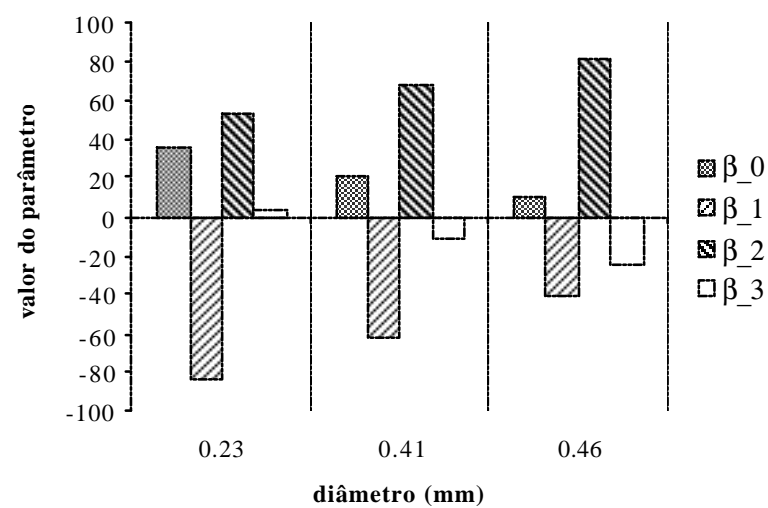

Figura 5.12 - (a) curvas analíticas ajustadas para sedimentação de areias com diferentes diâmetros;

(b) variação dos parâmetros da equação analítica proposta com o diâmetro da partícula de areia

Seguindo esta idéia, a figura 5.12 apresenta resultados do ajuste da equação sugerida a dados experimentais de areias com diferentes diâmetros (BALDOCK et al., 2004). Note-se 
que, para cada diâmetro, pode-se ajustar perfeitamente uma curva particular. Note-se ainda que os parâmetros apresentam também sensível variação com o diâmetro da partícula.

Outras equações ainda podem ser obtidas, permitindo relacionar cada parâmetro com o diâmetro da partícula. Os dados disponíveis sugerem ajustes por polinômios de segunda ordem, os quais estão relacionados na tabela 5.2.

Tabela 5.2 - Variação dos parâmetros da equação (5.50) com o diâmetro da partícula de areia em sedimentação

\begin{tabular}{l|l}
\hline \hline$\beta_{0}(\mathrm{D})$ & $-734,93 \cdot D^{2}+398,47 \cdot D-17,888$ \\
\hline$\beta_{1}(\mathrm{D})$ & $1209,80 \cdot D^{2}-653,97 \cdot D+3,873$ \\
& $840,89 \cdot D^{2}-454,32 \cdot D+113,05$ \\
\hline$\beta_{2}(\mathrm{D})$ & $-734,66 \cdot D^{2}+391,31 \cdot D-47,928$ \\
\hline$\beta_{3}(\mathrm{D})$ & \\
\hline \hline
\end{tabular}

As relações obtidas nesta seção demonstram que a variação da velocidade de sedimentação depende não somente da concentração de partículas, mas também do seu diâmetro. A função analítica obtida (equação (5.50)) permite abranger todos os cenários, de acordo com o ajuste adequado de seus parâmetros. De especial interesse são as relações fornecidas pela tabela 5.2, permitindo generalizar casos práticos de sedimentação de areias.

Outrossim é possível verificar que a equação proposta apresenta coerência para menores ordens de truncamento. Baldock et al. (2004), apresentaram uma breve revisão de literatura que se baseia na proposição semi-empírica de Richardson e Zaki (1954), a qual também pode ser obtida da equação (5.50) com truncamento de segunda ordem, impondo $\beta_{o}=\beta_{2}=0$. Tem-se, neste caso:

$$
V_{p} / V_{o}=(1-\phi)^{\beta_{1}} / 2
$$

Hawksley (1951), citado por Wan e Wang (1994), apresentou uma interessante equação, representada com as constantes aqui definidas: 


$$
V_{p} / V_{H}=\xi \cdot e^{\left(-\frac{\beta_{o}}{2} \cdot \frac{\phi}{1-k \cdot \phi}\right)} \cdot(1-\phi)^{2}
$$

A equação (5.50) é muito semelhante à equação (5.49) (truncamento de primeira ordem), considerando $\beta_{1}=4$ e $V_{o}=V_{H} \xi$. Para Hawksley, o fator $\xi$ vale $2 / 3$ para eventos com floculação e 1 para eventos sem floculação, $\beta_{o}=5$ para esferas e $k=39 / 64$ em qualquer situação. Na presente dedução evidentemente tem-se $k=1$ e $\xi=1$.

Assim, o presente trabalho não apenas resgatou uma formulação não divulgada, mas desenvolveu a mesma em detalhes. As análises mostraram que a referida formulação generaliza uma série de proposições semi-empíricas vistas na literatura de sedimentação, bastando considerar as menores ordens de truncamento. $\mathrm{O}$ trabalho de recuperação de dados de sedimentação, bem como de comparação entre resultados experimentais e o equacionamento teórico com coeficientes ajustados, representou uma investigação voltada para aspectos fenomenológicos reais, que mostram a preocupação existente com o entendimento físico dos problemas estudados.

\section{8 - ANÁLISE DA VARIAÇÃO DA FORMA DE FUNDO}

Um dos avanços principais desenvolvidos neste trabalho consiste na avaliação da evolução da concentração de sedimentos transportados pelo escoamento e, concomitantemente, na estimativa de eventuais variações da altura dos depósitos. Assim, a conformação de fundo dos canais, decorrente da sobreposição dos processos de erosão e sedimentação, é atualizada a cada passo de tempo. Os princípios básicos para avaliar essas alterações são a conservação de massa, aplicada às células adjacentes ao leito, além do já comentado fluxo de massa de ressuspensão. A estimativa da posição dos depósitos de sedimento é, na prática, a locação da malha lagrangeana, em se utilizando o Método de Fronteira Imersa.

A aplicação de um balanço de massa nas células adjacentes ao leito permite estimar se existe um fluxo resultante de sedimentação ou de ressuspensão, o qual irá determinar a nova posição da malha lagrangeana. Este balanço utiliza os fluxos de massa advectivos e difusivos, conforme ilustra a figura 5.13. É comum encontrar na literatura de transporte de sedimentos 
equações que levam em conta apenas o fluxo advectivo de massa. O exemplo talvez mais comum seja a chamada equação de Exner que, na sua forma mais tradicional é aplicada para escoamentos integrados na vertical (ao longo da profundidade). Todavia, é aconselhável impor um nível de detalhamento maior quando o balanço é feito num elemento infinitesimal, neste caso, numa célula próxima ao leito. Este detalhamento acrescenta ambém os fluxos difusivos, os quais não podem ser desprezados nas proximidades dos leitos dos canais.

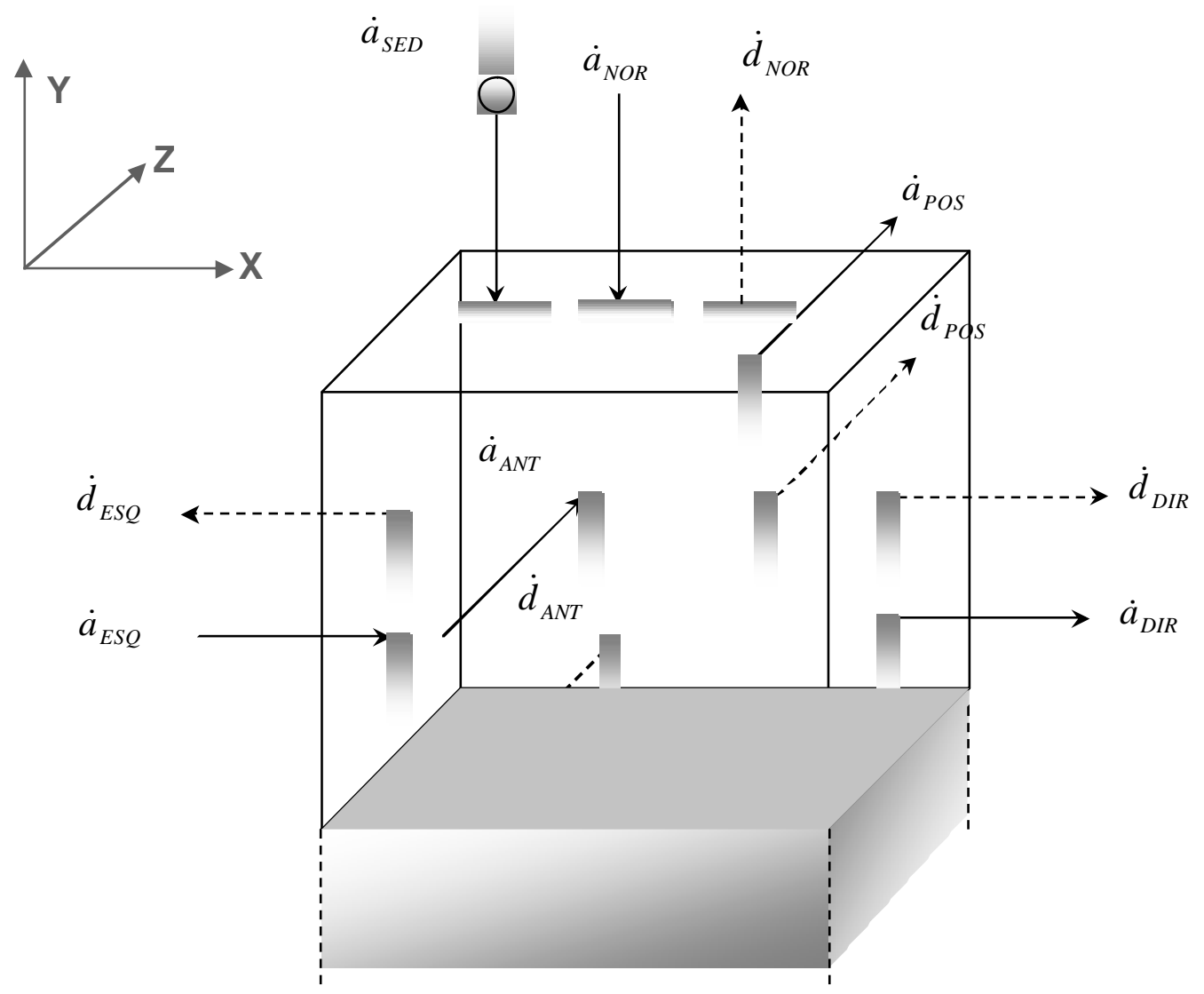

Figura 5.13 - Fluxos advectivos $(\dot{a})$ e difusivos $(\dot{d})$ de sedimentos nas faces das células adjacentes ao leito do canal

Seguindo o esquema da figura 5.13, cada fluxo de massa pode ser calculado como:

- $\quad \dot{a}_{D I R}=u_{i, j+1, k} \cdot c_{D I R}$

- $\quad \dot{a}_{E S Q}=u_{i, j, k} \cdot c_{E S Q}$

- $\quad \dot{a}_{A N T}=w_{i, j, k} \cdot c_{A N T}$;

- $\quad \dot{a}_{P O S}=w_{i, j, k+1} \cdot c_{P O S}$ 
- $\quad \dot{a}_{N O R}=v_{i-1, j, k} \cdot c_{N O R}$;

- $\quad \dot{a}_{N O R}=w_{s} \cdot c_{N O R}, \quad$ em que: $w_{s}=$ velocidade de sedimentação $\left[\mathrm{LT}^{-1}\right]$;

- $\dot{d}_{D I R}=D_{E F} \cdot \frac{c_{i, j, k}-c_{i, j+1, k}}{\Delta x}$

- $\dot{d}_{E S Q}=D_{E F} \cdot \frac{c_{i, j, k}-c_{i, j-1, k}}{\Delta x}$

- $\dot{d}_{A N T}=D_{E F} \cdot \frac{c_{i, j, k}-c_{i, j, k-1}}{\Delta z}$

- $\dot{d}_{P O S}=D_{E F} \cdot \frac{c_{i, j, k}-c_{i, j, k+1}}{\Delta z}$

- $\dot{d}_{N O R}=D_{E F} \cdot \frac{c_{i, j, k}-c_{i-1, j, k}}{\Delta y}$

Note-se que, por uma convenção geral, o fluxo difusivo é considerado positivo quando sai da célula. O fluxo difusivo na face inferior, que representa o leito do canal, foi desconsiderado porque, nessa posição, a difusividade turbulenta sub-malha é teoricamente nula e os efeitos da difusão molecular são irrelevantes quando comparados à difusão turbulenta. Assim, um fluxo resultante, em cada célula próxima do leito, pode ser calculado como:

$$
\dot{d}_{R E S}=\left(\dot{a}_{E S Q}+\dot{a}_{A N T}+\dot{a}_{S E D}\right)-\left(\dot{a}_{D I R}+\dot{a}_{P O S}+\dot{a}_{N O R}+\dot{d}_{D I R}+\dot{d}_{E S Q}+\dot{d}_{N O R}+\dot{d}_{A N T}+\dot{d}_{P O S}\right)
$$

Por uma breve análise do equacionamento acima, se $\dot{d}_{R E S}>0$, há um acúmulo de material na célula (formação de depósito). Por outro lado, se $\dot{d}_{R E S}<0$, existe um déficit de sedimento na célula (erosão). Todavia, os fluxos de massa relacionados pela equação (5.57) somente são diferentes de zero se existir concentração de sedimentos nas células vizinhas do fundo do canal. Conforme já foi comentado nos itens anteriores, o leito também pode atuar como uma fonte de sedimentos, quando condições cisalhantes críticas são sobrepujadas. Isto condiciona um fluxo adicional de ressuspensão $\left(\dot{f}_{R E S S}\right)$ que, somado ao fluxo resultante da equação 5.57), origina um fluxo de massa global. Com este fluxo de massa é possível calcular a variação local de cota do leito, de acordo com: 
$\Delta_{1}=\frac{\left(\dot{d}_{R E S}-\dot{f}_{R E S S}\right) \cdot \Delta t}{\rho_{s} \cdot(1-\lambda)}$

Em que:

- $\rho_{s}=$ massa específica do sedimento $\left[\mathrm{ML}^{-3}\right]$;

- $\lambda=$ porosidade dos depósitos;

- $\Delta_{1}=$ variação da cota do leito [L].

Por uma breve análise da equação (5.58) pode-se concluir que:

- se $\Delta_{1}>0$ : o leito ganhou material (formação de depósito);

- $\quad$ se $\Delta_{1}<0$ : houve perda de material do leito (erosão).

Ainda na equação (5.58), o sinal negativo foi introduzido para representar corretamente o efeito erosivo decorrente do fluxo $\dot{f}_{R E S S}$. A porosidade dos depósitos depende fundamentalmente do diâmetro do sedimento, além de outros fatores como a forma da partícula, e pode ser estimada pela seguinte relação empírica (KOMURA, 1961), escrita para depósitos de sedimentos saturados de água:

$$
\lambda=0,245+0,0864 \cdot D^{-0,21} \quad, \operatorname{com} 4 \cdot 10^{-4} \leq D \leq 30 \mathrm{~mm}
$$

Em que: $D=$ diâmetro médio (em centímetros) dos sedimentos $\left(D_{50}\right)[\mathrm{L}]$.

Em síntese, os desenvolvimentos conduzidos até aqui explicitaram duas formas de variação da forma de fundo:

- por balanço de massa quando há fluxos de sedimentos que cruzam as faces das células adjacentes ao leito;

- por cisalhamento quando a velocidade crítica de para iminência de erosão é superada.

Finalmente, as variações locais das cotas da malha lagrangeana podem ser obtidas pela sobreposição desses dois efeitos, ou, matematicamente: 


$$
y_{k}^{n+1}=y_{k}^{n}+\left(\Delta_{1}\right)
$$

Em que:

- $n$ = nível de tempo;

- $y_{k}=$ cota do ponto lagrangeano $k$ ( altura do leito) [L].

É importante comentar que, em decorrência das análises conduzidas nessa seção, o ponto lagrangeano $k$ deve estar localizado na projeção do centro de cada célula adjacente ao leito. Isto pode ser melhor ilustrado pela figura 5.14, a qual demonstra haver uma certa equivalência entre as posições $x_{k}$ e $z_{k}$ (coordenadas longitudinais e transversais, respectivamente) da malha lagrangeana e as posições $x$ e $z$ (centro das células) da malha euleriana. Em contrapartida, a altura da malha lagrangeana $\left(y_{k}\right)$ é independente da malha de discretização, sendo determinada exclusivamente pelos eventuais processos de deposição e erosão estimados

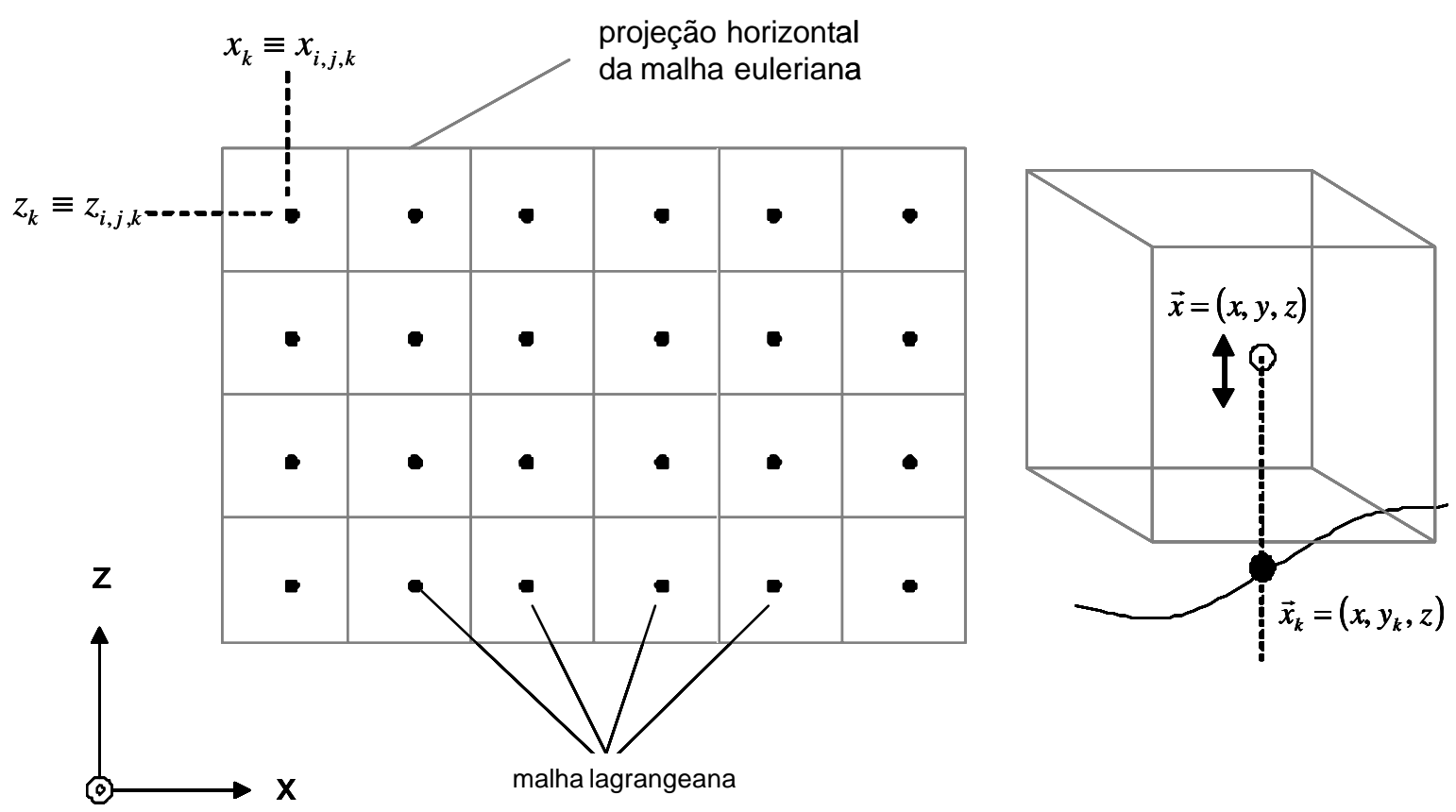

Figura 5.14 - Equivalência entre as malhas lagrangeana e euleriana. O ponto lagrangeano $k$, onde é feita a análise de variação de cota, apresenta as mesmas coordenadas x e z (longitudinal e transversal) do centro da célula adjacente. Apenas é permitida a variação da cota $y_{k}$, a qual é calculada de acordo com os métodos descritos 


\section{9 - FLUXOGRAMA GLOBAL DE CÁLCULO}

Apesar de reunir uma vasta gama de metodologias específicas, o código computacional desenvolvido neste trabalho pode ser estruturado de acordo com o fluxograma ilustrado a pela figura 5.15.

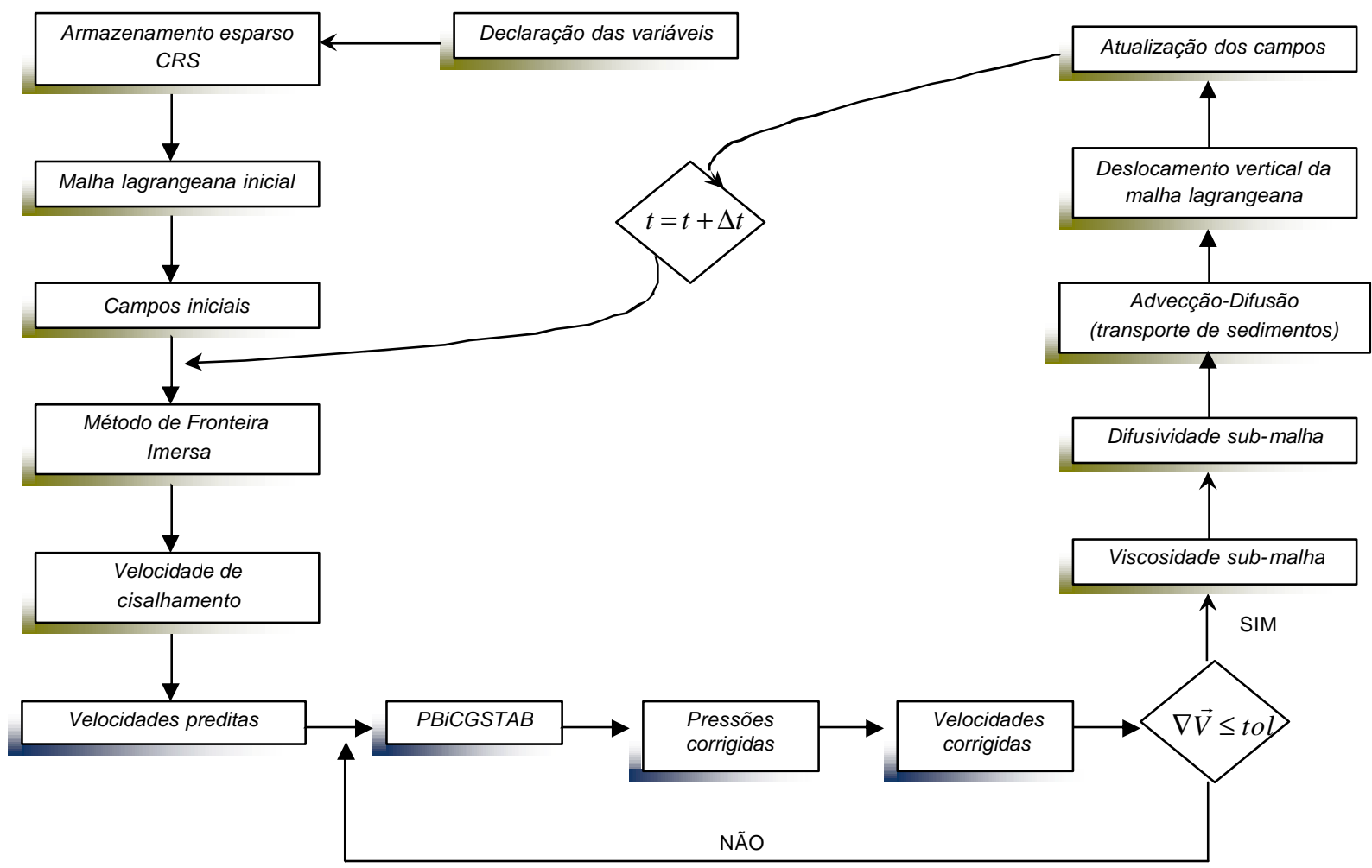

Figura 5.15 - Fluxograma resumo do código computacional 


\section{$6 \quad$ Resultados}

Neste capítulo resumem-se os detalhes da montagem e os resultados das simulações realizadas. Vale ressaltar que, no decorrer da pesquisa, as primeiras simulações abrangeram casos mais simplificados, fato que permitiu um melhor aprendizado e fixação dos métodos descritos no capítulo anterior. Naturalmente partiu-se dos casos mais simples até que fossem atingidos os casos tridimensionais mais complexos. Dessa maneira, inicialmente são apresentadas simulações de casos mais elementares, os quais propiciaram o confronto da metodologia utilizada com resultados analíticos e experimentais. Além disso, a apresentação de casos gradativamente mais complexos é bastante oportuna, uma vez que permite visualizar a sequiência natural desenvolvida pelo modelador ao longo dos trabalhos. Ainda assim, a passagem do código para problemas tridimensionais demandou uma série de simulações "teste" ou "intermediárias" sujeitas a ajustes, até alcançar os casos apresentados a seguir. De maneira geral, todas as simulações seguiram procedimentos semelhantes no que diz respeito ao tratamento do domínio de escoamento. A rigor foram modificadas, nos diferentes casos, as condições hidrodinâmicas e de concentração (dados de entrada ou condições de contorno).

No processamento dos códigos computacionais, referentes às simulações aqui apresentadas, foram utilizados os computadores Pentium $4(3.2 \mathrm{GHz})$ e Xeon $(3.2 \mathrm{GHz})$, separadamente, cada um com 1.0 GB de memória RAM. Não houve qualquer forma de processamento paralelo.

\section{1 - ESCOAMENTO ENTRE PLACAS PLANAS PARALELAS}

É conveniente lembrar que a busca de soluções analíticas para as equações de NavierStokes requer a imposição de uma série de condições simplificadoras, as quais não são aconselhadas para a solução de escoamentos reais. Ainda assim, esses casos, extremamente simplificados, são interessantes no contexto de permitir parâmetros comparativos para modelos numéricos mais complexos. O escoamento laminar entre placas planas paralelas, que 
sob condições de gradiente de pressão constante é também chamado de escoamento de Poiseuille, é um dos poucos casos onde uma série de simplificações torna viável a solução analítica das equações de Navier-Stokes. Diante disso, pode-se, por exemplo, verificar o comportamento do Método de Fronteira Imersa na modelagem virtual de paredes sólidas. A comparação com a solução analítica introduz um crédito para aplicação do modelo em casos mais próximos da realidade.

Neste exemplo, o domínio real de escoamento, representado pela figura 6.1, é estendido para um domínio computacional com a parede inferior modelada como fronteira imersa.

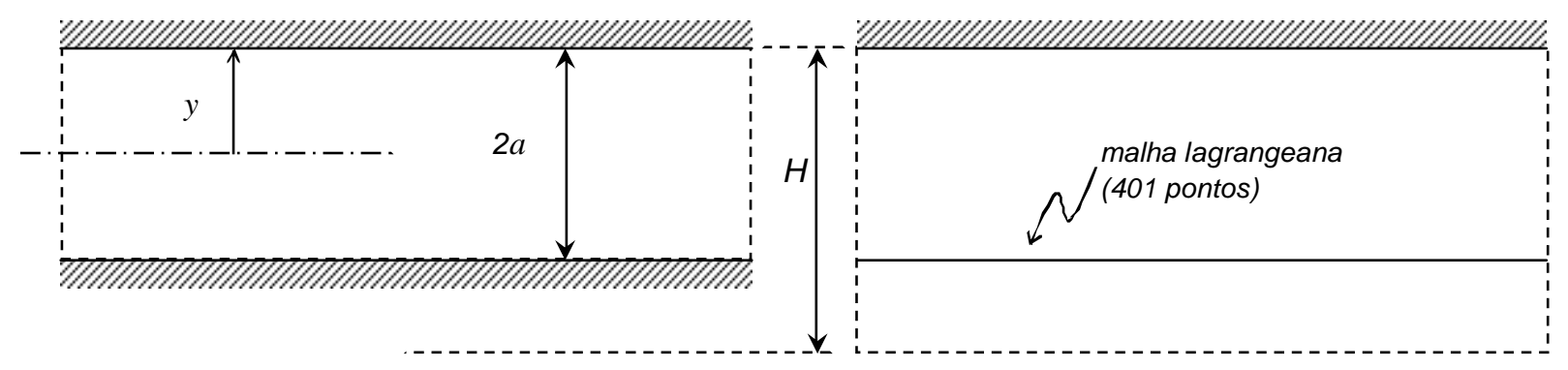

Figura 6.1 - Escoamento entre placas planas paralelas com domínio de escoamento estendido e parede inferior modelada pela malha lagrangeana

A solução analítica deste escoamento é fornecida por:

$$
u=-\frac{\partial p}{\partial x} \cdot \frac{a^{2}}{2 \cdot \mu} \cdot\left(1-\frac{y^{2}}{a^{2}}\right)
$$

Em que:

$$
\begin{aligned}
& \text { - } \frac{\partial p}{\partial x}=\text { gradiente de pressão }\left[\mathrm{ML}^{-2} \mathrm{~T}^{-2}\right] ; \\
& \text { - } \mu=\text { viscosidade dinâmica do fluido }\left[\mathrm{ML}^{-1} \mathrm{~T}^{-1}\right] .
\end{aligned}
$$

Dentre as simplificações necessárias para a obtenção da equação (6.1) citam-se a laminaridade do escoamento, o gradiente de pressão constante e a variação preponderante das grandezas (velocidade e pressão) na direção longitudinal.

Para efeito da simulação numérica, todo o domínio computacional foi discretizado por uma malha cartesiana de $200 \times 50$ células com dimensões $\Delta x=0,005 \mathrm{me} \Delta y=0,001 \mathrm{~m}$, enquanto que a malha lagrangeana foi constituída por 401 pontos espaçados de $\Delta x / 2$. 
Considerou-se um escoamento de água a uma temperatura de $20^{\circ} \mathrm{C}$, o que fornece uma viscosidade dinâmica fixa de $\mu=10^{-3} \mathrm{Kg} /(\mathrm{m} . \mathrm{s})$. Um perfil uniforme de velocidade foi imposto na entrada do domínio de forma a gerar um número de Reynolds igual a 40 ( $R e=40$, levando em conta a largura da região de interesse do escoamento). A parede superior foi modelada como fronteira sólida clássica, enquanto que condições de simetria foram impostas na fronteira lateral inferior. Vale lembrar que condições simétricas impõem gradientes normais nulos para as velocidades longitudinais e estabelece a inexistência de fluxo de massa perpendicular ao eixo de simetria. Derivadas normais nulas foram adotadas na saída do domínio. Como condição inicial, o mesmo perfil de velocidade da entrada foi adotado em toda a região de escoamento. A simulação "caminhou" em marcha temporal, pelo esquema explícito de Adams-Bashforth de segunda ordem, até atingir o regime permanente. Os passos de tempo foram levemente incrementados de $10^{-4} \mathrm{~s}$ (nos níveis iniciais) até um valor máximo de $5.10^{-2} \mathrm{~s}$. O uso de passos de tempo menores no início da simulação é uma alternativa interessante para um reconhecimento mais suave da fronteira imersa pelo fluido.

A figura 6.2 ilustra o perfil de velocidade simulado, juntamente com o campo de força disseminado dentro do domínio estendido (inclusive na região inferior que não é de interesse final).

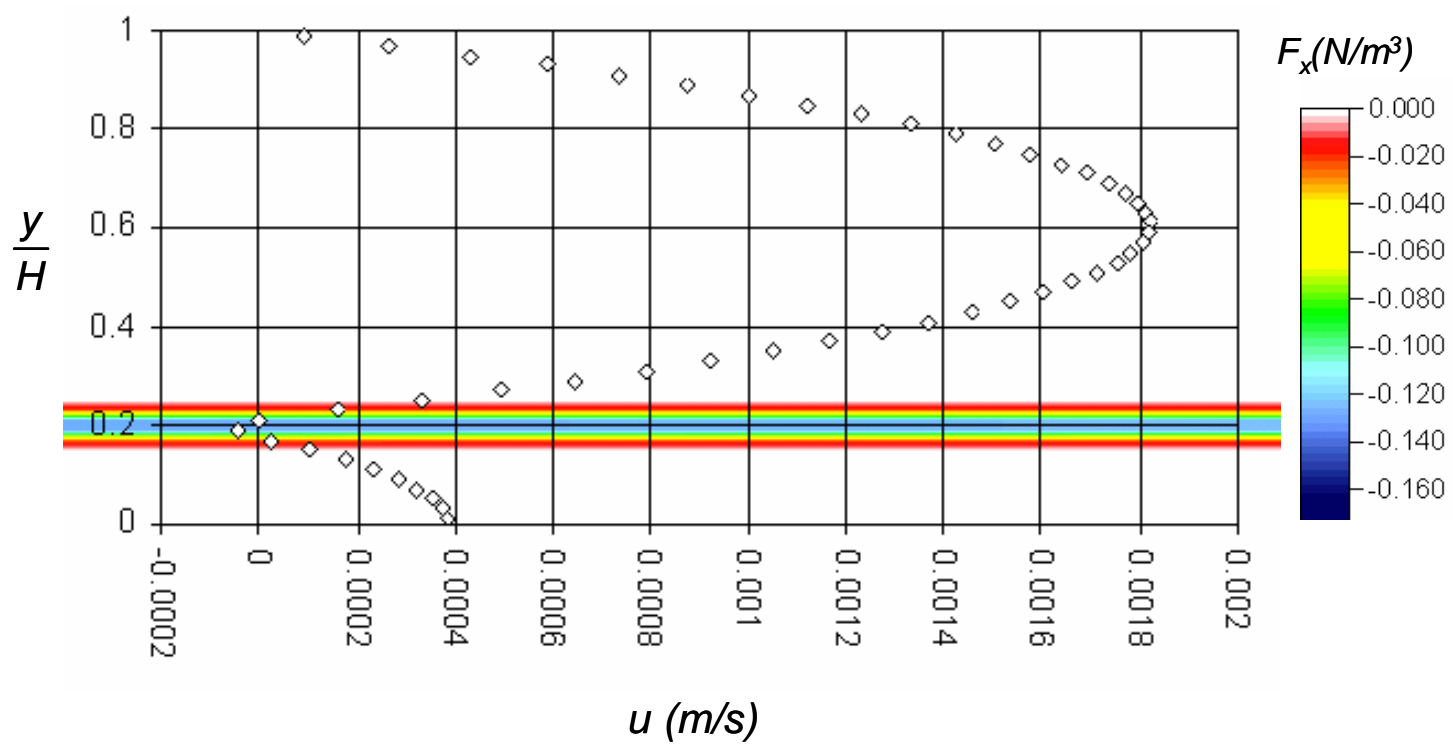

Figura 6.2 - Perfil de velocidade e campo de força euleriano no regime permanente

É interessante notar que, neste caso, o campo de força longitudinal $\left(F_{x}\right)$ é negativo. Isto indica uma propensão de frear o fluido na vizinhança da malha lagrangeana, impondo 
virtualmente a condição de não deslizamento. O campo de força vertical $\left(F_{y}\right)$, por sua vez, é anulado à medida que o escoamento se desenvolve longitudinalmente. Esta tendência é natural, uma vez que as componentes verticais de velocidade são nulas no escoamento completamente desenvolvido. Nessa situação, a pressão decai linearmente na direção longitudinal, acarretando um gradiente constante. É também conveniente comentar que o Método de Fronteira Imersa busca impor a condição de não deslizamento sobre a malha lagrangeana, mas não consegue eliminar completamente a velocidade sobre a fronteira. Como qualquer método numérico há o surgimento de resíduos, de forma que a velocidade do fluido sobre a interface, apesar de bem próxima, não é exatamente igual à velocidade da interface. Assim, os resíduos do Método de Fronteira Imersa podem ser sintetizados pelo fator $L_{2}$, calculado, para casos bidimensionais como este, como:

$$
L_{2}=\sqrt{\sum_{k} \frac{u_{k}^{2}+v_{k}^{2}}{N_{k}}}
$$

Em que:

- $u_{k}, v_{k}=$ componentes de velocidade do fluido sobre a interface $\left[\mathrm{LT}^{-1}\right]$;

- $\quad N_{k}=$ número total de pontos lagrangeanos.

A figura 6.3 ilustra o decaimento e a estabilização do fator $L_{2}$ quando o escoamento tende ao regime permanente.

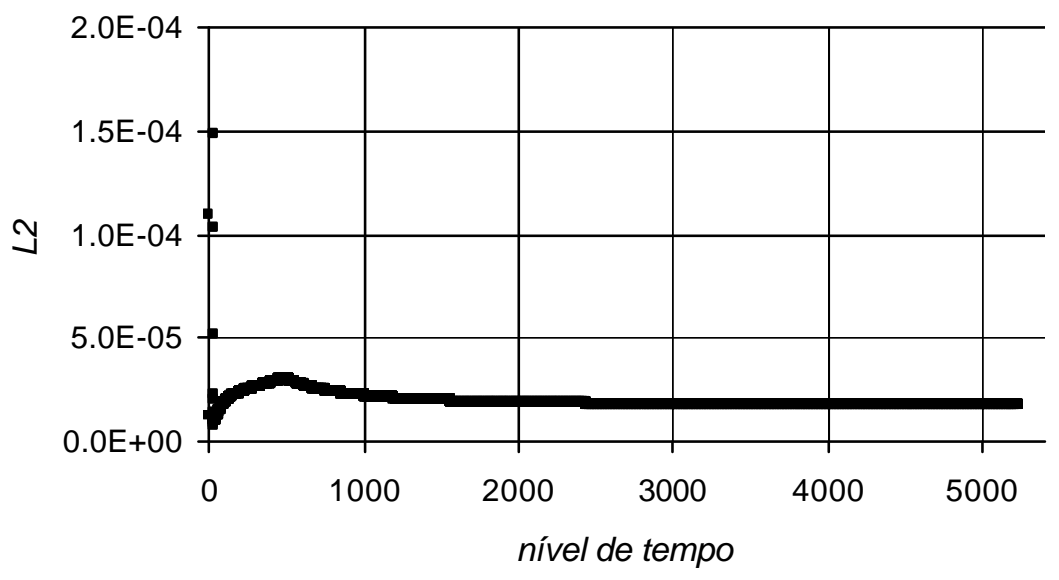

Figura 6.3 - Variação temporal do fator $L_{2}$ para o escoamento entre placas paralelas 
A presente simulação demonstrou que, apesar da existência de resíduos, o Método de Fronteira Imersa foi fidedigno na reprodução do efeito da parede inferior, fato que pode ser ainda destacado pela comparação entre os resultados numéricos simulados e a solução analítica (ver figura 6.4).
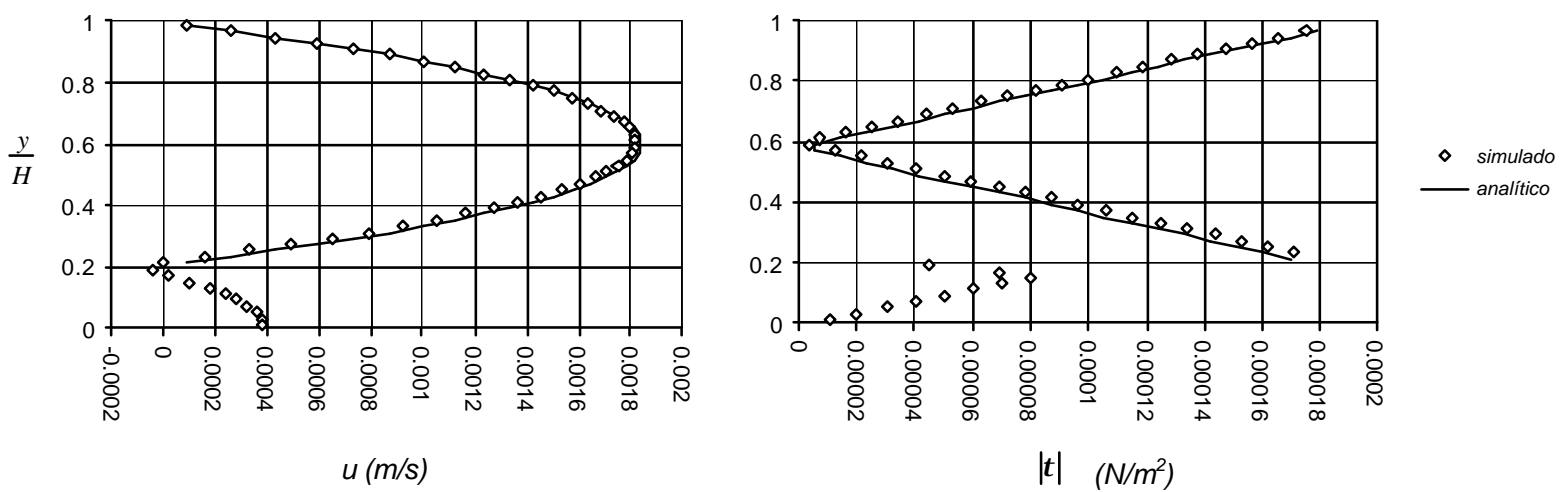

$|\tau|\left(N / m^{2}\right)$

Figura 6.4 - Comparação entre perfis simulados e teóricos de velocidade e de tensão cisalhante

Por uma breve análise da figura 6.4 percebe-se que o método numérico reproduziu corretamente o perfil parabólico de velocidade, além do perfil linear de tensão cisalhante. Neste último caso, é possível perceber a tendência de anulação da tensão no eixo do escoamento. Este resultado era esperado, uma vez que não existe gradiente vertical de velocidade nessa região $(d u / d y=0)$.

A simulação deste caso simples credencia não só o Método de Fronteira Imersa, como também todos os esquemas numéricos de discretização espacial e de avanço temporal descritos no capítulo anterior, para o tratamento de casos mais complexos, conforme é demonstrado a seguir.

\section{2 - ESCOAMENTO SOBRE FORMA DE FUNDO ONDULADA}

Geometrias onduladas são normalmente encontradas nos fundos de canais naturais. De uma maneira geral, essas formas são divididas em pequenas ondulações ("ripples"), dunas e anti-dunas, sendo esta classificação decorrente do diâmetro médio do sedimento e das condições de escoamento, os quais geram ondulações com amplitudes e comprimentos de onda variados. 
Na descrição deste item, o Método de Fronteira Imersa atuou, em conjunto com os procedimentos da Simulação de Grandes Escalas, na simulação de um escoamento turbulento sobre um fundo ondulado fixo. Percebe-se aqui, a tendência de modelar casos mais simples para situações paulatinamente mais complexas e reais. Assim, a interface, inicialmente plana no item anterior, foi transformada para uma fronteira imersa senoidal, ao passo que um modelo de turbulência também foi introduzido. Assim, pode-se verificar se os campos hidrodinâmicos simulados reproduzem com similitude os padrões de escoamento existentes sobre formas de fundo onduladas.

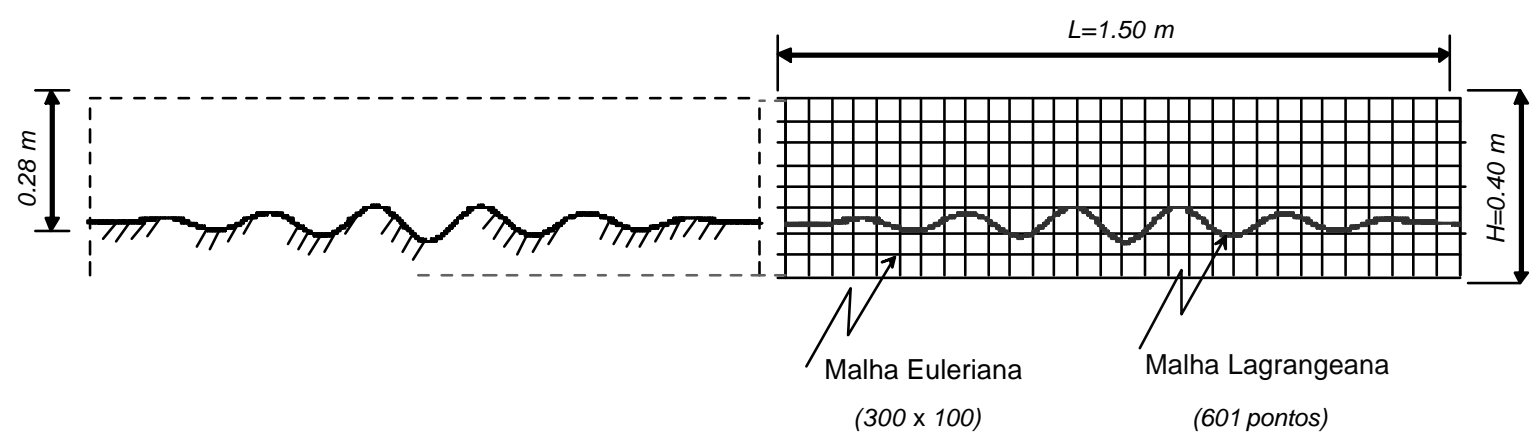

Figura 6.5 - Esquema do domínio real de escoamento estendido para o domínio de cálculo (retangular) com inserção da malha lagrangeana

A simulação utilizou o domínio de escoamento ilustrado pela figura 6.5. Essa região foi estendida para uma área retangular, discretizada por uma malha cartesiana uniforme, constituída por 300 x 100 células nas direções longitudinal e vertical, respectivamente. Todo o domínio computacional foi simulado como se estivesse ocupado por um único fluido. Um perfil uniforme de velocidade foi imposto como condição de entrada. Dessa forma, o número de Reynolds resultante, levando em conta a altura da região de interesse do canal, foi de 8400 . A forma de fundo do canal (interface imersa) foi ajustada de forma a apresentar ondulações com amplitudes e comprimentos de onda variáveis ao longo da direção longitudinal. Diante da fixação do domínio estendido de cálculo, os limites laterais foram tratados como fronteiras de simetria clássicas, enquanto que derivadas normais nulas foram impostas na saída. Aplicaram-se campos iniciais nulos para a pressão nas células internas do domínio. As velocidades foram inicializadas com o mesmo perfil da entrada do domínio. A malha lagrangeana foi delineada com espaçamentos horizontais de $\Delta x / 2$ entre os pontos interfaciais. Em relação ao tratamento numérico, todas as derivadas espaciais foram discretizadas por 
Diferenças Centrais de segunda ordem. Os procedimentos de cálculo avançaram explicitamente no tempo com incrementos de $10^{-3} \mathrm{~s}$, de acordo com o esquema de AdamsBashforth de segunda ordem.

Como na simulação anterior, o resíduo $\left(L_{2}\right)$ do Método de Fronteira Imersa também decaiu com o tempo, atingindo um valor aproximadamente estável da ordem de $10^{-4}$ (ver figura 6.6). Este valor é considerado bastante satisfatório diante do valor do número de Reynolds simulado.

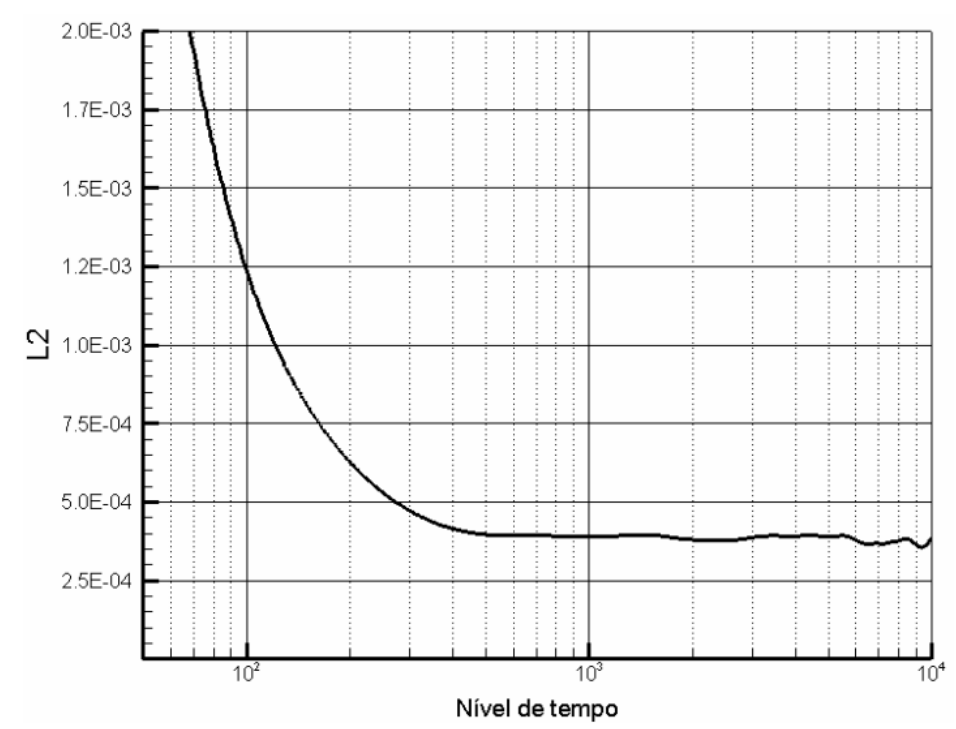

Figura 6.6 - Variação do fator residual $L_{2}$ com os níveis de tempo

A figura 6.7 ilustra a evolução temporal dos vetores de velocidade nas dunas centrais do domínio de escoamento. É possível perceber a formação de estruturas turbilhonares de grande escala a partir das cristas dessas ondulações. Vale lembrar que apenas a região situada acima da interface é de interesse final. Apesar disso, o campo de força foi também disseminado na porção inferior, fato que permitiu a simulação de um domínio computacional retangular, muito mais simplificado. Também é possível perceber porque as estruturas de grande escala, formadas a jusante das cristas das dunas, podem ser classificadas como coerentes: aqui, o tempo médio decorrido, desde formação da estrutura vorticosa e a sua destruição no vale, foi de 25 segundos, aproximadamente, durante os quais houve a manutenção de uma forma bem definida (ver figura 6.7). 

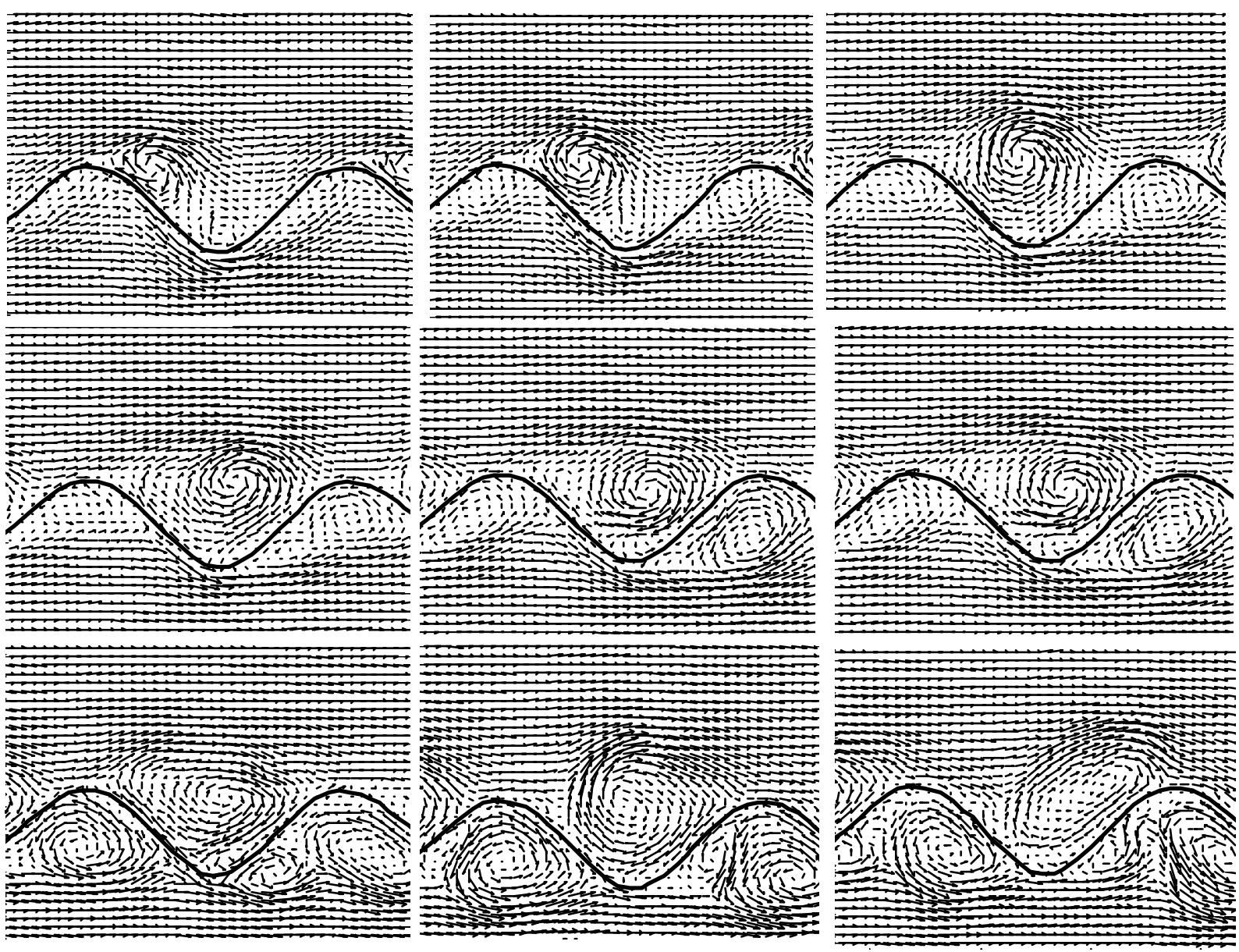

Figura 6.7 - Evolução temporal dos vetores de velocidade. Destaque para a formação de estruturas turbilhonares de grande escala a jusante das cristas das dunas

A figura 6.8 ilustra a evolução temporal das componentes horizontal e vertical do vetor velocidade. Nesta figura, e também nas subseqüentes, o tempo foi adimesionalizado como $t^{+}=t \cdot U_{b} / H$, onde $H$ representa a altura total do domínio e $U_{b}$ a velocidade média ao longo da linha transversal. A visualização das componentes de velocidade constitui uma alternativa interessante, uma vez que estes campos representam os resultados diretos, obtidos a partir da solução numérica das equações filtradas de Navier-Stokes. Note-se que os maiores gradientes de velocidade ocorrem justamente nos vales das dunas, caracterizando elevadas tensões de cisalhamento nessas regiões. Ainda nesses setores, a presença de componentes positivas e negativas sugere haver recirculação de fluido. 

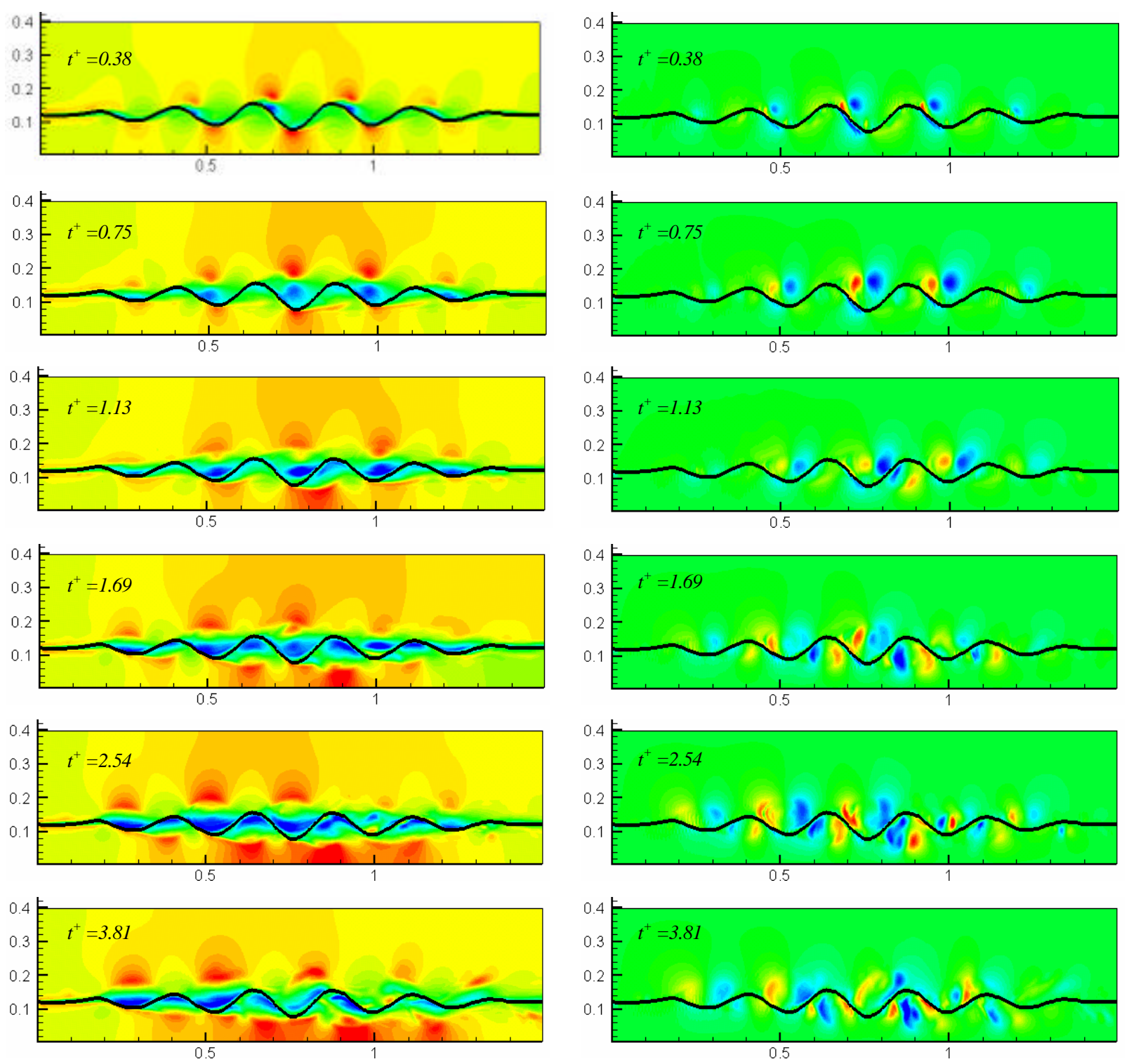

U: $-0.0499 \quad-0.0313 \quad-0.0126 \quad 0.0060 \quad 0.0246 \quad 0.0433 \quad 0.0619$

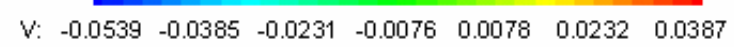

Figura 6.8 - Evolução temporal das componentes horizontal e vertical de velocidade [m/s]

Embora esta forma de visualização permita explicitar os locais onde ocorrem os maiores gradientes de velocidade, a representação gráfica de outra grandeza, a vorticidade, é mais favorável para uma visão global do movimento dos fluidos. A vorticidade $\left(\frac{\partial u}{\partial y}-\frac{\partial v}{\partial x}\right)$ pode ser entendida como a tendência do fluido girar em torno de um eixo perpendicular ao plano das velocidades. Assim, pontos com elevadas concentrações de vorticidade correspondem às regiões de linha de corrente recirculantes, de acordo com a figura 6.9. 

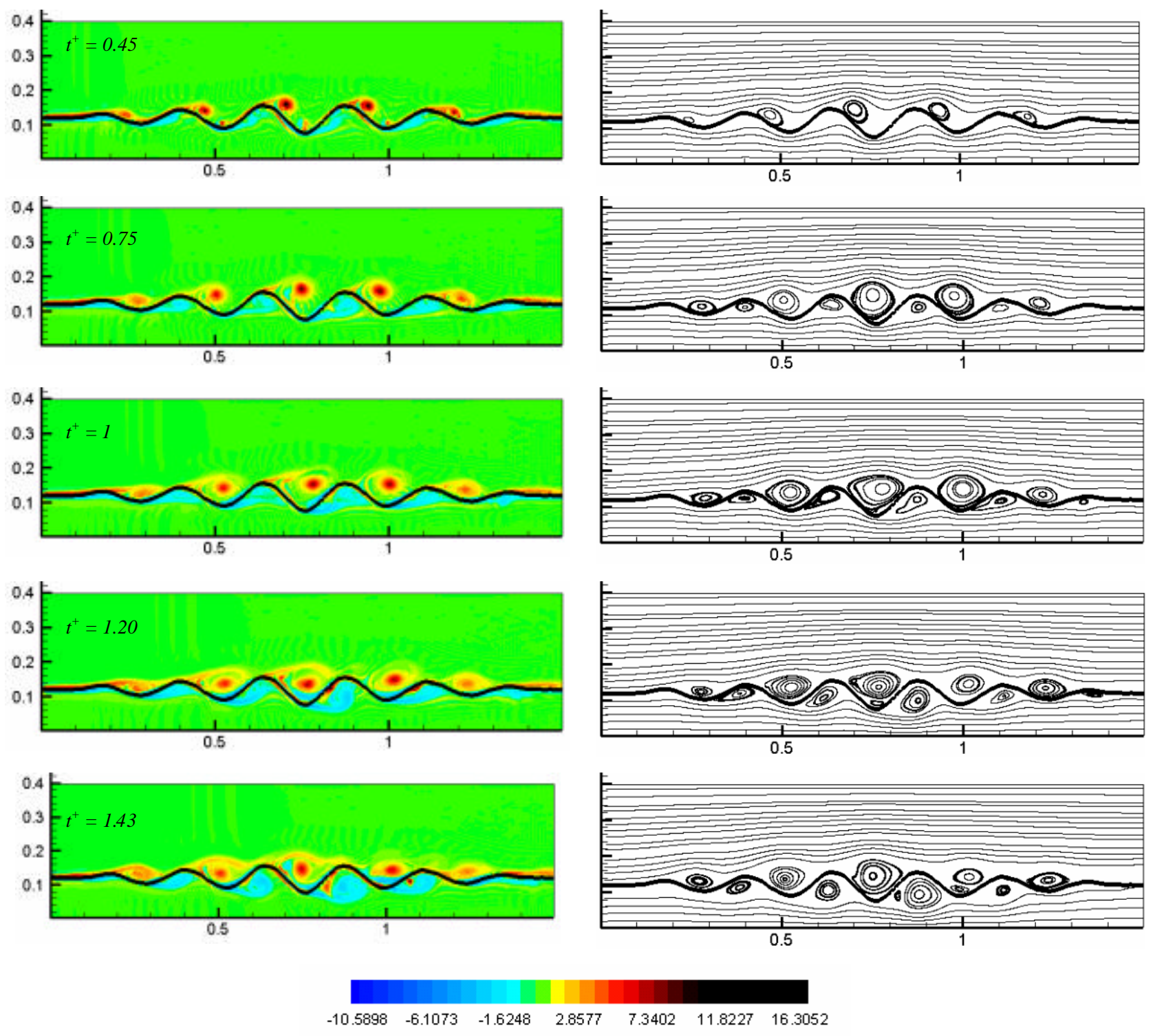

Figura 6.9 - Evolução temporal da vorticidade $[\mathrm{m} /(\mathrm{s} . \mathrm{m})]$ e das linhas de corrente.Percebe-se que os vales das dunas constituem regiões propensas a apresentar recircula ções de fluido

A previsão de zonas de recirculação nos vales também pode ser confrontada com visualizações experimentais de escoamentos sobre formas onduladas. A figura 6.10 vem indicar que a simulação reproduziu padrões esperados para este tipo de escoamento. Rousseaux et al. (2004) realizaram visualizações de escoamentos experimentais sobre dunas, através da adição de um traçador passivo (ORGASOL) e iluminação a laser. Notadamente, é possível verificar estreita semelhança entre os padrões simulados e visualizados. 

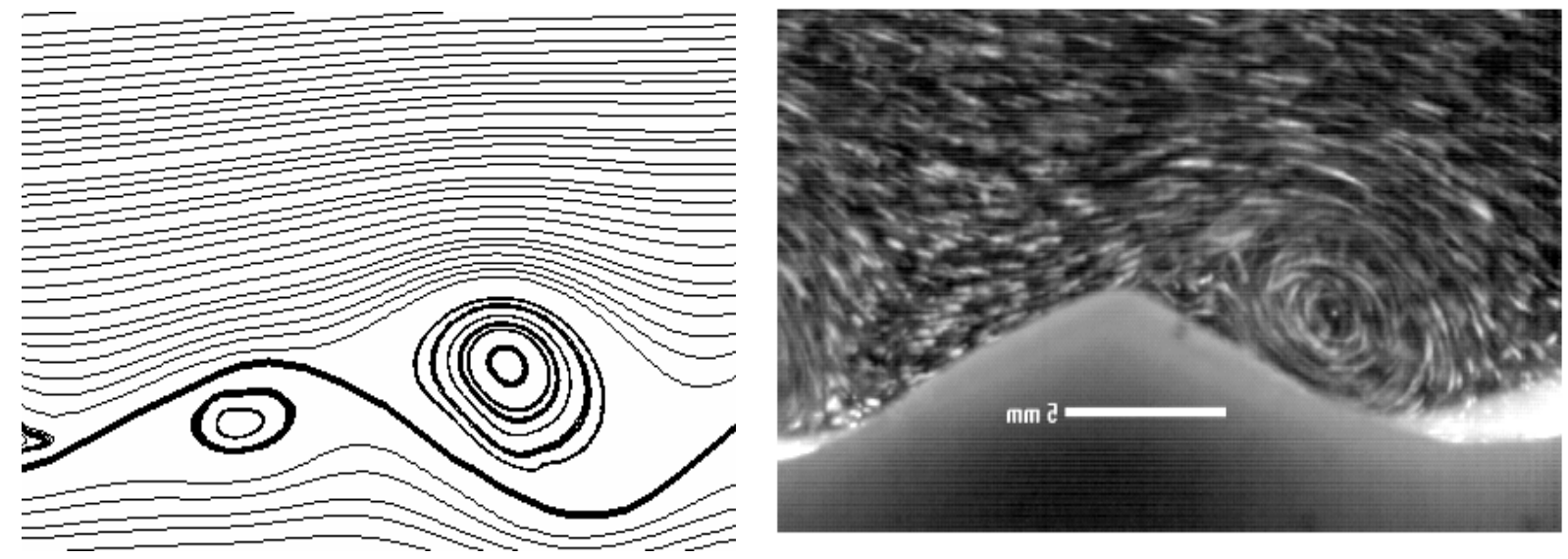

Figura 6.10 - Estrutura turbilhonar de grande escala formada a jusante da crista de uma duna: comparação entre linhas de corrente instantâneas, simuladas neste trabalho, e visualizações experimentais de Rousseaux et al. (2004)

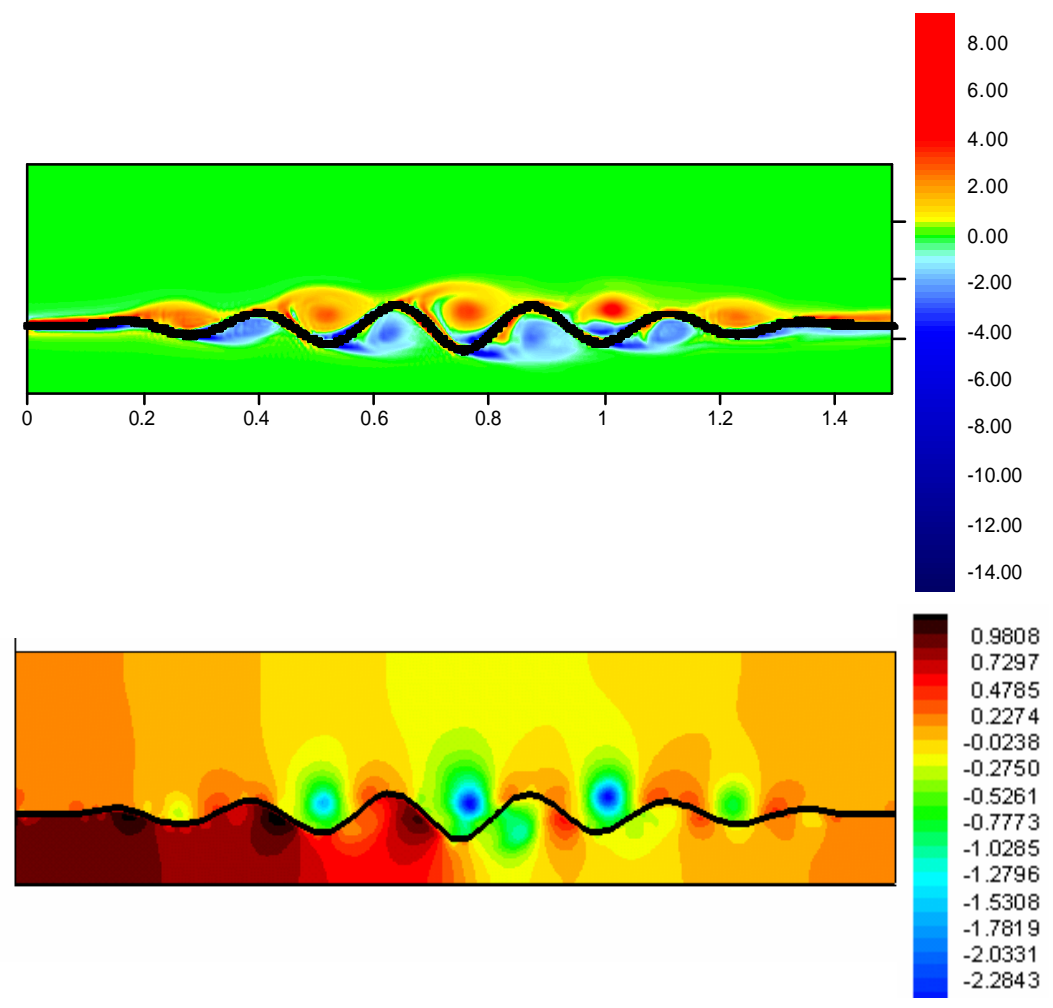

Figura 6.11 - Campos médios de vorticidade $[\mathrm{m} /(\mathrm{s} . \mathrm{m})]$ e pressão $\left[\mathrm{N} / \mathrm{m}^{2}\right]$. As estruturas turbilhonares de grande escala apresentam correlação espacial com os setores de baixa pressão. Todavia, a colisão dessas estruturas com as cristas das dunas acarreta setores de elevada pressão, imediatamente a montante das mesmas. As médias temporais foram calculadas sobre um intervalo de sessenta segundos 
Lesieur (1997) destaca que, geralmente, uma estrutura turbilhonar coerente apresenta correlação espacial e temporal com campos de baixa pressão. Isto ocorre porque as parcelas de fluido transportadas nessa estrutura apresentam um balanço aproximado entre a força centrífuga e o gradiente de pressão. Os resultados aqui obtidos, ilustrados pelos campos de vorticidade e pressão (figura 6.11), apresentam coerência com essas observações. É importante concluir que as regiões de baixa pressão apresentam concentrações de vorticidade suficientemente elevadas que impõem trajetórias recirculantes aos fluidos. A simulação também reproduziu a presença de regiões de elevada pressão, denotando a colisão de parcelas de fluido com as dunas, imediatamente a montante das cristas.
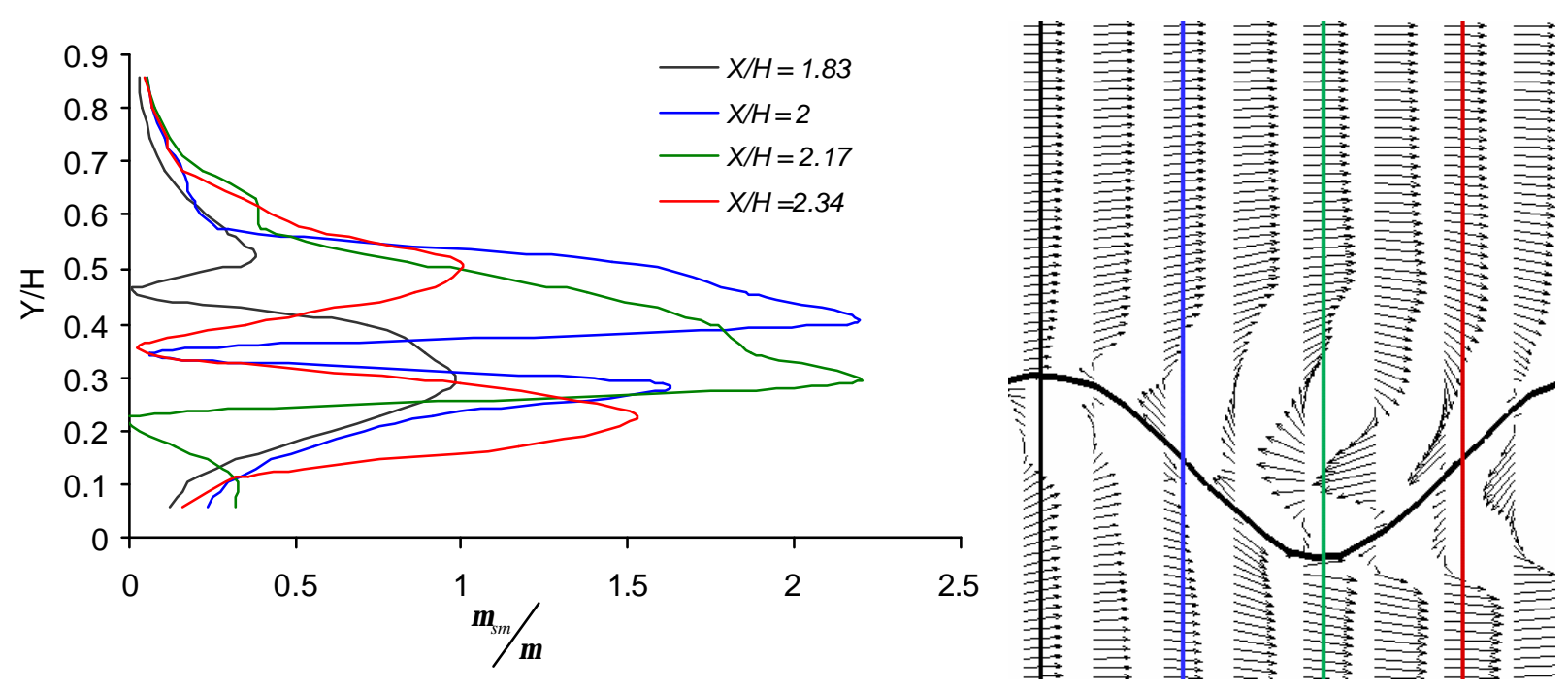

Figura 6.12 - Viscosidade sub-malha (adimensionalizada) na duna central do domínio. As maiores viscosidades turbulentas ocorrem onde os gradientes locais de velocidade são mais acentuados. Os vetores de velocidade representam médias temporais calculadas no decorrer de sessenta segundos

Para a simulação de escoamentos com números de Reynolds mais elevados (superiores a 500, no caso de canais) é aconselhável a aplicação de um modelo de turbulência, sem o qual haveria perda de estabilidade do código. Vale aqui a ressalva de que a demanda por este tipo de modelagem decorre da utilização de malhas ainda bastante grosseiras para capturar todas as escalas de turbulência. A Simulação de Grandes Escalas (SGE), ainda que seja uma das metodologias mais modernas para o tratamento numérico da turbulência, utiliza malhas com 
escalas de corte na faixa inercial do espectro, portanto, ainda distantes do severo refinamento requerido por uma Simulação Numérica Direta (SND).

Aqui, a SGE foi utilizada juntamente com o modelo sub-malha de Smagorinsky. Conforme já foi comentado no capítulo dedicado a este tema, o modelo de Smagorinsky calcula uma viscosidade turbulenta sub-malha a partir dos gradientes locais de velocidade. A constante $\left(C_{s}\right)$ adotada foi de 0,23 (valor intermediário entre a faixa recomendada de $0,1 \mathrm{a}$ 0,33). Para reduzir a viscosidade turbulenta nas paredes, utilizou-se o amortecimento parietal de van Driest. A figura 6.12 ilustra a variação da viscosidade sub-malha na duna central do domínio de escoamento. Percebe-se que seu valor é mais acentuado onde os gradientes de velocidade são maiores, ao passo que existe a tendência de anulação junto das paredes. Esta última tendência decorre do já comentado amortecimento parietal.

(a)
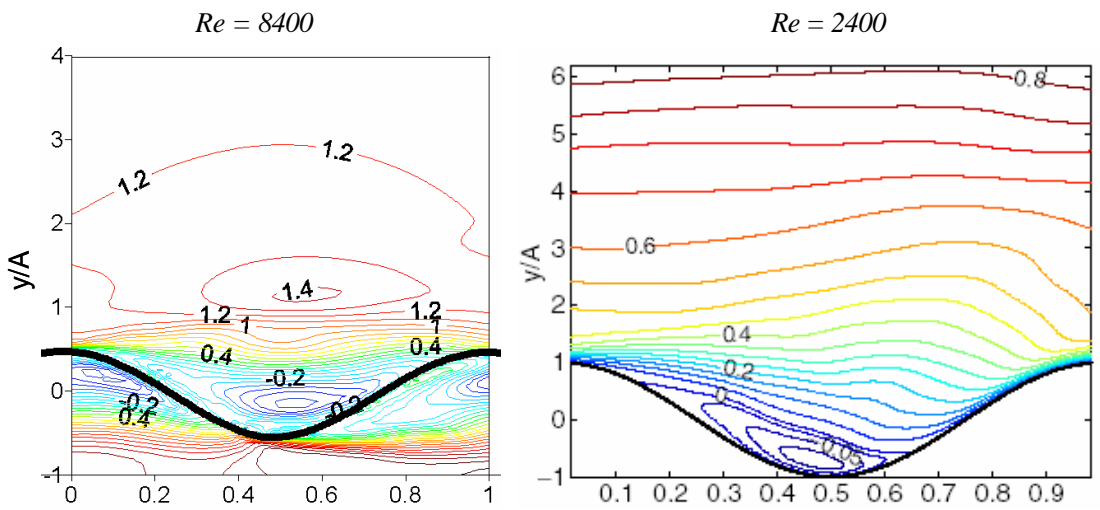

(b)
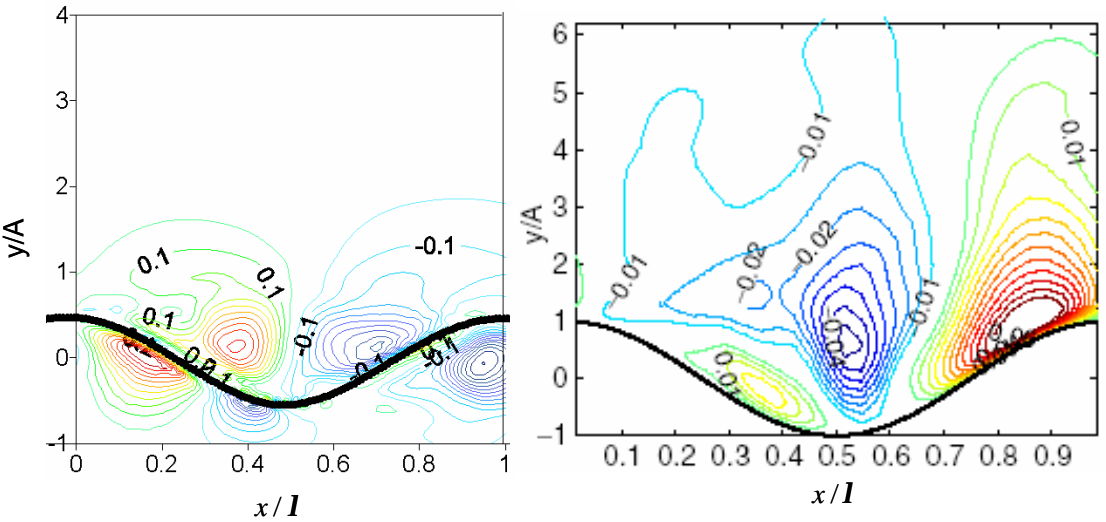

Figura 6.13 - Comparações entre os resultados da presente simulação $(\operatorname{Re}=8400)$ e as Simulações de Grandes Escalas sobre coordenadas curvilineas (Re=2400), realizadas por Tseng e Ferziger (2004):

(a) campos médios adimensionalizados de velocidade longitudinal $\left(u / U_{b}\right) ;(b)$ campos médios adimensionalizados de velocidade vertical $\left(\mathrm{v} / U_{b}\right)$. Neste caso, $\lambda$ representa o comprimento de onda e A representa a amplitude da ondulação 
As simulações com a fronteira virtual imersa também podem ser confrontadas com outras formas numéricas mais tradicionais de tratamento de geometrias. A figura 6.13 compara os resultados simulados neste trabalho (utilizando o Método de Fronteira Imersa) com as simulações de Tseng e Ferziger (2004). Os referidos autores também utilizaram a Simulação de Grandes Escalas no tratamento da turbulência. Todavia, o domínio de escoamento foi discretizado de uma maneira tradicional, utilizando a discretização coincidente com a fronteira (malhas não ortogonais). Nesse contexto, o número de Reynolds resultante foi de 2400, inferior ao valor da presente simulação. A despeito dessa diferença, os padrões observados nos dois escoamentos também foram similares.

Na figura 6.13, $A$ é a amplitude da duna central e $\lambda$ o seu comprimento de onda. $U_{b}$ é a velocidade média do corpo do escoamento (tomada ao longo da vertical). É possível verificar que o aumento do número de Reynolds condiciona campos de velocidade mais acentuados nos vales.

De uma maneira geral, os resultados obtidos através do uso conjugado do Método de Fronteira Imersa e da Simulação de Grandes Escalas, reproduziram, com bom desempenho, as estruturas formadas nos escoamentos sobre fundos ondulados. Diante disso é possível destacar, por exemplo, a captura dos turbilhões de grande escala, fortes condicionantes do transporte de partículas nos escoamentos aluviais. Este fato atribui uma credencial para a metodologia utilizada, visando o estudo do transporte de sedimentos sobre formas de fundo não consolidadas, a partir da inclusão da equação de transporte de massa e dos fluxos de ressuspensão, conforme descrevem os itens seguintes.

\section{3 - SIMULAÇÃO DO TRANSPORTE DE SEDIMENTOS SOBRE FORMAS DE FUNDO ALUVIAIS (CASO BIDIMENSIONAL)}

Neste item, o código computacional assume sua forma bidimensional completa, com a anexação da equação de Advecção-Difusão, dos critérios de erosão, dos eventuais fluxos de ressuspensão e do cálculo instantâneo das novas cotas de fundo do canal.

A figura 6.14 ilustra a transformação do domínio de escoamento real no domínio computacional estendido, com o uso das malhas euleriana e lagrangeana. Assim, a malha lagrangeana representa a interface entre os depósitos de material não consolidado e o escoamento, compondo a própria ondulação imposta como condição inicial. Esses depósitos 
de fundo foram constituídos de areia fina, com diâmetro médio $\left(D_{50}\right)$ de $0,12 \mathrm{~mm}$ e massa específica de $2650 \mathrm{Kg} / \mathrm{m}^{3}$. A forma de fundo, delineada pela malha lagrangeana, pode ser alterada em função dos processos de deposição/erosão eventualmente verificados. Nesse contexto residiu a principal motivação para o uso do Método de Fronteira Imersa, uma vez que domínios com geometrias de conformações transientes podem ser tratados pelo acoplamento das malhas euleriana e lagrangeana. Dessa forma, apenas deve ocorrer alteração da interface lagrangeana, ao passo que a malha de discretização é mantida fixa e ortogonal.

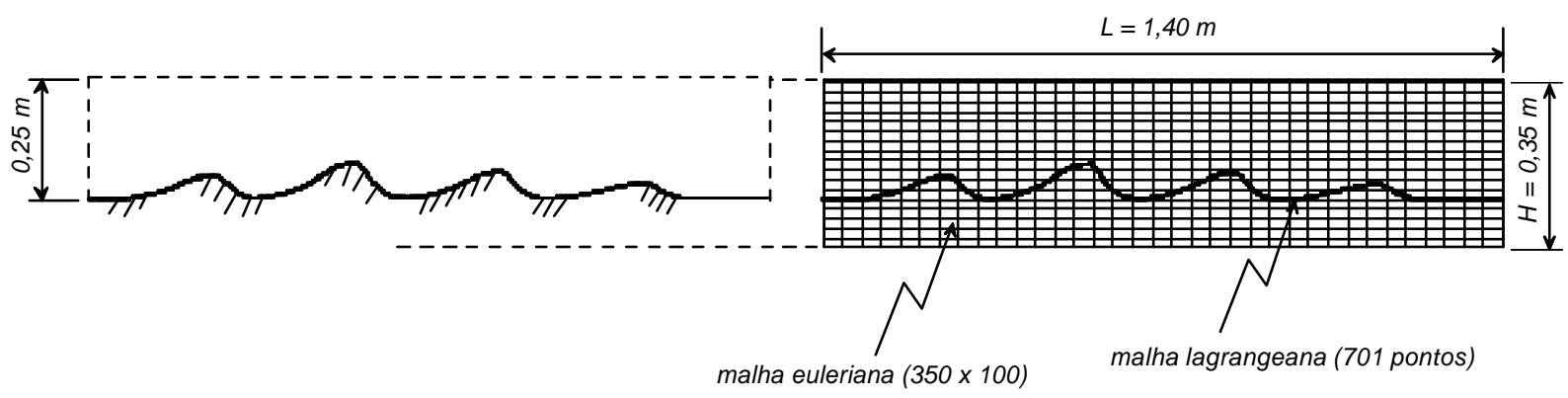

Figura 6.14 - Transformação do domínio real no domínio computacional estendido

O domínio computacional foi discretizado por uma malha com 350 x 100 células nas direções longitudinal e vertical, respectivamente. A malha lagrangeana foi definida como um conjunto de 701 pontos, horizontalmente espaçados de $\Delta x / 2$. Embora seja perfeitamente possível desvincular as malhas euleriana e lagrangeana, optou-se por fazê-lo apenas na direção vertical. Assim, à medida que os processos de deposição/erosão condicionam alterações na forma de fundo, não há necessidade de reconstrução global da malha lagrangeana (remalhagem), uma vez que apenas os deslocamentos verticais (mudanças de cota) são considerados.

Um perfil uniforme de velocidade foi imposto como condição de entrada. Dessa forma, o número de Reynolds resultante, levando em conta a altura da região de interesse do canal, foi de 8750. Diante da fixação do domínio estendido de cálculo, os limites laterais foram tratados como fronteiras de simetria clássicas, enquanto que derivadas normais nulas foram impostas na saída. Aplicaram-se campos iniciais nulos para a pressão nas células internas do domínio. As velocidades foram inicializadas com o mesmo perfil da entrada do domínio. Em relação ao tratamento numérico, todas as derivadas espaciais foram discretizadas 
por Diferenças Centrais de segunda ordem. Os procedimentos de cálculo avançaram explicitamente no tempo com passos variáveis $10^{-6} s$ (nos instantes iniciais), incrementados suavemente, por uma progressão geométrica de razão 1,10 , até um valor constante de $10^{-3} \mathrm{~s}$, de acordo com o esquema de Adams-Bashforth de segunda ordem.

No tratamento da equação de Advecção-Difusão, foram impostas condições de fluxo nulo na entrada e nas laterais superior e inferior, enquanto que derivadas normais nulas foram adotadas na saída do domínio de escoamento. De maneira idêntica ao tratamento das equações filtradas de Navier-Stokes, todas as derivadas espaciais foram discretizadas por Diferenças Centrais de segunda ordem, enquanto que o esquema explícito de Adams-Bashforth de segunda ordem determinou o avanço temporal das concentrações. Toda a região foi inicializada com concentrações nulas. Para evitar o transporte de sedimentos através das paredes de fundo, condições de fluxo nulo foram impostas nas faces das células que cruzam a malha lagrangeana. Este procedimento evita a passagem de sedimentos para a região inferior da malha lagrangeana, de forma que as concentrações nesses setores permaneceram nulas. A despeito disso, o próprio leito atuou como uma fonte de sedimentos, quando condições bcais críticas de ressuspensão foram sobrepujadas $\left(u_{*}>u_{*}\right.$ rr $)$. Nessas circunstâncias, existiu um fluxo de ressuspensão $\left(\dot{f}_{R E S S}\right)$ responsável pela introdução de concentrações no escoamento, a partir das células adjacentes ao leito.

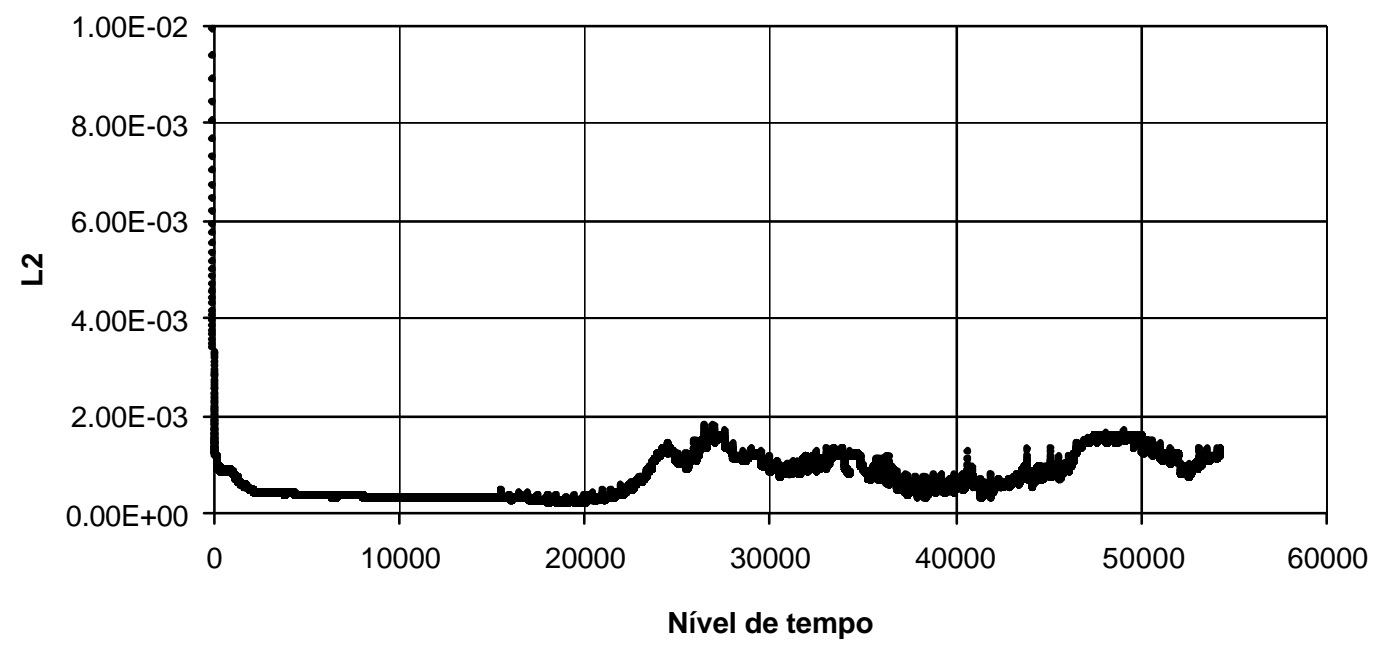

Figura 6.15 - Variação do fator residual $L_{2}$ com os níveis de tempo 
A figura 6.15 ilustra a variação do fator residual $L_{2}$ ao longo da marcha temporal. Percebe-se uma tendência de declínio, a qual é interrompida quando as alterações na forma de fundo se tornam mais intensas. De fato, o caráter transiente do problema impede uma estabilização mais suave dos resíduos, uma vez que existem células que estão ora dentro da região de interesse do escoamento (acima da interface imersa), ora fora dessa região (abaixo da interface imersa).

Conforme já foi comentado no item anterior, a visualização dos campos de vorticidade fornece uma noção considerável acerca do movimento dos fluidos. Nesse contexto, a figura 6.16 ilustra a evolução temporal da vorticidade. Nessa figura e também nas subseqüentes, vale lembrar que o tempo foi adimesionalizado como $t^{+}=t \cdot U_{b} / H$, onde $H$ representa a altura total do domínio e $U_{b}$ a velocidade média ao longo da linha transversal. Percebe-se nitidamente a formação de estruturas turbilhonares de grande escala nas camadas cisalhantes livres que surgem a jusante de cada duna. Note-se que, com o decorrer do tempo, essas estruturas atingem alturas consideráveis a partir do fundo do canal. Esse mecanismo é o principal gerador de turbulência na superfície livre dos cursos de água naturais, atuando como um importante agente na reaeração dos mesmos. Além disso, segundo destacam Nezu e Nakagawa (1993), turbilhões de grande escala estão associados com movimentos ascendentes ("boils") que podem apresentar surgimento na superfície de rios e estuários. Ainda de acordo com esses autores, tais movimentos podem ser convenientemente divididos em três tipos. Os "boils" de primeira espécie surgem a jusante de dunas ou de grandes ondulações. Grandes "boils" podem carrear quantidades consideráveis de sedimentos suspensos até a superfície livre. Os "boils" de segunda espécie estão associados com movimentos celulares de correntes transversais ao escoamento principal e, portanto, só podem ser estimados por simulações tridimensionais. Os "boils" de terceira espécie estão associados com movimentos explosivos, intensos o suficiente para permitir a chegada de turbilhões menores até a superfície livre. Essas estruturas geralmente emergem fracamente, sendo de difícil observação na superfície dos rios. 

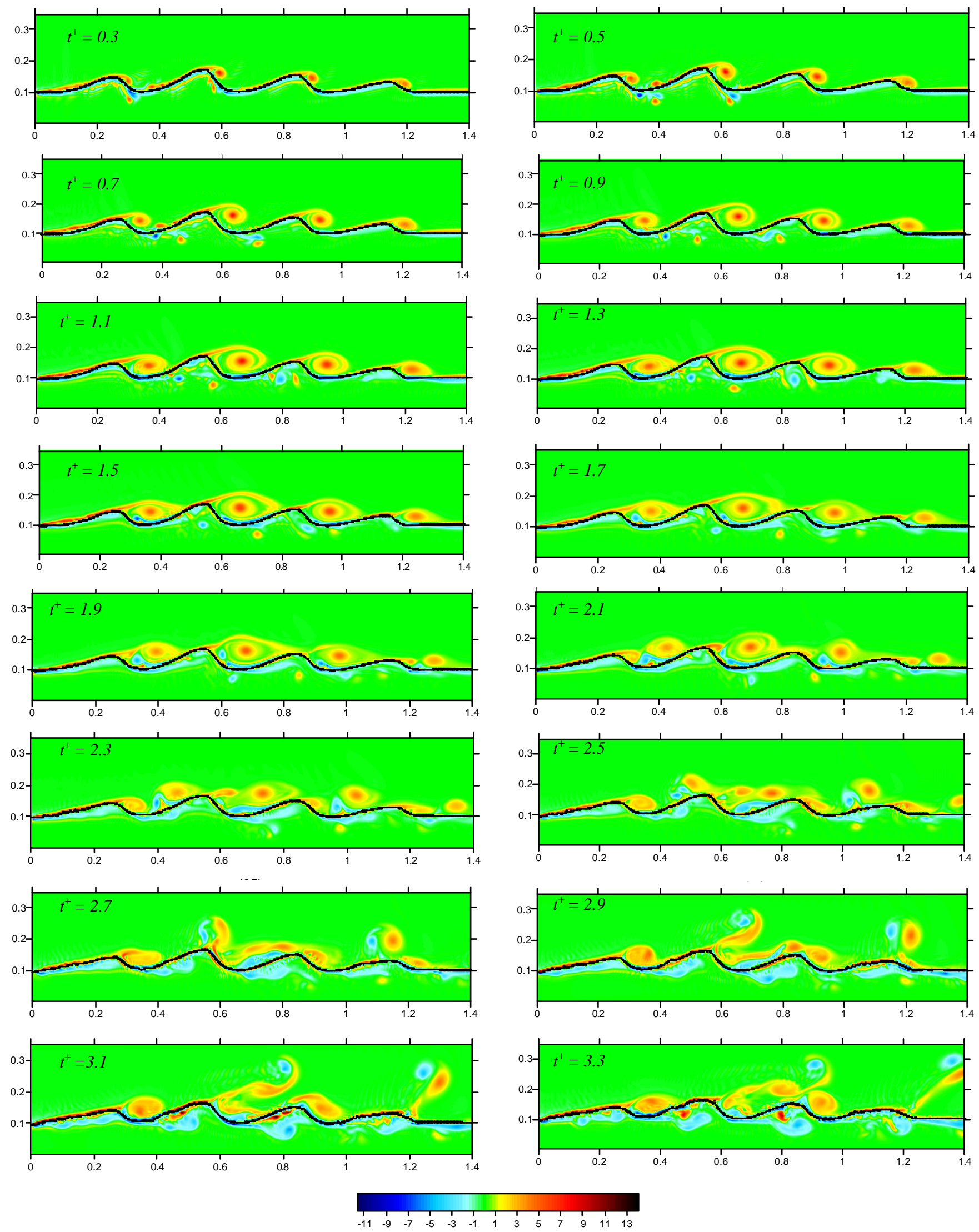

Figura 6.16 - Evolução temporal da vorticidade $[\mathrm{m} /($ s.m)](continua) 

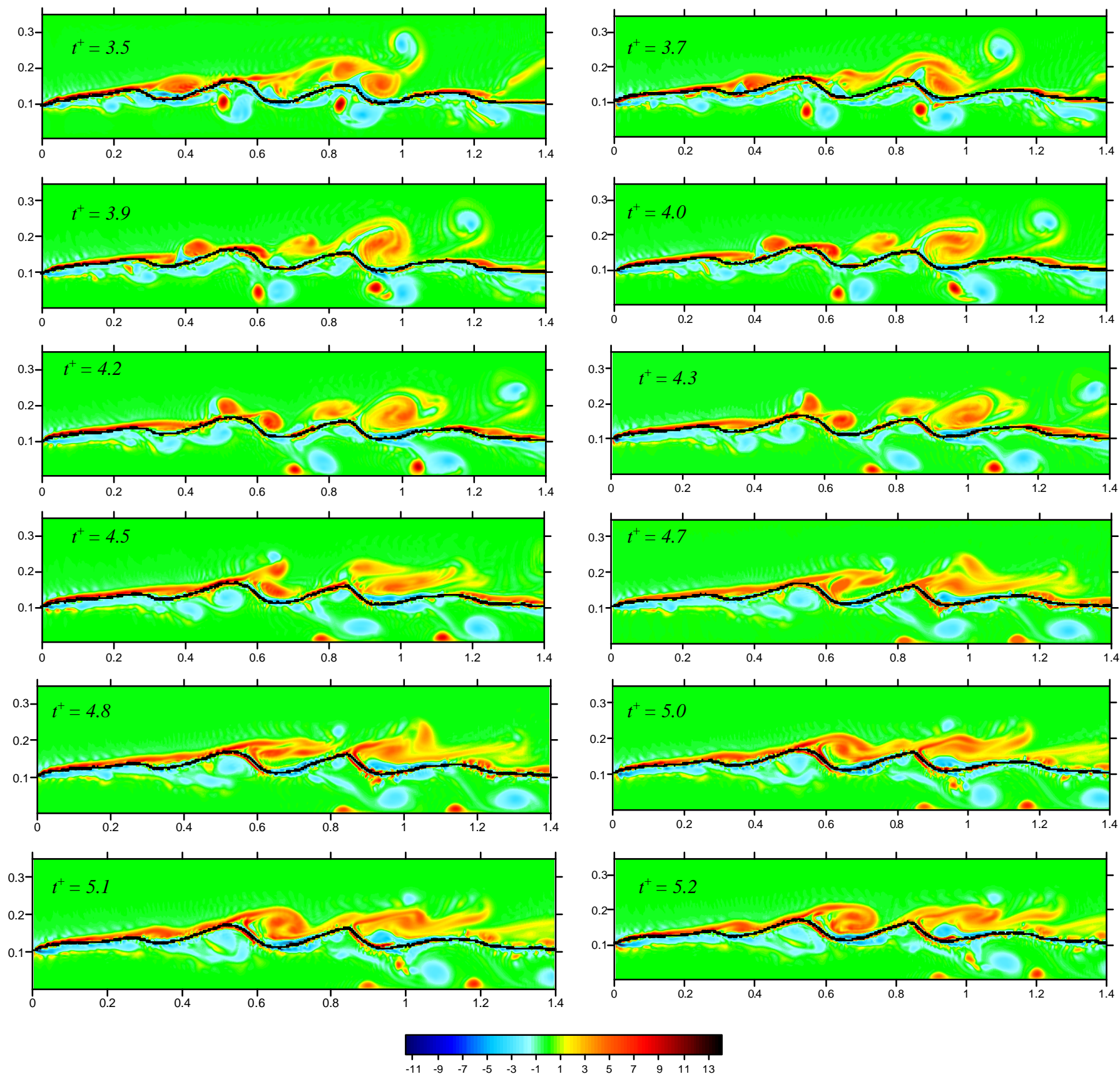

Figura 6.16 - Evolução temporal da vorticidade $[\mathrm{m} /(\mathrm{s.m})]$ (conclusão)

É possível perceber que a simulação não somente previu o surgimento de estruturas vorticosas de grande escala nos vales das dunas, mas também, em se utilizando a classificação sugerida por Nezu e Nakagawa (1993), movimentos que se aproximam dos chamados "boils" de primeira espécie. No primeiro caso, os movimentos podem ser identificados como zonas recirculatórias instantâneas nos vales, enquanto que, no segundo caso, como correntes ascendentes, originadas pela indução de estruturas contra-rotativas a partir do fundo do canal. O chamado aparelhamento de vórtices, isto é, a aglutinação estruturas vorticosas próximas e de mesmo sinal (mesmo sentido de rotação) também foi verificado. Essas constatações podem 
ser reforçadas pela visualização dos vetores de velocidade e as respectivas linhas de corrente, conforme ilustra a figura 6.17.
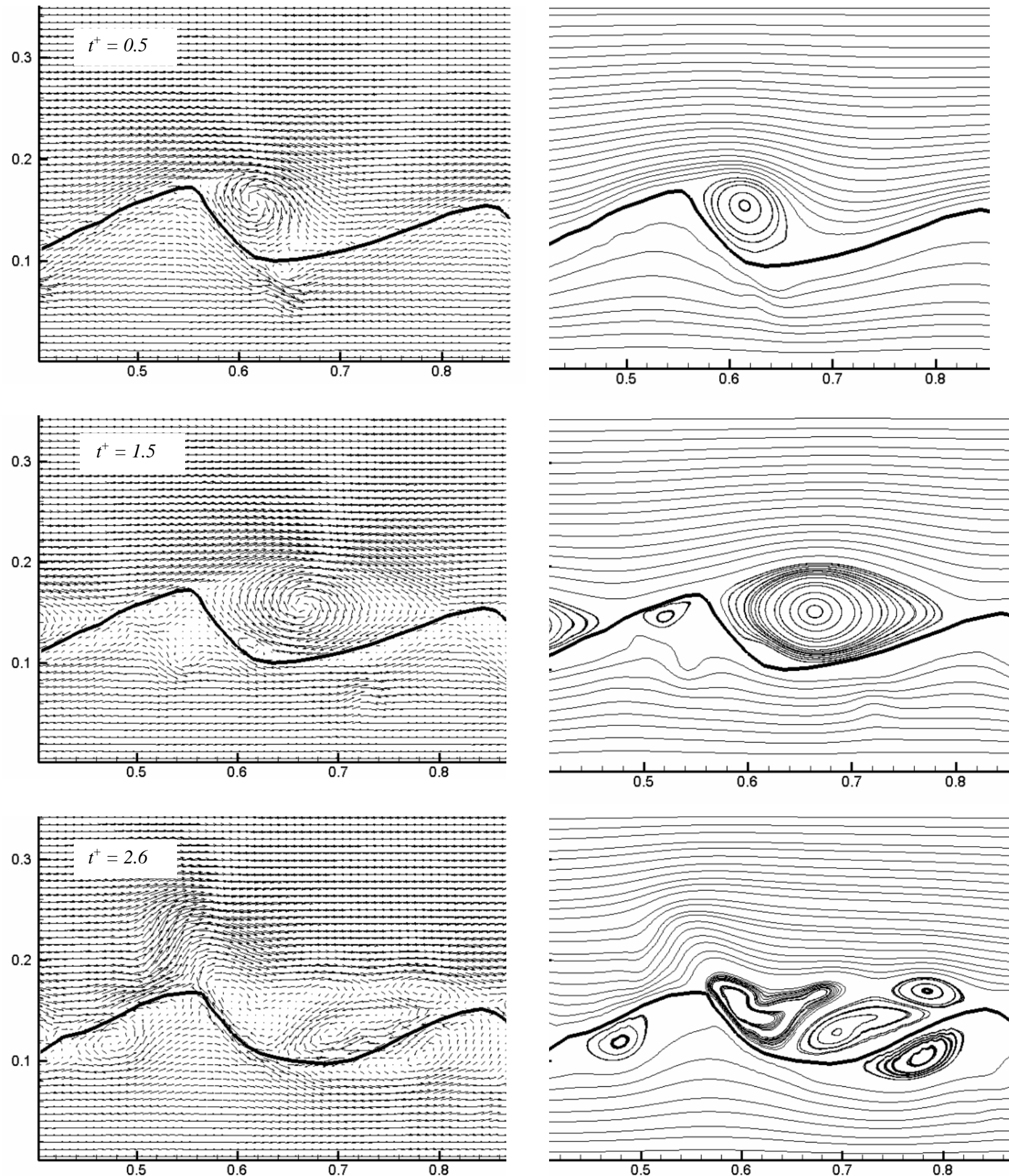

Figura 6.17 - Campos instantâneos de velocidade e linhas de corrente correlatas. Verifica-se a formação de zonas de recirculação instantâneas e movimentos ascendentes a partir do fundo do canal (continua) 

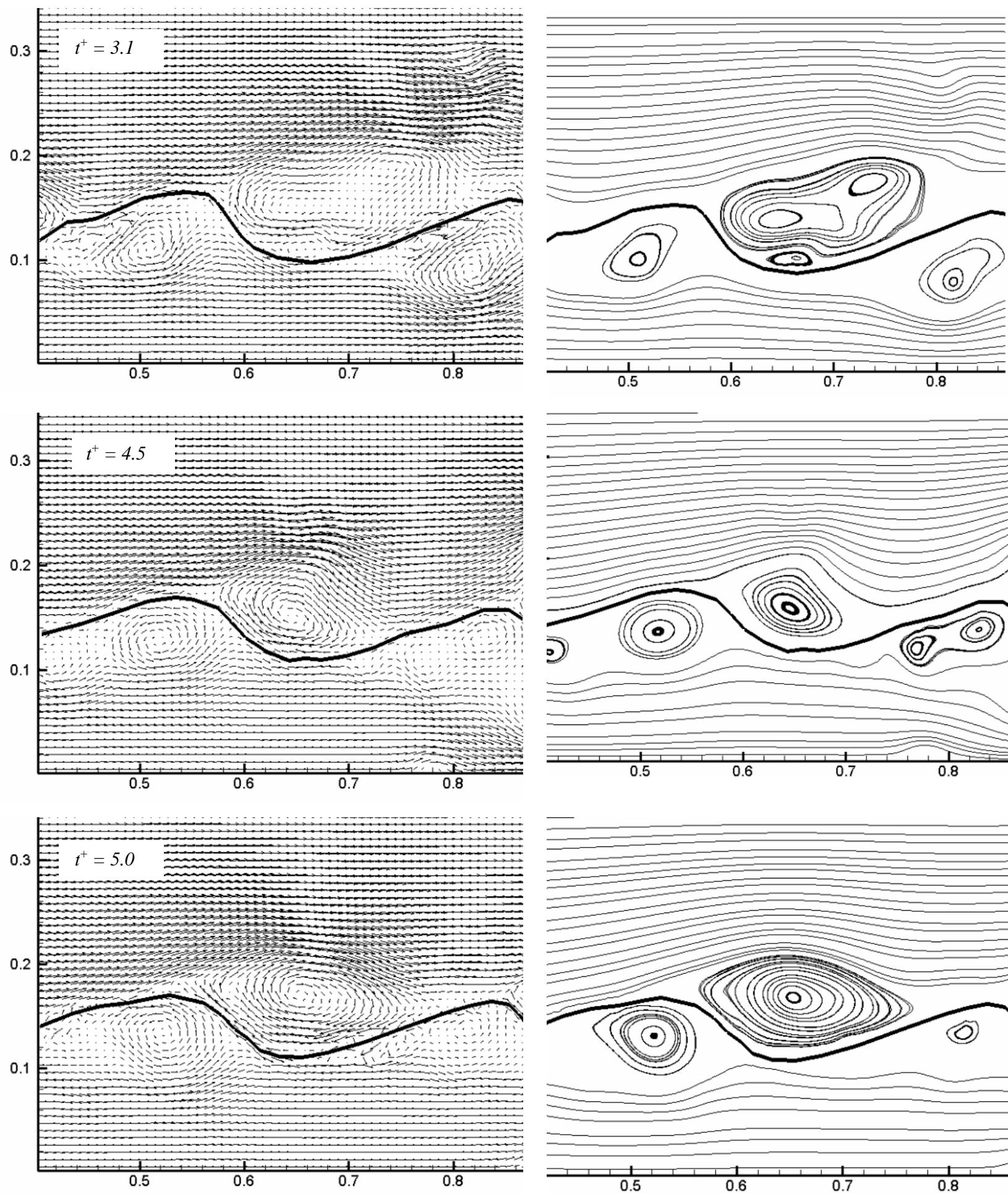

Figura 6.17 - Campos instantâneos de velocidade e linhas de corrente correlatas. Verifica-se a formação de zonas de recirculação instantâneas e movimentos ascendentes a partir do fundo do canal (conclusão) 
A difusividade efetiva do escoamento seguiu distribuições semelhantes às da viscosidade sub-malha, apresentando valores mais acentuados nas regiões onde os gradientes locais de velocidade são maiores. Vale lembrar que, de acordo com a metodologia utilizada, existe uma proporcionalidade aproximada entre os coeficientes de difusão do escoamento (viscosidade turbulenta efetiva) e o coeficiente de difusão de massa (difusividade turbulenta efetiva). A figura 6.18 ilustra uma dessas distribuições instantâneas na duna central do domínio.
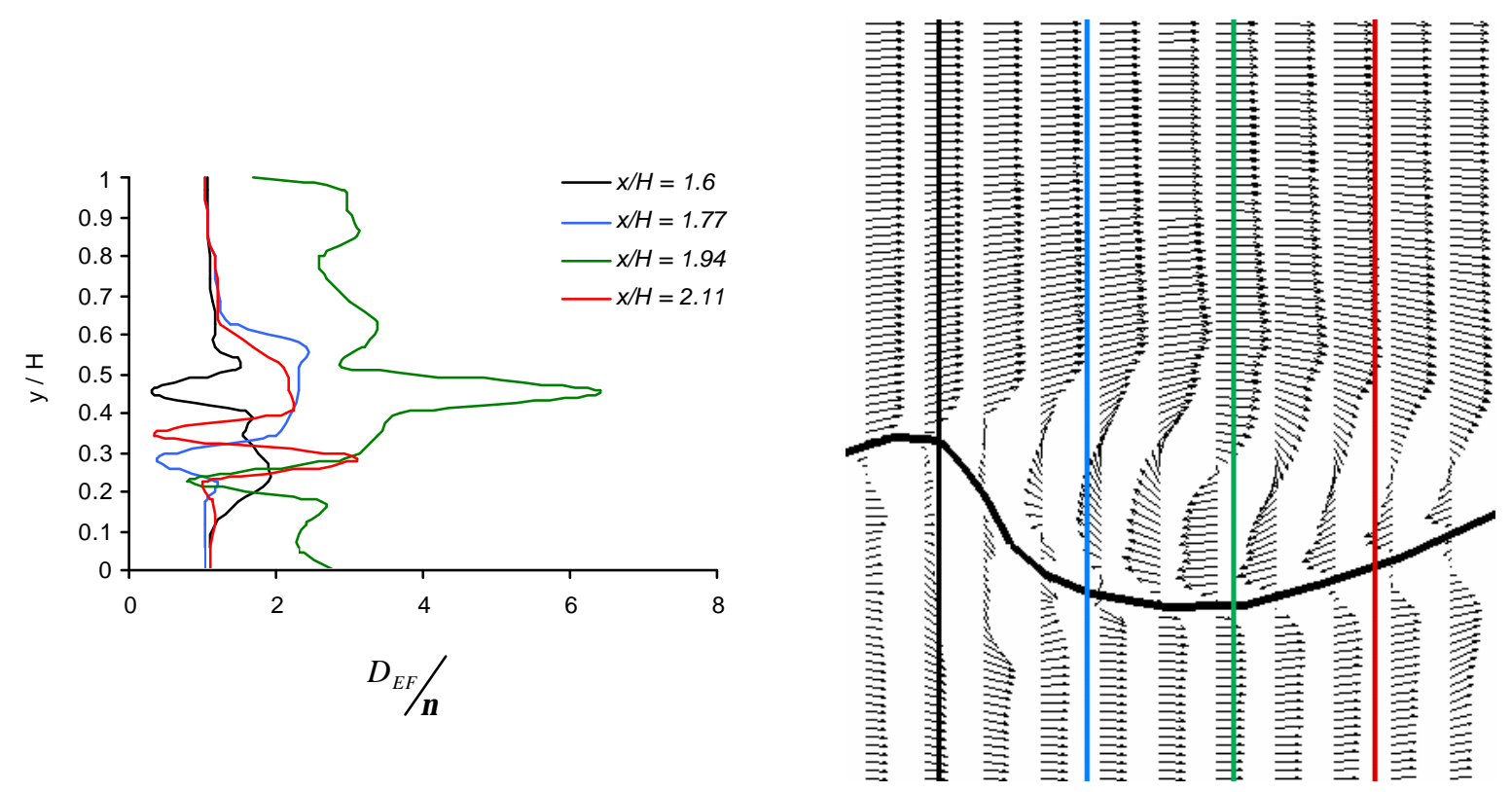

Figura 6.18 - Distribuição instantânea $\left(t^{+}=1.7\right)$ do coeficiente de difusão efetivo na duna central

Quando condições cisalhantes críticas sobre o fundo do canal foram superadas, criaram-se condições para a ressuspensão de sedimentos em direção ao corpo do escoamento (ver figura 6.19). Isto condicionou fluxos de massa diferentes de zero, responsáveis pela inserção de concentrações no escoamento. Em se utilizando a equação de Advecção-Difusão, essa tendência pode ser observada como concentrações que surgem preferencialmente nos locais onde a velocidade de cisalhamento é mais elevada. 

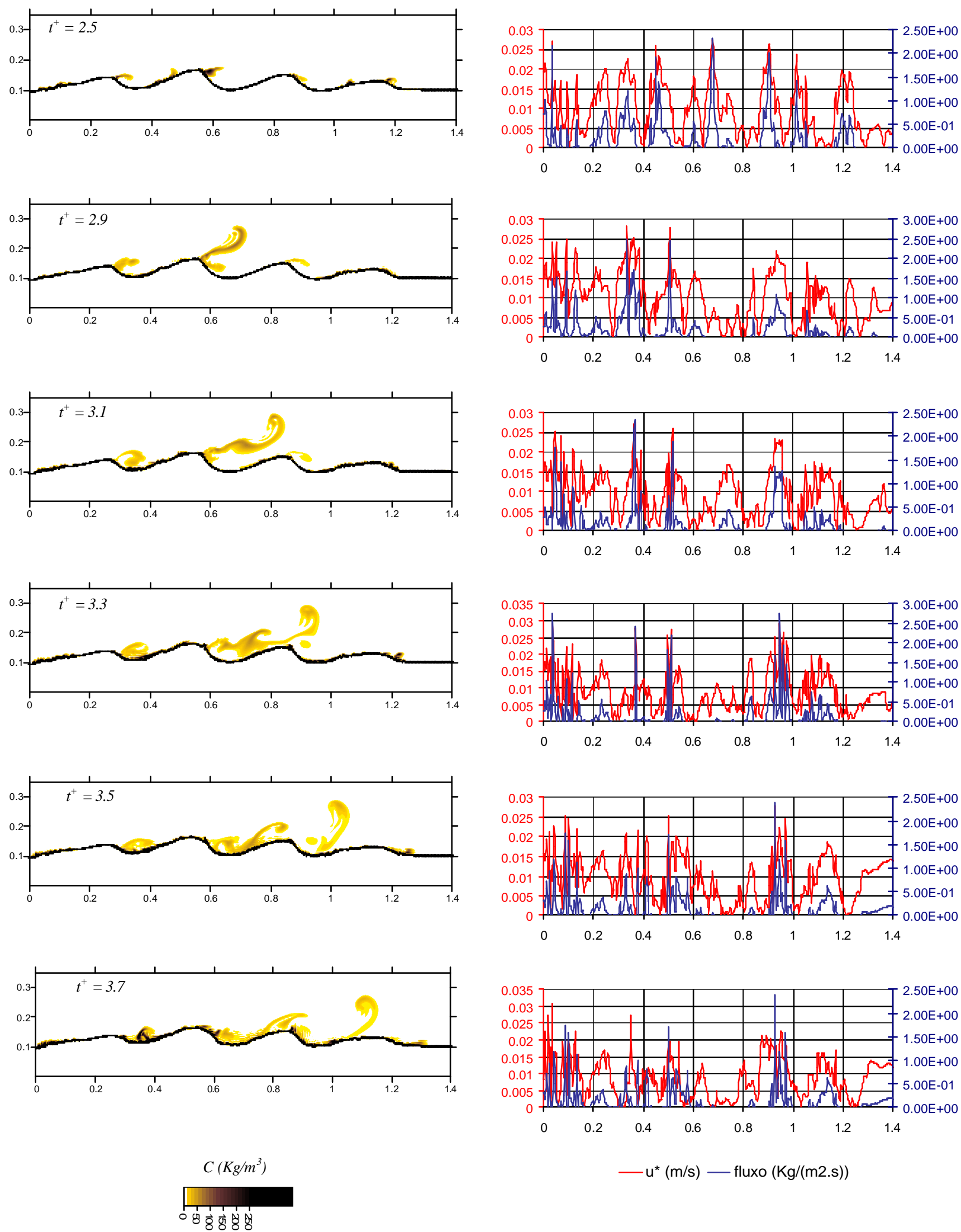

$-u^{*}(\mathrm{~m} / \mathrm{s})$-fluxo $(\mathrm{Kg} /(\mathrm{m} 2 . \mathrm{s}))$

Figura 6.19 - Evolução temporal da concentração de sedimentos em correlação com velocidades de cisalhamento e fluxos de ressuspensão no fundo do canal (continua) 

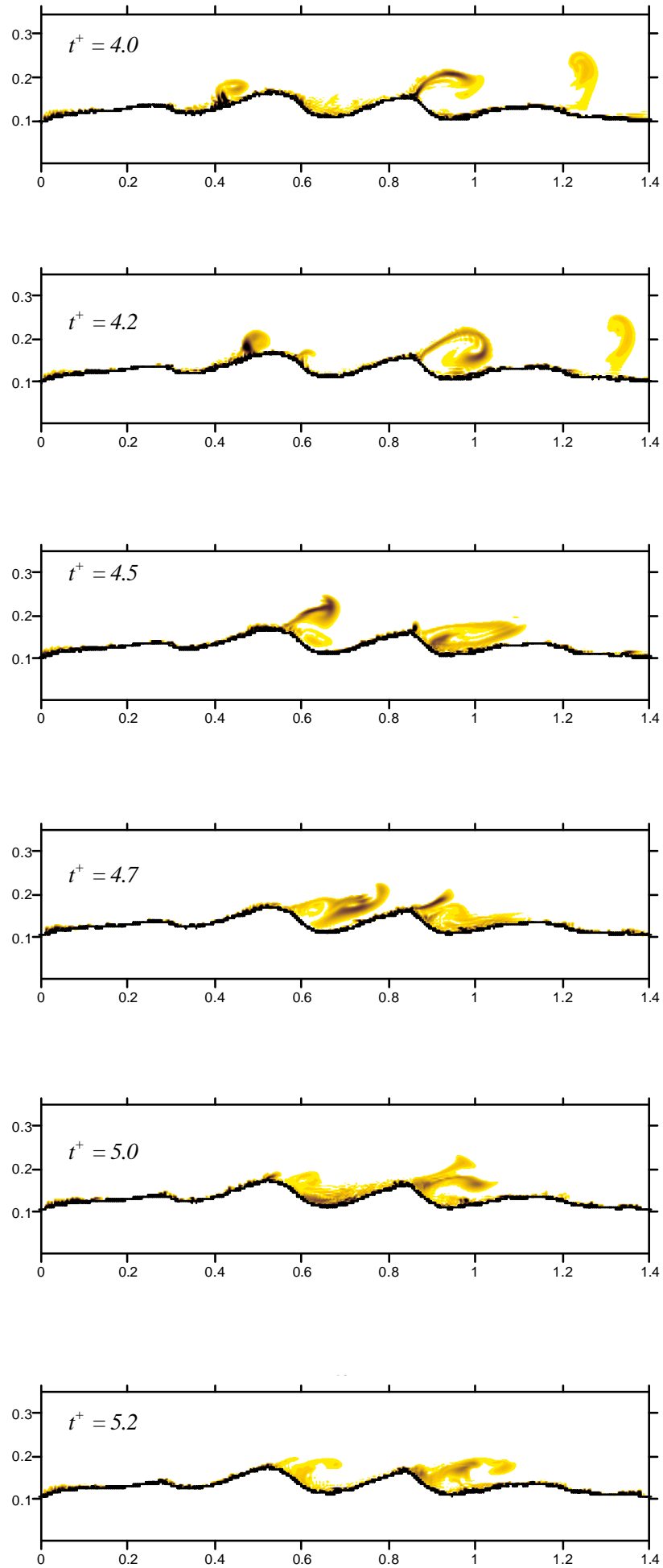

$C\left(K g / m^{3}\right)$
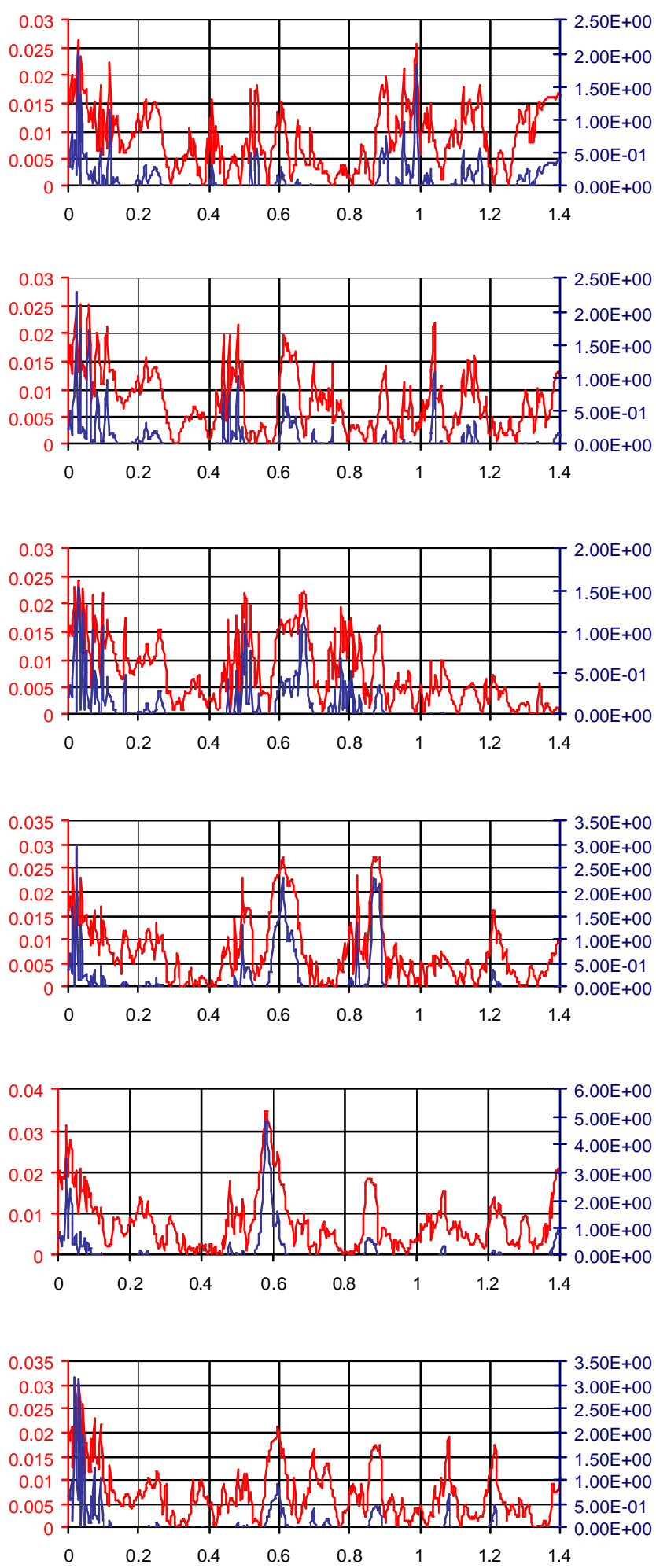

$-\mathrm{u}^{*}(\mathrm{~m} / \mathrm{s})$ - fluxo $(\mathrm{Kg} /(\mathrm{m} 2 . \mathrm{s}))$

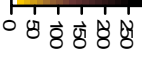

Figura 6.19 - Evolução temporal da concentração de sedimentos em correlação com velocidades de cisalhamento e fluxos de ressuspensão no fundo do canal (conclusão) 
Por uma breve análise da figura 6.19, é possível perceber o carreamento de sedimentos a jusante das cristas, além de uma tendência evidente de acúmulo nas proximidades do fundo (maiores concentrações) (ver também a figura 6.20). Esta última tendência evidencia o efeito decisivo da velocidade de sedimentação. Percebe-se também a tendência de soerguimento de sedimentos em suspensão, por movimentos ascendentes, a jusante das cristas. A estimativa deste efeito condiz com as assertivas de Nezu e Nakagawa (1993) em relação à importância dos "boils" de primeira espécie na condução de partículas suspensas em direção a porções do escoamento distantes do fundo do canal.
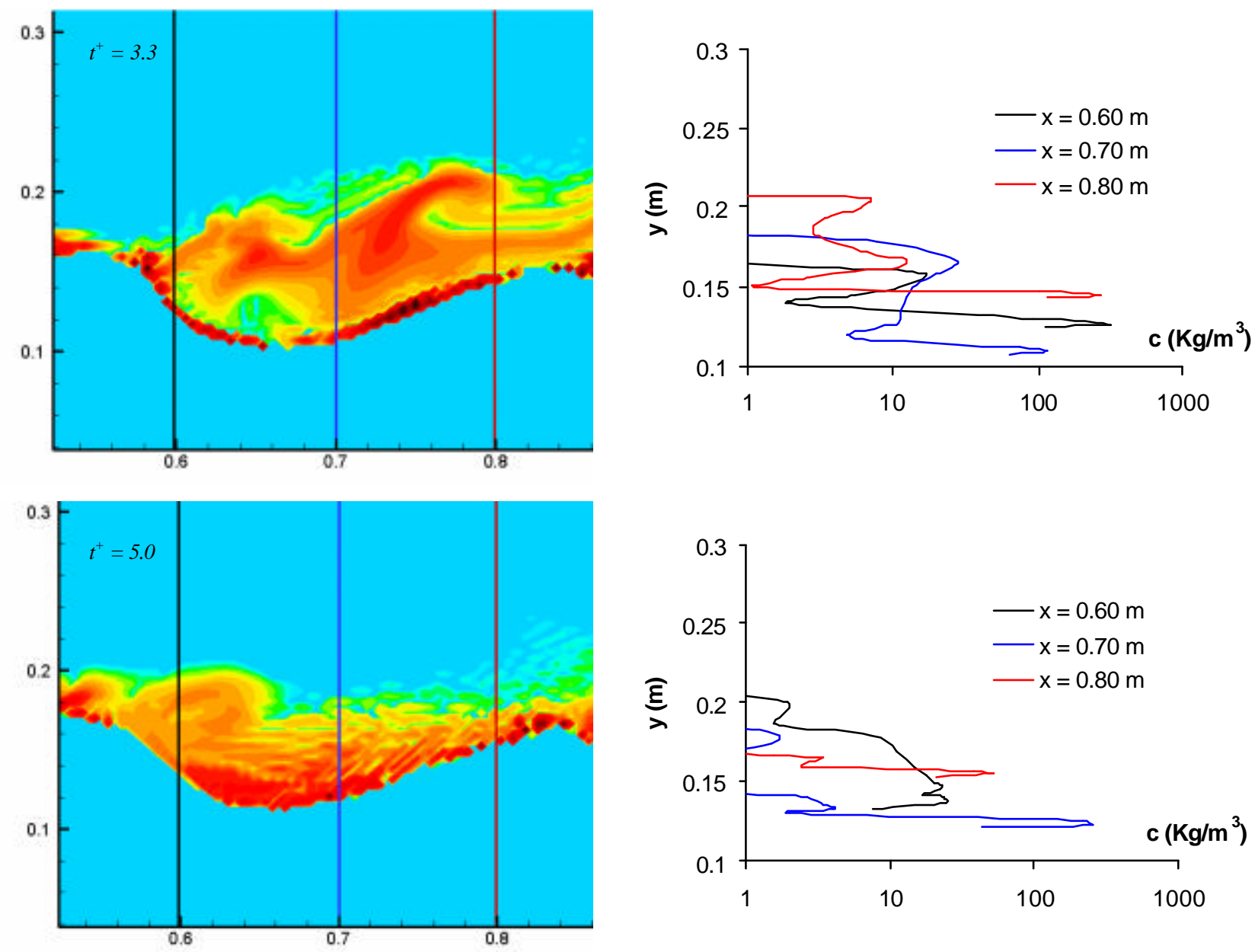

Figura 6.20 - Perfis de concentração no vale central do domínio: percebe-se que as maiores concentrações de sedimentos são mantidas junto ao fundo do canal, fato que destaca a influência da velocidade de sedimentação 

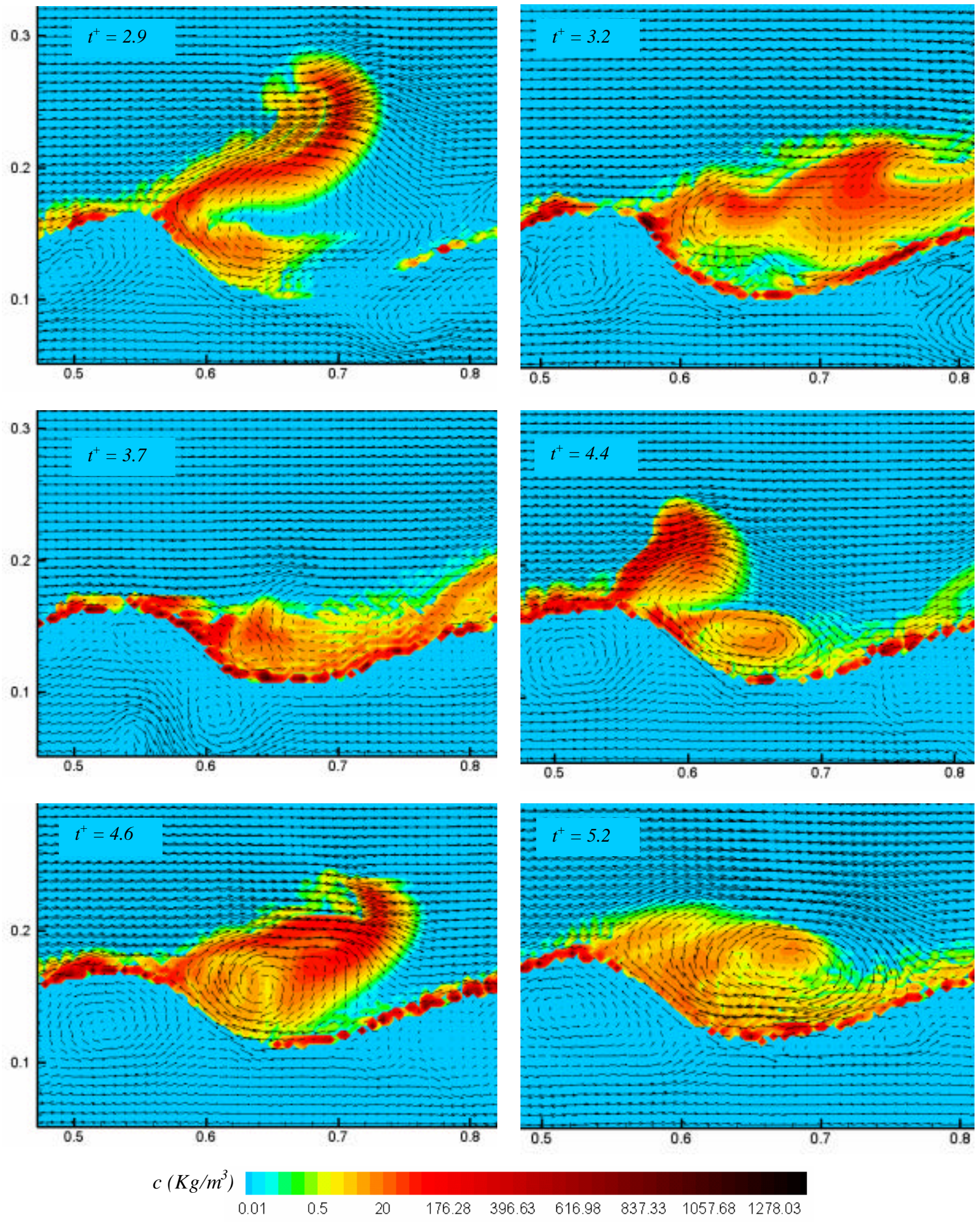

Figura 6.21 - Lançamento de sedimentos a jusante das cristas por estruturas turbilhonares de grande escala 
O lançamento preferencial de sedimentos a partir das cristas das ondulações pode ser observado por uma breve análise da figura 6.21. A formação de estruturas turbilhonares de grande escala, com ocorrência preferencial nessas regiões, constitui o principal mecanismo de injeção de sedimentos suspensos no escoamento.
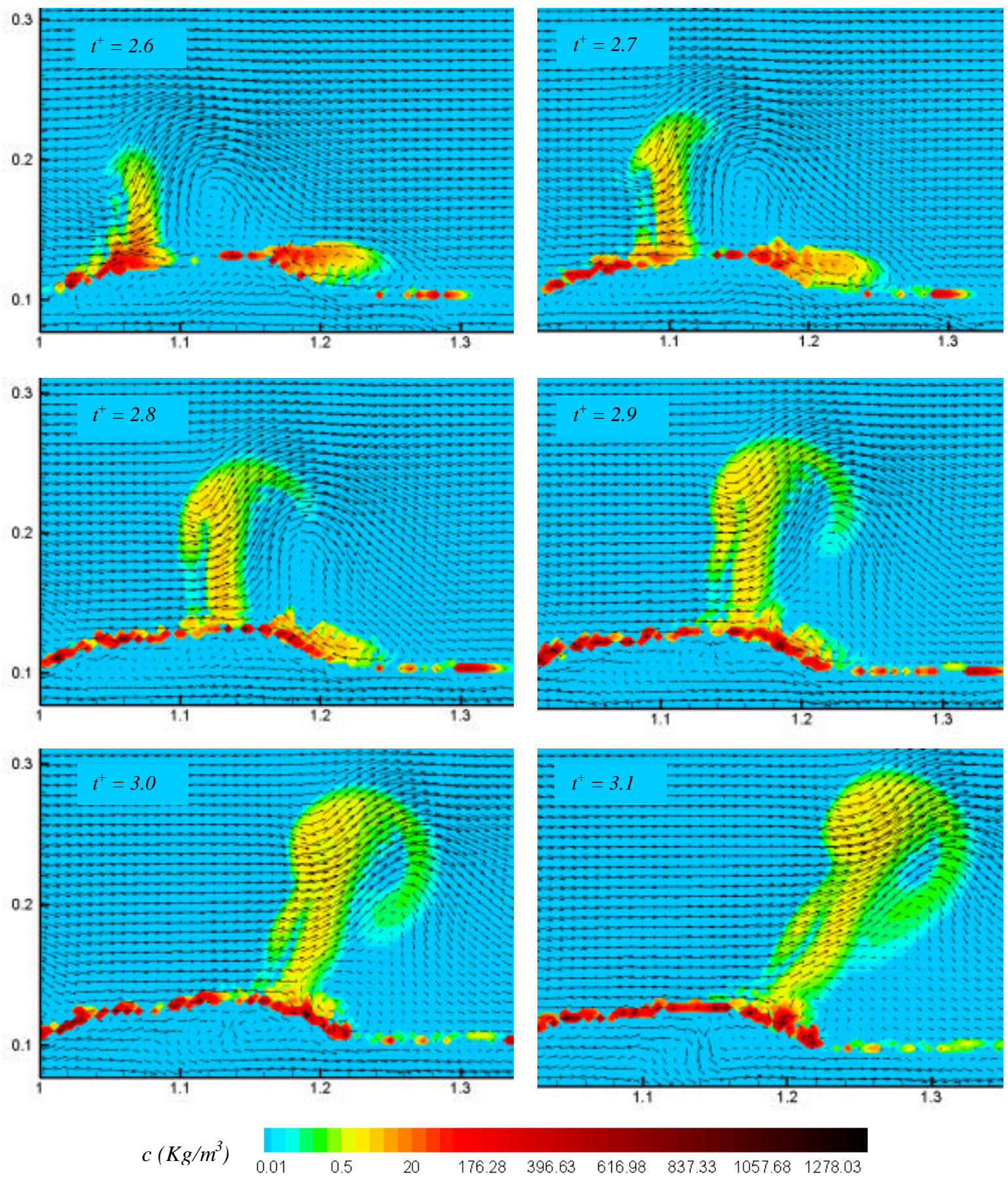

Figura 6.22 - Lançamento de sedimentos na forma de estruturas tipo "cogumelo" 
A distribuição de sedimentos suspensos em forma de "cogumelo" constitui outra estrutura interessante que foi devidamente capturada pela simulação. A figura 6.22 ilustra este tipo de lançamento. Seguramente, esses movimentos capturados não constituem estruturas tipo "grampo de cabelo" ou "ferradura", que são comuns em instabilidades de camada-limite. Nota-se aqui, movimentos de fluido preferencialmente verticais. A forma de "cogumelo" surge na distribuição de concentrações, devido à composição, sobre o sedimento, das velocidades do escoamento e da velocidade de sedimentação. Ainda, comparando as figuras 6.21 e 6.22, é possível perceber que a magnitude (em termos de concentração) dos lançamentos tipo "cogumelo" é inferior à dos la nçamentos que ocorrem a jusante das cristas.

De uma forma mais geral, nota-se que as maiores concentrações de sedimentos se restringem ao entorno do fundo do canal, ao passo que existe lançamento preferencial de "franjas" de sedimentos suspensos a partir das cristas das dunas. Essas verificações indicam que a hipótese seguida neste trabalho, a de se trabalhar unicamente com uma equação de transporte (equação de Advecção-Difusão), também pode estabelecer naturalmente os limites entre regiões de transporte de fundo e transporte em suspensão. No caso dos modelos de transporte clássicos, os quais utilizam equações semi-empíricas diferentes para cada setor, há a necessidade de pré-fixação das duas regiões. Essa pré-fixação é feita por critérios empíricos, de forma que não há ainda um consenso geral entre eles. Todavia, o critério de Einstein $(1942,1950)$ é mais utilizado, estipulando a região limítrofe como duas vezes o diâmetro médio do sedimento, medida a partir do leito. Vale lembrar que a fixação desse limite é puramente empírica.

O desprendimento de sedimentos a partir das cristas das dunas, previsto pela condição de contorno de fluxo de ressuspensão, embutida na equação de Advecção-Difusão, pode ainda ser qualitativamente comparado com resultados numéricos que utilizam modelos lagrangeanos de transporte de particulados (equação de Maxey-Riley). A figura 6.23 compara os resultados da presente simulação (que utilizou a equação de Advecção-Difusão), com Simulações de Grandes Escalas realizadas por Chang e Scotti (2003) (que utilizaram MaxeyRiley para um número finito de partículas). Ainda que as condições dos escoamentos, das geometrias e dos sedimentos não sejam rigorosamente iguais, percebe-se que padrões muito similares são observados entre as duas simulações. 
(a)
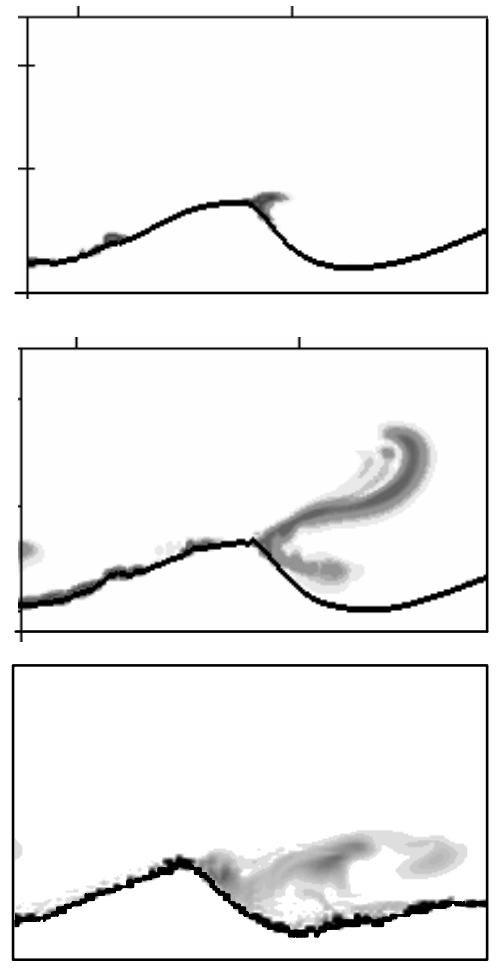

(b)
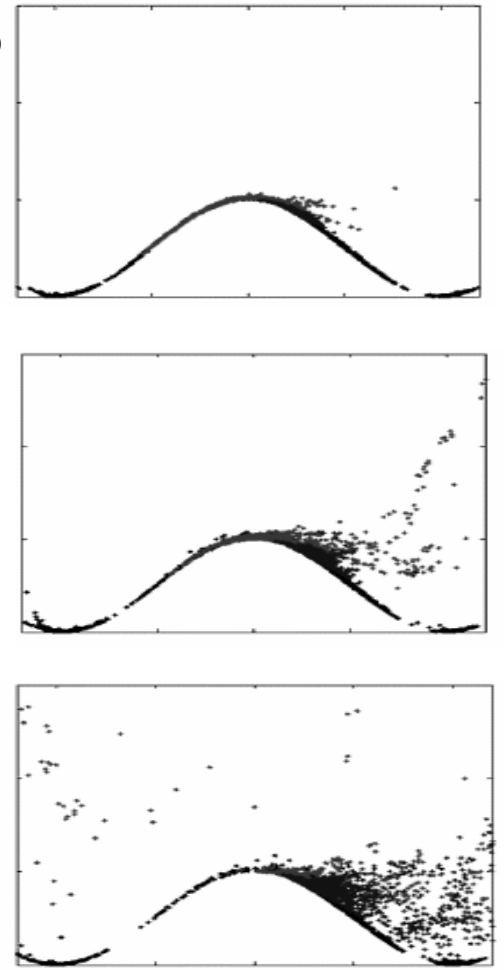

Figura 6.23 - Comparação qualitativa entre resultados instantâneos da presente simulação (com a equação de Advecção-Difusão) e a simulação realizada por Chang e Scotti (2003) (com a equação de Maxey-Riley). No caso (a) tem-se: Re $=8750$ (baseado na altura efetiva do canal), e sedimento com densidade de 2,65; No caso (b) tem-se Re=6500 (baseado na altura do canal) e sedimento com densidade de 1,50

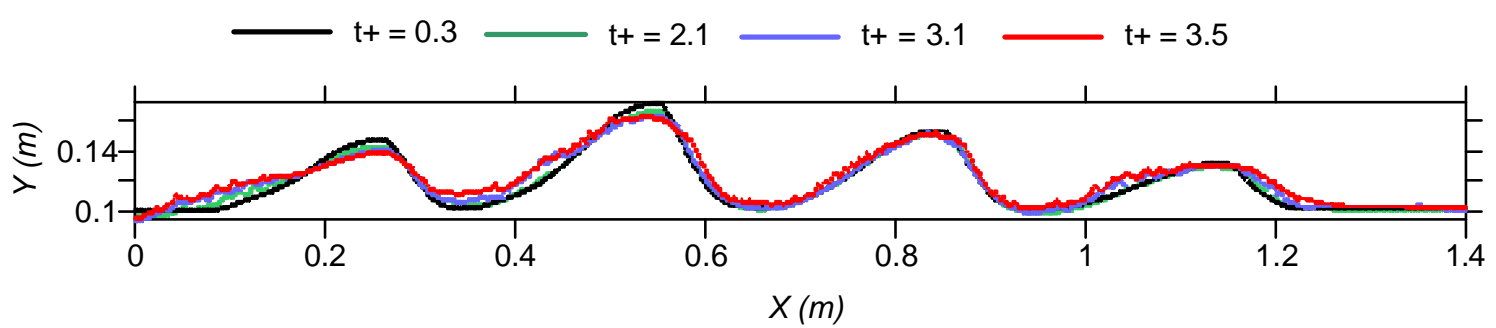

Figura 6.24 - Evolução temporal da forma de fundo, representada por deformações na malha lagrangeana

Em decorrência da ação dos processos concomitantes de erosão e deposição, a simulação previu deformações na forma de fundo, fato que acrescentou o caráter transiente do escoamento. A figura 6.24 ilustra a evolução do fundo do canal, aqui representado pela malha 
lagrangeana. Nota-se a tendência de formação de depósitos nos vales e de erosão nas cristas. As deformações se tornam mais acentuadas com o decorrer do tempo, uma vez que concentrações diferentes de zero passam a preencher as células adjacentes ao leito. Dessa forma, os balanços de massa nessas células, além dos eventuais fluxos de ressuspensão, proporcionam alterações mais sensíveis nas cotas da malha lagrangeana. Durante o período de tempo simulado (sessenta segundos) não foi possível verificar deslocamento de dunas. Não obstante, uma análise expedita da figura 6.24 revela uma suave tendência de deslocamento longitudinal dessas ondulações.

\section{4 - SIMULAÇÃO DO TRANSPORTE DE SEDIMENTOS SOBRE FORMAS DE FUNDO ALUVIAIS (CASO TRIDIMENSIONAL)}

O domínio de escoamento, utilizado neste caso, foi baseado em um trecho de um canal experimental, construído no Laboratório de Hidráulica Ambiental da Escola de Engenharia de São Carlos. Vale ressaltar que o referido experimento foi realizado como parte de um outro projeto de pesquisa, o qual visou estudar a questão do assoreamento de reservatórios. Assim, a condição inicial da simulação partiu de dunas reais formadas nesse trecho experimental. Dessa forma, o domínio computacional estendido é ilustrado pela figura 6.25. A composição da malha euleriana utilizou 90 × 45 x 30 células nas direções longitudinal, vertical e transversal, respectivamente. A malha lagrangeana, por sua vez, foi discretizada com $181 \times 61$ pontos nas direções longitudinal e transversal. Embora, a rigor, essas duas malhas possam ser independentes, optou-se por manter uma determinada equivalência entre elas. Este procedimento foi necessário na realização do balanço de massa e na verificação do cisalhamento no leito, os quais são reguladores de alterações nas cotas de fundo. Assim, os pontos interfaciais foram espaçados de $\Delta x / 2$ na direção longitudinal e $\Delta z / 2$ na direção transversal, sendo que somente a sua cota (posição vertical) foi eventualmente alterada. A figura 6.26 ilustra, com maior detalhamento, essa distribuição. 


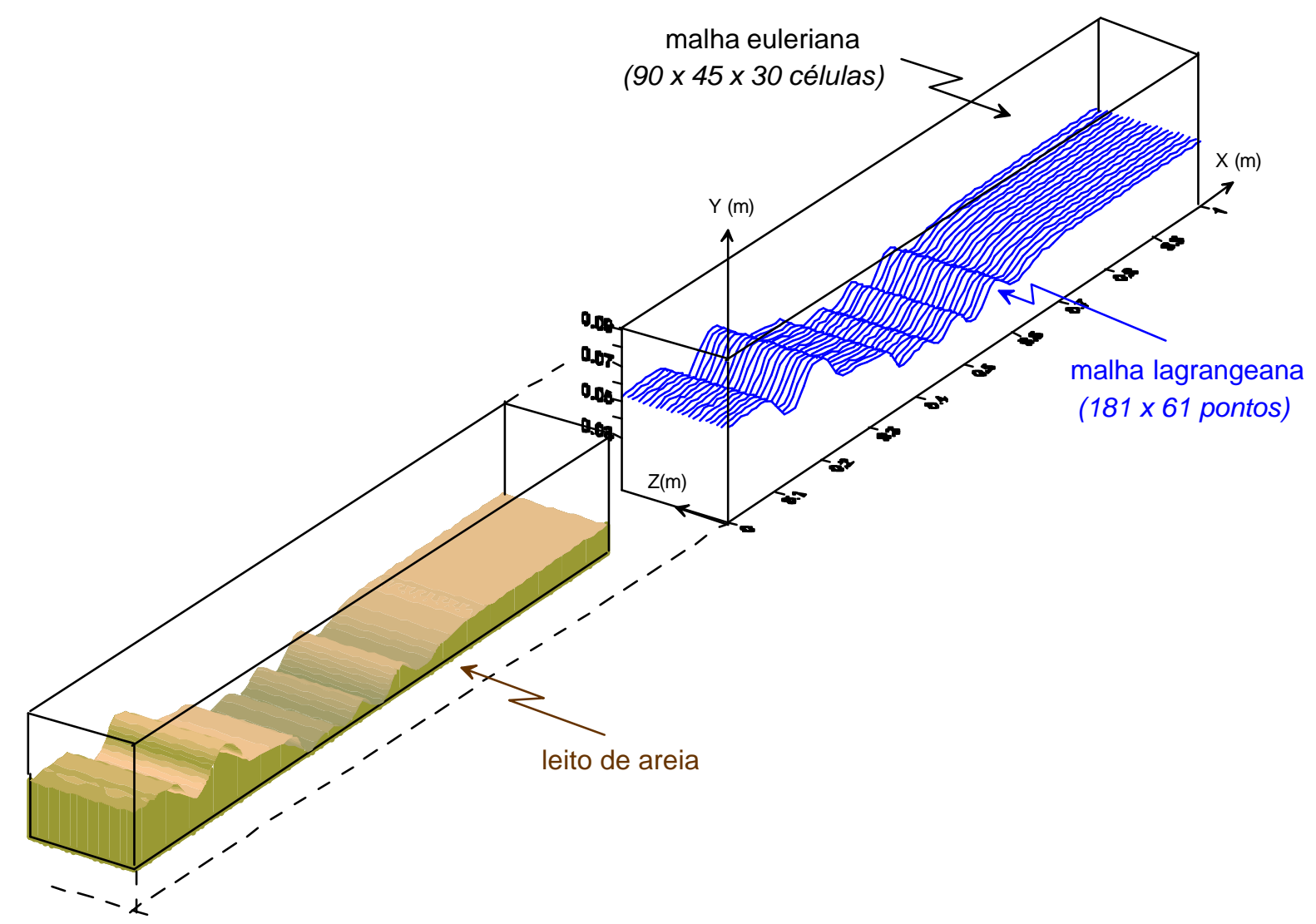

Figura 6.25 - Transformação do domínio de escoamento real para o domínio computacional, discretizado pelas malhas euleriana e lagrangeana
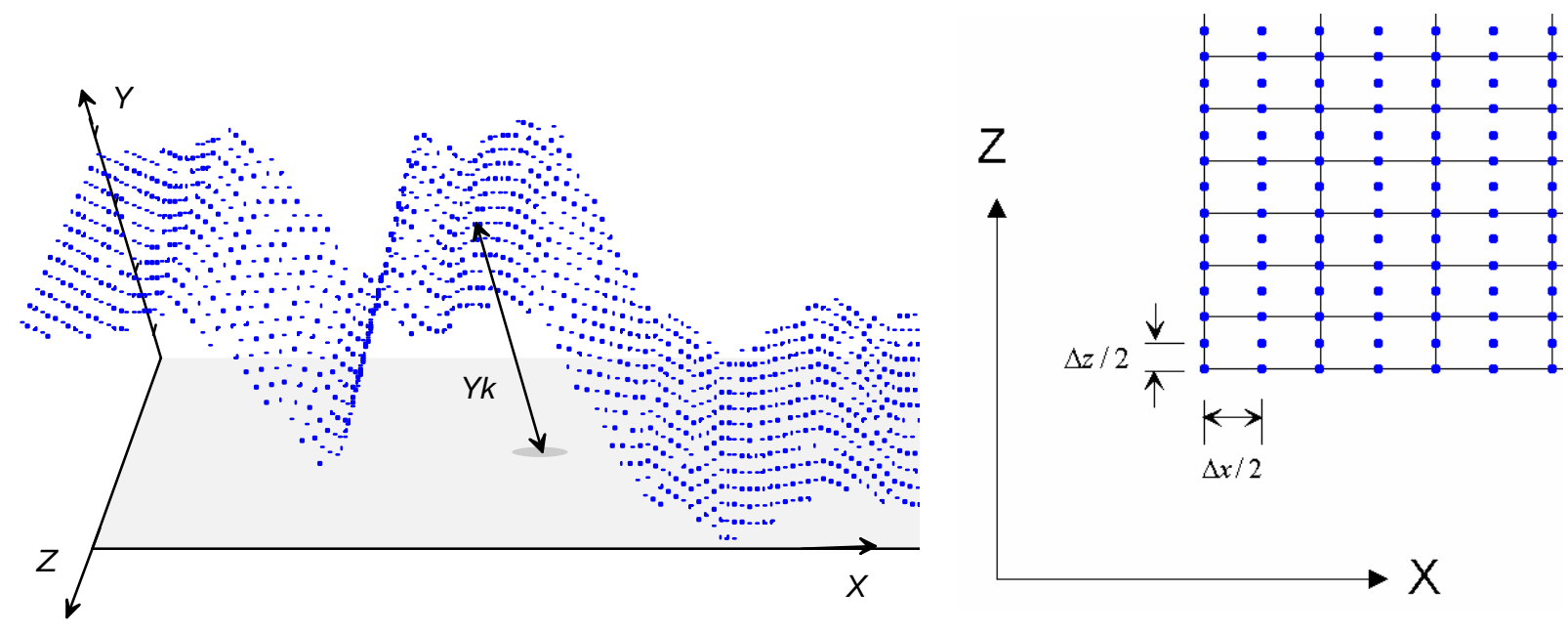

Figura 6.26 - Distribuição dos pontos lagrangeanos ao longo do domínio computacional. Esses pontos possuem coordenadas fixas ao longo das direções longitudinal e transversal. Apenas a cota é totalmente independente da malha euleriana e pode variar livremente em decorrência dos eventuais processos de deposição e erosão estimados 


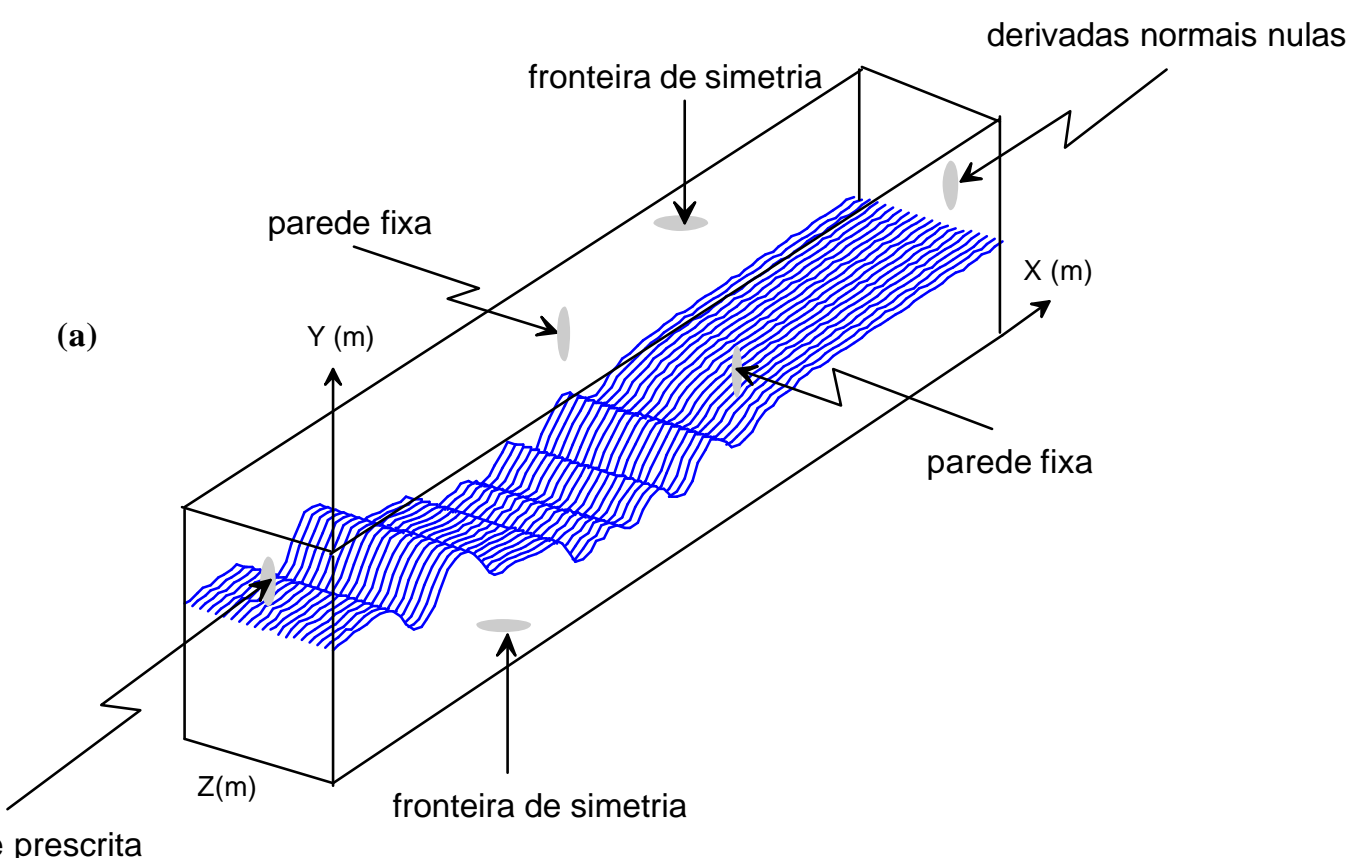

velocidade prescrita

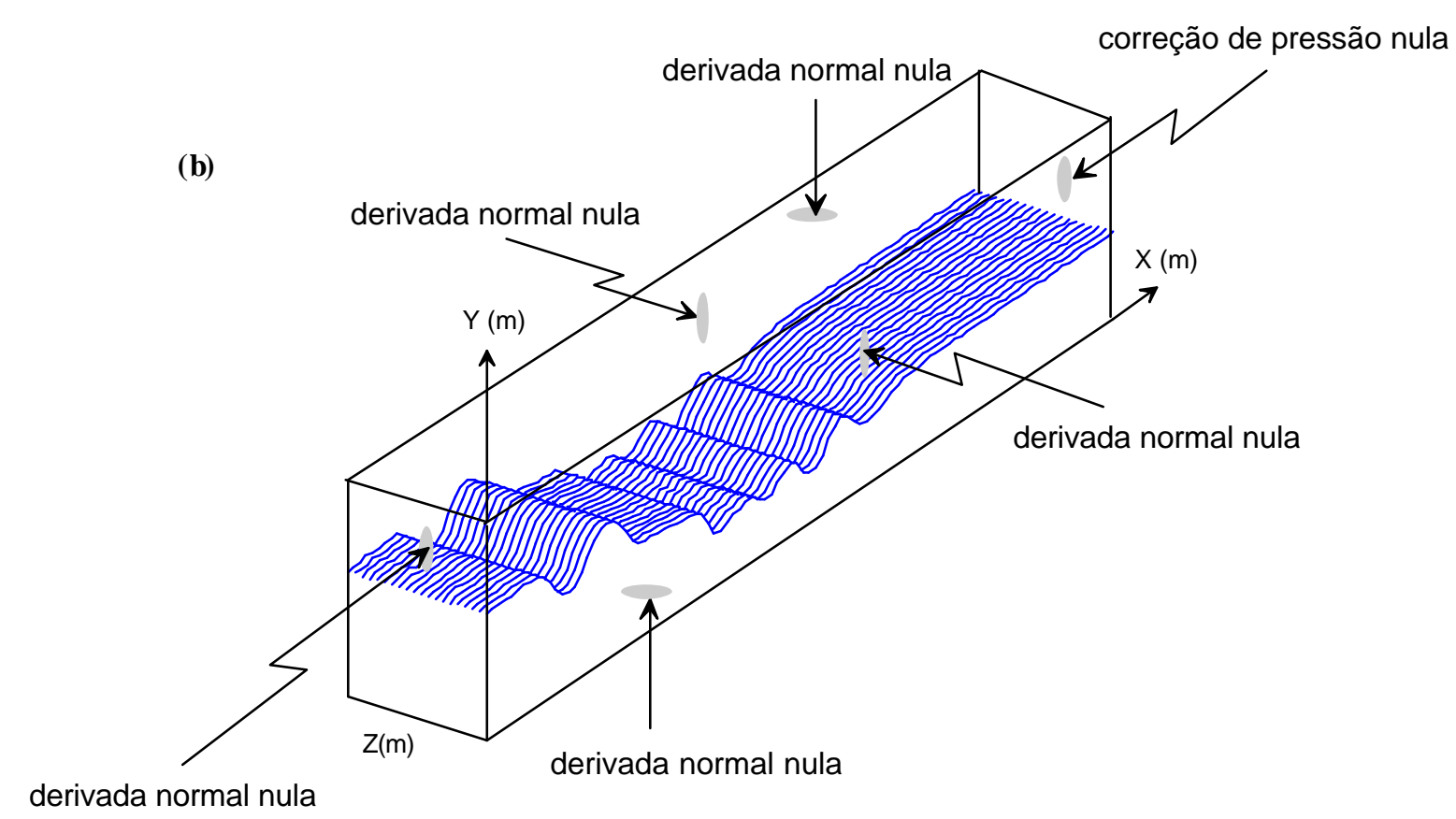

Figura 6.27 - Condições de contorno: (a) para as componentes de velocidade; (b) para os termos de correção de pressão

As condições de contorno, para os campos hidrodinâmicos, foram impostas como simetria nas faces superior e inferior do domínio, paredes sólidas (não deslizamento) nas laterais, perfil de velocidade prescrito na entrada e derivadas nulas (em relação ao eixo longitudinal) na saída. Para os termos de correção de pressão, utilizados na equação de Poisson, foram impostas derivadas normais nulas em todas as fronteiras, exceto na saída do 
domínio, onde se adotaram termos de correção nulos (ver figura 6.27). Isto se justifica pelas condições de contorno de simetria e de paredes sólidas estipuladas para as velocidades normais às fronteiras, as quais não são prescritas apenas na saída.

Como condição inicial, ao longo de todo o domínio, foi adotado o mesmo perfil uniforme de velocidade da entrada. Na região inferior à malha lagrangeana, o referido perfil foi imposto como $1 \%$ da velocidade na região de interesse (acima da interface). Essas distribuições de velocidade foram introduzidas de forma a provocar um número de Reynolds resultante de 3000. Esse valor baseou-se na altura efetiva de entrada do canal e na velocidade média ao longo da seção transversal. Não se pode perder de vista que os perfis de velocidade foram atribuídos tanto acima quanto abaixo da interface, muito embora só a região superior à malha lagrangeana seja de interesse final. A pressão foi inicializada com campos nulos. As velocidades vertical e transversal também foram atribuídas como nulas para efeito de inicialização dos cálculos.

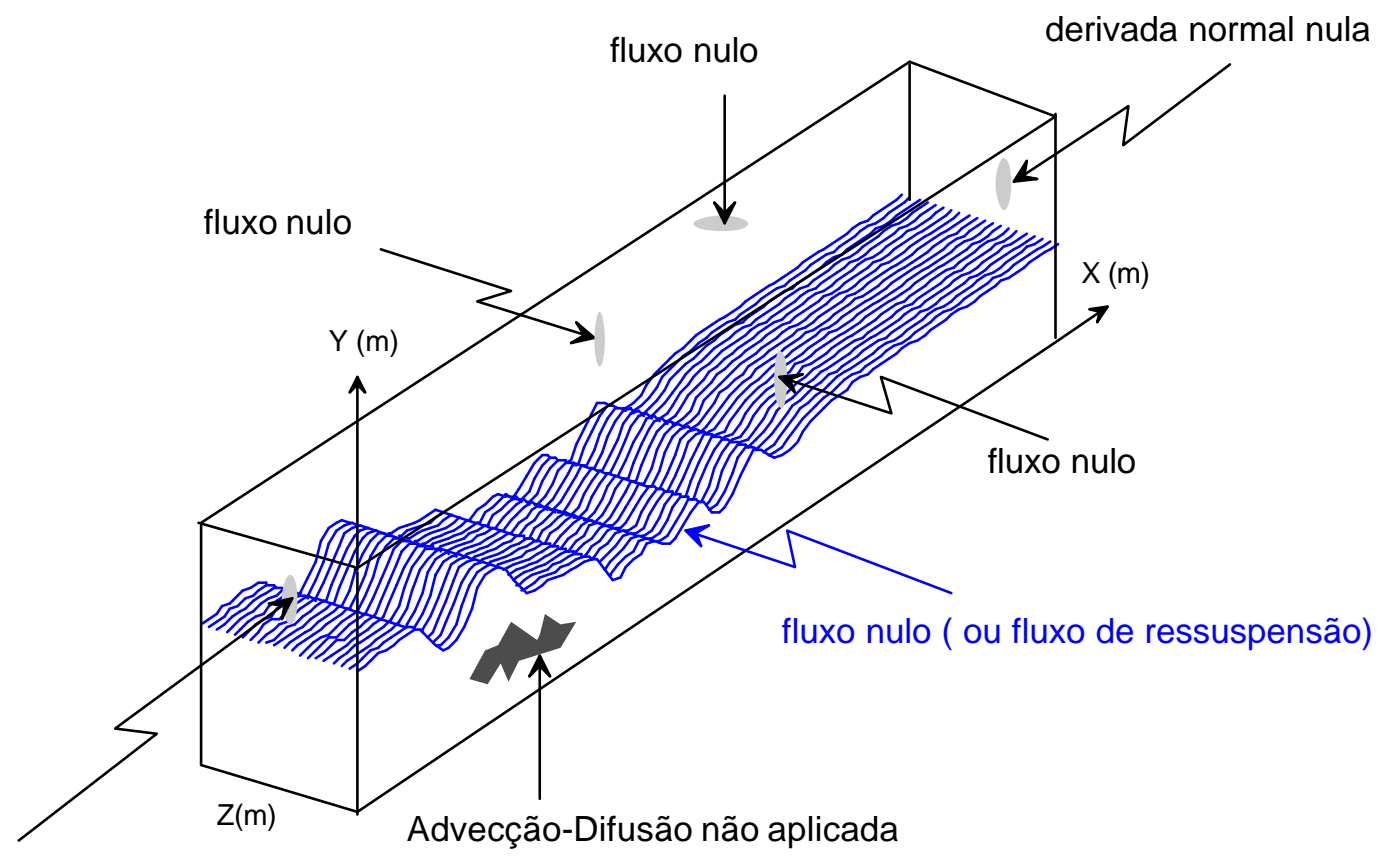

fluxo de massa prescrito

Figura 6.28- Condições de contorno para a equação de Advecção-Difusão (concentração de sedimentos) 
Para as concentrações de sedimento, foram impostas condições de fluxo de massa prescrito na entrada do canal, fluxo nulo na fronteira superior e nas laterais, e derivadas normais nulas na saída (ver figura 6.28). A equação de Advecção-Difusão só foi aplicada na região de interesse do escoamento, de forma que fluxos de massa nulos foram adotados nas faces das células interceptadas pela malha lagrangena. Este artifício evita a passagem de concentrações para a região inferior, o que é fisicamente incorreto, uma vez que o fundo do canal retém sedimentos. Não obstante, quando circunstâncias de cisalhamento críticas sobre o leito são sobrepujadas, o fluxo de ressuspensão $\left(\dot{f}_{R E S S}\right)$ foi introduzido como condição de contorno para as células adjacentes à malha lagrangeana. No interior do domínio de escoamento foram adotadas condições iniciais de concentrações nulas.

Na discretização das equações diferenciais governantes (Navier-Stokes, Continuidade, Poisson e Advecção-Difusão) foi utilizado o esquema de Diferenças Centrais de segunda ordem. No avanço temporal, foram adotados esquemas explícitos (por razões já comentadas no capítulo anterior). Assim, para o cálculo dos campos de velocidade (por Navier-Stokes) vigorou o esquema de Adams-Bashforth de quarta ordem, enquanto que, para o cálculo das concentrações (Advecção-Difusão), vigorou o esquema de Adams-Bashforth de segunda ordem. No que diz respeito à utilização dos avanços temporais explícitos, há que se cuidar dos valores do incremento de tempo. Incrementos grandes são fortes condicionantes de instabilidade no código. Nesse contexto, os cálculos foram inicializados com passos de $10^{-4} \mathrm{~s}$, os quais foram suavemente elevados até valores de $10^{-3} \mathrm{~s}$ por uma progressão geométrica de razão 1,05. O modelo Função Estrutura de Velocidade de segunda ordem foi utilizado no cálculo das viscosidades e difusividades turbulentas sub-malha.

No uso do Método de Fronteira Imersa, a distribuição dos seis pontos auxiliares (os detalhes foram descritos no capítulo específico desse método) seguiu o esquema ilustrado pela figura 6.29. Note-se que os pontos 3 e 4 estão sempre dispostos acima da interface. Os pontos 1 e 2 apresentam disposição no sentido montante/jusante até a metade do comprimento do canal, com inversão deste sentido a partir do início da metade final. Procedimento semelhante foi utilizado na fixação dos pontos 5 e 6 , tomando como referência a metade da largura do canal. Especificamente no caso dos pontos auxiliares 1 e 2, a regra acima deve ser transformada de forma a manter os pontos sempre acima da interface. Assim, na região das dunas, o sentido de disposição desses pontos foi de montante/jusante nos declives e de jusante/montante nos aclives. Assim, cumpre-se uma das determinações do Modelo Físico Virtual: a de locar os pontos auxiliares sempre na região de interesse do escoamento. 


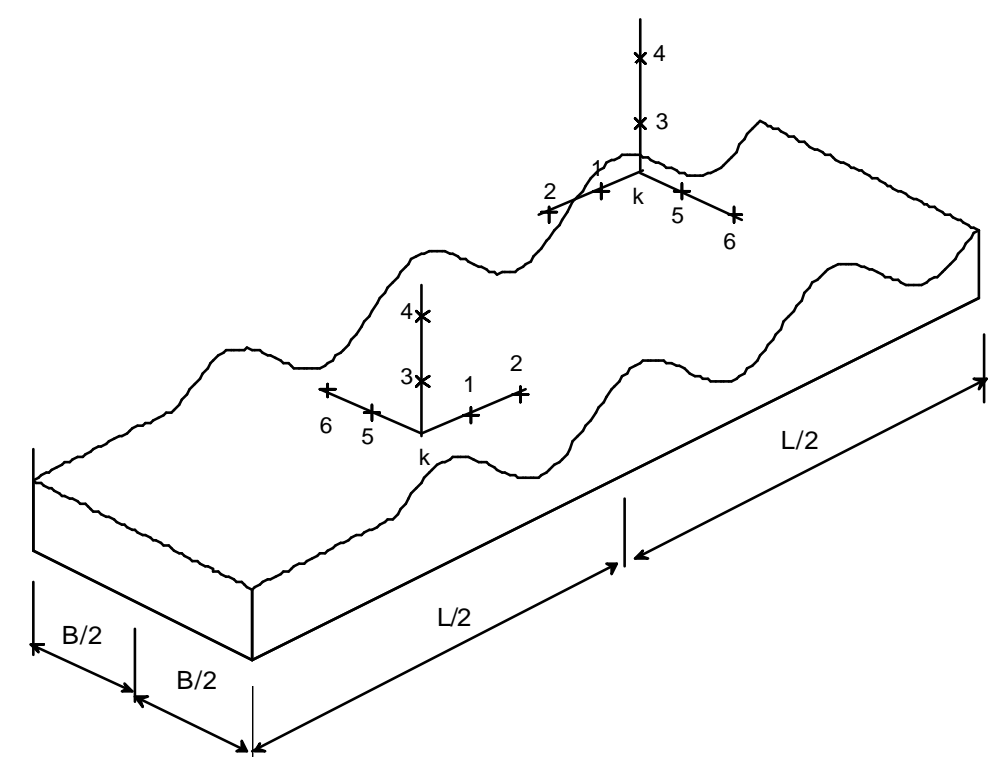

Figura 6.29 - Esquema de distribuição dos pontos auxiliares a partir da interface imersa (croquis)

(a)

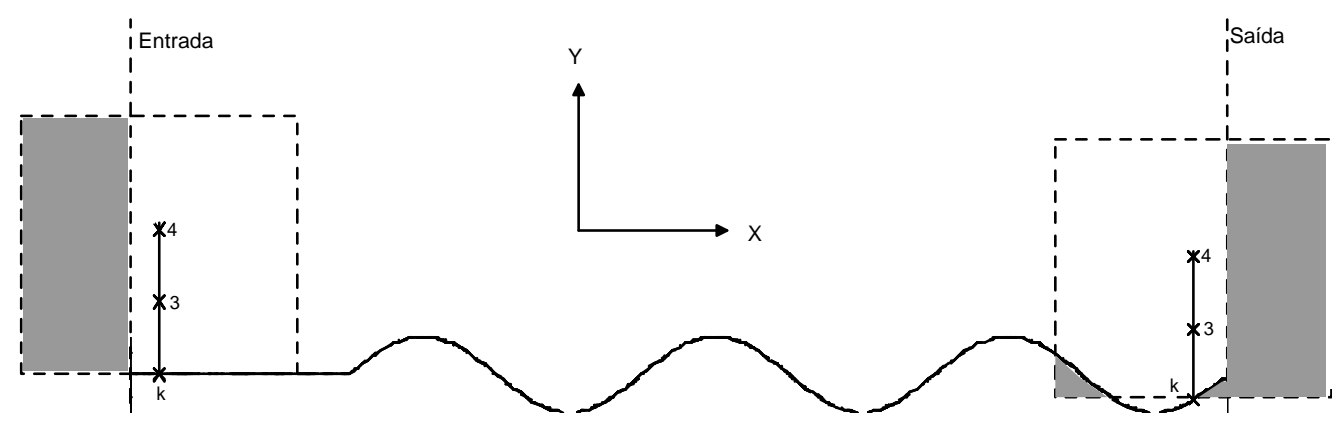

(b)
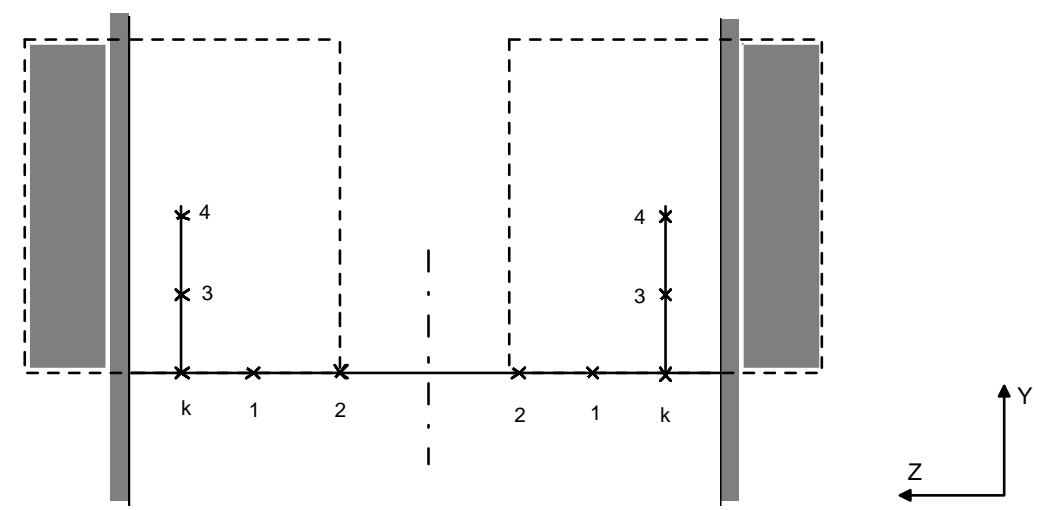

Figura 6.30 - Esquema (croquis) da região de interpolação para o ponto auxiliar 4: (a) vista lateral; (b) vista frontal. As regiões situadas fora do domínio e abaixo da interface (hachuras) não são aproveitadas 
A região de interpolação, das velocidades e da pressão, para os pontos auxiliares foi estabelecida como um paralelepípedo de lados $4 \Delta x$ x $4 \Delta y \times 4 \Delta z$ centrado em cada ponto auxiliar. Segundo os preceitos do Modelo Físico Virtual, somente células situadas dentro da região de interesse do escoamento devem ser contribuintes, o que acarreta a exclusão de pontos fora do domínio e abaixo da interface (ver figura 6.30).

È conveniente lembrar que, pelo Método de Fronteira Imersa, o campo de força disseminado no interior do domínio de escoamento, é o responsável pela imposição virtual da condição de não deslizamento sobre paredes sólidas. Todavia, ao se considerar uma fronteira fixa, as velocidades não são rigorosamente anuladas ao longo da interface, ainda que sejam reduzidas consideravelmente. Essa redução, conforme já foi comentado, é sintetizada pelo fator $L_{2}$, que, no caso tridimensional utiliza informações das três componentes de velocidade do fluido sobre a fronteira, de acordo com:

$$
L_{2}=\sqrt{\sum_{k} \frac{u_{k}^{2}+v_{k}^{2}+w_{k}^{2}}{N_{k}}}
$$

Onde, relembrando:

- $\quad u_{k}, v_{k}, w_{k}=$ componentes de velocidade do fluido sobre a interface $\left[\mathrm{LT}^{-1}\right]$;

- $N_{k}=$ número total de pontos lagrangeanos.

A distribuição do resíduo $L_{2}$, ao longo da marcha temporal, é ilustrada pela figura 6.31. Percebe-se, neste caso, uma rápida tendência de estabilização com valores na ordem de $8.10^{-4}$. Esta ordem de grandeza não é muito diferente daquelas obtidas com discretização clássica coincidente com a fronteira. Esta observação vem indicar que a construção da malha lagrangeana, dispondo tridimensionalmente os pontos lagrangeanos, segundo os moldes recém comentados, constitui uma alternativa consistente. 


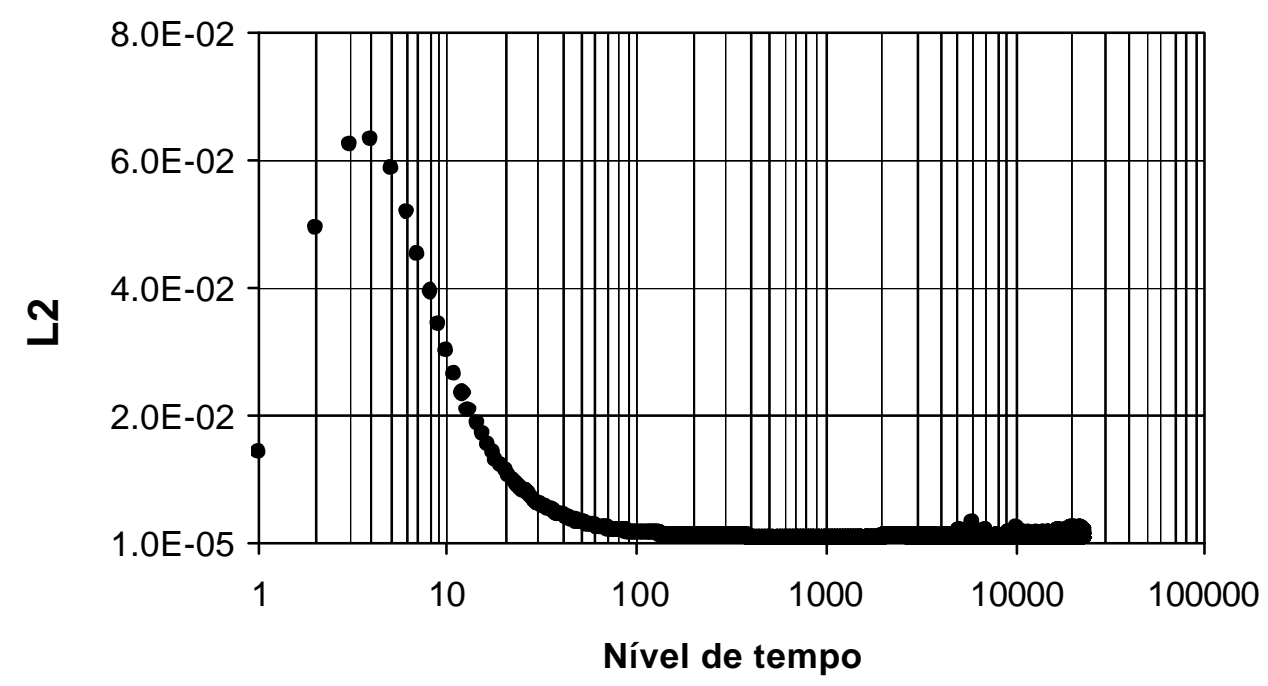

Figura 6.31 - Evolução temporal do fator residual $L_{2}$.

As figuras 6.32 a 6.34 ilustram a distribuição espacial das componentes instantâneas de velocidade na região de interesse do escoamento. Por uma breve análise dessas figuras, é possível verificar zonas onde os gradientes de velocidade são elevados, constituindo camadas cisalhantes livres, condicionantes de estruturas turbulentas de grande escala. Esses elevados gradientes surgem preferencialmente nos vales (com campos de $u$ e $v$ inflexionais) e nas proximidades das paredes laterais (com campos de $w$ inflexionais).

Os campos de velocidade inflexionais ocorrem quando há mudança no sentido dos vetores (em decorrência da mudança de sinal de uma ou duas componentes). Evidentemente, essa mudança de sentido acarreta maiores gradientes locais e, conseqüentemente, elevada produção de tensões cisalhantes. A figura 6.35 permite visualizar alguns desses campos inflexionais através dos vetores de velocidade tangentes ao plano longitudinal que passa pelo eixo do canal. 

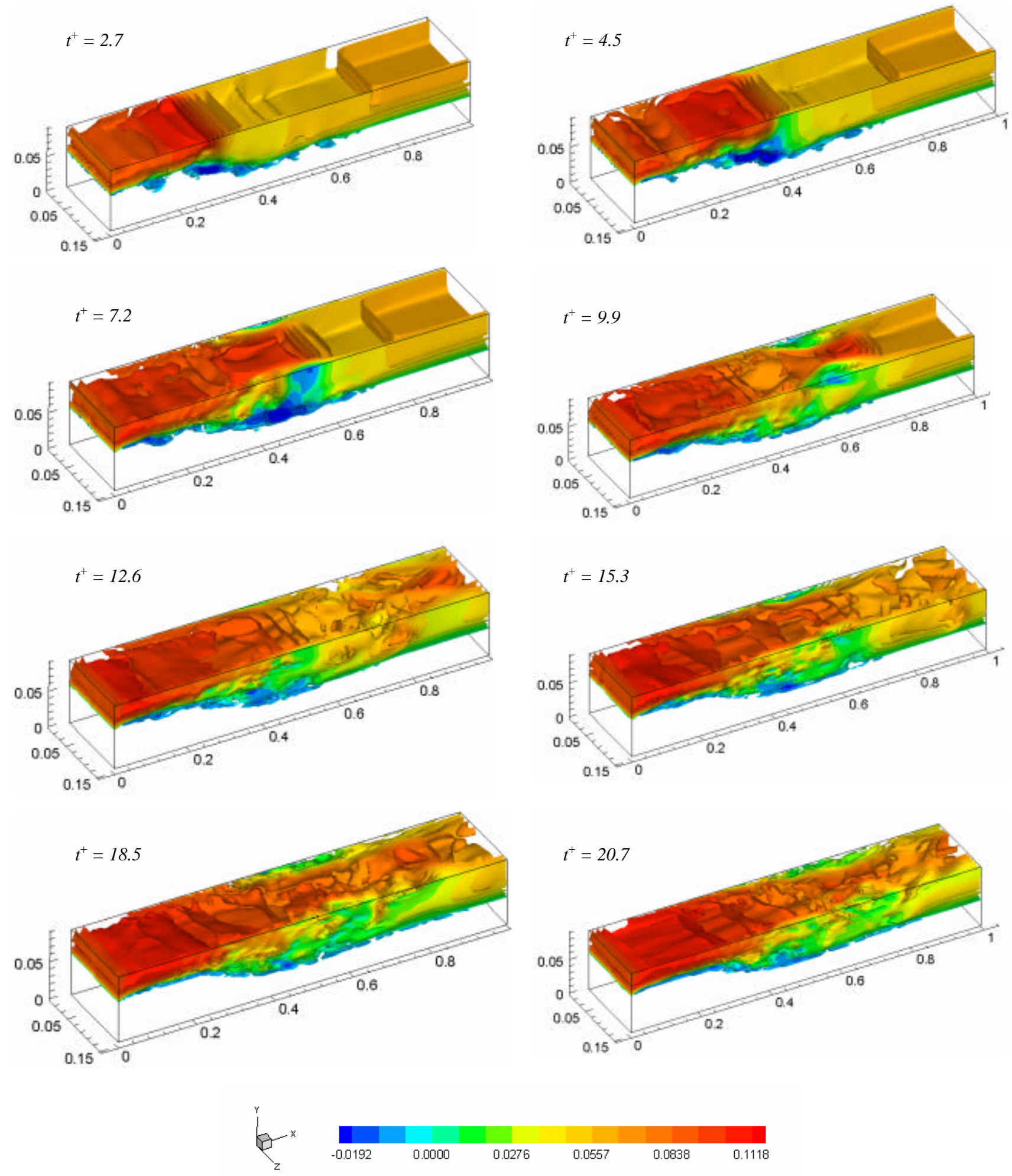

Figura 6.32 - Iso-superfícies instantâneas da componente longitudinal de velocidade [m/s] 

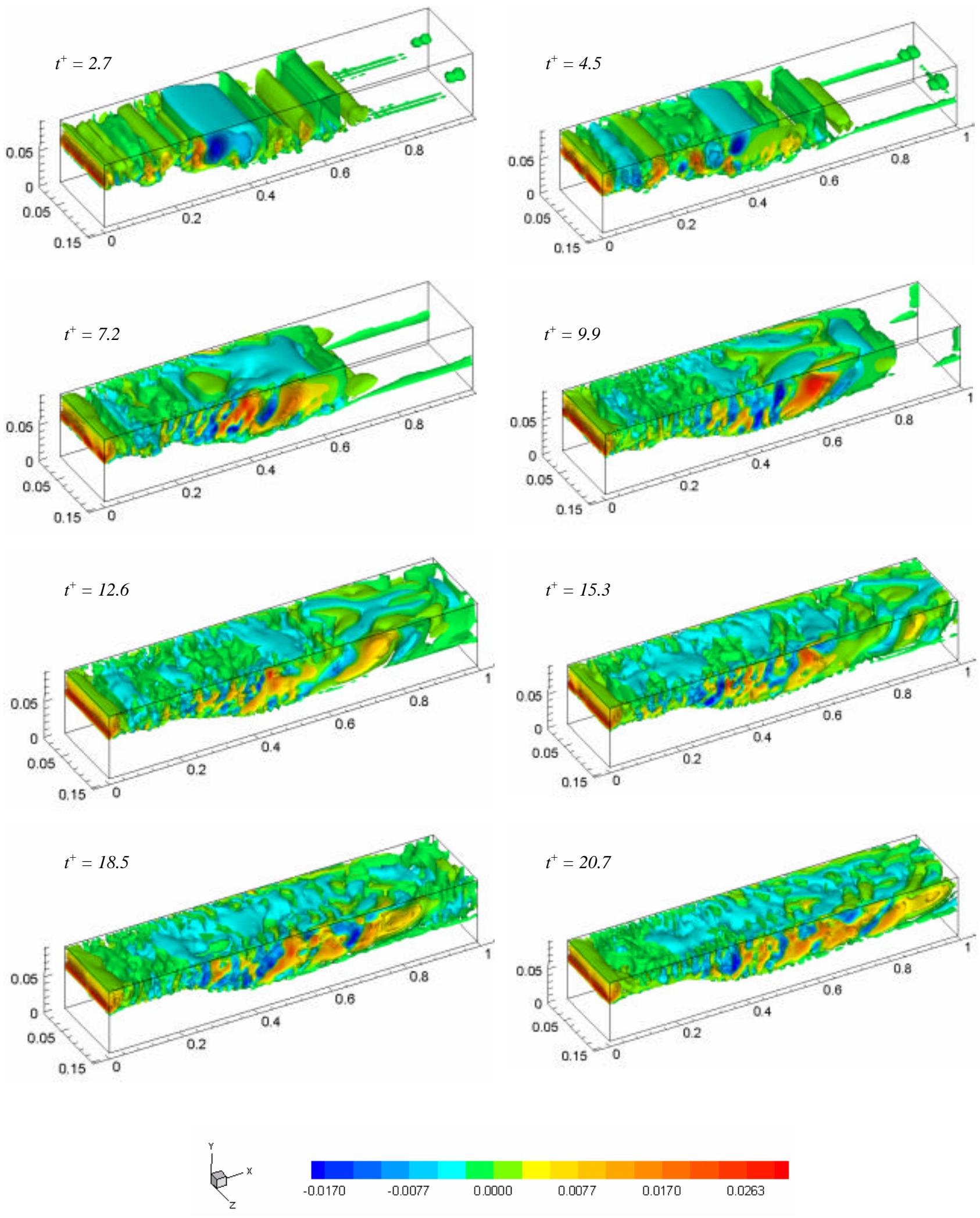

Figura 6.33 - Iso-superfícies instantâneas da componente vertical de velocidade [m/s] 

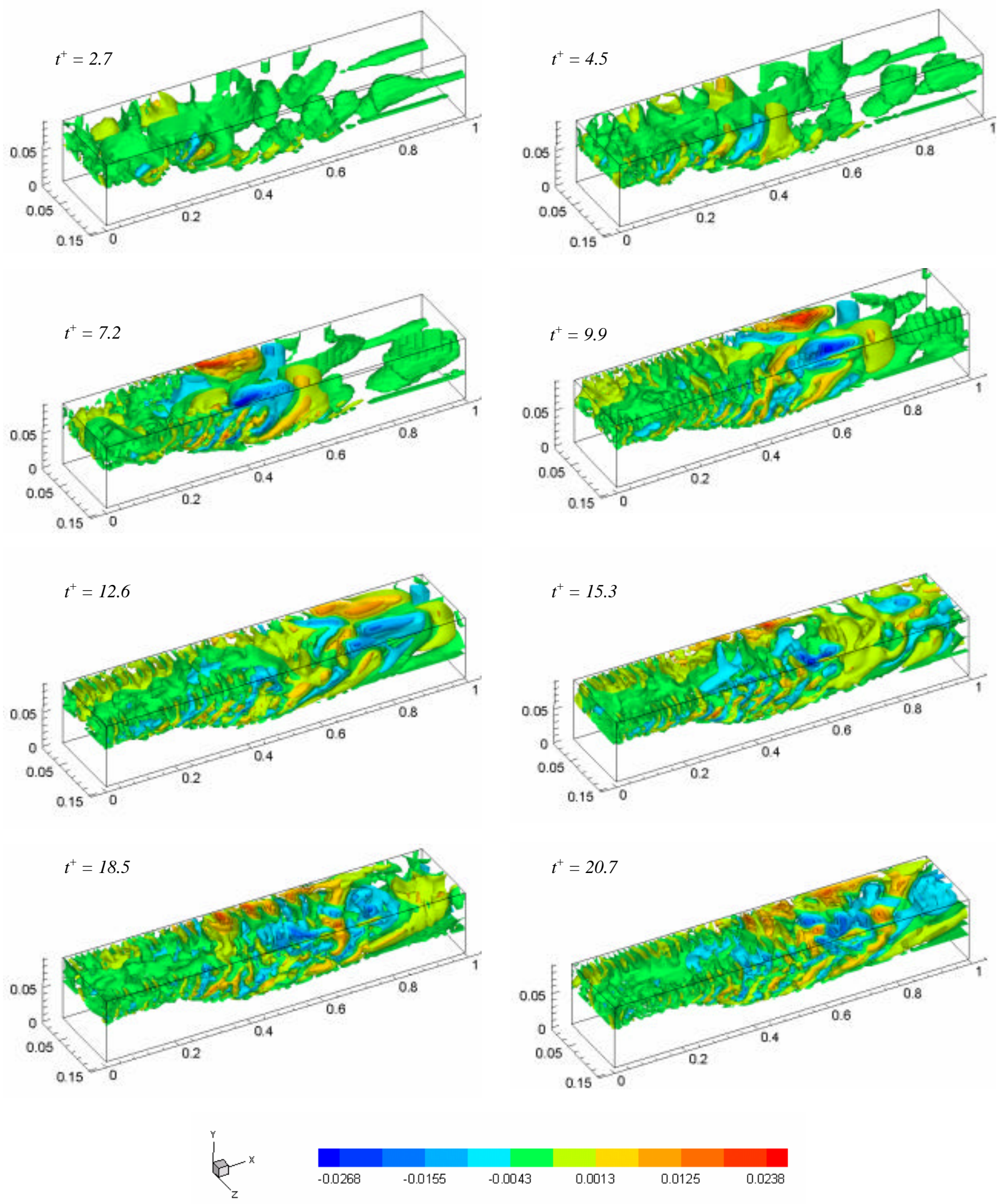

Figura 6.34 - Iso-superfícies instantâneas da componente transversal de velocidade [m/s] 

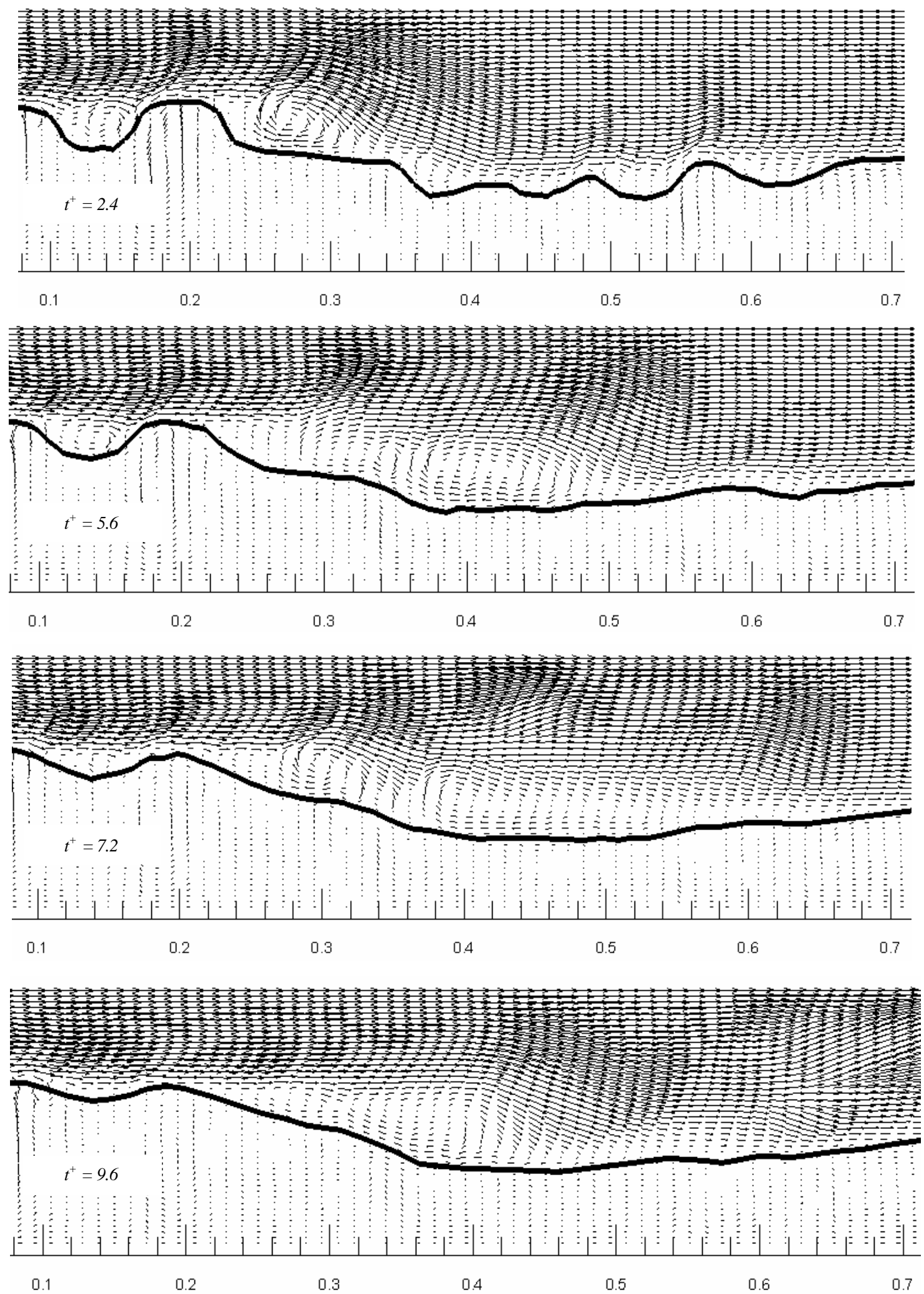

Figura 6.35 - Vetores de velocidade tangentes ao plano longitudinal central (continua) 


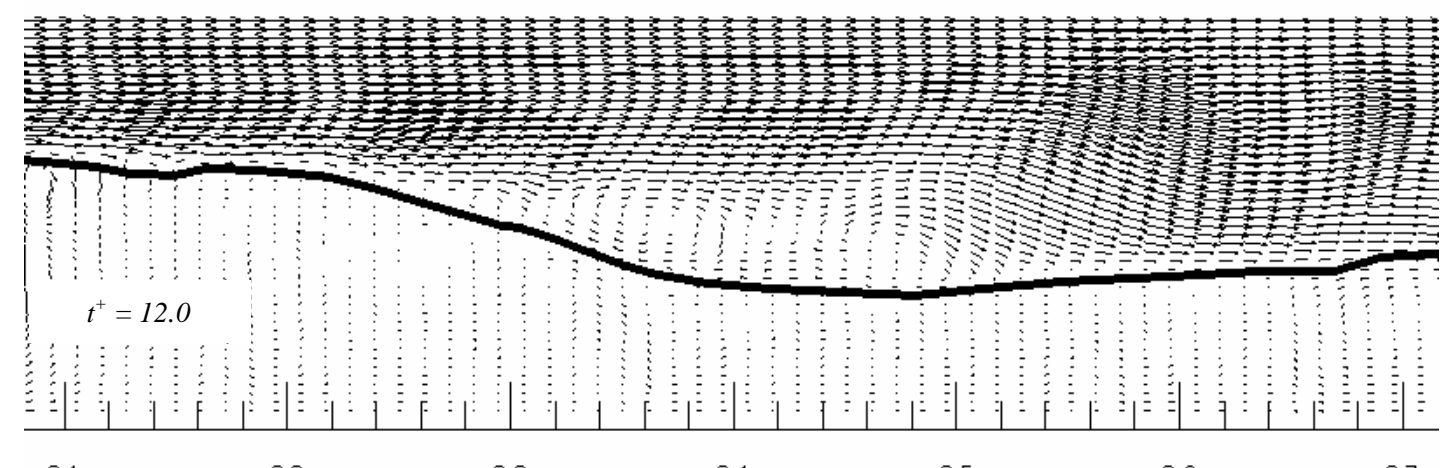

0.2

0.3

0.4

0.5

0.6

0.7

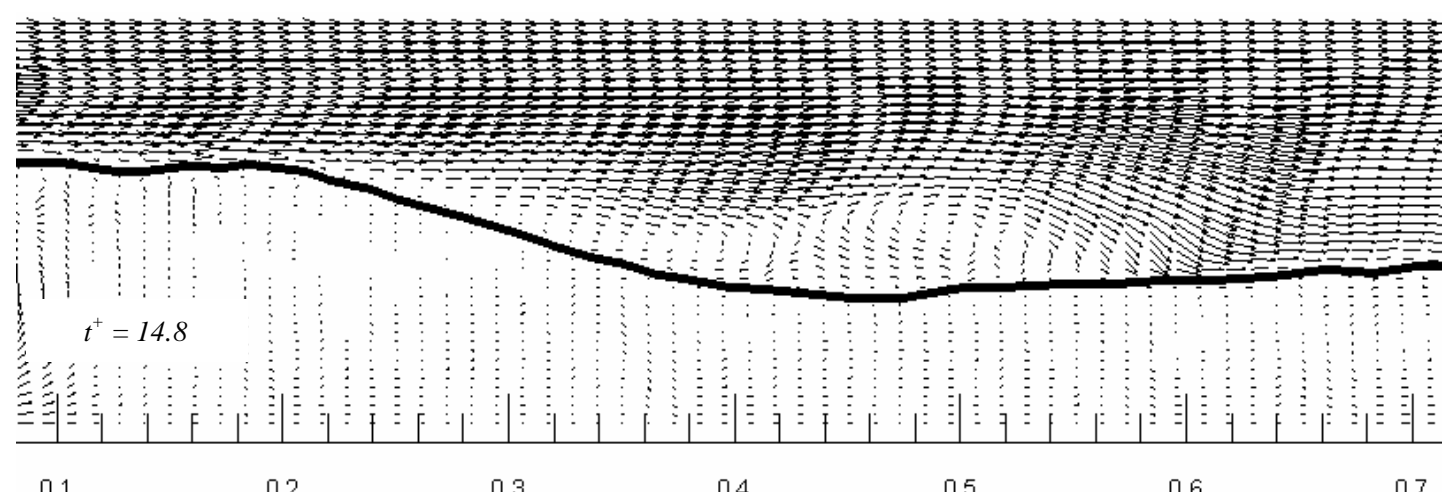

0.1

0.2

0.3

0.4

0.5

0.6

0.7

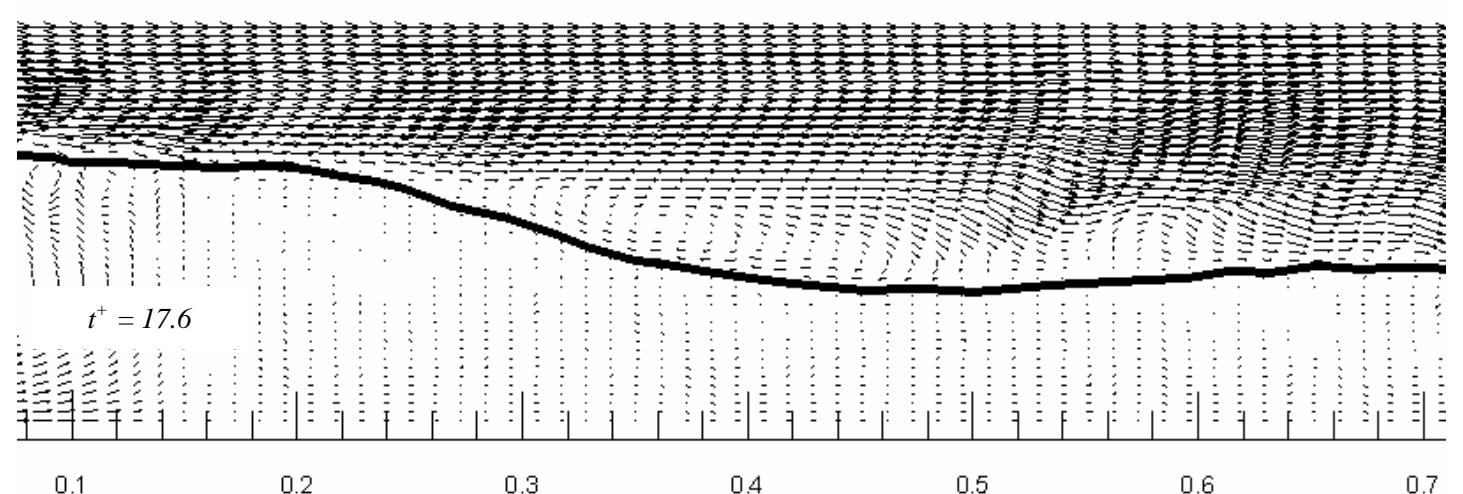

0.1

0.2

0.3

0.4

0.5

0.6

0.7

Figura 6.35 - Vetores de velocidade tangentes ao plano longitudinal central (conclusão)

Por uma breve análise da figura 6.35 é possível notar que a forma de fundo sofre deformações com o decorrer do tempo. Estas alterações morfológicas serão discutidas adiante, por conveniência. Por ora, é interessante comentar que, na primeira metade do canal, a forma de fundo assume um aspecto semelhante ao de um difusor com elevada declividade. Neste tipo de geometria, especialmente no declive, é comum a formação de regiões de escoamento inverso na proximidade da parede. Esta tendência foi devidamente capturada pela simulação e pode ser caracterizada como zonas de recirculação formadas junto ao declive assumido pelo leito do canal. 

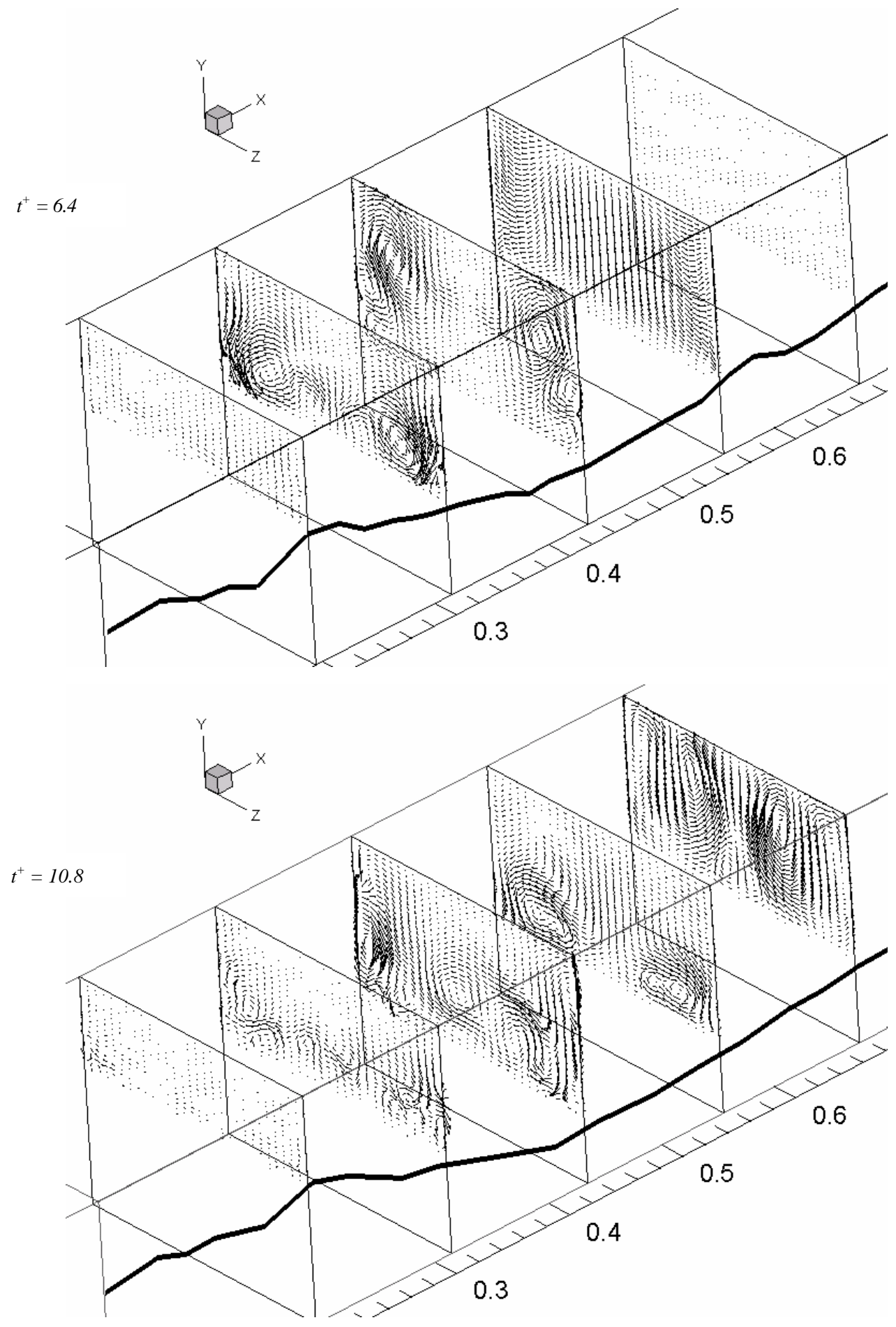

Figura 6.36 - Visualização de movimentos transversais (continua) 

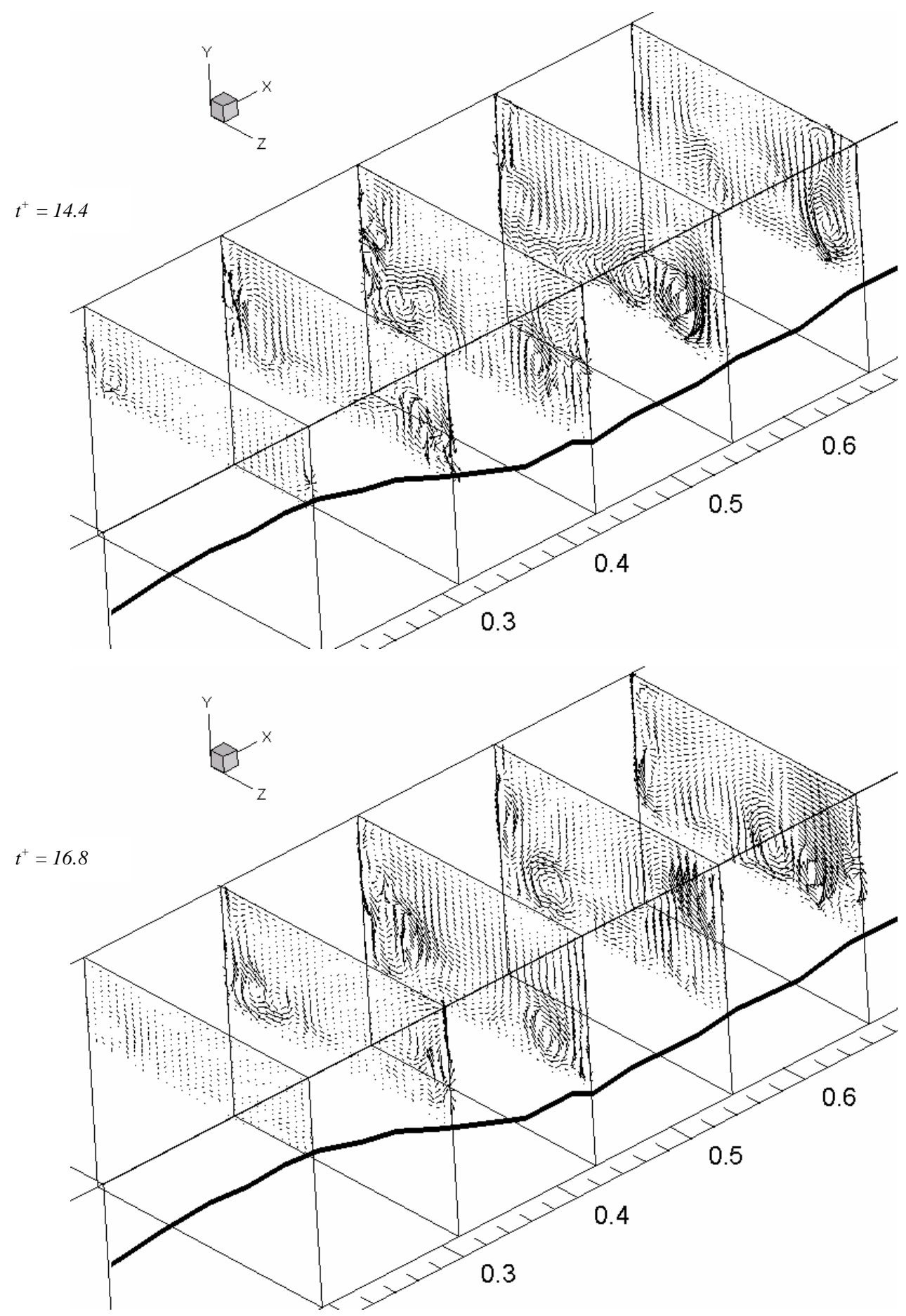

Figura 6.36 - Visualização de movimentos transversais (conclusão)

A figura 6.36 evidencia a formação de estruturas turbilhonares secundárias através dos campos de vetores tangentes aos planos transversais. A simulação previu o surgimento preferencial dessas estruturas nas porções côncavas das dunas. Esse comportamento se assemelha aos movimentos secundários de Görtler, muito embora a confirmação da captura 
desse tipo de estrutura exija a aplicação de esquemas numéricos espaciais de ordens mais elevadas. Vale ressaltar que as estruturas de Görtler são verificadas essencialmente nas proximidades de paredes côncavas.
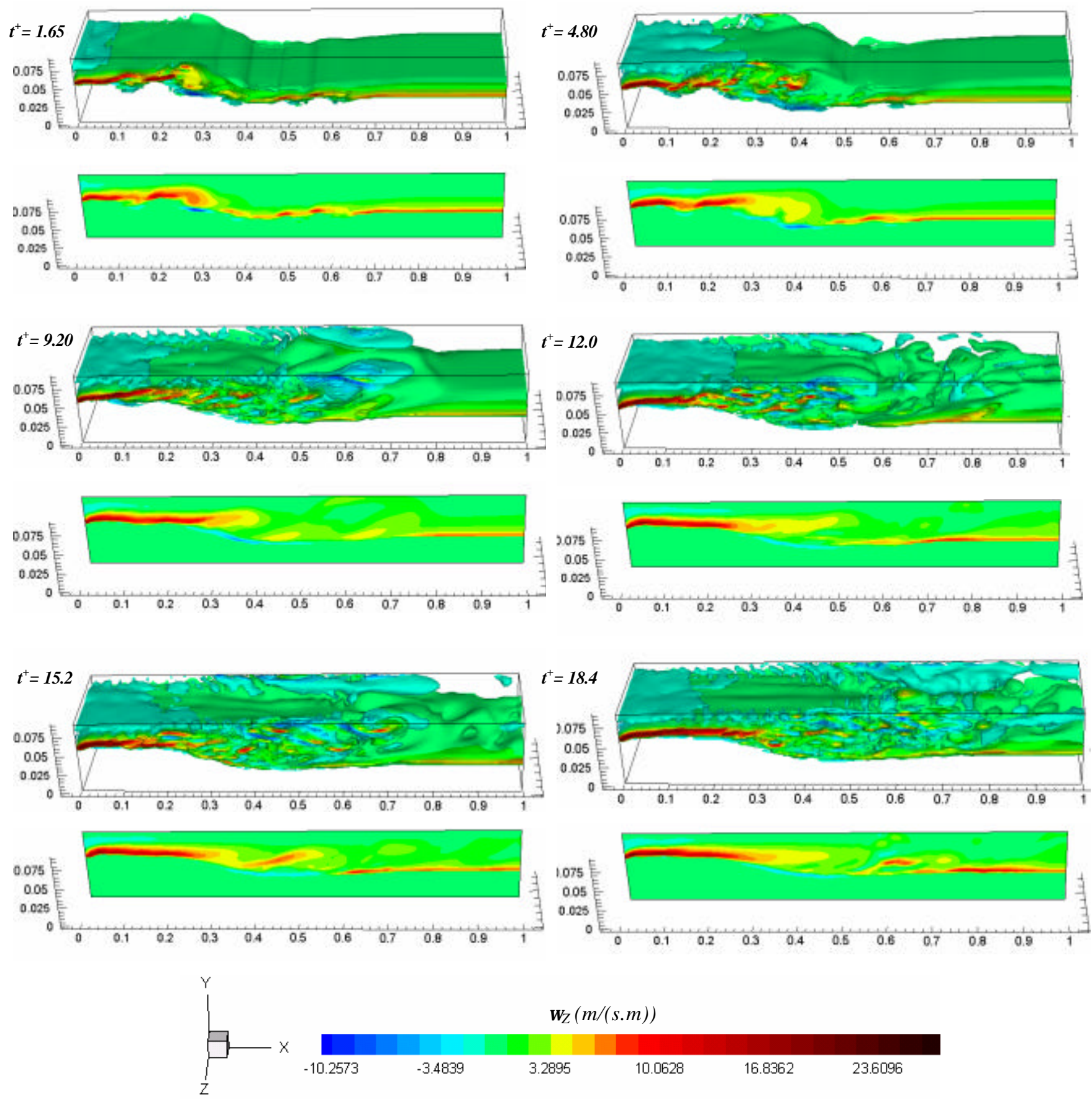

Figura 6.37 - Vorticidade $\left(\omega_{Z}\right)$ em torno do eixo transversal (Z): Iso-superfícies e curvas de contorno instantâneas no plano que passa pelo eixo do canal 
O surgimento de estruturas turbilhonares de grande escala a partir das cristas das ondulações é ilustrado pela figura 6.37. Neste contexto, as iso-superfícies representam a distribuição de vorticidade em torno do eixo transversal (eixo Z). As maiores tendências de rotação de fluido ocorrem em torno deste eixo porque os efeitos advectivos conduzem o escoamento em planos preferencialmente longitudinais. Além disso, as maiores diferenças entre as cotas de fundo ocorrem longitudinalmente. Conforme já foi comentado previamente, esses movimentos são os principais condicionantes da ressuspensão e transporte de sedimentos a partir do leito dos canais naturais.

Já foi devidamente comentado que os procedimentos da Simulação de Grandes Escalas dispõem de um modelo de viscosidade turbulenta sub-malha, sem o qual, em se utilizando malhas ainda relativamente grosseiras, haveria divergência potencial na solução numérica das equações governantes. A figura 6.38 elucida a distribuição da viscosidade e difusividade efetivas. Vale lembrar que, de maneira diferente das simulações dos itens anteriores, este item adotou a modelagem sub-malha Função Estrutura de Velocidade de segunda ordem. Neste caso, a viscosidade adicional depende da diferença de velocidade entre pontos vizinhos, e não dos gradientes locais de velocidade (como no modelo de Smagorinsky, por exemplo). Não obstante, ambos os modelos são equivalentes, apenas não sendo recomendados para escoamentos que transicionam à turbulência. Por uma análise sucinta da figura 6.38, percebe-se que as maiores viscosidades sub-malha ocorrem nas regiões onde as diferenças de velocidade são mais pronunciadas, sejam elas nas proximidades das paredes (laterais ou de fundo), ou nas camadas cisalhantes livres que surgem nos vales das dunas. Também é possível notar a correlação espacial e temporal entre viscosidade e difusividade sub-malha, uma vez que, em decorrência da metodologia utilizada, existe uma proporcionalidade aproximada entre ambos os valores (ver capítulo de Metodologia). 

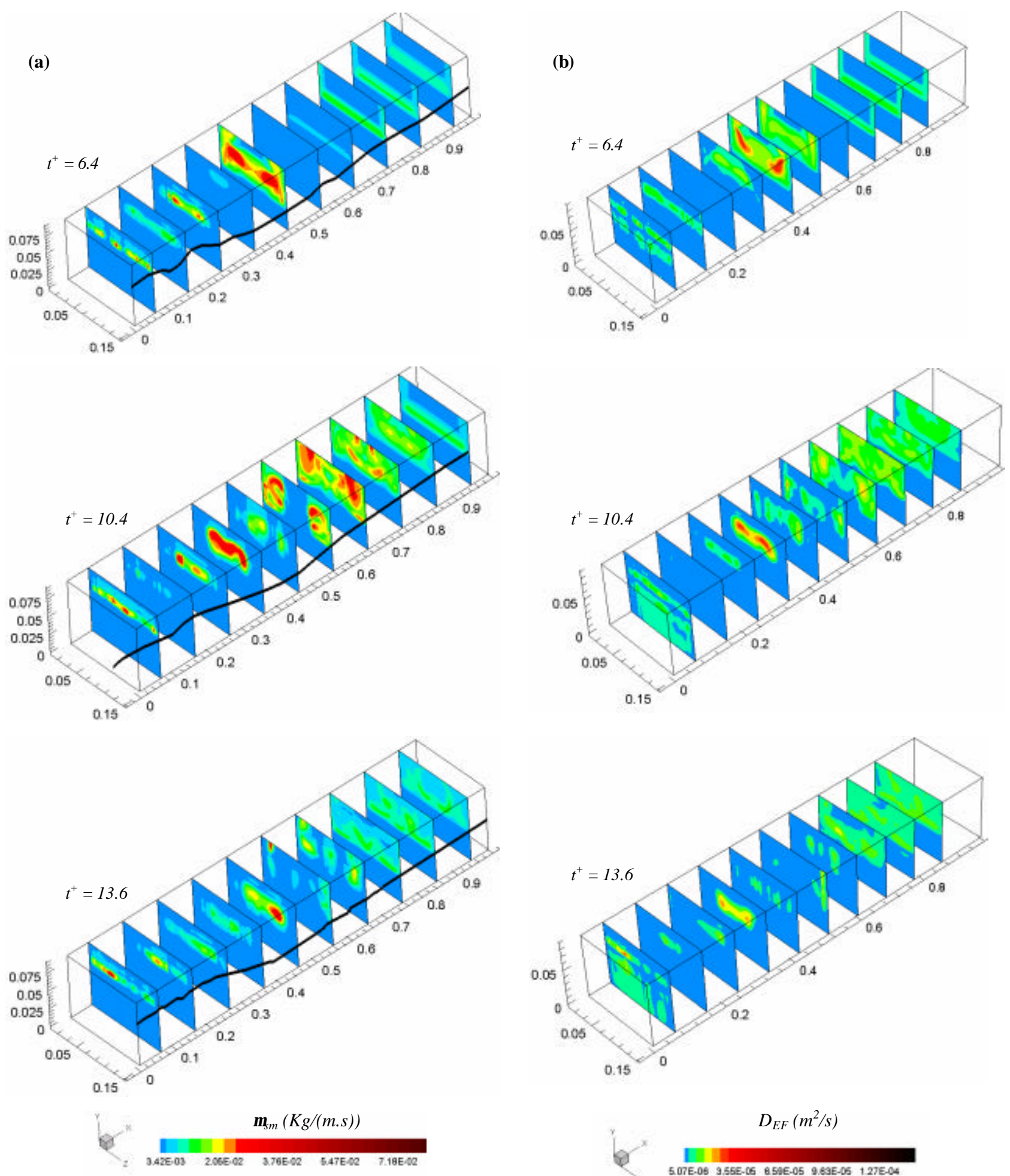

$D_{E F}\left(m^{2} / s\right)$

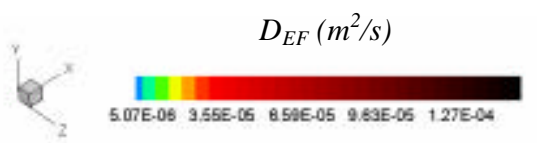

Figura 6.38 - (a)Iso-superficies de viscosidade turbulenta sub-malha; (b) Planos transversais com contornos de difusividade efetiva (molecular + turbulenta sub-malha) 

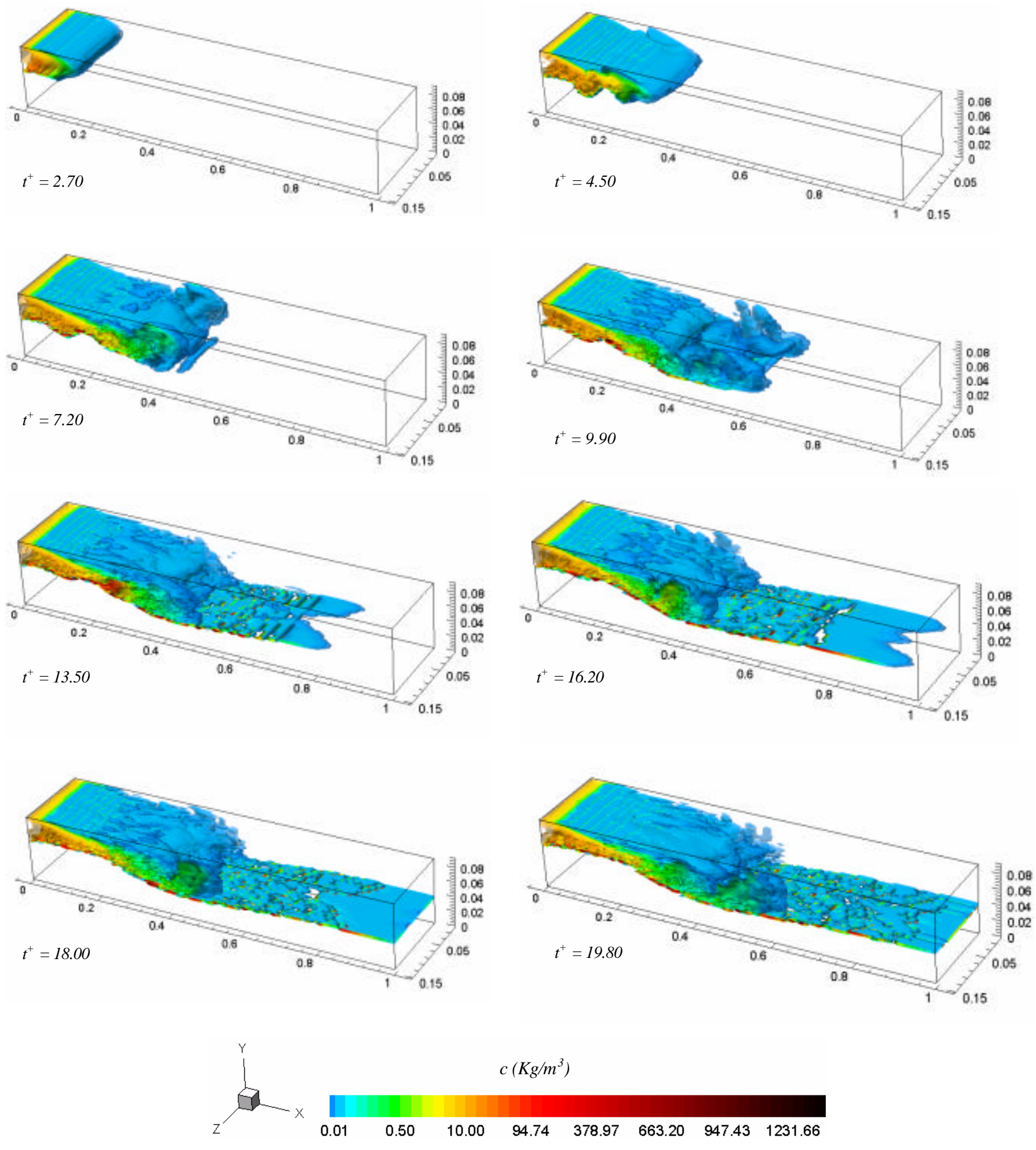

Figura 6.39 - Evolução temporal da concentração de sedimentos

A evolução temporal da distribuição de sedimentos é ilustrada pela figura 6.39, a qual relaciona as iso-superfícies de concentração ao longo do domínio. Note-se que os sedimentos foram introduzidos, em sua maior parte, na entrada do canal através da condição de contorno 
de fluxo prescrito. Nesta simulação adotou-se um fluxo de massa de $0,96 \mathrm{Kg} /\left(\mathrm{m}^{2} . \mathrm{s}\right)$, com distribuição uniforme a partir da entrada do canal. Note-se que a frente de concentrações avançou, na primeira metade do canal, com sensível inclinação para baixo. Esta verificação destaca o efeito da velocidade de sedimentação sobre as partículas de sedimento. A tendência de deposição também foi verificada na segunda metade do domínio, onde o avanço da frente de concentrações se restringiu, basicamente, às regiões próximas do leito. Nas condições simuladas, a maior quantidade de sedimentos originou-se do afluxo na entrada do domínio. Também na entrada do canal, o leito atuou como fonte de concentrações, embora em contribuições muito mais discretas.

Notadamente, consideráveis concentrações convergem verticalmente, em direção às porções mais baixas do leito. Esta observação revela a influência marcante da velocidade de sedimentação das partículas. As seções horizontais, representadas pela figura 6.40, ilustram uma distribuição instantânea de concentrações. Neste caso, a posição de cada plano foi adimensionalizada, dividindo a cota pela altura total do domínio computacional $\left(h^{+}=y / H\right)$.
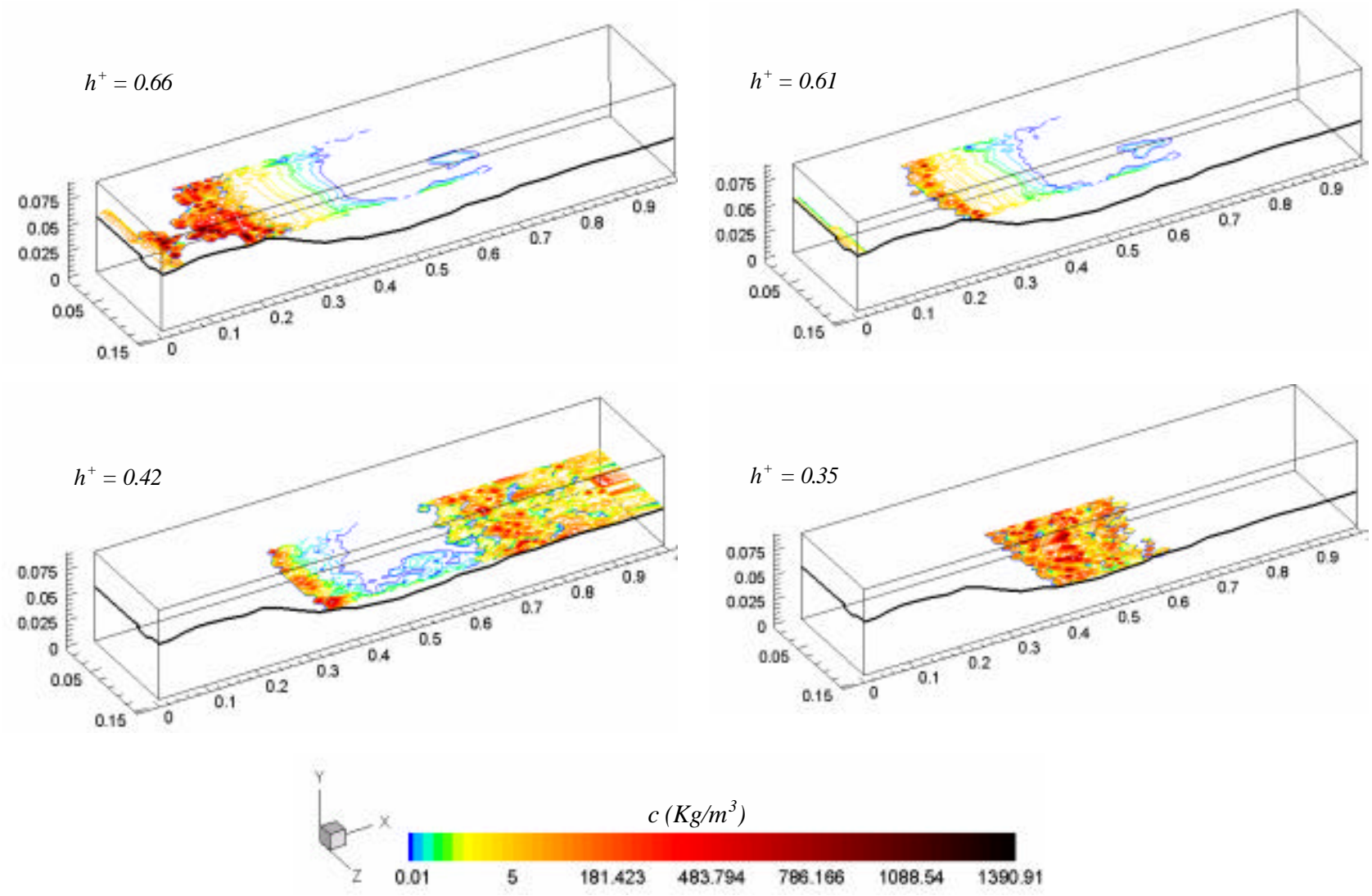

Figura 6.40 - Campos instantâneos $\left(t^{+}=20.70\right)$ de concentração de sedimentos. Representação de diferentes planos horizontais. A posição vertical de cada corte foi adimensionalizada como $h^{+}=y / H$ 
Conforme já foi comentado, as estruturas turbilhonares de grande escala, formam-se preferencialmente a partir dos pontos de maior cota das ondulações (cristas). Apesar da propensão de deposição, condicionada pela velocidade de sedimentação das partículas, esses turbilhões constituem o principal mecanismo de injeção de sedimentos suspensos no escoamento. A figura 6.41 ilustra esta tendência, verificada para o plano vertical que passa pelo eixo do canal.
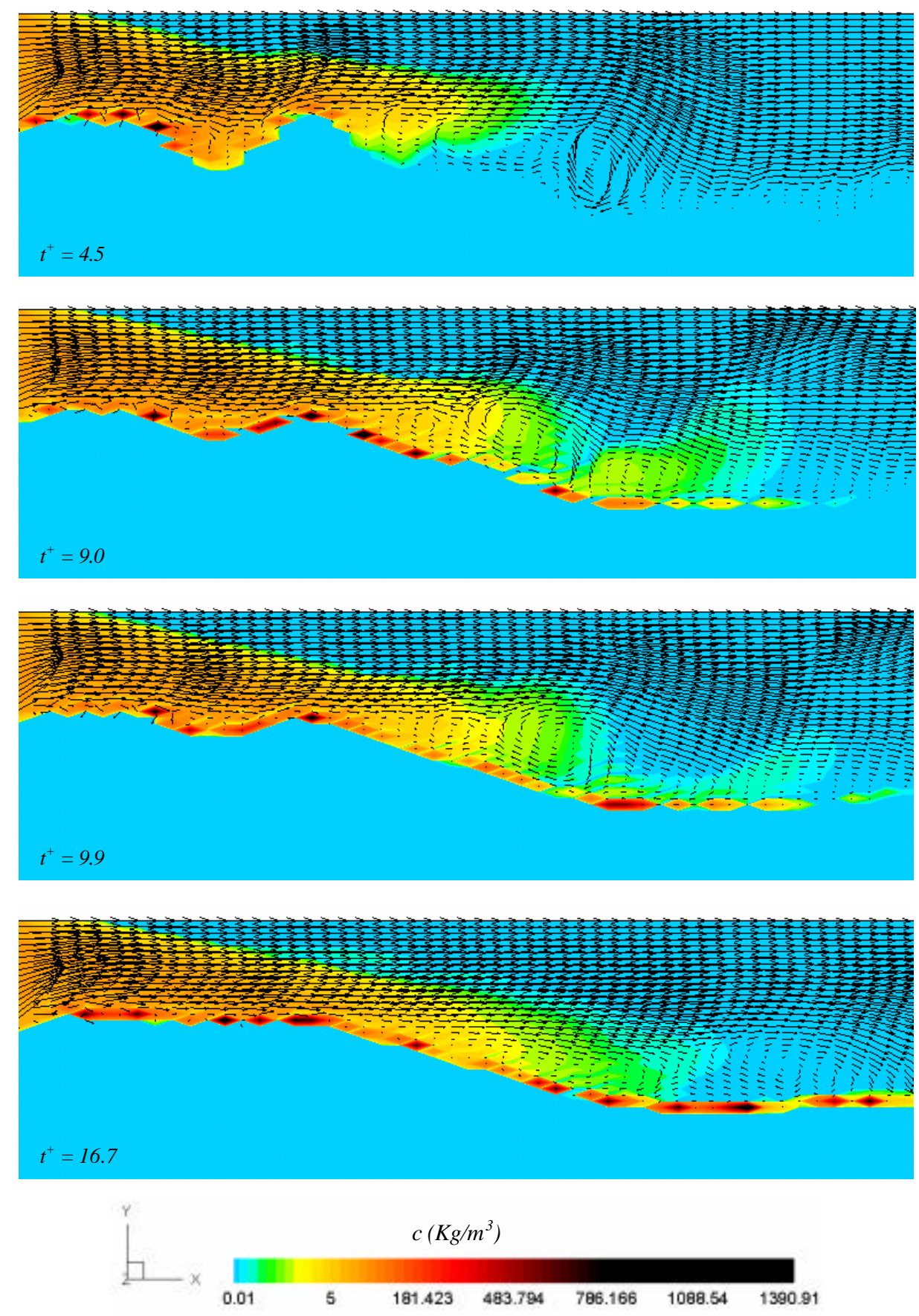

Figura 6.41 - Lançamento de sedimentos por estruturas turbilhonares no plano vertical que passa pelo eixo do domínio de escoamento 
Os processos de deposição e erosão, verificados pela simulação, condicionam, fatalmente, alterações nas cotas do leito do canal. Essas modificações foram devidamente ratificadas pelos resultados e são ilustradas pela figura 6.42 .
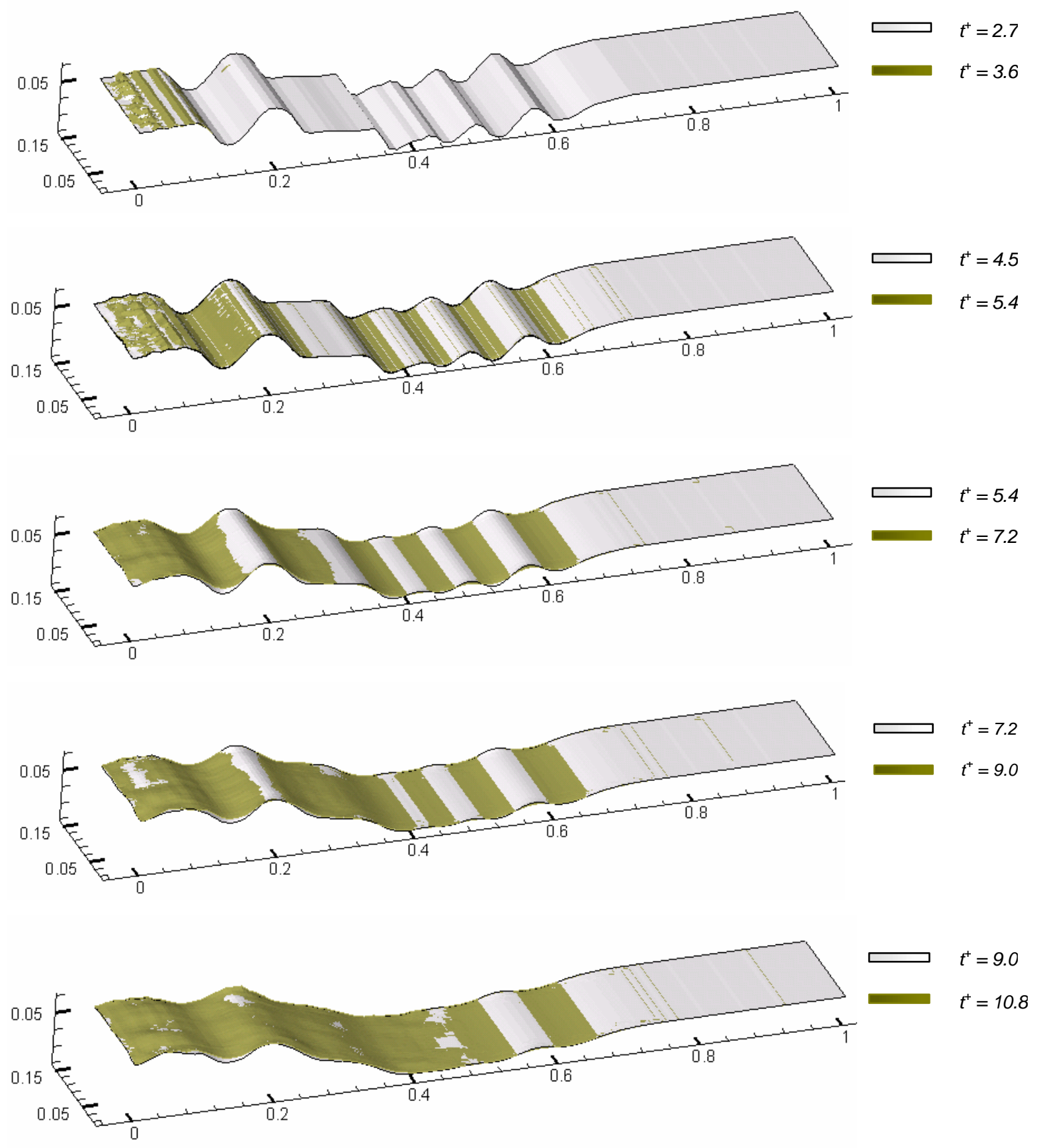

Figura 6.42 - Evolução temporal da forma de fundo (continua) 

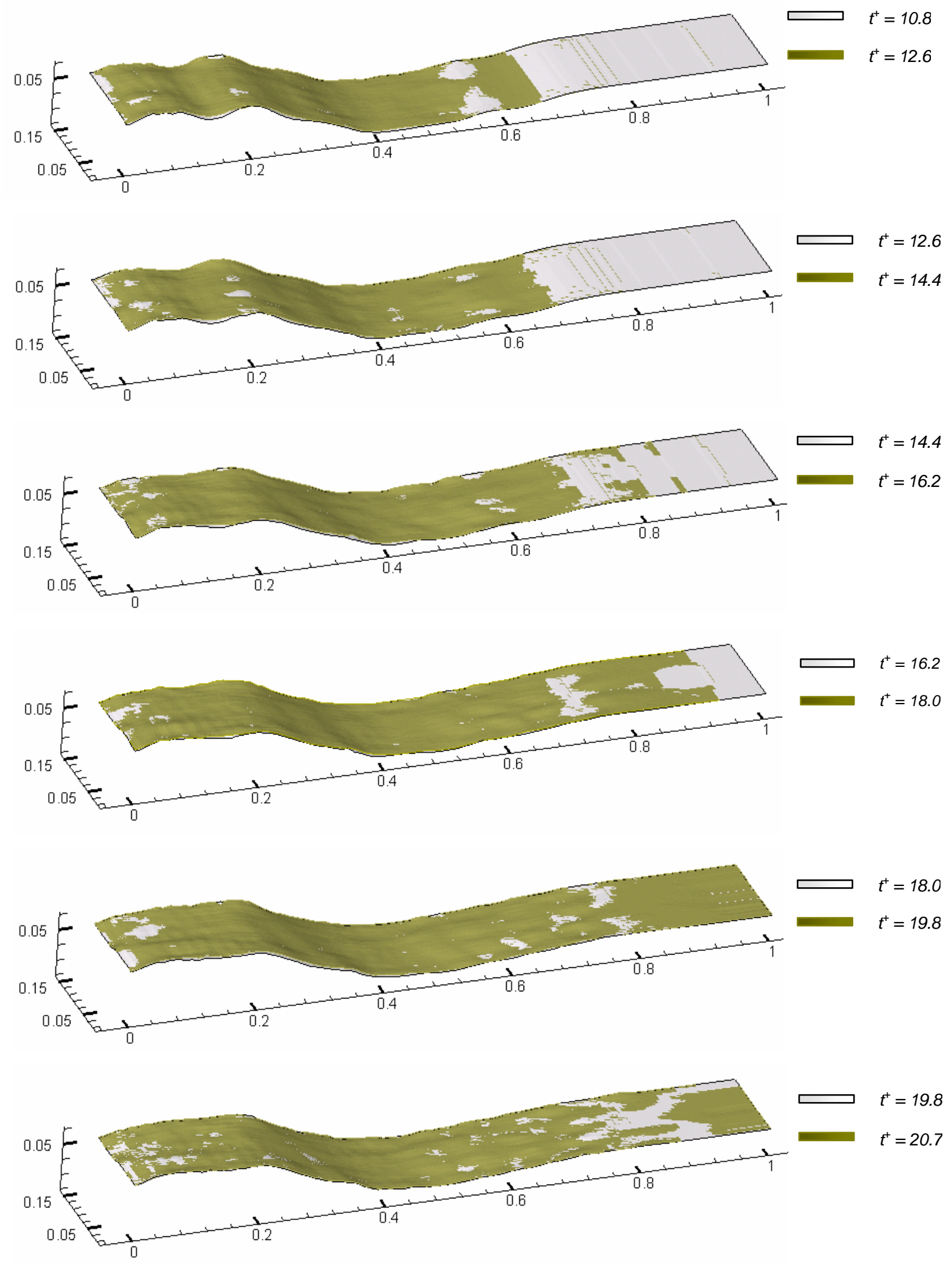

Figura 6.42 - Evolução temporal da forma de fundo (conclusão) 
A figura 6.42 estabelece uma comparação ilustrativa entre duas geometrias consecutivas, revelando as diversas formas assumidas pelo leito ao longo do tempo. Neste caso, as diferenças relativas entre as duas formas de fundo podem ser confrontadas, evidenciando as zonas de deposição e de erosão. Confirmando a tendência anunciada pelos campos de concentração, percebem-se zonas preferenciais de deposição (coloração mais escura) na entrada do canal e nos vales das ondulações. No primeiro caso, esta tendência é favorecida pela injeção de sedimentos na entrada do domínio, ao passo que, no segundo caso, a velocidade de sedimentação das partículas atua como fator preponderante. Também é possível perceber que as frentes de deposição avançam longitudinalmente pelo canal, fato que reforça a importância da velocidade de sedimentação. As zonas de erosão ocorrem mais assiduamente nas proximidades das cristas. Não obstante, em linhas gerais, os resultados mostram que o processo de sedimentação é sobressalente. Com o decorrer do tempo, as dunas intermediárias tendem a desaparecer, muito embora pequenas zonas de erosão ainda sejam observadas.

Os resultados, anunciados pelo presente modelo e código computacional, reproduziram padrões físicos esperados para escoamentos naturais, onde os processos de erosão e sedimentação atuam concomitantemente. Todavia, durante o intervalo simulado, não foi possível verificar deslocamentos longitudinais das dunas. Neste contexto, o custo computacional ainda atua como uma barreira que deve ser superada. Basta citar, como exemplo, que a simulação de um tempo físico de vinte e três segundos ocorreu às expensas de aproximadamente trinta dias de cálculos, num processador Xeon $3.2 \mathrm{GHz}$. O capítulo seguinte tece alguns comentários que sugerem aperfeiçoamentos possíveis nesta questão. 


\section{$7 \quad$ Conclusões}

Diante do que foi exposto nos capítulos anteriores, pode-se retirar uma conclusão global de que as metodologias utilizadas e desenvolvidas ao longo deste trabalho indicam uma diretriz fisicamente coerente para o estudo do transporte de sedimentos em escoamentos turbulentos. Considerando o aspecto inovador de vários procedimentos aqui adotados, essa afirmação adquire um caráter de relevância. A utilização das equações governantes (NavierStokes, Continuidade e Advecção-Difusão), em duas e três dimensões, atribui uma maior generalidade ao fenômeno estudado. Para isto, basta citar que a maioria dos modelos comerciais de transporte de sedimentos utiliza equações simplificadas que restrigem sua aplicação a casos unidimensionais, ou, no máximo, bidimensionais. Além disso, os referidos modelos costumam abarcar uma carga considerável de empirismo através da utilização de metodologias clássicas.

O uso da equação de Advecção-Difusão permite avaliar a evolução espaço/temporal da concentração de sedimentos, constituindo uma alternativa viável para escoamentos reais que, na sua maioria, transportam cargas consideráveis de partículas. A equação de AdvecçãoDifusão encontra, neste contexto, vantagem expressiva em relação à equação de Maxey-Riley, que avalia o deslocamento de partículas individuais, não sendo, portanto, indicada para escoamentos fluviais, ou seja, para as engenharias que consideram escoamentos em grandes dimensões. Além disso, uma futura ampliação do modelo para escoamentos em escalas de campo (rios, estuários e reservatórios) pode ser mais facilmente viabilizada com o uso da equação de Advecção-Difusão. Apesar desse comentário, é importante frisar que os resultados obtidos a partir da evolução dos campos de concentração mostraram comportamento semelhante àquele observado na análise das partículas isoladas, inclusive com o "lançamento" para o interior do escoamento.

Este trabalho incorporou efetivamente ao menos duas metodologias "modernas" na modelagem de escoamentos: a Simulação de Grandes Escalas e o Método de Fronteira Imersa. Vale dizer que, no atual estado da arte, não se tem notícias de nenhum modelo 
comercial, aplicado aos problemas de Engenharia Civil e de Recursos Hídricos, que tenha acoplado estas duas ferramentas. Vale aqui abrir um parêntese para reafirmar a relevância de se pesquisar e incorporar novas metodologias, não somente ao estudo do transporte de sedimentos, mas também em qualquer estudo científico, sem as quais o estado de conhecimento permaneceria estacionário. Apesar da vastidão da atual matriz de conhecimentos (pelo menos do ponto de vista do homem contemporâneo), uma quantidade enorme de fenômenos sem explicação definitiva desafia seriamente a argúcia da comunidade científica. Para citar um exemplo mais próximo, a turbulência e o transporte de sedimentos ainda se encaixam neste rol de fenômenos. A busca de parte dessas explicações exige a criação de novas alternativas, além da exploração criativa das metodologias já existentes.

A Simulação de Grandes Escalas constitui uma das metodologias de simulação da turbulência mais estudadas e utilizadas na atualidade. Com ela pode-se estimar o comportamento físico de um escoamento, sem a severa discretização espacial e temporal da Simulação Numérica Direta e sem o elevado grau de modelação atribuído aos modelos clássicos, que prevêem apenas campos médios temporais. Assim, a tendência natural dos estudos que envolvem os fundamentos dos fenômenos de deposição e erosão em leitos aluviais, como é o caso deste trabalho, é de acompanhar a evolução "quase instantânea" dos campos hidrodinâmicos e de concentração, em vez da evolução dos seus campos médios. O código computacional aqui utilizado foi integralmente gerado, em todos os seus pormenores, no contexto deste trabalho. As nuanças nos diferentes cálculos permitiram obter resultados ainda não relatados na literatura da área, apesar de os "conceitos gerais", como aqueles vinculados à Simulação de Grandes Escalas, serem de conhecimento geral.

Da mesma forma, demonstra-se neste trabalho que o Método de Fronteira Imersa se adequa muito bem aos fenômenos aqui estudados, onde o fundo dos canais pode assumir formas variadas ao longo do tempo. Neste contexto, a utilização de malhas não estruturadas impossibilitaria a adoção de um sistema de coordenadas, além de dificultar deveras a implementação de um código. A utilização da discretização coincidente com a fronteira determinaria a transformação contínua das equações para um novo sistema de coordenadas, além do uso excessivo de interpolações. De fato, é extremamente dificultoso e computacionalmente oneroso tratar escoamentos com fronteiras transientes através de métodos clássicos de discretização. Por isso os princípios do Método de Fronteira Imersa, ou seja, de manter a malha de discretização fixa e ortogonal e de estimar um campo de força que simule virtualmente a condição de não deslizamento do fluido sobre as paredes de fundo, encaixam-se perfeitamente ao estudo do transporte de sedimentos. As simulações aqui 
realizadas revelam que o uso conjugado da Simulação de Grandes Escalas e do Método de Fronteira Imersa constitui uma ferramenta de alto potencial de aplicação na hidráulica fluvial. Novamente, a literatura trazia aplicações isoladas das duas ferramentas, sem considerar, entretanto, o transporte de sedimentos. Assim, verifica-se que a utilização criativa de conceitos existentes permitiu um substancial incremento na qualidade dos resultados de transporte de sedimentos.

É conveniente destacar que, durante a execução dos trabalhos, houve zelo em buscar formulações baseadas em princípios físicos bem fundamentados, utilizando apenas em última hipótese relações empíricas da literatura. Deixa-se claro que não se critica o empirismo, ou seja, não se questiona a validade da observação e das equações dela oriundas (filosoficamente pode-se questionar se alguma solução pode ser buscada sem ter havido antes uma observação de um problema). Apenas buscou-se que este trabalho fosse conduzido prioritariamente por equações matemáticas dedutíveis de princípios físicos consolidados e princípios matemáticos clássicos. Basta para isto citar, como exemplo, a elaboração de uma nova formulação para a velocidade de sedimentação, baseada no decaimento da energia cinética. A literatura fornece uma gama enorme de formulações similares que levam em conta escoamentos concentrados de sedimentos. Todavia, grande parte dessas formulações apresenta caráter empírico ou semiempírico. A formulação analítica aqui deduzida é mais geral, cobrindo dados experimentais, pela conveniente calibração dos seus parâmetros. Em contrapartida, pela complexidade inerente aos fenômenos de turbulência e transporte de sedimentos, não se pôde privar totalmente de opções empíricas, como foi o caso dos critérios de erosão e dos fluxos de ressuspensão, os quais se mostraram bastante adequados nas simulações realizadas.

De uma maneira geral, os resultados obtidos conseguiram reproduzir comportamentos coerentes para escoamentos sobre leitos não consolidados. A verificação do desprendimento de estruturas turbilhonares de grande escala a jusante das cristas das ondulações, a formação de zonas de recirculação instantâneas nos vales e a migração de movimentos gerados no fundo em direção ao corpo principal do escoamento, são apenas alguns dos exemplos que foram devidamente capturados pelas simulações. Esta observação vem destacar que a Simulação de Grandes Escalas é uma metodologia poderosa no estudo físico dos movimentos dos fluidos, conseguindo capturar estruturas que dificilmente seriam evidenciadas pelos modelos clássicos de turbulência.

A não partição do domínio em regiões de transporte de fundo e em suspensão constitui, pelo menos pelo critério do pesquisador, uma das vantagens do código desenvolvido. Essa divisão do escoamento, em duas regiões, é um resquício dos modelos 
clássicos de transporte de sedimentos, ainda utilizada por grande parte dos códigos comerciais. Vale, contudo lembrar que os próprios autores dessas teorias clássicas não chegaram a um consenso sobre um critério claro de divisão dessas duas regiões. No presente trabalho mostra-se que é possível considerar o transporte de sedimentos em todo o domínio de escoamento, utilizando apenas a equação de Advecção-Difusão. Os resultados obtidos reforçam a coerência dessa premissa, pois foram claramente observadas elevadas concentrações nas proximidades do leito, fato que destaca o efeito decisivo da velocidade de sedimentação das partículas. O transporte de concentrações por estruturas de grande escala ("lançamento" para o interior do escoamento) também constitui um importante padrão aqui reproduzido, não encontrado na literatura consultada, a partir dos conceitos aqui utilizados.

O custo computacional ainda persiste como uma barreira para aplicação do código em escoamentos com escalas de campo (rios, estuários, etc.). Isto foi perceptível nas simulações tridimensionais, onde os tempos físicos de execução superaram três semanas (em se utilizando isoladamente os modernos processadores Xeon (3.2 GHz) e Pentium 4 (3.2 GHz)). Nestes casos, o processamento paralelo ainda é uma necessidade. Este fator introduz alguns aspectos limitantes, como por exemplo, o uso de mais de um processador, a inadequação do ambiente Windows e a remodelação do código para permitir a correta distribuição de tarefas entre os diferentes processadores. A simulação de escoamentos a elevados números de Reynolds destaca ainda mais essas limitações, uma vez que a necessidade de uma discretização mais refinada é um fator que inevitavelmente amplia não só o número de operações, como também a memória requerida. Dessa forma existe um encarecimento do custo computacional, visto que o número de iterações por unidade de tempo aumenta consideravelmente.

Sintetizando as conclusões anteriores, pode-se afirmar que:

A Simulação de Grandes Escalas, associada ao Método de Fronteira Imersa, considerando velocidade de sedimentação conforme aqui modelada, e ainda utilizando a equação de Advecção-Difusão como ferramenta de transporte de massa, mostrourse altamente adequada à estimativa do transporte de sedimentos pela água.

Todos os códigos foram criados no contexto deste trabalho. Os questionamentos de ordem física, que conduziram a formulações originais, foram aqui implementados pela primeira vez

Com o estudo aprofundado dos fenômenos, o surgimento de sugestões que possam introduzir melhorias ao modelo é inevitável. Os resultados aqui obtidos são animadores, mas sugere-se que alguns fatores sejam estudados para tornar o código computacional mais eficiente em termos de custo computacional. Nesse caso, a paralelização do código é um fator 
a ser considerado. Frisa-se que o código responde bem, porém morosamente, na forma como está apresentado (em simulações tridimensionais, especificamente). Por outro lado, não se pode negar que quanto mais rigorosa é a análise de um problema, novos detalhes surgem a serem resolvidos. No decorrer deste trabalho, muitas idéias surgiram, como, por exemplo, a de estudar o comportamento da superfície livre utilizando o Método de Fronteira Imersa aplicado na interface entre dois fluidos imiscíveis (água e ar, neste caso). Uma segunda possibilidade é atribuir as viscosidades e massas específicas do fluido como funções da concentração de sedimentos (sedimento não passivo). Vê-se, também, a possibilidade da discretização da curva granulométrica do sedimento, permitindo a aplicação de diferentes equações de Advecção-Difusão para cada classe de diâmetros. O estudo de erosão das margens, levando em conta o Método de Fronteira Imersa, também pode somar-se a estas sugestões. Nota-se que, a despeito da perspicácia dos estudos aqui conduzidos, o tema ainda assume consideráveis desdobramentos. O estabelecimento do término deste trabalho foi apenas condicionado pelas limitações de tempo. O ideal seria avançar continuamente na busca de todas as respostas. Mas é preciso reconhecer que um fenômeno, cuja descrição matemática se iniciou há cento e cinqüenta anos e que ainda não conseguiu ser completamente descrito, ainda carece de muitos outros estudos aprofundados. Diante disso, é necessário adotar um posicionamento humilde diante da complexidade dos fenômenos estudados, admitindo que a elaboração de um código completo e a disponibilização do mesmo é uma tarefa grande demais para um só trabalho de pesquisa.

Finalmente, nesta derradeira parte dos trabalhos, a despeito dos ajustes já comentados, afirma-se que a metodologia, aqui descrita, funciona como uma apreciável ferramenta no estudo do transporte de sedimentos. Espera-se que este trabalho constitua apenas um primeiro passo e que a jornada nessa área, de alguma forma, possa por ele ser impulsionada. 


\section{Referências}

BALDOCK, T.E., TOMKINS, M.R., NIELSEN, P., HUGHES, M.G.; Settling Velocity of Sediments_at High Concentrations. Coastal Engineering, 51, pp.: 91-100, 2004.

BHATTACHARJEE, A.; NO, C.S. Random scattering and anisotropic turbulence of shear alfvén wave packets, The Astrophysical Journal, 548, pp. 318-322, 2001.

BARRET, R., BERRY, M., CHAN, T. F., DEMMEL, J., DONATO, J. M., DONGARRA, J., EIJKHOUT, V., POZO, R., ROMINE, C., \& VAN DER VORST, H, Templates for the solution of linear systems: building blocks for iterative methods. SIAM. Philadelphia/PA; 1994.

BORGES, A.R.J.; SARAIVA, J.A.G., An erosion technique for assessing ground level winds. Wind Engineering, vol.1, Oxford:Pergamon Press, pp.235-242, 1980.

CHANG, Y.S.; SCOTTI, A., Entrainment and suspension of sediments into a turbulent flow over ripples. Journal of Turbulence (http://jot.iop.org/), vol. 19, No.4, pp. 2-18, 2003.

COLEMAN, N. L. Flume studies of the sediment transfer coefficient, Water Resources, v.6, n.3, 1970.

EINSTEIN, H. A. Formulae for the transportation of bed-load. Trans. of ASCE, v.107, p. 561$597,1942$.

EINSTEIN, H. A . The bed load function for sediment transportation in open channel flow. United States Department of Agriculture, Technical Bulletin, n. 1026, p. 25, 1950.

FERNANDEZ LUQUE, R., Erosion and transport of bed load sediment, Dissertation, KRIPS Repro BV, Meppel, The Netherlands, 1974.

FERZIGER, J.H., PERIC, M., Computational methods for fluid dynamics, $2^{\text {nd }}$ rev. ed. Springer, New York, 1999.

FINDIKAKIS, A.N., STREET, R.L., An algebraic model for sub-grid scale turbulence in stratified flows, Journal of the Atmospheric Sciences, 36, No.10, pp.1934-1949, 1979.

FORTUNA, A . O . Técnicas Computacionais para Dinâmica dos Fluidos: conceitos básicos e aplicações. Editora da Universidade de São Paulo, São Paulo, SP, 2000. 
GARCIA, M.H.; LOPEZ, F.; NINO, Y. Characterization of near-bed coherent structures in turbulent open channel flow using synchronized high-speed video and hot-film measurements. Exp. in Fluids, v.19, p. 16-28, 1995.

GARCIA, M.H.; NINO, Y.; LOPEZ, F. Chapter 3: Laboratory observations of particle entrainment into suspension by turbulent bursting. Coherent flow structures in open channels, Wiley, New York, 1996.

GERMANO, M., PIOMELLI, U., MOIN, P., CABOT, W.H., A dynamic sub-grid scale eddy viscosity model, Phys. Fluids A3, 7, pp. 1760-1765, 1991.

GOLDSTEIN, D., ADACHI, T., SAKATA, H., Modeling a No-Slip Flow with an External Force Field, Journal Computational Physics, 105, 354, 1993.

GRAF, W. H., Hydraulics of sediment transport. McGraw-Hill Book Company; 1970.

GRASS, A . J. The influence of boundary layer turbulence on the mechanism of sediment transport. Mechanics of Sediment Transport, Rotterdam: Balkema, p. 3-17, 1983.

GYR, A .; SCHMID A . Turbulent flows over smooth erodible sand beds in flumes. Journal of Hydraulic Engineering, v.35, n.4, p. 525-544, 1997.

HAPPEL, J., BRENNER, H.; "Low Reynolds Number Hydrodinamics", Prentice-Hall Inc., Englewood Cliffs, N.J., U.S.A., 1965.

JURIC, D., Computation of phase change, Ph. D. Thesis, Mech. Eng. Univ. of Michigan, USA, 1996.

KAFTORI, D.; HETSRONI, G.; BANERJEE, S. Particle behaviour in the turbulent boundary layer. I. motion, deposition and entrainment. Phys. Fluids, v.7, n.5, p. 1095-1106, 1995.

KLINE, S.J., REYNOLDS,W.C., SCHRAUB,F.A., RUNSTADLER,P.W., The structure of turbulent boundary layers, Journal of Fluid Mechanics, 12, pp.741-773, 1967.

KOMURA, S., Bulk properties of river bed sediments, its applications to sediment hydraulics, Proceedings of the $11^{\text {th }}$ Japan National Congress for Applied Mechanics, pp.227$231,1961$.

LESIEUR, M. Turbulence in Fluids. Kluwer Academic Publishers, Netherlands, 1997.

LIM, S.; PESKIN, C.S., Simulations of the whirling instability by the immersed boundary method. J. Sci, Comput.; vol. 25, No. 6, pp. 2066-2083, 2004.

LIMA E SILVA, A. L. F., Desenvolvimento e implementação de uma nova metodologia para modelagem de escoamentos sobre geometrias complexas: Método da Fronteira Imersa com Modelo Físico Virtual. Tese de doutorado, Universidade Federal de Uberlândia/ Minas Gerais/ Brasil; 2002. 
LIMA E SILVA, A. L. F., SILVEIRA NETO, A., \& DAMASCENO, J.J.R., Numerical simulation of two-dimensional flows over a circular cylinder using the immersed boundary method. Journal of Computational Physics, 189, pp.351-370; 2003.

MALISKA, C.R., Transferência de Calor e Mecânica dos Fluidos Computacional: Fundamentos e Coordenadas Generalizadas, Ed. LTC, Rio de Janeiro, 1995.

.MARCHIOLI, C.; SOLDATI, A. Mechanisms for particle transfer and segregation in a turbulent boundary layer. Journal of Fluid Mechanics, v.468, p.283-315, 2002.

Mc LAUGHLIN, J. B. Inertial migration of a small sphere in linear shear flows; J. Fluid Mechanics, 224, p.261-274, 1991.

MERKEL, W.; Untersuchungen über das Verhalten das belebten Schlammes im System Belebungs-Nachklärbecken, Gewässerchutz-Wasser-Abwasser, No.5, Institut für Siedlungswasserwirtschaft, TH, Aachen, 1971.

MÉTAIS, O., LESIEUR, M., Spectral large-eddy simulations of isotropic and stablystratified turbulence, Journal of Fluid Mechanics, 239, pp.157-194, 1992.

MURPHY, P.J.; AGUIRRE, E.J. Bed load or suspended load. Journal of Hydraulic Engineering, ASCE, v.111, n.1, p. 93-107, 1985.

NAKAGAWA, H.; TSUJIMOTO, T. Sand bed instability due to bed-load motion. Journal of the Hydraulics Division, ASCE, v.106, n. HY12, 1980.

NEZU, I.; NAKAGAWA H. Turbulence in open-channel flows. IAHR Monograph Series, A. A . Balkema, Rotterdam, Brookfield, 1993.

PATANKAR, S. V. Numerical Heat transfer and Fluid Flows. Hemisphere Publishing Co. New York, 1980.

PESKIN, C. S., Numerical analysis of blood flow in the heart. Journal of Computational Physics, 25, 200; 1977.

PILLER, M. Simulazione diretta e large eddy di flussi turbolenti isocorici. Tesi di laurea in Fisica Tecnica, Università degli Studi di Trieste, Facoltà di Ingegneria, Trieste, Italia, 1997.

PIOMELLI, U., Large-eddy simulation: achievements and challenges, Progress in Aerospace Sciences, 35, pp.335-362, 1999.

RASHIDI, M.; HETSRONI, G.; BANERJEE, S. Particle-turbulence interaction in a boundary layer. International Journal of Multiphase Flow, v.16, n.6, p.935-949, 1990. 
RICHARDSON, J.F., ZAKI, W.N.; "Sedimentation and Fluidisation: Part 1", Trans. Inst. Chem. Eng., 32, pp.: 35-53, 1954.

RIJN , L. C. van, Sediment pick-up functions. Journal of Hydraulic Engineering, vol.110, No.10, 1984.

RIJN, L.C. van. Sediment transport, part I: bed load transport. Journal of Hydraulic Engineering, ASCE, v.110, n.10, p. 1431-1456, 1984a.

RIJN, L.C. van. Sediment transport, part II: suspended load transport. Journal of Hydraulic Engineering, ASCE, v.110, n.11, p. 1613-1641, 1984b.

RODI, W. Turbulence models and their application in hydraulics: a state-of-art review. IAHR Monograph Series, A . A . Balkema, Rotterdam, Brookfield, 2000.

ROUSEAUX, G., YOSHIKAWA, H., WEISFREID, J.E.; Dynamics of transient eddy above rolling-grain ripples. Physics of fluids, v.16, n.4, p.1049-1058, 2004.

SAIKI, E. M., BIRINGEN, S. Numerical simulation of a cylinder in uniform flow: application of a virtual boundary method, Journal of Computational Physics, 123, pp.450$465,1995$.

SCHULZ, H. E.; ALAMY FILHO, J. E. Velocidade de sedimentação para conjunto de partículas e sua dependência para com a concentração de sedimentos - uma abordagem partindo da quantificação da energia cinética, Revista Ciência e Engenharia, ano 14, N. 2, 2005 .

SCHULZ, H.E., O essencial em fenômenos de transporte. Escola de Engenharia de São Carlos, São Carlos, SP, Brasil, 2003.

SECHET, P.; LE GUENNEC, B. Bursting phenomenon and incipient motion of solid particles in bed-load transport. Journal of Hydraulic Engineering, v.37, n.5, p. 683696, 1999;

SHIELDS, A. Anwendung der ahnlichkeitsmechanik und der turbulenzfors-chung and die geschiebebewegung. Preussischen Versuchanstalt für Wasserbau und Schiffbau, Berlin, n.26, 1936.

SILVEIRA NETO, A., GRAND, D., MÉTAIS, O., LESIEUR, M., A numerical investigation of the coherent structures of turbulence behind a backward-facing step, Int. Journal of Fluid Mechanics, 256, pp.1-25, 1993.

SILVEIRA NETO, A., Turbulência nos Fluidos Aplicada. Apostila - Universidade Federal de Uberlândia, Programa de Pós-Graduação em Engenharia Mecânica; Uberlândia, 2003. 
SOUZA, F. J. Simulação de grandes escalas de escoamentos em um hidrociclone. Tese de doutoramento, Universidade Federal de Uberlândia, Faculdade de Engenharia Mecânica, Uberlândia, Brasil, 2003.

SUMER, B.M. Recent developments on the mechanics of sediment suspension. Transport of Suspended Soils in Open Channels, Rotterdam: Balkema, p. 3-22, 1986.

SUTHERLAND, A . J. Proposed mechanism for sediment entrainment by turbulent flows. Journal of Geophysical Research, v.72, p. 6183-6194, 1967.

TOMKINS, M.R., BALDOCK, T.E., NIELSEN, P.; Hindered Settling Velocity for Sand, Abstract ICCE, 2004.

TROUW, K., WILLIAMS, J.J., ROSE, C. P.; Modelling sand ressuspension by waves over a rippled bed. Estuarine, coastal and shelf science, v.50, p. 143-151, 2000.

TSENG, Y. H., FERZIGER, J. H., A ghost-cell immersed boundary method for flow in complex geometry. Journal of Computational Physics, 192, p.593-623; 2003.

TSENG, Y. H., FERZIGER, J. H., Large-eddy simulation of turbulent wavy boundary flow illustration of vortex dynamics. Journal of Turbulence, 5, p.1-23; 2004.

UNVERDI, S. O., TRYGGVASON, G., A Front-tracking method for viscous incompressible, multi-fluid flows. Journal of Computational Physics, 100, pp.25-37, 1992.

WAN, Z., WANG, Z; “Hyperconcentrated Flow”, IAHR Monograph, Balkema, pp.: 290, 1994.

WANG, Q. ; SQUIRES, K. D. Large-eddy simulation of particle deposition in a vertical turbulent channel flow. Int. Journal Multiphase Flow, v.22, n.4, p.667-683, 1996.

WHITE, B. R.; SHULZ, J.C. Magnus effect in saltation. Journal of Fluid Mechanics, v.81, p.507, 1977.

YE, T., MITTAL, R., UDAYKUMAR, H. S., SHYY, W., A Cartesian grid method for viscous incompressible flows with complex immersed boundaries. American Institute of Aeronautics and Astronautics (AIAA), 3312, pp.1-11; 1999.

ZEDLER, E.A., STREET, R.L. Large-eddy simulation of sediment transport: currents over ripples. Journal of Hydraulic Engineering, ASCE, n.127, n.6, p. 444-452, 2001. 


\section{Apêndices}

\section{APÊNDICE A - DISCRETIZAÇÃO DAS EQUAÇÕES FILTRADAS DE NAVIER-STOKES (CASO TRIDIMENSIONAL)}

Convém, de início, reescrever as equações filtradas de Navier-Stokes na sua forma completa, ou seja, com o termo fonte de força euleriana e com a viscosidade turbulenta submalha. Assim, na forma tensorial:

$$
\rho \frac{\partial u_{i}}{\partial t}+\rho \frac{\partial\left(u_{j} \cdot u_{i}\right)}{\partial x_{j}}=-\frac{\partial P}{\partial x_{i}}+\frac{\partial}{\partial x_{j}}\left[\left(\mu+\mu_{s m}\right) \cdot\left(\frac{\partial u_{i}}{\partial x_{j}}+\frac{\partial u_{j}}{\partial x_{i}}\right)\right]+F_{i}
$$

A decomposição da equação (A.1), nas diferentes direções, consiste no passo imediatamente anterior ao processo de discretização por Diferenças Centrais de segunda ordem, o que é mostrado a seguir. Vale lembrar que a indexação $(i, j, k)$ das variáveis discretas segue o esquema ilustrado pela figura 5.2.

\section{A.1.1 - COMPONENTE DAS EQUAÇÕES DE NAVIER-STOKES NA DIREÇÃO LONGITUDINAL (DIREÇÃO X)}

A decomposição da equação tensorial (equação (B.1)) na direção longitudinal, leva a:

$$
\begin{aligned}
& \rho \frac{\partial u}{\partial t}+\rho \frac{\partial(u \cdot u)}{\partial x}+\rho \frac{\partial(v \cdot u)}{\partial y}+\rho \frac{\partial(w \cdot u)}{\partial z}=-\frac{\partial P}{\partial x}+2 \frac{\partial}{\partial x}\left[\left(\mu+\mu_{s m}\right) \frac{\partial u}{\partial x}\right]+\frac{\partial}{\partial y}\left[\left(\mu+\mu_{s m}\right) \frac{\partial u}{\partial y}\right]+ \\
& +\frac{\partial}{\partial z}\left[\left(\mu+\mu_{s m}\right) \frac{\partial u}{\partial z}\right]+\frac{\partial}{\partial y}\left[\left(\mu+\mu_{s m}\right) \frac{\partial v}{\partial x}\right]+\frac{\partial}{\partial z}\left[\left(\mu+\mu_{s m}\right) \frac{\partial w}{\partial x}\right]+F_{x}
\end{aligned}
$$

- Parcela advectiva $\rho \frac{\partial(u \cdot u)}{\partial x}$ : 


$$
\rho \frac{\partial(u \cdot u)}{\partial x}=\rho\left(\frac{1}{\Delta x}\right) \cdot\left[\left(\frac{u_{i, j+2, k}+u_{i, j+1, k}}{2}\right)^{2}-\left(\frac{u_{i, j+1, k}+u_{i, j, k}}{2}\right)^{2}\right]
$$

- Parcela advectiva $\rho \frac{\partial(v \cdot u)}{\partial y}$ :

$$
\rho \frac{\partial(v \cdot u)}{\partial y}=\rho\left(\frac{1}{\Delta y}\right) \cdot\left[\left(\frac{v_{i-1, j+1, k}+v_{i-1, j, k}}{2} \cdot\left(\frac{u_{i-1, j+1, k}+u_{i, j+1, k}}{2}\right)-\frac{v_{i, j+1, k}+v_{i, j, k}}{2} \cdot\left(\frac{u_{i, j+1, k}+u_{i+1, j+1, k}}{2}\right)\right)\right]
$$

- Parcela advectiva $\rho \frac{\partial(w \cdot u)}{\partial z}$ :

$$
\rho \frac{\partial(w \cdot u)}{\partial z}=\rho\left(\frac{1}{\Delta z}\right) \cdot\left[\left(\frac{w_{i, j+1, k+1}+w_{i, j, k+1}}{2} \cdot\left(\frac{u_{i, j+1, k}+u_{i, j+1, k+1}}{2}\right)-\frac{w_{i, j+1, k}+w_{i, j, k}}{2} \cdot\left(\frac{u_{i, j+1, k}+u_{i, j+1, k-1}}{2}\right)\right)\right]
$$

- Parcela de pressão $\frac{\partial P}{\partial x}$ :

$$
\frac{\partial P}{\partial x}=\frac{P_{i, j+1 . k}-P_{i, j, k}}{\Delta x}
$$

- Parcela difusiva $\frac{\partial}{\partial x}\left[\left(\mu+\mu_{s m}\right) \frac{\partial u}{\partial x}\right]$ :

$$
\frac{\partial}{\partial x}\left[\left(\mu+\mu_{s m}\right) \frac{\partial u}{\partial x}\right]=\left(\frac{1}{\Delta x}\right) \cdot\left[\left(\mu+\mu_{s m}\right)_{i, j+1, k}\left(\frac{u_{i, j+2, k}-u_{i, j+1, k}}{\Delta x}\right)-\left(\mu+\mu_{s m}\right)_{i, j, k}\left(\frac{u_{i, j+1, k}-u_{i, j, k}}{\Delta x}\right)\right]
$$

- Parcela difusiva $\frac{\partial}{\partial y}\left[\left(\mu+\mu_{s m}\right) \frac{\partial u}{\partial y}\right]$ :

$$
\frac{\partial}{\partial y}\left[\left(\mu+\mu_{s m}\right) \frac{\partial u}{\partial y}\right]=\left(\frac{1}{\Delta y}\right) \cdot\left[\left(\mu+\mu_{s m}\right)_{N O R}\left(\frac{u_{i-1, j+1, k}-u_{i, j+1, k}}{\Delta y}\right)-\left(\mu+\mu_{s m}\right)_{S U L}\left(\frac{u_{i, j+1, k}-u_{i+1, j, k}}{\Delta y}\right)\right]
$$

Onde: 


$$
\begin{aligned}
& \left(\mu+\mu_{s m}\right)_{N O R}=\frac{1}{4}\left[\left(\mu+\mu_{s m}\right)_{i, j, k}+\left(\mu+\mu_{s m}\right)_{i-1, j, k}+\left(\mu+\mu_{s m}\right)_{i-1, j+1, k}+\left(\mu+\mu_{s m}\right)_{i, j+1, k}\right] \\
& \left(\mu+\mu_{s m}\right)_{S U L}=\frac{1}{4}\left[\left(\mu+\mu_{s m}\right)_{i, j, k}+\left(\mu+\mu_{s m}\right)_{i+1, j, k}+\left(\mu+\mu_{s m}\right)_{i+1, j+1, k}+\left(\mu+\mu_{s m}\right)_{i, j+1, k}\right]
\end{aligned}
$$

- $\quad$ Parcela difusiva $\frac{\partial}{\partial z}\left[\left(\mu+\mu_{s m}\right) \frac{\partial u}{\partial z}\right]$ :

$$
\frac{\partial}{\partial z}\left[\left(\mu+\mu_{s m}\right) \frac{\partial u}{\partial z}\right]=\left(\frac{1}{\Delta z}\right) \cdot\left[\left(\mu+\mu_{s m}\right)_{P O S}\left(\frac{u_{i, j+1, k+1}-u_{i, j+1, k}}{\Delta z}\right)-\left(\mu+\mu_{s m}\right)_{A N T}\left(\frac{u_{i, j+1, k}-u_{i, j, k-1}}{\Delta z}\right)\right]
$$

Onde:

$$
\begin{aligned}
& \left(\mu+\mu_{s m}\right)_{P O S}=\frac{1}{4}\left[\left(\mu+\mu_{s m}\right)_{i, j, k}+\left(\mu+\mu_{s m}\right)_{i, j, k+1}+\left(\mu+\mu_{s m}\right)_{i, j+1, k+1}+\left(\mu+\mu_{s m}\right)_{i, j+1, k}\right] \\
& \left(\mu+\mu_{s m}\right)_{A N T}=\frac{1}{4}\left[\left(\mu+\mu_{s m}\right)_{i, j, k}+\left(\mu+\mu_{s m}\right)_{i, j+1, k}+\left(\mu+\mu_{s m}\right)_{i, j+1, k-1}+\left(\mu+\mu_{s m}\right)_{i, j, k-1}\right]
\end{aligned}
$$

- Parcela difusiva $\frac{\partial}{\partial y}\left[\left(\mu+\mu_{s m}\right) \frac{\partial v}{\partial x}\right]$ :

$$
\frac{\partial}{\partial y}\left[\left(\mu+\mu_{s m}\right) \frac{\partial v}{\partial x}\right]=\left(\frac{1}{\Delta y}\right) \cdot\left[\left(\mu+\mu_{s m}\right)_{N O R}\left(\frac{v_{i-1, j+1, k}-v_{i-1, j, k}}{\Delta x}\right)-\left(\mu+\mu_{s m}\right)_{S U L}\left(\frac{v_{i, j+1, k}-v_{i, j, k}}{\Delta x}\right)\right]
$$

Onde:

$$
\begin{aligned}
& \left(\mu+\mu_{s m}\right)_{N O R}=\frac{1}{4}\left[\left(\mu+\mu_{s m}\right)_{i, j, k}+\left(\mu+\mu_{s m}\right)_{i-1, j, k}+\left(\mu+\mu_{s m}\right)_{i-1, j+1, k}+\left(\mu+\mu_{s m}\right)_{i, j+1, k}\right] \\
& \left(\mu+\mu_{s m}\right)_{S U L}=\frac{1}{4}\left[\left(\mu+\mu_{s m}\right)_{i, j, k}+\left(\mu+\mu_{s m}\right)_{i+1, j, k}+\left(\mu+\mu_{s m}\right)_{i+1, j+1, k}+\left(\mu+\mu_{s m}\right)_{i, j+1, k}\right]
\end{aligned}
$$

- $\quad$ Parcela difusiva $\frac{\partial}{\partial z}\left[\left(\mu+\mu_{s m}\right) \frac{\partial w}{\partial x}\right]$ :

$$
\frac{\partial}{\partial z}\left[\left(\mu+\mu_{s m}\right) \frac{\partial w}{\partial x}\right]=\left(\frac{1}{\Delta z}\right) \cdot\left[\left(\mu+\mu_{s m}\right)_{P O S}\left(\frac{w_{i, j+1, k+1}-w_{i, j, k+1}}{\Delta x}\right)-\left(\mu+\mu_{s m}\right)_{A N T}\left(\frac{w_{i, j+1, k}-w_{i, j, k}}{\Delta x}\right)\right]
$$


Onde:

$$
\begin{aligned}
& \left(\mu+\mu_{s m}\right)_{P O S}=\frac{1}{4}\left[\left(\mu+\mu_{s m}\right)_{i, j, k}+\left(\mu+\mu_{s m}\right)_{i, j, k+1}+\left(\mu+\mu_{s m}\right)_{i, j+1, k+1}+\left(\mu+\mu_{s m}\right)_{i, j+1, k}\right] \\
& \left(\mu+\mu_{s m}\right)_{A N T}=\frac{1}{4}\left[\left(\mu+\mu_{s m}\right)_{i, j, k}+\left(\mu+\mu_{s m}\right)_{i, j+1, k}+\left(\mu+\mu_{s m}\right)_{i, j+1, k-1}+\left(\mu+\mu_{s m}\right)_{i, j, k-1}\right]
\end{aligned}
$$

- Parcela de força euleriana $F_{x}$ :

$$
F_{x}=F_{x} \quad i, j+1, k
$$

\section{A.1.2 - COMPONENTE DAS EQUAÇÕES DE NAVIER-STOKES NA DIREÇÃO VERTICAL (DIREÇÃO Y)}

A decomposição da equação tensorial (equação (A.1)), na direção vertical, leva a:

$$
\begin{aligned}
& \rho \frac{\partial v}{\partial t}+\rho \frac{\partial(u \cdot v)}{\partial x}+\rho \frac{\partial(v \cdot v)}{\partial y}+\rho \frac{\partial(w \cdot v)}{\partial z}=-\frac{\partial P}{\partial y}+\frac{\partial}{\partial x}\left[\left(\mu+\mu_{s m}\right) \frac{\partial v}{\partial x}\right]+2 \cdot \frac{\partial}{\partial y}\left[\left(\mu+\mu_{s m}\right) \frac{\partial v}{\partial y}\right]+ \\
& +\frac{\partial}{\partial z}\left[\left(\mu+\mu_{s m}\right) \frac{\partial v}{\partial z}\right]+\frac{\partial}{\partial x}\left[\left(\mu+\mu_{s m}\right) \frac{\partial u}{\partial y}\right]+\frac{\partial}{\partial z}\left[\left(\mu+\mu_{s m}\right) \frac{\partial w}{\partial y}\right]+F_{y}
\end{aligned}
$$

- Parcela advectiva $\rho \frac{\partial(u \cdot v)}{\partial x}$ :

$$
\rho \frac{\partial(u \cdot v)}{\partial x}=\rho\left(\frac{1}{\Delta x}\right) \cdot\left[\left(\frac{u_{i-1, j+1, k}+u_{i, j+1, k}}{2} \cdot\left(\frac{v_{i-1, j+1, k}+v_{i-11, k}}{2}\right)-\frac{u_{i-1, j, k}+u_{i, j, k}}{2} \cdot\left(\frac{v_{i-1, j, k}+v_{i-1, j-1, k}}{2}\right)\right)\right]
$$

- Parcela advectiva $\rho \frac{\partial(v \cdot v)}{\partial y}$ :

$$
\rho \frac{\partial(v \cdot v)}{\partial y}=\rho\left(\frac{1}{\Delta y}\right) \cdot\left[\left(\frac{v_{i-2, j, k}+v_{i-1, j, k}}{2}\right)^{2}-\left(\frac{v_{i-1, j, k}+v_{i, j, k}}{2}\right)^{2}\right]
$$

- Parcela advectiva $\rho \frac{\partial(w \cdot v)}{\partial z}$ : 
$\rho \frac{\partial(w \cdot v)}{\partial z}=\rho\left(\frac{1}{\Delta z}\right) \cdot\left[\left(\frac{w_{i, j, k+1}+w_{i-1, j, k+1}}{2} \cdot\left(\frac{v_{i-1, j, k+1}+v_{i-11, k}}{2}\right)-\frac{w_{i, j, k}+w_{i-1, j, k}}{2} \cdot\left(\frac{v_{i-1, j, k}+v_{i-1, j, k-1}}{2}\right)\right)\right]$

- Parcela de pressãa $\frac{\partial P}{\partial y}$ :

$\frac{\partial P}{\partial y}=\frac{P_{i-1, j . k}-P_{i, j, k}}{\Delta y}$

- Parcela difusiva $\frac{\partial}{\partial x}\left[\left(\mu+\mu_{s m}\right) \frac{\partial v}{\partial x}\right]$ :

$\frac{\partial}{\partial x}\left[\left(\mu+\mu_{s m}\right) \frac{\partial v}{\partial x}\right]=\left(\frac{1}{\Delta x}\right) \cdot\left[\left(\mu+\mu_{s m}\right)_{D I R} \cdot \frac{v_{i-1, j+1, k}-v_{i-1, j, k}}{\Delta x}-\left(\mu+\mu_{s m}\right)_{E S Q} \cdot \frac{v_{i-1, j, k}-v_{i-1, j-1, k}}{\Delta x}\right]$

Onde:

$$
\begin{aligned}
& \left(\mu+\mu_{s m}\right)_{D I R}=\frac{1}{4}\left[\left(\mu+\mu_{s m}\right)_{i, j, k}+\left(\mu+\mu_{s m}\right)_{i-1, j, k}+\left(\mu+\mu_{s m}\right)_{i-1, j+1, k}+\left(\mu+\mu_{s m}\right)_{i, j+1, k}\right] \\
& \left(\mu+\mu_{s m}\right)_{E S Q}=\frac{1}{4}\left[\left(\mu+\mu_{s m}\right)_{i, j, k}+\left(\mu+\mu_{s m}\right)_{i, j-1, k}+\left(\mu+\mu_{s m}\right)_{i-1, j-1, k}+\left(\mu+\mu_{s m}\right)_{i-1, j, k}\right]
\end{aligned}
$$

- Parcela difusiva $\frac{\partial}{\partial y}\left[\left(\mu+\mu_{s m}\right) \frac{\partial v}{\partial y}\right]$ :

$$
\frac{\partial}{\partial y}\left[\left(\mu+\mu_{s m}\right) \frac{\partial v}{\partial y}\right]=\left(\frac{1}{\Delta y}\right) \cdot\left[\left(\mu+\mu_{s m}\right)_{i-1, j, k} \cdot \frac{v_{i-2, j, k}-v_{i-1, j, k}}{\Delta y}-\left(\mu+\mu_{s m}\right)_{i, j, k} \cdot \frac{v_{i-1, j, k}-v_{i, j, k}}{\Delta y}\right]
$$

- Parcela difusiva $\frac{\partial}{\partial z}\left[\left(\mu+\mu_{s m}\right) \frac{\partial v}{\partial z}\right]$ :

$$
\frac{\partial}{\partial z}\left[\left(\mu+\mu_{s m}\right) \frac{\partial v}{\partial z}\right]=\left(\frac{1}{\Delta z}\right) \cdot\left[\left(\mu+\mu_{s m}\right)_{P O S} \cdot \frac{v_{i-1, j, k+1}-v_{i-1, j, k}}{\Delta z}-\left(\mu+\mu_{s m}\right)_{A N T} \cdot \frac{v_{i-1, j, k}-v_{i-1, j, k-1}}{\Delta z}\right]
$$


Onde:

$$
\begin{aligned}
& \left(\mu+\mu_{s m}\right)_{P O S}=\frac{1}{4}\left[\left(\mu+\mu_{s m}\right)_{i, j, k}+\left(\mu+\mu_{s m}\right)_{i-1, j, k}+\left(\mu+\mu_{s m}\right)_{i-1, j, k+1}+\left(\mu+\mu_{s m}\right)_{i, j, k+1}\right] \\
& \left(\mu+\mu_{s m}\right)_{A N T}=\frac{1}{4}\left[\left(\mu+\mu_{s m}\right)_{i, j, k}+\left(\mu+\mu_{s m}\right)_{i, j, k-1}+\left(\mu+\mu_{s m}\right)_{i-1, j, k-1}+\left(\mu+\mu_{s m}\right)_{i-1, j, k}\right]
\end{aligned}
$$

- Parcela difusiva $\frac{\partial}{\partial x}\left[\left(\mu+\mu_{s m}\right) \frac{\partial u}{\partial y}\right]$ :

$$
\frac{\partial}{\partial x}\left[\left(\mu+\mu_{s m}\right) \frac{\partial u}{\partial y}\right]=\left(\frac{1}{\Delta x}\right) \cdot\left[\left(\mu+\mu_{s m}\right)_{D I R} \cdot \frac{u_{i-1, j+1, k}-u_{i, j+1, k}}{\Delta y}-\left(\mu+\mu_{s m}\right)_{E S Q} \cdot \frac{u_{i-1, j, k}-u_{i, j, k}}{\Delta y}\right]
$$

Onde:

$$
\begin{aligned}
& \left(\mu+\mu_{s m}\right)_{D I R}=\frac{1}{4}\left[\left(\mu+\mu_{s m}\right)_{i, j, k}+\left(\mu+\mu_{s m}\right)_{i-1, j, k}+\left(\mu+\mu_{s m}\right)_{i-1, j+1, k}+\left(\mu+\mu_{s m}\right)_{i, j+1, k}\right] \\
& \left(\mu+\mu_{s m}\right)_{E S Q}=\frac{1}{4}\left[\left(\mu+\mu_{s m}\right)_{i, j, k}+\left(\mu+\mu_{s m}\right)_{i, j-1, k}+\left(\mu+\mu_{s m}\right)_{i-1, j-1, k}+\left(\mu+\mu_{s m}\right)_{i-1, j, k}\right]
\end{aligned}
$$

- Parcela difusiva $\frac{\partial}{\partial z}\left[\left(\mu+\mu_{s m}\right) \frac{\partial w}{\partial y}\right]$ :

$$
\frac{\partial}{\partial z}\left[\left(\mu+\mu_{s m}\right) \frac{\partial w}{\partial y}\right]=\left(\frac{1}{\Delta z}\right) \cdot\left[\left(\mu+\mu_{s m}\right)_{P O S} \cdot \frac{w_{i-1, j, k+1}-w_{i, j, k+1}}{\Delta y}-\left(\mu+\mu_{s m}\right)_{A N T} \cdot \frac{w_{i-1, j, k}-w_{i, j, k}}{\Delta y}\right]
$$

Onde:

$$
\begin{aligned}
& \left(\mu+\mu_{s m}\right)_{P O S}=\frac{1}{4}\left[\left(\mu+\mu_{s m}\right)_{i, j, k}+\left(\mu+\mu_{s m}\right)_{i-1, j, k}+\left(\mu+\mu_{s m}\right)_{i-1, j, k+1}+\left(\mu+\mu_{s m}\right)_{i, j, k+1}\right] \\
& \left(\mu+\mu_{s m}\right)_{A N T}=\frac{1}{4}\left[\left(\mu+\mu_{s m}\right)_{i, j, k}+\left(\mu+\mu_{s m}\right)_{i, j, k-1}+\left(\mu+\mu_{s m}\right)_{i-1, j, k-1}+\left(\mu+\mu_{s m}\right)_{i-1, j, k}\right]
\end{aligned}
$$

\section{- $\quad$ Parcela de força euleriana $F_{y}$ :}

$$
F_{y}=F_{y} \quad{ }_{i-1, j, k}
$$




\section{A.1.3 - COMPONENTE DAS EQUAÇÕES DE NAVIER-STOKES NA DIREÇÃO} TRANSVERSAL (DIREÇÃO Z)

A decomposição da equação tensorial (equação (A.1)), na direção transversal, leva a:

$$
\begin{aligned}
& \rho \frac{\partial w}{\partial t}+\rho \frac{\partial(u \cdot w)}{\partial x}+\rho \frac{\partial(v \cdot w)}{\partial y}+\rho \frac{\partial(w \cdot w)}{\partial z}=-\frac{\partial P}{\partial y}+\frac{\partial}{\partial x}\left[\left(\mu+\mu_{s m}\right) \frac{\partial w}{\partial x}\right]+\frac{\partial}{\partial y}\left[\left(\mu+\mu_{s m}\right) \frac{\partial w}{\partial y}\right]+ \\
& +2 \cdot \frac{\partial}{\partial z}\left[\left(\mu+\mu_{s m}\right) \frac{\partial w}{\partial z}\right]+\frac{\partial}{\partial x}\left[\left(\mu+\mu_{s m}\right) \frac{\partial u}{\partial z}\right]+\frac{\partial}{\partial y}\left[\left(\mu+\mu_{s m}\right) \frac{\partial v}{\partial z}\right]+F_{z}
\end{aligned}
$$

- Parcela advectiva $\rho \frac{\partial(u \cdot w)}{\partial x}$ :

$$
\rho \frac{\partial(u \cdot w)}{\partial x}=\rho\left(\frac{1}{\Delta x}\right) \cdot\left[\left(\frac{u_{i, j+1, k}+u_{i, j+1, k+1}}{2} \cdot\left(\frac{w_{i, j+1, k+1}+w_{i, j, k+1}}{2}\right)-\frac{u_{i, j, k}+u_{i, j, k+1}}{2} \cdot\left(\frac{w_{i, j, k+1}+w_{i, j-1, k+1}}{2}\right)\right)\right]
$$

- Parcela advectiva $\rho \frac{\partial(v \cdot w)}{\partial y}$ :

$$
\rho \frac{\partial(v \cdot w)}{\partial y}=\rho\left(\frac{1}{\Delta y}\right) \cdot\left[\left(\frac{v_{i-1, j, k+1}+v_{i-1, j, k}}{2} \cdot\left(\frac{w_{i-1, j, k+1}+w_{i, j, k+1}}{2}\right)-\frac{v_{i, j, k+1}+v_{i, j, k}}{2} \cdot\left(\frac{w_{i, j, k+1}+w_{i+1, j, k+1}}{2}\right)\right)\right]
$$

- Parcela advectiva $\rho \frac{\partial(w \cdot w)}{\partial z}$ :

$$
\rho \frac{\partial(w \cdot w)}{\partial z}=\rho\left(\frac{1}{\Delta z}\right) \cdot\left[\left(\frac{w_{i, j, k+2}+w_{i, j, k+1}}{2}\right)^{2}-\left(\frac{w_{i, j, k+1}+w_{i, j, k}}{2}\right)^{2}\right]
$$

- Parcela de pressão $\frac{\partial P}{\partial z}$ :

$$
\frac{\partial P}{\partial z}=\frac{P_{i, j . k+1}-P_{i, j, k}}{\Delta z}
$$


- Parcela difusiva $\frac{\partial}{\partial x}\left[\left(\mu+\mu_{s m}\right) \frac{\partial w}{\partial x}\right]$ :

$$
\frac{\partial}{\partial x}\left[\left(\mu+\mu_{s m}\right) \frac{\partial w}{\partial x}\right]=\left(\frac{1}{\Delta x}\right) \cdot\left[\left(\mu+\mu_{s m}\right)_{D I R} \cdot \frac{w_{i, j+1, k+1}-w_{i, j, k+1}}{\Delta x}-\left(\mu+\mu_{s m}\right)_{E S Q} \cdot \frac{w_{i, j, k+1}-w_{i, j-1, k+1}}{\Delta x}\right]
$$

Onde:

$$
\begin{aligned}
& \left(\mu+\mu_{s m}\right)_{D I R}=\frac{1}{4}\left[\left(\mu+\mu_{s m}\right)_{i, j, k}+\left(\mu+\mu_{s m}\right)_{i, j, k+1}+\left(\mu+\mu_{s m}\right)_{i, j+1, k+1}+\left(\mu+\mu_{s m}\right)_{i, j+1, k}\right] \\
& \left(\mu+\mu_{s m}\right)_{E S Q}=\frac{1}{4}\left[\left(\mu+\mu_{s m}\right)_{i, j, k}+\left(\mu+\mu_{s m}\right)_{i, j-1, k}+\left(\mu+\mu_{s m}\right)_{i, j-1, k+1}+\left(\mu+\mu_{s m}\right)_{i, j, k+1}\right]
\end{aligned}
$$

- Parcela difusiva $\frac{\partial}{\partial y}\left[\left(\mu+\mu_{s m}\right) \frac{\partial w}{\partial y}\right]$ :

$$
\frac{\partial}{\partial y}\left[\left(\mu+\mu_{s m}\right) \frac{\partial w}{\partial y}\right]=\left(\frac{1}{\Delta y}\right) \cdot\left[\left(\mu+\mu_{s m}\right)_{N O R} \cdot \frac{w_{i-1, j, k+1}-w_{i, j, k+1}}{\Delta y}-\left(\mu+\mu_{s m}\right)_{S U L} \cdot \frac{w_{i, j, k+1}-w_{i+1, j, k+1}}{\Delta y}\right]
$$

Onde:

$$
\begin{aligned}
& \left(\mu+\mu_{s m}\right)_{N O R}=\frac{1}{4}\left[\left(\mu+\mu_{s m}\right)_{i, j, k}+\left(\mu+\mu_{s m}\right)_{i, j, k+1}+\left(\mu+\mu_{s m}\right)_{i-1, j, k+1}+\left(\mu+\mu_{s m}\right)_{i-1, j, k}\right] \\
& \left(\mu+\mu_{s m}\right)_{S U L}=\frac{1}{4}\left[\left(\mu+\mu_{s m}\right)_{i, j, k}+\left(\mu+\mu_{s m}\right)_{i, j, k+1}+\left(\mu+\mu_{s m}\right)_{i+1, j, k+1}+\left(\mu+\mu_{s m}\right)_{i+1, j, k}\right]
\end{aligned}
$$

- Parcela difusiva $\frac{\partial}{\partial z}\left[\left(\mu+\mu_{s m}\right) \frac{\partial w}{\partial z}\right]$ :

$$
\frac{\partial}{\partial z}\left[\left(\mu+\mu_{s m}\right) \frac{\partial w}{\partial z}\right]=\left(\frac{1}{\Delta z}\right) \cdot\left[\left(\mu+\mu_{s m}\right)_{i, j, k+1} \cdot \frac{w_{i, j, k+2}-w_{i, j, k+1}}{\Delta z}-\left(\mu+\mu_{s m}\right)_{i, j, k} \cdot \frac{w_{i, j, k+1}-w_{i, j, k}}{\Delta z}\right]
$$

- Parcela difusiva $\frac{\partial}{\partial x}\left[\left(\mu+\mu_{s m}\right) \frac{\partial u}{\partial z}\right]$ : 


$$
\frac{\partial}{\partial x}\left[\left(\mu+\mu_{s m}\right) \frac{\partial u}{\partial z}\right]=\left(\frac{1}{\Delta x}\right) \cdot\left[\left(\mu+\mu_{s m}\right)_{D I R} \cdot \frac{u_{i, j+1, k+1}-w_{i, j+1, k}}{\Delta z}-\left(\mu+\mu_{s m}\right)_{E S Q} \cdot \frac{u_{i, j, k+1}-u_{i, j, k}}{\Delta z}\right]
$$

Onde:

$$
\begin{aligned}
& \left(\mu+\mu_{s m}\right)_{D I R}=\frac{1}{4}\left[\left(\mu+\mu_{s m}\right)_{i, j, k}+\left(\mu+\mu_{s m}\right)_{i, j, k+1}+\left(\mu+\mu_{s m}\right)_{i, j+1, k+1}+\left(\mu+\mu_{s m}\right)_{i, j+1, k}\right] \\
& \left(\mu+\mu_{s m}\right)_{E S Q}=\frac{1}{4}\left[\left(\mu+\mu_{s m}\right)_{i, j, k}+\left(\mu+\mu_{s m}\right)_{i, j-1, k}+\left(\mu+\mu_{s m}\right)_{i, j-1, k+1}+\left(\mu+\mu_{s m}\right)_{i, j, k+1}\right]
\end{aligned}
$$

- Parcela difusiva $\frac{\partial}{\partial y}\left[\left(\mu+\mu_{s m}\right) \frac{\partial \nu}{\partial z}\right]$ :

$$
\frac{\partial}{\partial y}\left[\left(\mu+\mu_{s m}\right) \frac{\partial v}{\partial z}\right]=\left(\frac{1}{\Delta y}\right) \cdot\left[\left(\mu+\mu_{s m}\right)_{N O R} \cdot \frac{v_{i-1, j, k+1}-v_{i-1, j, k}}{\Delta z}-\left(\mu+\mu_{s m}\right)_{S U L} \cdot \frac{v_{i, j, k+1}-v_{i, j, k}}{\Delta z}\right]
$$

Onde:

$$
\begin{aligned}
& \left(\mu+\mu_{s m}\right)_{N O R}=\frac{1}{4}\left[\left(\mu+\mu_{s m}\right)_{i, j, k}+\left(\mu+\mu_{s m}\right)_{i-1, j, k}+\left(\mu+\mu_{s m}\right)_{i-1, j, k+1}+\left(\mu+\mu_{s m}\right)_{i, j, k+1}\right] \\
& \left(\mu+\mu_{s m}\right)_{S U L}=\frac{1}{4}\left[\left(\mu+\mu_{s m}\right)_{i, j, k}+\left(\mu+\mu_{s m}\right)_{i, j, k+1}+\left(\mu+\mu_{s m}\right)_{i+1, j, k+1}+\left(\mu+\mu_{s m}\right)_{i+1, j, k}\right]
\end{aligned}
$$

- Parcela de força euleriana $F_{z}$ :

$$
F_{z}=F_{z} \quad i, j, k+1
$$




\section{APÊNDICE B - DISCRETIZAÇÃO DA EQUAÇÃO DE ADVECÇÃO- DIFUSÃO FILTRADA (CASO TRIDIMENSIONAL)}

Seja a equação de transporte de massa escrita na forma tensorial:

$$
\frac{\partial c}{\partial t}+u_{i} \frac{\partial c}{\partial x_{i}}=\frac{\partial}{\partial x_{i}}\left(D_{i} \frac{\partial c}{\partial x_{i}}\right)+\frac{\partial\left(w_{s} \cdot c\right)}{\partial x_{3}}
$$

O tratamento numérico da equação de Advecção-Difusão também é feito por Diferenças Finitas aplicadas sobre malhas deslocadas (assim, as concentrações são armazenadas no centro das células). A decomposição da equação tensorial acima, para três dimensões, origina:

$$
\frac{\partial c}{\partial t}+\frac{\partial(u \cdot c)}{\partial x}+\frac{\partial(v \cdot c)}{\partial y}+\frac{\partial(w \cdot c)}{\partial z}=\frac{\partial}{\partial x}\left(D_{E F} \frac{\partial c}{\partial x}\right)+\frac{\partial}{\partial y}\left(D_{E F} \frac{\partial c}{\partial y}\right)+\frac{\partial}{\partial z}\left(D_{E F} \frac{\partial c}{\partial z}\right)+\frac{\partial\left(w_{s} \cdot c\right)}{\partial y}
$$

As parcelas discretas da equação (B.2), oriundas do esquema de Diferenças Centrais de segunda ordem, são destacadas a seguir.

- Parcela de transporte advectivo $\frac{\partial(u \cdot c)}{\partial x}$ :

$$
\frac{\partial(u \cdot c)}{\partial x}=\frac{u_{i, j+1, k} \cdot\left(\frac{c_{i, j+1, k}+c_{i, j, k}}{2}\right)-u_{i, j, k} \cdot\left(\frac{c_{i, j, k}+c_{i, j-1, k}}{2}\right)}{\Delta x}
$$

- Parcela de transporte advectivo $\frac{\partial(v \cdot c)}{\partial y}$ :

$$
\frac{\partial(v \cdot c)}{\partial y}=\frac{v_{i-1, j, k} \cdot\left(\frac{c_{i-1, j, k}+c_{i, j, k}}{2}\right)-v_{i, j, k} \cdot\left(\frac{c_{i, j, k}+c_{i+1, j, k}}{2}\right)}{\Delta y}
$$


- Parcela de transporte advectivo $\frac{\partial(w \cdot c)}{\partial z}$ :

$\frac{\partial(w \cdot c)}{\partial z}=\frac{w_{i, j, k+1} \cdot\left(\frac{c_{i, j, k+1}+c_{i, j, k}}{2}\right)-w_{i, j, k} \cdot\left(\frac{c_{i, j, k}+c_{i, j, k-1}}{2}\right)}{\Delta z}$

- Parcela de transporte difusivo $\frac{\partial}{\partial x}\left(D_{E F} \cdot \frac{\partial c}{\partial x}\right)$ :

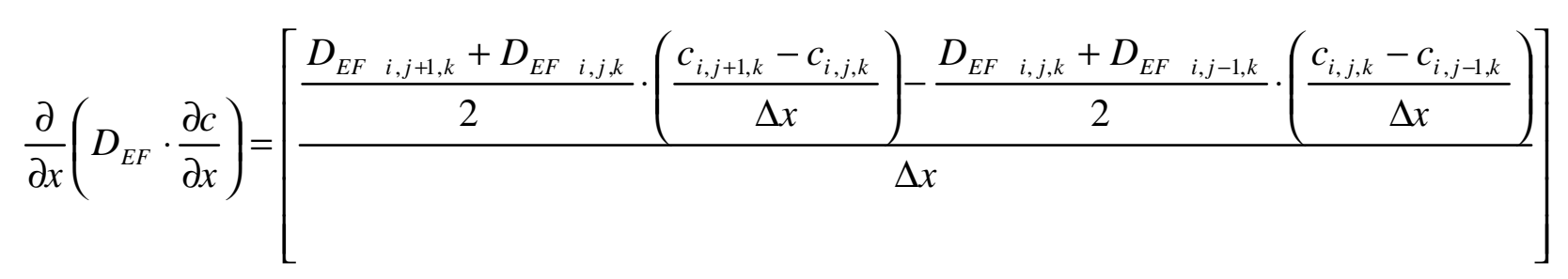

- Parcela de transporte difusivo $\frac{\partial}{\partial y}\left(D_{E F} \cdot \frac{\partial c}{\partial y}\right)$ :

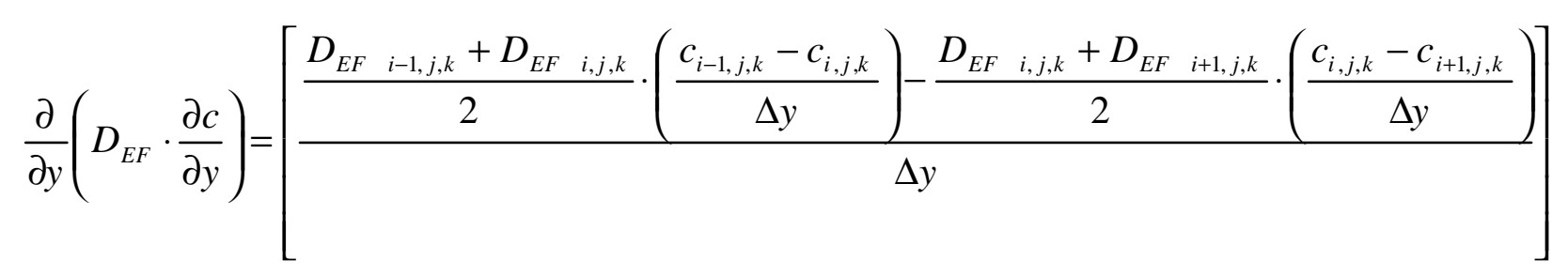

- Parcela de transporte difusivo $\frac{\partial}{\partial z}\left(D_{E F} \cdot \frac{\partial c}{\partial z}\right)$ :

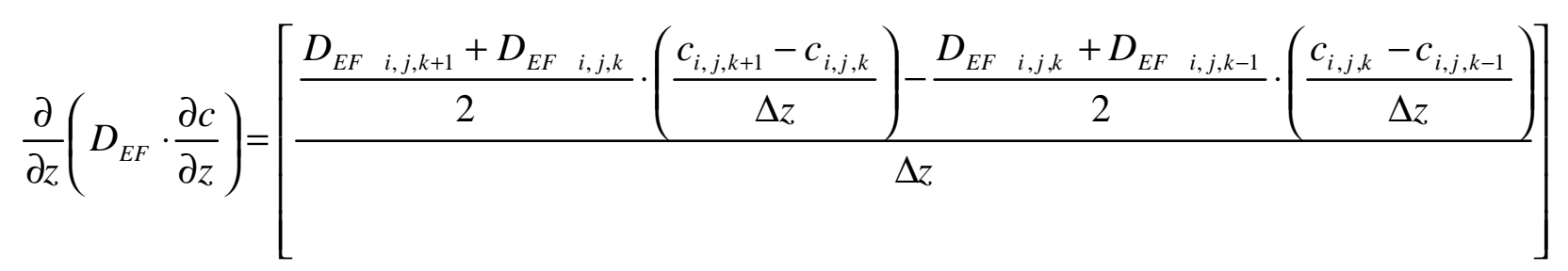

- Parcela de sedimentação (para células não adjacentes ao leito) $\frac{\partial\left(w_{s} \cdot c\right)}{\partial y}$ : 


$$
\frac{\partial\left(w_{s} \cdot c\right)}{\partial y}=\frac{\frac{w_{s i-1, j, k} \cdot c_{i-1, j, k}+w_{s i, j, k} \cdot c_{i, j, k}}{2}-\frac{w_{s \quad i, j, k} \cdot c_{i, j, k}+w_{s i+1, j, k} \cdot c_{i+1, j, k}}{2}}{\Delta y}
$$

- Parcela de sedimentação (para células adjacentes ao leito) $\frac{\partial\left(w_{s} \cdot c\right)}{\partial y}$ :

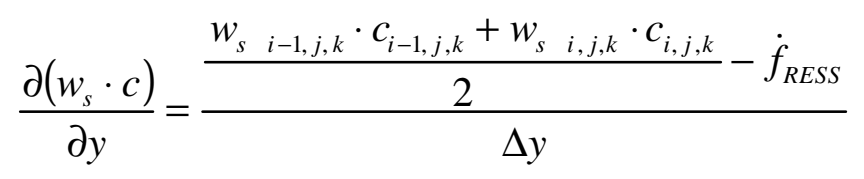




\section{APÊNDICE C - DISCRETIZAÇÃO DAS EQUAÇÕES FILTRADAS DE NAVIER-STOKES (CASO BIDIMENSIONAL)}

Convém, de início, reescrever as equações filtradas de Navier-Stokes na sua frma completa, ou seja, com o termo fonte de força euleriana e com a viscosidade turbulenta submalha. Assim, na forma tensorial:

$$
\rho \frac{\partial u_{i}}{\partial t}+\rho \frac{\partial\left(u_{j} \cdot u_{i}\right)}{\partial x_{j}}=-\frac{\partial P}{\partial x_{i}}+\frac{\partial}{\partial x_{j}}\left[\left(\mu+\mu_{s m}\right) \cdot\left(\frac{\partial u_{i}}{\partial x_{j}}+\frac{\partial u_{j}}{\partial x_{i}}\right)\right]+F_{i}
$$

A decomposição da equação (C.1), nas diferentes direções, consiste no passo imediatamente anterior ao processo de discretização por Diferenças Centrais de segunda ordem, o que é mostrado a seguir. Vale lembrar que a indexação $(i, j)$ das variáveis discretas segue o esquema ilustrado pela figura 5.2.

\section{C.1.1 - COMPONENTE DAS EQUAÇÕES DE NAVIER-STOKES NA DIREÇÃO LONGITUDINAL (DIREÇÃO X)}

A decomposição da equação tensorial (equação $(C .1)$ ) na direção longitudinal, leva a:

$$
\begin{aligned}
& \rho \frac{\partial u}{\partial t}+\rho \frac{\partial(u \cdot u)}{\partial x}+\rho \frac{\partial(v \cdot u)}{\partial y}=-\frac{\partial P}{\partial x}+2 \frac{\partial}{\partial x}\left[\left(\mu+\mu_{s m}\right) \frac{\partial u}{\partial x}\right]+\frac{\partial}{\partial y}\left[\left(\mu+\mu_{s m}\right) \frac{\partial u}{\partial y}\right]+ \\
& +\frac{\partial}{\partial y}\left[\left(\mu+\mu_{s m}\right) \frac{\partial v}{\partial x}\right]+F_{x}
\end{aligned}
$$

- Parcela advectiva $\rho \frac{\partial(u \cdot u)}{\partial x}$ :

$$
\rho \frac{\partial(u \cdot u)}{\partial x}=\rho\left(\frac{1}{\Delta x}\right) \cdot\left[\left(\frac{u_{i, j+2}+u_{i, j+1}}{2}\right)^{2}-\left(\frac{u_{i, j+1}+u_{i, j}}{2}\right)^{2}\right]
$$


- Parcela advectiva $\rho \frac{\partial(v \cdot u)}{\partial y}$ :

$$
\rho \frac{\partial(v \cdot u)}{\partial y}=\rho\left(\frac{1}{\Delta y}\right) \cdot\left[\left(\frac{v_{i-1, j+1}+v_{i-1, j}}{2} \cdot\left(\frac{u_{i-1, j+1}+u_{i, j+1}}{2}\right)-\frac{v_{i, j+1}+v_{i, j}}{2} \cdot\left(\frac{u_{i, j+1}+u_{i+1, j+1}}{2}\right)\right)\right]
$$

- Parcela de pressão $\frac{\partial P}{\partial x}$ :

$$
\frac{\partial P}{\partial x}=\frac{P_{i, j+1}-P_{i, j}}{\Delta x}
$$

- Parcela difusiva $\frac{\partial}{\partial x}\left[\left(\mu+\mu_{s m}\right) \frac{\partial u}{\partial x}\right]$ :

$$
\frac{\partial}{\partial x}\left[\left(\mu+\mu_{s m}\right) \frac{\partial u}{\partial x}\right]=\left(\frac{1}{\Delta x}\right) \cdot\left[\left(\mu+\mu_{s m}\right)_{i, j+1}\left(\frac{u_{i, j+2}-u_{i, j+1}}{\Delta x}\right)-\left(\mu+\mu_{s m}\right)_{i, j}\left(\frac{u_{i, j+1}-u_{i, j}}{\Delta x}\right)\right]
$$

- Parcela difusiva $\frac{\partial}{\partial y}\left[\left(\mu+\mu_{s m}\right) \frac{\partial u}{\partial y}\right]$ :

$$
\frac{\partial}{\partial y}\left[\left(\mu+\mu_{s m}\right) \frac{\partial u}{\partial y}\right]=\left(\frac{1}{\Delta y}\right) \cdot\left[\left(\mu+\mu_{s m}\right)_{N O R}\left(\frac{u_{i-1, j+1}-u_{i, j+1}}{\Delta y}\right)-\left(\mu+\mu_{s m}\right)_{S U L}\left(\frac{u_{i, j+1}-u_{i+1, j}}{\Delta y}\right)\right]
$$

Onde:

$$
\begin{aligned}
& \left(\mu+\mu_{s m}\right)_{N O R}=\frac{1}{4}\left[\left(\mu+\mu_{s m}\right)_{i, j}+\left(\mu+\mu_{s m}\right)_{i-1, j}+\left(\mu+\mu_{s m}\right)_{i-1, j+1}+\left(\mu+\mu_{s m}\right)_{i, j+1}\right] \\
& \left(\mu+\mu_{s m}\right)_{S U L}=\frac{1}{4}\left[\left(\mu+\mu_{s m}\right)_{i, j}+\left(\mu+\mu_{s m}\right)_{i+1, j}+\left(\mu+\mu_{s m}\right)_{i+1, j+1}+\left(\mu+\mu_{s m}\right)_{i, j+1}\right]
\end{aligned}
$$

- $\quad$ Parcela difusiva $\frac{\partial}{\partial y}\left[\left(\mu+\mu_{s m}\right) \frac{\partial v}{\partial x}\right]$ : 


$$
\frac{\partial}{\partial y}\left[\left(\mu+\mu_{s m}\right) \frac{\partial v}{\partial x}\right]=\left(\frac{1}{\Delta y}\right) \cdot\left[\left(\mu+\mu_{s m}\right)_{N O R}\left(\frac{v_{i-1, j+1}-v_{i-1, j}}{\Delta x}\right)-\left(\mu+\mu_{s m}\right)_{S U L}\left(\frac{v_{i, j+1}-v_{i, j}}{\Delta x}\right)\right]
$$

Onde:

$$
\begin{aligned}
& \left(\mu+\mu_{s m}\right)_{N O R}=\frac{1}{4}\left[\left(\mu+\mu_{s m}\right)_{i, j}+\left(\mu+\mu_{s m}\right)_{i-1, j}+\left(\mu+\mu_{s m}\right)_{i-1, j+1}+\left(\mu+\mu_{s m}\right)_{i, j+1}\right] \\
& \left(\mu+\mu_{s m}\right)_{s U L}=\frac{1}{4}\left[\left(\mu+\mu_{s m}\right)_{i, j}+\left(\mu+\mu_{s m}\right)_{i+1, j}+\left(\mu+\mu_{s m}\right)_{i+1, j+1}+\left(\mu+\mu_{s m}\right)_{i, j+1}\right]
\end{aligned}
$$

- Parcela de força euleriana $F_{x}$ :

$F_{x}=F_{x} \quad i, j+1$

\section{C.1.2 - COMPONENTE DAS EQUAÇÕES DE NAVIER-STOKES NA DIREÇÃO VERTICAL (DIREÇÃO Y)}

A decomposição da equação tensorial (equação $(C .1)$ ), na direção vertical, leva a:

$$
\begin{aligned}
& \rho \frac{\partial v}{\partial t}+\rho \frac{\partial(u \cdot v)}{\partial x}+\rho \frac{\partial(v \cdot v)}{\partial y}=-\frac{\partial P}{\partial y}+\frac{\partial}{\partial x}\left[\left(\mu+\mu_{s m}\right) \frac{\partial v}{\partial x}\right]+2 \cdot \frac{\partial}{\partial y}\left[\left(\mu+\mu_{s m}\right) \frac{\partial v}{\partial y}\right]+ \\
& +\frac{\partial}{\partial x}\left[\left(\mu+\mu_{s m}\right) \frac{\partial u}{\partial y}\right]+F_{y}
\end{aligned}
$$

- Parcela advectiva $\rho \frac{\partial(u \cdot v)}{\partial x}$ :

$$
\rho \frac{\partial(u \cdot v)}{\partial x}=\rho\left(\frac{1}{\Delta x}\right) \cdot\left[\left(\frac{u_{i-1, j+1}+u_{i, j+1}}{2} \cdot\left(\frac{v_{i-1, j+1}+v_{i-1, j}}{2}\right)-\frac{u_{i-1, j}+u_{i, j}}{2} \cdot\left(\frac{v_{i-1, j}+v_{i-1, j-1}}{2}\right)\right)\right]
$$

- Parcela advectiva $\rho \frac{\partial(v \cdot v)}{\partial y}$ : 
$\rho \frac{\partial(v \cdot v)}{\partial y}=\rho\left(\frac{1}{\Delta y}\right) \cdot\left[\left(\frac{v_{i-2, j}+v_{i-1, j}}{2}\right)^{2}-\left(\frac{v_{i-1, j}+v_{i, j}}{2}\right)^{2}\right]$

- Parcela de pressão $\frac{\partial P}{\partial y}$ :

$\frac{\partial P}{\partial y}=\frac{P_{i-1, j}-P_{i, j}}{\Delta y}$

- Parcela difusiva $\frac{\partial}{\partial x}\left[\left(\mu+\mu_{s m}\right) \frac{\partial v}{\partial x}\right]$ :

$$
\frac{\partial}{\partial x}\left[\left(\mu+\mu_{s m}\right) \frac{\partial v}{\partial x}\right]=\left(\frac{1}{\Delta x}\right) \cdot\left[\left(\mu+\mu_{s m}\right)_{D I R} \cdot \frac{v_{i-1, j+1}-v_{i-1, j}}{\Delta x}-\left(\mu+\mu_{s m}\right)_{E S Q} \cdot \frac{v_{i-1, j}-v_{i-1, j-1}}{\Delta x}\right]
$$

Onde:

$$
\begin{aligned}
& \left(\mu+\mu_{s m}\right)_{D I R}=\frac{1}{4}\left[\left(\mu+\mu_{s m}\right)_{i, j}+\left(\mu+\mu_{s m}\right)_{i-1, j}+\left(\mu+\mu_{s m}\right)_{i-1, j+1}+\left(\mu+\mu_{s m}\right)_{i, j+1}\right] \\
& \left(\mu+\mu_{s m}\right)_{E S Q}=\frac{1}{4}\left[\left(\mu+\mu_{s m}\right)_{i, j}+\left(\mu+\mu_{s m}\right)_{i, j-1}+\left(\mu+\mu_{s m}\right)_{i-1, j-1}+\left(\mu+\mu_{s m}\right)_{i-1, j}\right]
\end{aligned}
$$

- Parcela difusiva $\frac{\partial}{\partial y}\left[\left(\mu+\mu_{s m}\right) \frac{\partial \nu}{\partial y}\right]$ :

$$
\frac{\partial}{\partial y}\left[\left(\mu+\mu_{s m}\right) \frac{\partial v}{\partial y}\right]=\left(\frac{1}{\Delta y}\right) \cdot\left[\left(\mu+\mu_{s m}\right)_{i-1, j} \cdot \frac{v_{i-2, j}-v_{i-1, j}}{\Delta y}-\left(\mu+\mu_{s m}\right)_{i, j} \cdot \frac{v_{i-1, j}-v_{i, j}}{\Delta y}\right]
$$

- Parcela difusiva $\frac{\partial}{\partial x}\left[\left(\mu+\mu_{s m}\right) \frac{\partial u}{\partial y}\right]$ :

$$
\frac{\partial}{\partial x}\left[\left(\mu+\mu_{s m}\right) \frac{\partial u}{\partial y}\right]=\left(\frac{1}{\Delta x}\right) \cdot\left[\left(\mu+\mu_{s m}\right)_{D I R} \cdot \frac{u_{i-1, j+1}-u_{i, j+1}}{\Delta y}-\left(\mu+\mu_{s m}\right)_{E S Q} \cdot \frac{u_{i-1, j}-u_{i, j}}{\Delta y}\right]
$$

Onde: 


$$
\begin{aligned}
& \left(\mu+\mu_{s m}\right)_{D I R}=\frac{1}{4}\left[\left(\mu+\mu_{s m}\right)_{i, j}+\left(\mu+\mu_{s m}\right)_{i-1, j}+\left(\mu+\mu_{s m}\right)_{i-1, j+1}+\left(\mu+\mu_{s m}\right)_{i, j+1}\right] \\
& \left(\mu+\mu_{s m}\right)_{E S Q}=\frac{1}{4}\left[\left(\mu+\mu_{s m}\right)_{i, j}+\left(\mu+\mu_{s m}\right)_{i, j-1}+\left(\mu+\mu_{s m}\right)_{i-1, j-1}+\left(\mu+\mu_{s m}\right)_{i-1, j}\right]
\end{aligned}
$$

- $\quad$ Parcela de força euleriana $F_{y}$ :

$$
F_{y}=F_{y} \quad i_{-1, j}
$$




\section{APÊNDICE D - DISCRETIZAÇÃO DA EQUAÇÃO DE ADVECÇÃO- DIFUSÃO FILTRADA (CASO BIDIMENSIONAL)}

Seja a equação de transporte de massa escrita na forma tensorial:

$$
\frac{\partial c}{\partial t}+u_{i} \frac{\partial c}{\partial x_{i}}=\frac{\partial}{\partial x_{i}}\left(D_{i} \frac{\partial c}{\partial x_{i}}\right)+\frac{\partial\left(w_{s} \cdot c\right)}{\partial x_{3}}
$$

O tratamento numérico da equação de Advecção-Difusão também é feito por Diferenças Finitas aplicadas sobre malhas deslocadas (assim, as concentrações são armazenadas no centro das células). A decomposição da equação tensorial acima, para três dimensões, origina:

$\frac{\partial c}{\partial t}+\frac{\partial(u \cdot c)}{\partial x}+\frac{\partial(v \cdot c)}{\partial y}=\frac{\partial}{\partial x}\left(D_{E F} \frac{\partial c}{\partial x}\right)+\frac{\partial}{\partial y}\left(D_{E F} \frac{\partial c}{\partial y}\right)+\frac{\partial\left(w_{s} \cdot c\right)}{\partial y}$

As parcelas discretas da equação (D.2), oriundas do esquema de Diferenças Centrais de segunda ordem, são destacadas a seguir.

- Parcela de transporte advectivo $\frac{\partial(u \cdot c)}{\partial x}$ :

$$
\frac{\partial(u \cdot c)}{\partial x}=\frac{u_{i, j+1, k} \cdot\left(\frac{c_{i, j+1}+c_{i, j}}{2}\right)-u_{i, j, k} \cdot\left(\frac{c_{i, j}+c_{i, j-1}}{2}\right)}{\Delta x}
$$

- Parcela de transporte advectivo $\frac{\partial(v \cdot c)}{\partial y}$ :

$$
\frac{\partial(v \cdot c)}{\partial y}=\frac{v_{i-1, j} \cdot\left(\frac{c_{i-1, j}+c_{i, j}}{2}\right)-v_{i, j} \cdot\left(\frac{c_{i, j}+c_{i+1, j}}{2}\right)}{\Delta y}
$$


- Parcela de transporte difusivo $\frac{\partial}{\partial x}\left(D_{E F} \cdot \frac{\partial c}{\partial x}\right)$ :

$\frac{\partial}{\partial x}\left(D_{E F} \cdot \frac{\partial c}{\partial x}\right)=\left[\frac{\frac{D_{E F i, j+1}+D_{E F i, j}}{2} \cdot\left(\frac{c_{i, j+1}-c_{i, j}}{\Delta x}\right)-\frac{D_{E F i, j}+D_{E F i, j-1}}{2} \cdot\left(\frac{c_{i, j}-c_{i, j-1}}{\Delta x}\right)}{\Delta x}\right]$

- Parcela de transporte difusivo $\frac{\partial}{\partial y}\left(D_{E F} \cdot \frac{\partial c}{\partial y}\right)$ :

$\frac{\partial}{\partial y}\left(D_{E F} \cdot \frac{\partial c}{\partial y}\right)=\left[\frac{\frac{D_{E F i-1, j}+D_{E F i, j}}{2} \cdot\left(\frac{c_{i-1, j}-c_{i, j}}{\Delta y}\right)-\frac{D_{E F i, j}+D_{E F i+1, j}}{2} \cdot\left(\frac{c_{i, j}-c_{i+1, j}}{\Delta y}\right)}{\Delta y}\right]$

- Parcela de sedimentação (para células não adjacentes ao leito) $\frac{\partial\left(w_{s} \cdot c\right)}{\partial y}$ :

$\frac{\partial\left(w_{s} \cdot c\right)}{\partial y}=\frac{\frac{w_{s i-1, j} \cdot c_{i-1, j}+w_{s i, j} \cdot c_{i, j}}{2}-\frac{w_{s i, j} \cdot c_{i, j}+w_{s i+1, j} \cdot c_{i+1, j}}{2}}{\Delta y}$

- Parcela de sedimentação (para células adjacentes ao leito) $\frac{\partial\left(w_{s} \cdot c\right)}{\partial y}$ :

$$
\frac{\partial\left(w_{s} \cdot c\right)}{\partial y}=\frac{\frac{w_{s \quad i-1, j} \cdot c_{i-1, j}+w_{s i, j} \cdot c_{i, j}}{2}-\dot{f}_{R E S S}}{\Delta y}
$$

